LIDIANE MARIA DE ANDRADE

\title{
PRODUÇÃO DE MICROALGAS E CARACTERIZAÇÃO DE SUA COMPOSIÇÃO PROTÊICA E LIPÍDICA VIA ESPECTROMETRIA DE MASSAS
}




\section{PRODUÇÃO DE MICROALGAS E CARACTERIZAÇÃO DE SUA COMPOSIÇÃO PROTÊICA E LIPÍDICA VIA ESPECTROMETRIA DE MASSAS}

Tese apresentada à Escola Politécnica da Universidade de São Paulo para a obtenção do título de doutor em Engenharia Química.

Área de Concentração:

Engenharia Química

Orientador:

Prof Dr. Claudio Augusto Oller do Nascimento

Co-Orientadora:

Dra. Maria Anita Mendes

São Paulo 
Este exemplar foi revisado e corrigido em relação à versão original, sob responsabilidade única do autor e com a anuência de seu orientador.

São Paulo, 12 de novembro de 2014.

Assinatura do autor

Assinatura do orientador

Catalogação-na-publicação

Andrade, Lidiane Maria de

Produção de microalgas e caracterização de sua composição protêica e lipídica via espectrometria de massas / L.M. de Andrade. -- versão corr. -- São Paulo, 2014.

$141 \mathrm{p}$.

Tese (Doutorado) - Escola Politécnica da Universidade de São Paulo. Departamento de Engenharia Química.

1.Microalgas (Produção) 2.Composição protêica e lipídica 3.Espectrometria de massa I.Universidade de São Paulo. Escola Politécnica. Departamento de Engenharia Química II.t. 


\section{DEDICATÓRIA}

Dedico esta conquista primeiramente a meus pais, José e Maria Tereza pelo todo incentivo, confiança e amor incondicionais, e à meus avós, Pedro (in memoriam) e Elidia (in memoriam) que me ensinaram encontrar a felicidade na simplicidade das coisas e, ainda, me mostraram o verdadeiro significado da palavra "familia". Sem todos vocês nada disso teria se tornado real. Amo vocês para todo o sempre! 


\section{AGRADECIMENTOS}

À Deus, pelo dom da vida.

Ao meu irmão Cristiano, pelo amor, amizade e confiança, e pelas ricas discussões e auxílios especialmente no exame de qualificação e com a parte de estatística.Obrigada. Te amo.

A todos da minha família, tios(as), primos(as) pela confiança.

Ao Prof. Dr. Claudio Oller, pela amizade, orientação, apoio e por ter sido sempre presente, meu eterno muito obrigada.

À minha co-orientadora e amiga Dra. Maria Anita Mendes, por todo apoio dispensado e, em especial, por ter sido fundamental na escolha do meu doutorado sanduíche.

Ao INCT-CAPES pelo apoio financeiro desta pesquisa.

Ao Ciências sem Fronteiras pelo apoio financeiro durante o doutorado sanduíche.

A todos os funcionários e professores do departamento de Engenharia Química, por terem me recebido de braços abertos, em especial à Carminha, Elisete, Alexandre, Graça e Silvia.

Ao Prof. Dr. Armando Augusto Henriques Vieira, do Departamento de Ecologia e Biologia Evolutiva da Universidade Federal de São Carlos, pela gentil doação da nossa primeira cepa de microalga Chlorella vulgaris.

Ao Prof. Dr. Ernani Pinto, da Faculdade de Ciências Farmacêuticas da Universidade de São Paulo, por ter disponibilizado, gentilmente, seu laboratório logo no início dessa pesquisa, e ao Dr. Ronaldo Leal pelos valiosos ensinamentos.

Aos Dr. Sérgio Goldemberg e Dra. Daniela Silva, da empresa Algae Biotecnologia Ltda, pela gentil doação das cepas de microalgas Chlorella sp., Desmodesmus sp., Monoraphiudium sp. e Oocystis sp.

Aos grandes amigos que fiz ao longo desses 4 anos, cada um com sua contribuição especial, seja de cunho acadêmico ou não, o meu eterno muito obrigada: Paula Bruzadelle, Mariana de Paula, Meriellen Dias, Enrique Rosas, Renata Bastos, Talita Carmo, Bruno Karolski, Adriana Niño, Fabiana Sanches, Lina Palacio, Mariana Ciriaco, Celize Tcacenco, Celyna Karitas, Katia Ribeiro, Fernando Sassano, Lucas Groshe, Esmar Faben, Monica Baptiste, Monica Cardenas, Camila Hinsching, Ricardo Lee, Miguel Younes, Nataly Aranda, Marcelo Tempesta, Cintia Baptistuti, Letícia Mesquita, Carlos Silveira, Rodrigo Ramos, Jahn Pierre, Luís Fernando Mercier, Marilda Mendonça, Nadja Just, Louise Byrden, John Bastidas, Andressa Pilonetto, Tâmira Maia, Ellen Aquino, Rita Maria Alves, Carol Santos, Verônica Carranza, Leticia Veloso, Paulo Firmino, Nancy DeMeo,Andy Mac.

Ao pessoal da Bruker Daltonics, em especial Ulrich Giessmann, Paul Speir, Paul Kowalski, Amanda Bulman, Sergei Dikler Jane Kowalski, Anjali Alving, Michael Timmon e Matt Willetts por terem me recebido de braços abertos, e terem me proporcionado dias incríveis no mundo da espectrometria de massas. Agradeço também à Luiz Fernando e, principalmente, à Diego Assis, da Bruker do Brasil, por toda ajuda dispensada, especialmente às vésperas da minha viagem para Boston. 
Ainda, agradeço ao pessoal da SINC do Brasil, em especial ao Juarez pelo apoio ao meu doutorado sanduíche.

À minha família de Boston, Fernando, Laura, Sophia e Anna, que me acolheu com muito amor e amizade, e fez com que eu me sentisse parte da família, meu eterno obrigado.

Ao amigos que fiz em Boston, Zé e Eduardo; aos amigos do PUBBoston: Debora, Viviane, Larissa, Luciana, Naira, Pedro, Vitor, Edivandro, Jussara, Marina, Maria Emília, Eugenia, Giuseppe; e, em especial aos meu eternos irmãos Lucas Albrechet e André Gaeta pelos momentos incríveis que proporcionaram histórias e recordações que guardarei para sempre.

Às voleiboletes, pelas muitas demonstrações de determinação $e$ garra, que sempre levaram a grandes vitórias.

Aos amigos de Rio Claro, presentes em todos os momentos: Nathália, Maria Fernanda (Fezoca), Tatiana, Laís, Emília, Aline, Malu, Maíra, Sarah, Mariana, Sheila, Maria Fernanda de Arruda, Pedro Paulo, Ramon, Pedro, Caca, Bellini Juliano, Angelo, Luiz, Danilo e Dirceu.

Enfim agradeço aqui a todos aqueles (e são muitos) que de uma forma ou de outra fizeram parte da minha vida durante esse doutorado, À todos, o meu muito obrigada.

"Só enquanto eu respirar, vou me lembrar de vocês"

Fernando Anitelli 
"The only limit to our realization of tomorrow will be our doubts of today. Let us move forward with strong and active faith "

(Franklin D. Roosevelt) 


\section{SUMÁRIO}

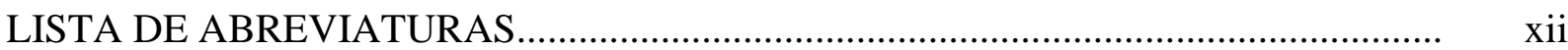

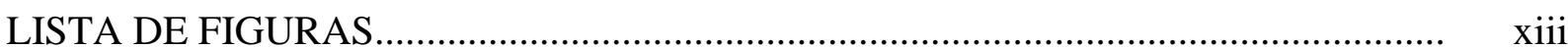

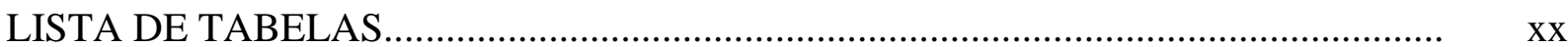

RESUMO

ABSTRACT

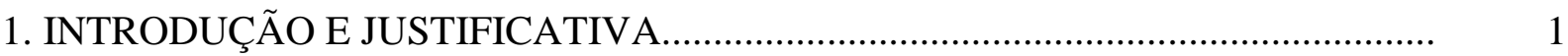

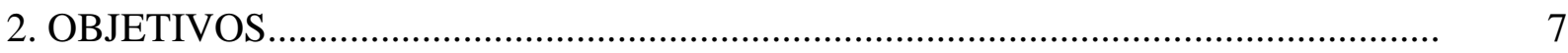

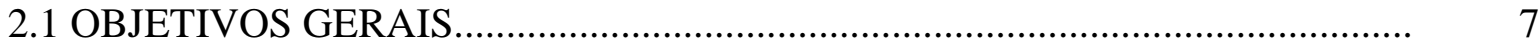

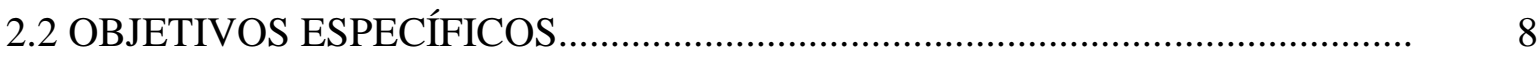

2.2.1 Estudo da cinética microbiana de crescimento das espécies Chlorella vulgaris, Chlorella sp., Desmodesmus sp., Monoraphidium sp. e Oocystis sp........ 8

2.2.2 Perfis proteicos de diferentes espécies de microalgas (Chlorella vulgaris, Chlorella sp., Desmodesmus sp., Monoraphidium sp., Oocystis sp.) utilizando espectrometria de massas

2.2.3 Identificação dos lipídios das diferentes espécies de microalgas (Chlorella vulgaris, Chlorella sp., Desmodesmus sp., Monoraphidium sp., Oocystis sp.)

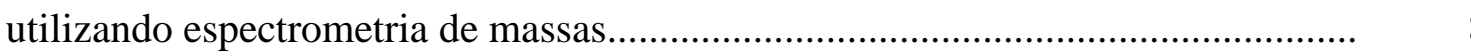

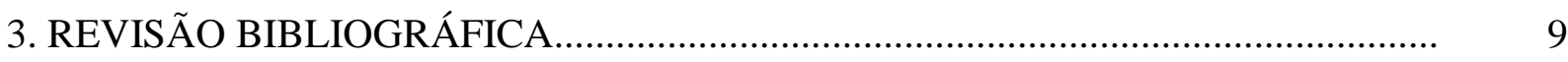

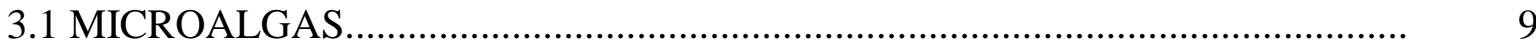

3.2 ESPÉCIES DE MICROALGAS...........................................................................

3.3 FATORES IMPORTANTES PARA O CRESCIMENTO DAS MICROALGAS. 13

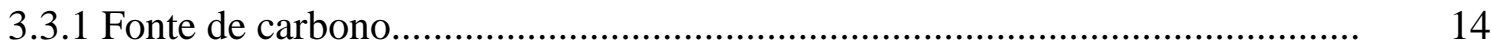

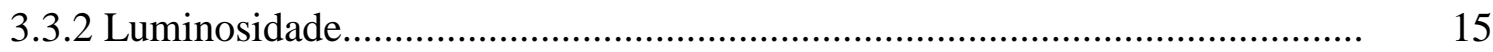

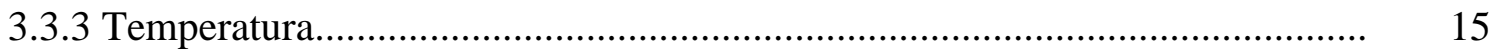


3.3.4 Agitação 16

3.3.5 $\mathrm{pH}$ 16

3.3.6 Fonte de nutrientes

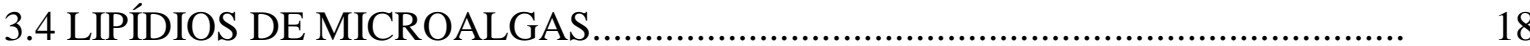

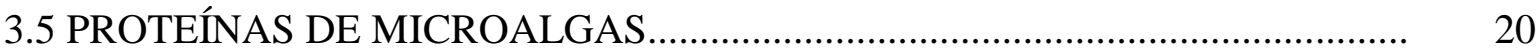

3.6 ESPECTROMETRIA DE MASSAS MALDI-TOF-MS........................................ 22

3.6.1 Fonte de ionização......................................................................................... 22

3.6.2 Analisador de massas................................................................... 22

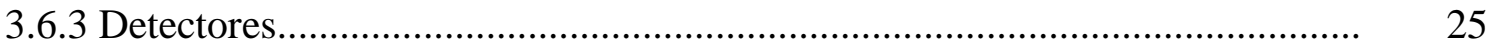

3.6.4 Placas "anchorchip" e "polished"........................................................... 25

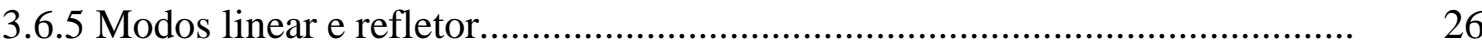

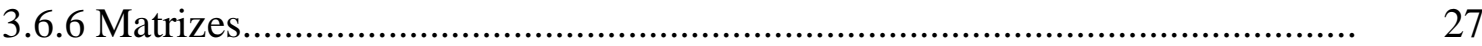

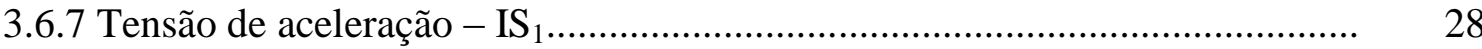

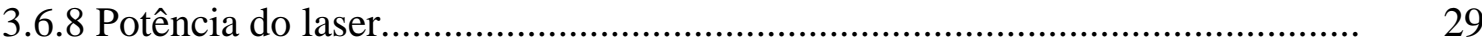

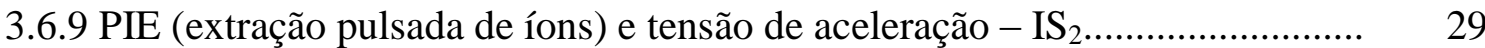

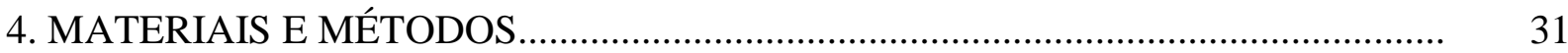

4.1 MATERIAIS E INSTRUMENTOS ................................................................. 31

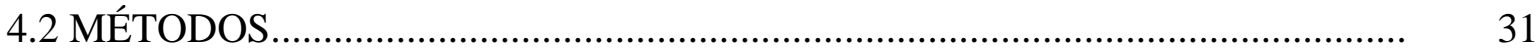

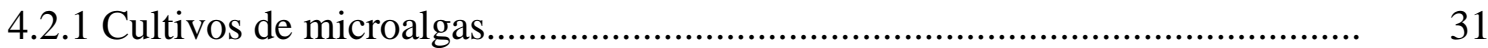

4.2.1.1 Espécies de microalgas estudadas....................................................... 31

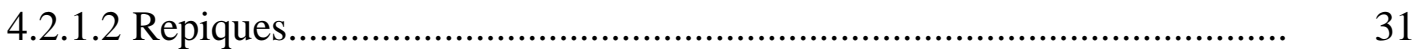

4.2.1.3 Meio de cultivo sintético WC............................................................. 32

4.2.1.4 Avaliação do crescimento................................................................... 33

4.2.1.5 Quantificação da concentração celular - Densidade Óptica x Massa Seca.

4.2.2 Extração e identificação de lipídios.................................................................. 34 
4.2.2.1 Extração de lipídios............................................................................... 34

4.2.2.2 Identificação de lipídios...................................................................... 34

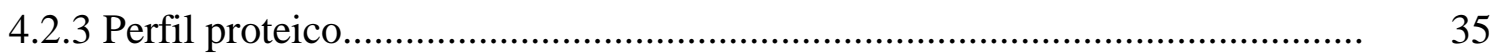

4.2.3.1 Preparo dos solventes................................................................. $\quad 35$

4.2.3.2 Limpeza das placas "anchorchip" e "polished"................................ 36

4.2.3.3 Preparo do calibrante................................................................... 36

4.2.3.4 Preparo das matrizes..................................................................... 37

4.2.3.5 Preparo das amostras e análise.................................................... 37

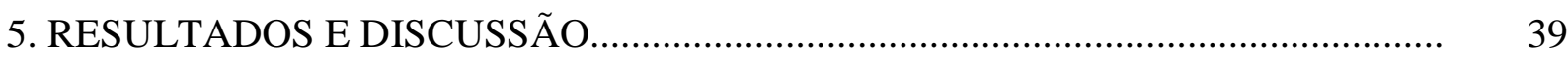

5.1 CULTIVOS DE MICROALGAS.............................................................. 39

5.1.1 Espécies de microalgas estudadas........................................................... $\quad 39$

5.1.2 Mapeamento do agitador orbital (Shaker)............................................... 40

5.1.3 Curva de crescimento para análise estatística.......................................... 42

5.1.4 Otimização do sistema de cultivo................................................................ 48

5.1.5 Curva de calibração para quantificação celular - Densidade Óptica (DO) x Concentração de Massa Seca (g/L) .................................................................... 51

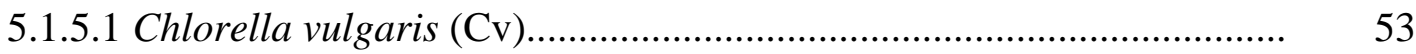

5.1.5.2 Chlorella sp. (Csp)................................................................. 53

5.1.5.3 Desmodesmus sp. (Dsp).......................................................... 54

5.1.5.4 Monoraphidium sp. (Msp)....................................................... 55

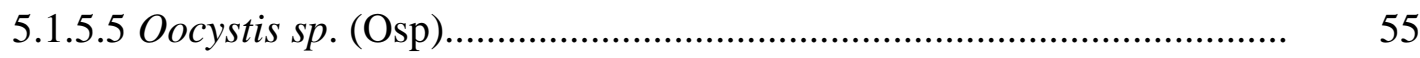

5.1.6 Curvas de crescimento e cinética das espécies estudadas............................. 56

5.1.6.1 Curvas de crescimento - Experimento I........................................ 56

5.1.6.1.1 Cinéticas de crescimento - Experimento I.............................. 58

5.1.6.2 Curvas de crescimento - Experimento II....................................... $\quad 59$

5.1.6.2.1 Cinéticas de crescimento - Experimento II.............................. 60 


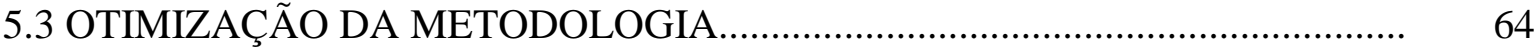

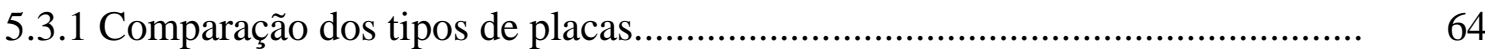

5.3.1.1 Calibração........................................................................................ 65

5.3.1.2 Análises das amostras de microalgas................................................. 65

5.3.2 Variável modo de análise: linear e refletor..................................................... 69

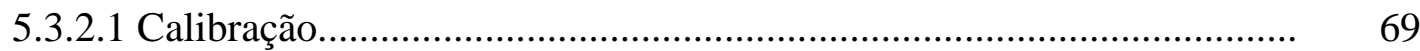

5.3.2.2 Análises das amostras de microalgas................................................ 69

5.3.3 Parâmetro PIE - Extração Pulsada de Íons (Pulsed Ion Extraction).............. 73

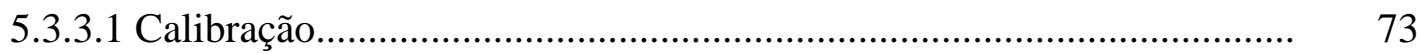

5.3.3.2 Análises das amostras de microalgas................................................... 73

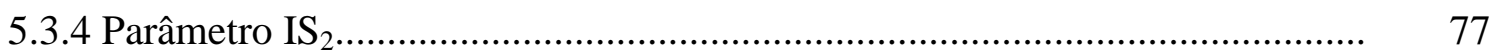

5.3.4.1 Calibração.................................................................................... $\quad 78$

5.3.4.2 Análises das amostras de microalgas................................................. 78

5.3.5 Estudo comparativo dos diferentes tipos de matrizes................................... 82

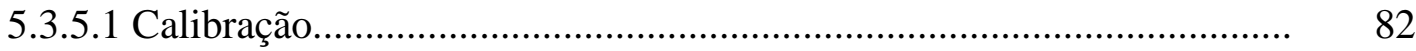

5.3.5.2 Análises das amostras de microalgas.................................................. 83

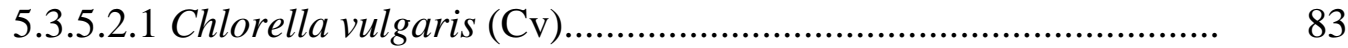

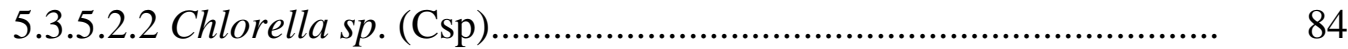

5.3.5.2.3 Desmodesmus sp. (Dsp)...................................................... $\quad 85$

5.3.5.2.4 Monoraphidium sp. (Msp).................................................. 86

5.3.5.2.5 Oocystis sp. (Osp)............................................................... 87

5.3.6 Estudo da concentração da matriz DHB....................................................... 91

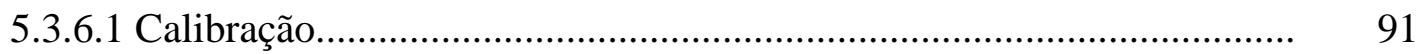

5.3.6.2 Análises das amostras de microalgas.............................................. 91 
5.3.7 Influência da concentração de TFA no solvente da matriz sDHB.................. 95

5.3.7.1 Calibração................................................................................... 96

5.3.7.2 Análises das amostras de microalgas................................................ 96

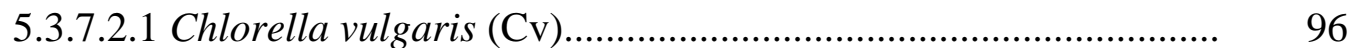

5.3.7.2.2 Chlorella sp. (Csp).............................................................. 97

5.3.7.2.3 Desmodesmus sp. (Dsp)........................................................ 98

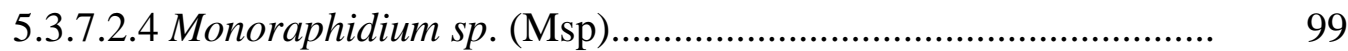

5.3.7.2.5 Oocystis sp. (Osp).............................................................. 100

5.3.8 Adição de isopropanol ao solvente da matriz sDHB..................................... 102

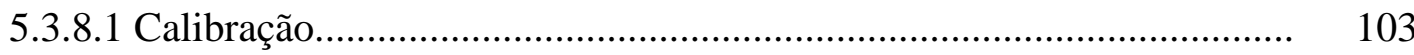

5.3.8.2 Análises das amostras de microalgas................................................. 103

5.3.9 Influência da concentração de TFA no solvente das microalgas..................... 107

5.3.9.1 Calibração......................................................................................... 107

5.3.9.2 Análises das amostras de microalgas................................................. 108

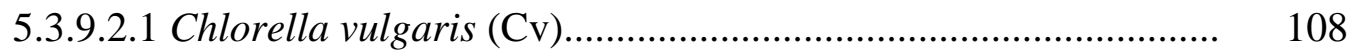

5.3.9.2.2 Chlorella sp. (Csp)................................................................ 109

5.3.9.2.3 Desmodesmus sp. (Dsp)...................................................... 109

5.3.9.2.4 Monoraphidium sp. (Msp)................................................... 110

5.3.9.2.5 Oocystis sp. (Osp)............................................................. 111

5.4 PERFIL PROTEICO AO LONGO DA CURVA DE CRESCIMENTO................ 113

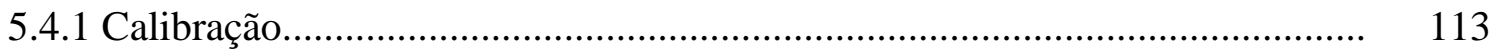

5.5 PERFIL LIPÍDICO DAS ESPÉCIES DE MICROALGAS ESTUDADAS........... 119

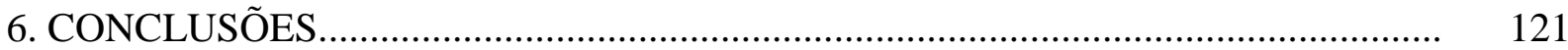

7.PUBLICAÇÕES E PARTICIPAÇÕES EM CONGRESSOS....................................... 124

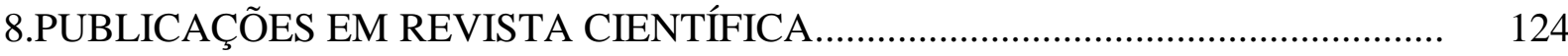


9.DOUTORADO SANDUÍCHE

10. SUGESTÕES PARA CONTINUIDADE DO TRABALHO.

11. REFERÊNCIAS BIBLIOGRÁFICAS.

12. ANEXOS

Anexo I: Lista de reagentes químicos

Anexo II: Lista de equipamentos

Anexo III: Curva cinética da fase exponencial em todas as posições do agitador orbital

Anexo IV: Dados de absorbância a 750nm ao longo da curva de crescimento utilizada na análise estatística.

Anexo V: Tabela de distribuição FSnedecor ao nível de probabilidade 5\% 


\section{LISTA DE ABREVIATURAS}

\begin{tabular}{|c|c|}
\hline Abreviação & Significado \\
\hline $\mathrm{ACN}$ & Acetonitrila \\
\hline $\mathrm{AF}$ & Ácido Fórmico \\
\hline $\mathrm{Cv}$ & Chlorella vulgaris \\
\hline Csp & Chlorella sp. \\
\hline Dsp & Desmodesmus sp. \\
\hline DAN & 1,5-Diaminonaftaleno \\
\hline DHAP & 5-Dihidroxiacetofenona \\
\hline DHB & Ácido Dihidroxibenzóico \\
\hline HCCA & Ácido $\alpha$-ciano-4-hidroxiciamico \\
\hline IS1 & Fonte de Íons 1 - Placa de MALDI \\
\hline IS2 & Fonte de Íons 2 - eletrodo \\
\hline ISO & Isopropanol \\
\hline ISOTA50 & ACN:0,1\% TFA:ISO (50:35:15 v/v) \\
\hline ISO1TA50 & ACN:1,0\% TFA:ISO (50:35:15 v/v) \\
\hline ISO2,5TA50 & ACN:2,5\% TFA:ISO (50:35:15 v/v) \\
\hline MS & Massa Seca \\
\hline MSA & Ácido 5-Metoxisalicílico \\
\hline Msp & Monoraphidium sp. \\
\hline Osp & Oocystis sp. \\
\hline PIE & Pulsed Ion Extraction (Extração Pulsada de Íons) \\
\hline SA & Ácido Sinapínico \\
\hline sDHB & DHB com $10 \%$ de ácido 2-hidroxi-5-methoxibenzóico \\
\hline TA30 & ACN:0,1\% TFA $(30: 70 \mathrm{v} / \mathrm{v})$ \\
\hline TA50 & ACN:0,1\% TFA $(50: 50 \mathrm{v} / \mathrm{v})$ \\
\hline TFA & Ácido Trifluoracético \\
\hline 1TA50 & ACN:1,0\%TFA $(50: 50 \mathrm{v} / \mathrm{v})$ \\
\hline $2,5 \mathrm{TA} 50$ & ACN:2,5\% TFA $(50: 50 \mathrm{v} / \mathrm{v})$ \\
\hline
\end{tabular}




\section{LISTA DE FIGURAS}

Figura 1: Consumo mundial de energia em diferentes setores de atividade.

Figura 2: Oferta brasileira de energia

Figura 3: Sinergia do grupo de microalgas.

Figura 4: Fases do crescimento de um micro-organismo.

Figura 5: Ionização da mistura amostra/matriz.

Figura 6: Ionização da amostra/matriz, aceleração pelo tubo de vôo e detecção dos íons.

Figura 7: Diagrama de um espectrômetro de massas do tipo MALDI-TOF-MS

Figura 8: Princípios básicos das placas "anchorchip" (A) e a tradicional "polished” (B) utilizadas na técnica de MALDI.

Figura 9: Diferença na resolução dos espectros adquiridos utilizando analisador de massas TOF nos modo linear (A) e refletor (B)

Figura 10: Influência da potência do laser aplicado sobre a qualidade dos espectros.

Figura 11: Relação entre a diferença de potência (dV) e a massa do íon em vários PIE....

Figura 12: Banco de culturas das microalgas estudadas.

Figura 13: Banco de culturas para realização dos experimentos.

Figura 14: Imagens adquiridas em microscópio das espécies Chlorella vulgaris, Chlorella sp., Desmodesmus sp., Monoraphidium sp. e Oocystis sp., respectivamente A, B, C, D e E, utilizadas nesse trabalho.

Figura 15: Esquema da incidência da intensidade luminosa nas posições do agitador orbital

Figura 16: Agitador orbital para cultivos das microalgas

Figura 17: Curva de crescimento para todas as posições do agitador orbital ao longo de 26 dias.

Figura 18: Curva cinética da fase exponencial na posição L1E1

Figura 19: Gráfico comparativo das linhas do agitador orbital de acordo com o crescimento celular. 
Figura 20: Otimização do sistema de cultivo de microalgas............................................... 48

Figura 21: Curva de crescimento (A) e cinética (B) para caracterização do pré-inóculo... 50

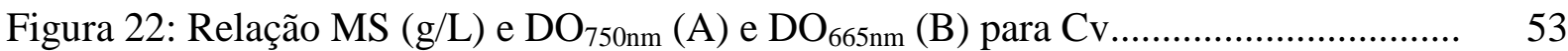

Figura 23: Relação MS (g/L) e $\mathrm{DO}_{750 \mathrm{~nm}}(\mathrm{~A})$ e $\mathrm{DO}_{665 \mathrm{~nm}}$ (B) para Csp............................... 54

Figura 24: Relação MS (g/L) e DO $\mathrm{DO}_{750 \mathrm{~nm}}(\mathrm{~A})$ e $\mathrm{DO}_{665 \mathrm{~nm}}$ (B) para Dsp.............................. 54

Figura 25: Relação MS (g/L) e $\mathrm{DO}_{750 \mathrm{~nm}}(\mathrm{~A})$ e $\mathrm{DO}_{665 \mathrm{~nm}}$ (B) para Msp.............................. 55

Figura 26: Relação MS (g/L) e $\mathrm{DO}_{750 \mathrm{~nm}}(\mathrm{~A})$ e $\mathrm{DO}_{665 \mathrm{~nm}}$ (B) para Osp............................. 56

Figura 27: Curvas de crescimento das espécies Cv (A), Csp (B), Dsp (C), Msp (D) e Osp (E) - experimento I

Figura 28: Cinéticas de crescimento das espécies Cv (A), Csp (B), Dsp (C), Msp (D) e Osp (E) do experimento I.

Figura 29: Curvas de crescimento das espécies Cv (A), Csp (B), Dsp (C), Msp (D) e Osp (E) - experimento II

Figura 30: Cinéticas de crescimento das espécies Cv (A), Csp (B), Dsp (C), Msp (D) e Osp (E) do experimento II.

Figura 31: Perfis dos espectros de massas do tipo MALDI-TOF de proteínas ao longo do crescimento do dia 0 ao dia 12 (coletas a cada 2 dias) da espécie $\mathrm{Cv}$.

Figura 32: Perfis dos espectros de massas do tipo MALDI-TOF de proteínas ao longo do crescimento do dia 0 ao dia 12 (coletas a cada 2 dias) da espécie Csp

Figura 33: Perfis dos espectros de massas do tipo MALDI-TOF de proteínas ao longo do crescimento do dia 0 ao dia 12 (coletas a cada 2 dias) da espécie Dsp.

Figura 34: Perfis dos espectros de massas do tipo MALDI-TOF de proteínas ao longo do crescimento do dia 0 ao dia 12 (coletas a cada 2 dias) da espécie Msp.

Figura 35: Perfis dos espectros de massas do tipo MALDI-TOF de proteínas ao longo do crescimento do dia 0 ao dia 12 (coletas a cada 2 dias) da espécie Osp.

Figura 36: Comparação dos perfis dos espectros de massas do tipo MALDI-TOF produzidos utilizando as placas "anchorchip" (A) e "polished" (B) no estudo da microalga $\mathrm{Cv}$ 
Figura 37: Comparação dos perfis dos espectros de massas do tipo MALDI-TOF produzidos utilizando as placas "anchorchip" (A) e "polished" (B) no estudo da microalga Csp.

Figura 38: Comparação dos perfis dos espectros de massas do tipo MALDI-TOF produzidos utilizando as placas "anchorchip" (A) e "polished" (B) no estudo da microalga Dsp

Figura 39: Comparação dos perfis dos espectros de massas do tipo MALDI-TOF produzidos utilizando as placas "anchorchip" (A) e "polished" (B) no estudo da microalga Msp.

Figura 40: Comparação dos perfis dos espectros de massas do tipo MALDI-TOF produzidos utilizando as placas "anchorchip" (A) e "polished" (B) no estudo da microalga Osp

Figura 41: Comparação dos perfis dos espectros de massas do tipo MALDI-TOF nos diferentes modos de análise linear (A) e refletor (B) no estudo da microalga $\mathrm{Cv}$.

Figura 42: Comparação dos perfis dos espectros de massas do tipo MALDI-TOF nos diferentes modos de análise linear (A) e refletor (B) no estudo da microalga Csp......

Figura 43: Comparação dos perfis dos espectros de massas do tipo MALDI-TOF nos diferentes modos de análise linear (A) e refletor (B) no estudo da microalga Dsp.....

Figura 44: Comparação dos perfis dos espectros de massas do tipo MALDI-TOF nos diferentes modos de análise linear (A) e refletor (B) no estudo da microalga Msp.

Figura 45: Comparação dos perfis dos espectros de massas do tipo MALDI-TOF nos diferentes modos de análise linear (A) e refletor (B) no estudo da microalga Osp.

Figura 46: Comparação dos perfis dos espectros de massas do tipo MALDI-TOF obtidos no diferentes valores de PIEs, 100ns (A), 250ns (B) e 450ns (C) utilizados no estudo da microalga $\mathrm{Cv}$

Figura 47: Comparação dos perfis dos espectros de massas do tipo MALDI-TOF obtidos no diferentes valores de PIEs, 100ns (A), 250ns (B) e 450ns (C) utilizados no estudo da microalga Csp. 
Figura 48: Comparação dos perfis dos espectros de massas do tipo MALDI-TOF obtidos no diferentes valores de PIEs, 100ns (A), 250ns (B) e 450ns (C) utilizados no estudo da microalga Dsp.

Figura 49: Comparação dos perfis dos espectros de massas do tipo MALDI-TOF obtidos no diferentes valores de PIEs, 100ns (A), 250ns (B) e 450ns (C) utilizados no estudo da microalga Msp.

Figura 50: Comparação dos perfis dos espectros de massas do tipo MALDI-TOF obtidos no diferentes valores de PIEs, 100ns (A), 250ns (B) e 450ns (C) utilizados no estudo da microalga Osp.

Figura 51: Comparação dos perfis dos espectros de massas do tipo MALDI-TOF de proteínas da microalga $\mathrm{Cv}$, obtidos com a variação dos valores de $\mathrm{IS}_{2}, 23 \mathrm{kV}(\mathrm{A}), 23,55$ $\mathrm{kV}(\mathrm{B})$ e $24 \mathrm{kV}(\mathrm{C})$

Figura 52: Comparação dos perfis dos espectros de massas do tipo MALDI-TOF de proteínas da microalga Csp, obtidos com a variação dos valores de $\mathrm{IS}_{2}, 23 \mathrm{kV}$ (A), $23,55 \mathrm{kV}(\mathrm{B})$ e $24 \mathrm{kV}(\mathrm{C})$

Figura 53: Comparação dos perfis dos espectros de massas do tipo MALDI-TOF de proteínas da microalga Dsp, obtidos com a variação dos valores de $\mathrm{IS}_{2}, 23 \mathrm{kV}$ (A), $23,55 \mathrm{kV}(\mathrm{B})$ e $24 \mathrm{kV}(\mathrm{C})$

Figura 54: Comparação dos perfis dos espectros de massas do tipo MALDI-TOF de proteínas da microalga Msp, obtidos com a variação dos valores de $\mathrm{IS}_{2}, 23 \mathrm{kV}$ (A), $23,55 \mathrm{kV}(\mathrm{B})$ e $24 \mathrm{kV}(\mathrm{C})$

Figura 55: Comparação dos perfis dos espectros de massas do tipo MALDI-TOF de proteínas da microalga Osp, obtidos com a variação dos valores de $\mathrm{IS}_{2}, 23 \mathrm{kV}$ (A), $23,55 \mathrm{kV}(\mathrm{B})$ e $24 \mathrm{kV}(\mathrm{C})$

Figura 56: Perfis de espectros de massas do tipo MALDI-TOF obtidos para a microalga Cv no estudo com as diferentes matrizes SA (A), HCCA (B), DHB (C) e sDHB (D)........

Figura 57: Perfis de espectros de massas do tipo MALDI-TOF obtidos para a microalga Csp no estudo com as diferentes matrizes SA (A), HCCA (B), DHB (C) e sDHB (D).....

Figura 58: Perfis de espectros de massas do tipo MALDI-TOF obtidos para a microalga Dsp no estudo com as diferentes matrizes SA (A), HCCA (B), DHB (C) e sDHB (D)...... 
Figura 59: Perfis de espectros de massas do tipo MALDI-TOF obtidos para a microalga Msp no estudo com as diferentes matrizes SA (A), HCCA (B), DHB (C) e sDHB (D).....

Figura 60: Perfis de espectros de massas do tipo MALDI-TOF obtidos para a microalga Osp no estudo com as diferentes matrizes SA (A), HCCA (B), DHB (C) e sDHB (D)......

Figura 61: Distribuição das matrizes SA (A), HCCA (B), DHB (C) e sDHB (D) nos "spots"......

Figura 62: Perfis de espectros de massas do tipo MALDI-TOF obtidos no estudo de diferentes teores de DHB em diferentes matrizes DHB (A), DHB45 (B) e sDHB (C) para a microalga $\mathrm{Cv}$.

Figura 63: Perfis de espectros de massas do tipo MALDI-TOF obtidos no estudo de diferentes teores de DHB em diferentes matrizes DHB (A), DHB45 (B) e sDHB (C) para a microalga Csp.

Figura 64: Perfis de espectros de massas do tipo MALDI-TOF obtidos no estudo de diferentes teores de DHB em diferentes matrizes DHB (A), DHB45 (B) e sDHB (C) para a microalga Dsp.

Figura 65: Perfis de espectros de massas do tipo MALDI-TOF obtidos no estudo de diferentes teores de DHB em diferentes matrizes DHB (A), DHB45 (B) e sDHB (C) para a microalga Msp.

Figura 66: Perfis de espectros de massas do tipo MALDI-TOF obtidos no estudo de diferentes teores de DHB em diferentes matrizes DHB (A), DHB45 (B) e sDHB (C) para a microalga Osp.

Figura 67: Perfis de espectros de massas do tipo MALDI-TOF obtido para a microalga $\mathrm{Cv}$ no estudo dos diferentes teores de TFA no solvente da matriz sDHB, TA50 (A), $1 \mathrm{TA} 50(\mathrm{~B})$ e $2,5 \mathrm{TA} 50(\mathrm{C})$

Figura 68: Perfis de espectros de massas do tipo MALDI-TOF obtido para a microalga Csp no estudo dos diferentes teores de TFA no solvente da matriz sDHB, TA50 (A), $1 \mathrm{TA50}(\mathrm{B})$ e $2,5 \mathrm{TA50}(\mathrm{C})$

Figura 69: Perfis de espectros de massas do tipo MALDI-TOF obtido para a microalga Dsp no estudo dos diferentes teores de TFA no solvente da matriz sDHB, TA50 (A), $1 \mathrm{TA} 50$ (B) e 2,5TA50 (C) 
Figura 70: Perfis de espectros de massas do tipo MALDI-TOF obtido para a microalga Msp no estudo dos diferentes teores de TFA no solvente da matriz sDHB, TA50 (A), $1 \mathrm{TA50}(\mathrm{B})$ e $2,5 \mathrm{TA} 50$ (C)

Figura 71: Perfis de espectros de massas do tipo MALDI-TOF obtido para a microalga Osp no estudo dos diferentes teores de TFA no solvente da matriz sDHB, TA50 (A), $1 \mathrm{TA50}(\mathrm{B})$ e $2,5 \mathrm{TA} 50$ (C)

Figura 72: Distribuição da matriz sDHB no "spot", sem adição de isopropanol (A) e com adição de isopropanol (B)

Figura 73: Comparação dos perfis dos espectros de massas do tipo MALDI-TOF utilizando os solventes TA50 (A) e ISOTA50 (B) na resuspensão da microalga Cv.....

Figura 74: Comparação dos perfis dos espectros de massas do tipo MALDI-TOF utilizando os solventes TA50 (A) e ISOTA50 (B) na resuspensão da microalga Csp........

Figura 75: Comparação dos perfis dos espectros de massas do tipo MALDI-TOF utilizando os solventes TA50 (A) e ISOTA50 (B) na resuspensão da microalga Dsp.......

Figura 76: Comparação dos perfis dos espectros de massas do tipo MALDI-TOF utilizando os solventes TA50 (A) e ISOTA50 (B) na resuspensão da microalga Msp.......

Figura 77: Comparação dos perfis dos espectros de massas do tipo MALDI-TOF utilizando os solventes TA50 (A) e ISOTA50 (B) na resuspensão da microalga Osp.......

Figura 78: Perfis de espectros de massas do tipo MALDI-TOF obtido no estudo dos diferentes solventes, TA50 (A), 1TA50 (B) e 2,5TA50 (C), utilizados na amostra da microalga $\mathrm{Cv}$

Figura 79: Perfis de espectros de massas do tipo MALDI-TOF obtido no estudo dos diferentes solventes, TA50 (A), 1TA50 (B) e 2,5TA50 (C), utilizados na amostra da microalga Csp.

Figura 80: Perfis de espectros de massas do tipo MALDI-TOF obtido no estudo dos diferentes solventes, TA50 (A), 1TA50 (B) e 2,5TA50 (C), utilizados na amostra da microalga Dsp.

Figura 81: Perfis de espectros de massas do tipo MALDI-TOF obtido no estudo dos diferentes solventes, TA50 (A), 1TA50 (B) e 2,5TA50 (C), utilizados na amostra da microalga Msp. 
Figura 82: Perfis de espectros de massas do tipo MALDI-TOF obtido no estudo dos diferentes solventes, TA50 (A), 1TA50 (B) e 2,5TA50 (C), utilizados na amostra da microalga Osp.

Figura 83: Perfis dos espectros de massas do tipo MALDI-TOF ao longo do crescimento do dia 0 ao dia 12 (coletas a cada 2 dias) da espécie $\mathrm{Cv}$ comparando os parâmetros e condições de análise antigos (A) e parâmetros e condições de análise otimizadas (B)

Figura 84: Perfis dos espectros de massas do tipo MALDI-TOF ao longo do crescimento do dia 0 ao dia 12 (coletas a cada 2 dias) da espécie Csp comparando os parâmetros e condições de análise antigos (A) e parâmetros e condições de análise otimizadas (B)

Figura 85: Perfis dos espectros de massas do tipo MALDI-TOF ao longo do crescimento do dia 0 ao dia 12 (coletas a cada 2 dias) da espécie Dsp comparando os parâmetros e condições de análise antigos (A) e parâmetros e condições de análise otimizadas (B)

Figura 86: Perfis dos espectros de massas do tipo MALDI-TOF ao longo do crescimento do dia 0 ao dia 12 (coletas a cada 2 dias) da espécie Msp comparando os parâmetros e condições de análise antigos (A) e parâmetros e condições de análise otimizadas (B)

Figura 87: Perfis dos espectros de massas do tipo MALDI-TOF ao longo do crescimento do dia 0 ao dia 12 (coletas a cada 2 dias) da espécie Osp comparando os parâmetros e condições de análise antigos (A) e parâmetros e condições de análise otimizadas (B) 


\section{LISTA DE TABELAS}

Tabela 1: Maiores emissores de $\mathrm{CO}_{2}$ na atmosfera

Tabela 2: Principais barreiras encontradas na utilização de microalga como fonte de biocombustível.

Tabela 3: Comparação de produção de óleo/biodiesel de diversas oleaginosas 10

Tabela 4: Teor lipídico e produtividade de diferentes espécies de microalgas. 11

Tabela 5: Macronutrientes para cultivos de microalgas. 16

Tabela 6: Principais ácidos graxos presentes em microalgas 18

Tabela 7: Composição do meio sintético WC

Tabela 8: Condições da análise cromatográfica.

Tabela 9: Composição da mistura de calibrantes de proteínas padrão

Tabela 10: Classificação das diferentes espécies de microalgas usadas nesse trabalho.....

Tabela 11: Medidas de intensidade luminosa em cada posição do agitador orbital sem a presença de erlenmeyers.

Tabela 12: Valores de $\mu_{\max }$ e $t_{d}$ para a curva de crescimento em cada posição do agitador orbital.

Tabela 13: Medidas de absorbância para as 3 linhas do agitador orbital utilizadas para análise estatística do dia 0 .....

Tabela 14: Análise de variância (ANOVA) para as 3 linhas do agitador orbital.

Tabela 15: Dados de carbono total (CT), carbono inorgânico total (CIT) e carbono orgânico total (COT) da amostra de Chlorella vulgaris após 26 dias

Tabela 16: Análise de variância (ANOVA) para as 12 posições do agitador orbital

Tabela 17: Medidas médias de intensidades luminosas para cada posição do agitador orbital.

Tabela 18: Medidas de densidade óptica para determinação do pré-inóculo.

Tabela 19: Coletas realizadas nos respectivos dias e posições do "shaker". 
Tabela 20: Leituras de densidade óptica a 750 e 665nm para quantificação celular 53

Tabela 21: Comparação dos resultados no uso das placas "polished" e "anchorchip"

Tabela 22: Estudo comparativo de diferentes modos de análise.

Tabela 23: Estudo comparativo de diferentes valores de PIEs.

Tabela 24: Estudo comparativo de diferentes valores para $\mathrm{IS}_{2}$ 74

Tabela 25: Estudo comparativo de diferentes matrizes. 81

Tabela 26: Estudo comparativo da concentração de DHB na matriz

Tabela 27: Estudo comparativo do aumento do teor de TFA no solvente da matriz sDHB.

Tabela 28: Estudo comparativo da adição de isopropanol ao solvente da matriz sDHB....

Tabela 29: Estudo comparativo do uso dos solventes TA50, 1TA50 e 2,5TA50 na amostra

Tabela 30: Perfil lipídico obtido através da cromatografia gasosa acoplada à espectrometria de massas para cultivos de microalgas de 12 e 8 dias 


\section{RESUMO}

As mudanças climáticas associadas às atividades humana são devidas principalmente às emissões de $\mathrm{CO}_{2}$ na atmosfera provenientes da queima de combustíveis de origem fóssil. Desta forma, faz-se necessária a substituição dessas fontes fósseis de geração de energia, por fontes renováveis. Dentre as alternativas de fontes renováveis, podemos destacar os biocombustíveis produzidos a partir de microalgas, as quais apresentam composição rica em óleos e proteínas. Um dos grandes desafios encontrados na conversão de biomassa em biocombustíveis é a caracterização detalhada das microalgas. A identificação de espécies através da espectrometria de massas com Ionização/Dessorção à Laser Assistida por Matriz acoplada a analisador por tempo de vôo (MALDI-TOF-MS) utilizada na análise de perfil de proteínas de micro-organismos, e posterior rápida identificação por comparação com os padrões armazenados em bancos de dados (fingerprint) tem se sobressaído. Existem poucos trabalhos na literatura abordando a identificação de espécies de microalgas utilizando a técnica de MALDI-TOF-MS e nenhum trabalho abordando a análise a partir do uso de células de microalgas liofilizadas. Desta forma, nesse trabalho foi estudada a influência de diversos parâmetros tais como placa, modo de análise, valor de PIE, valor de $\mathrm{IS}_{2}$, matriz e solvente de matriz e amostra nos espectros de massas do tipo MALDI-TOF-MS para análise do perfil proteico de células liofilizadas das espécies de microalgas Chlorella vulgaris, Chlorella sp., Desmodesmus sp., Monoraphidium sp. e Oocystis sp. Primeiramente, os cultivos foram realizados em um sistema de agitador orbital otimizado de tal maneira que todas as posições apresentassem as mesmas condições. Após os cultivos, as células foram secas para posterior análise de espectrometria de massas. Para determinação da metodologia que fornecesse os melhores espectros de massas, foram avaliados, aleatoriamente, 3 parâmetros: número de íons (P1), relação sinal/ruído do pico base (P2) e intensidade do pico base (P3). Foi observado que para a maioria das amostras de microalgas, os parâmetros que mais influenciaram na obtenção de espectros de massas do tipo MALDI-TOF bem resolvidos foram a placa, o modo de análise, valor de PIE, valor de $\mathrm{IS}_{2}$ e a matriz. As variações obtidas nos espectros de massas, quando utilizados diferentes solventes tanto para a matriz quanto para a amostra, bem como a adição de isopropanol com o objetivo de melhorar a distribuição da matriz sDHB na placa de amostragem, não foram tão significativas como as observadas para os outros parâmetros avaliados nesse estudo. Como conclusão, o uso da matriz sDHB, solvente TA50 para amostra e matriz, análise na placa "polished" sob as condições de análise PIE 100ns, IS 2 23kV 
mostraram-se muito mais efetivos para a análise de proteínas a partir de amostras de microalgas liofilizadas. A análise dos lipídios apresentou uma distribuição predominante dos ácidos graxos C16:0, C18:2 e C18:0 para os cultivos de 12 dias e C16:0, C18:2 e C22:6 para os cultivos de 8 dias. Entretanto, as proporções de C22:6 e C18:2 aumentaram para os cultivos de 8 dias. Dessa forma, as espécies de microalgas Chlorella vulgaris., Chlorella sp., Monoraphidium sp. e Oocystis sp. cultivadas por 8 dias podem ser convertidas em biocombustível por apresentarem ácidos graxos entre 14 e 18 carbonos e em sua composição. 


\begin{abstract}
Climate change associated to human activities are mainly due to $\mathrm{CO}_{2}$ emissions from combustion of fossil fuels in the atmosphere. Thus, it is necessary to replace these fossil sources of energy generation for renewable sources. Among the alternative of renewable sources, biofuels derived from microalgae is am potential alternative, since microalgae present in their composition fatty acids and proteins. Characterization of microalgae is one of the challenges in the conversion of their biomass into biofuels. The microorganism species identification by Matrix-Assisted Laser Desorption/Ionization Time-of-Flight Mass Spectrometry (MALDI-TOF-MS) thought the analysis of protein profile and subsequent fast identification by comparison with the standard protein profile (fingerprint) in the database has been outstanding. There are few studies in the literature about the identification of microalgae species using MALDI-TOF-MS technique and there is no one using cells of lyophilized microalgae. Thus, in this work was studied the influence of many parameters such as target, analysis mode, PIE, $\mathrm{IS}_{2}$ value, matrix, matrix solvent and sample solvent in the MALDI-TOF mass spectra for analysis of protein profile of lyophilized microalgae cells for the species Chlorella vulgaris cells, Chlorella sp., Desmodesmus sp., Monoraphidium sp. and Oocystis $s p$. Cultivations were carried out using an optimized shaker system, where all positions presented the same conditions. After the cultivation, the cells were dried for subsequent mass spectrometric analysis. To achieve the best mass spectra profile, 3 parameters were arbitrarily evaluated: number of ions (P1), base peak signal/noise ratio (P2) and base peak intensity (P3). It was observed for most microalgae samples, MALDI-TOF mass spectra profile were most influenced by target, analysis mode, PIE value, IS $_{2}$ value and the matrix. Variations in the mass spectra obtained when different solvents were used (for matrix and sample) as well as the addition of isopropanol in order to improve the distribution of sDHB matrix on the spot, were not significant as that observed for the other parameters. In conclusion, the use of sDHB matrix, TA50 solvent for sample and matrix, analysis in polished target plate under the following analysis conditions: a PIE $100 \mathrm{~ns}$, a IS $23 \mathrm{kV}$, provided to be more effective for the analysis of protein from lyophilized microalgae cells. Lipid analysis of 12 days cultivated microalgae showed a predominant distribution of the C16:0, C18:2 and C18:0. The 8 days cultivation presented a distribution of C16:0, C18:2 and C22:6, but with C22:6 e C18:2 in a higher proportion. Since biofuel are produced by using the C14-C18 fatty acid contained in their composition, 8 days cultivation showed to be most effective for this purpose.
\end{abstract}




\section{INTRODUÇÃO E JUSTIFICATIVA}

As mudanças climáticas que tem sido associadas à atividade humana vêm causando efeitos tais como aumento do número de desertos, furacões, ciclones, derretimento das calotas polares e altas temperaturas.

Segundo a agência espacial americana, elevações constantes na temperatura são registradas desde 1880 (VOILAND, 2010). Segundo a Organização Meteorológica MundialOMM, 2013 foi o sétimo ano mais quente desde o início dos registros em 1850, com uma tendência para episódios climáticos extremos como o tufão Haiyan nas Filipinas, ondas de calor recordes na Austrália, enchentes do Sudão à Europa e o verão mais quente registrado no Japão em toda a história (JORNAL A FOLHA DE SÃO PAULO, 2013).

$\mathrm{O}$ aquecimento global tem sido associado mais especificamente ao aumento da emissão de gases poluentes na atmosfera, principalmente devido à queima de combustíveis de origem fóssil como gás natural, carvão e petróleo (CAVALLARO, MONDELLO, \& FRENI, 2001).

A preocupação com os rumos que o mundo tem tomado em termos ambientais tem levado autoridades globais e organizações internacionais a unir forças na tomada de medidas que, em linhas gerais, minimizem a poluição.

Em 1971, foi realizado em Founex, na Suíça, um encontro preliminar em que países em desenvolvimento e desenvolvidos discutiram questões sobre problemas ambientais, justificando que a conservação do meio ambiente não era barreira para o desenvolvimento (CORREA DO LAGO, 2006).

A $43^{\circ}$ Sessão da Assembléia Geral das Nações Unidas de 1988, aprovou a Resolução 43/196, que propunha realizar até 1992 uma nova conferência sobre temas ambientais. Essa Conferência das Nações Unidas sobre Meio Ambiente e Desenvolvimento, popularmente conhecida como Rio 92 (realizada no Rio de Janeiro), na qual os países iniciaram as ações de proteção ao meio ambiente, contou com a presença de 178 países e 112 chefes de estado.

Em 2002, foi realizada, em Johannesburgo, a chamada Rio +10 , com o intuito de revisar os 10 anos do progresso alcançado na implantação dos resultados da Rio 92, bem como revigorar o compromisso global para o desenvolvimento sustentável (CORREA DO LAGO, 2006).

A Rio +20, realizada em 2012, no Rio de Janeiro, teve como balanço final o comprometimento dos estados-membros de investir nos próximos 10 anos em projetos, 
parcerias, programas e ações nas áreas de transporte, energia, economia verde, mudanças climáticas, entre outros, associados a sustentabilidade (REVISTA BRASILIS, 2012).

Entretanto, segundo dados do IEA (INSTITUTE ENERGY AGENCY, 2008) o principal setor consumidor de energia é o de transportes (27,6\% do consumo mundial), seguido pelo setor industrial (26,5\%), Figura 1.

Em média, para cada 3,8 litros de gasolina consumidos por um automóvel são liberados $10 \mathrm{~kg}$ de $\mathrm{CO}_{2}$ na atmosfera (KNOTHE, KRAL, GERPEN, \& RAMOS, 2006). A Tabela 1 apresenta os 10 países que mais emitem $\mathrm{CO}_{2}$, bem como a relação dessas emissões de $\mathrm{CO}_{2}$ por habitante, e ainda a posição que o Brasil ocupa, com relação aos dados de 2006.

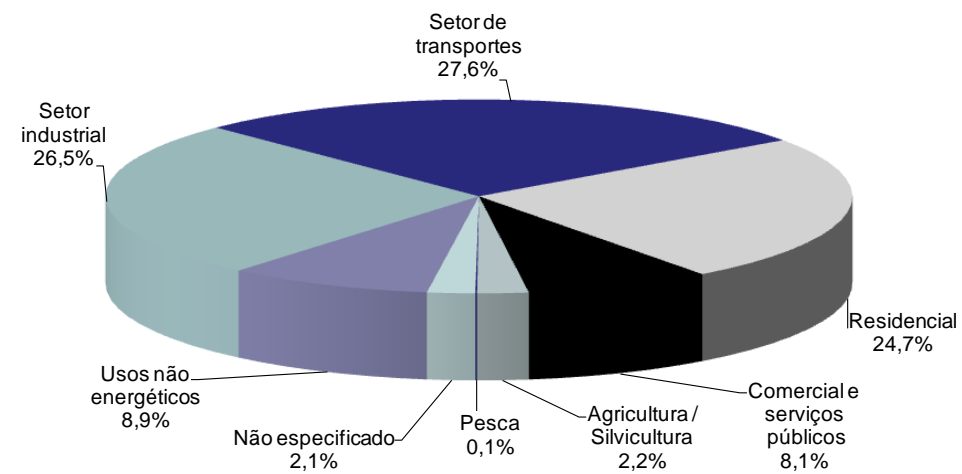

Figura 1: Consumo mundial de energia em diferentes setores de atividades.

Tabela 1: Países emissores de $\mathrm{CO}_{2}$ na atmosfera (VAUGHAN, 2009)

\begin{tabular}{|c|c|c|c|}
\hline & $\begin{array}{c}\text { Milhões de Toneladas } \\
\text { de } \mathrm{CO}_{2} / \text { ano }\end{array}$ & $\begin{array}{l}\text { \% do Total } \\
\text { Mundial }\end{array}$ & $\begin{array}{c}\text { Toneladas de } \mathrm{CO}_{2} \\
\text { por habitante }\end{array}$ \\
\hline $\left.1^{\circ}\right)$ China & $6.017,69$ & 20,64 & 4,58 \\
\hline $\left.2^{\circ}\right)$ EUA & $5.902,75$ & 20,24 & 19,78 \\
\hline $3^{\circ}$ ) Rússia & $1.704,36$ & 5,84 & 12,00 \\
\hline $4^{\circ}$ ) Índia & $1.293,17$ & 4,43 & 1,16 \\
\hline $\left.5^{\circ}\right)$ Japão & $1.246,76$ & 4,28 & 9,78 \\
\hline $\left.6^{\circ}\right)$ Alemanha & 857,60 & 2,94 & 10,40 \\
\hline $7^{\circ}$ ) Canadá & 614,33 & 2,11 & 18,81 \\
\hline $8^{\circ}$ ) Reino Unido & 585,71 & 2,01 & 9,66 \\
\hline $\left.9^{\circ}\right)$ Coréia do Sul & 514,53 & 1,76 & 10,53 \\
\hline $\left.10^{\circ}\right) \operatorname{Irã}$ & 471,48 & 1,62 & 7,25 \\
\hline $\left.17^{\circ}\right)$ Brasil & 377,24 & 1,29 & 2,01 \\
\hline
\end{tabular}

Fonte: World Resources Institute - Indicadores de Análises Climáticas 
Tendo em vista que o $\mathrm{CO}_{2}$ é um dos principais gases emitidos na atmosfera pelos setores de transportes e industrial, foi assinado no Japão, em 1997, o protocolo de Kyoto (vigente a partir de 16 de fevereiro de 2005), o qual estabelece metas aos países desenvolvidos, responsáveis por $55 \%$ dos poluentes emitidos, com destaque para emissões de $\mathrm{CO}_{2}$ para que reduzam de 2008 até 2012, suas emissões em 5,2\% em relação aos dados de 1990 (JORNAL O ESTADO DE SÃO PAULO, 2005).

Em 2007, o Mandato de Bali definiu medidas a serem tomadas após 2012. Entre tais medidas encontram-se o compromisso dos países desenvolvidos em reduzir as emissões em pelo menos 30\% até 2020 (em relação a 1990) e com a descarbonização (mais de 85\%) até 2050; e a criação de um novo Mecanismo de Desenvolvimento de Tecnologias Limpas para os países em desenvolvimento visando tecnologias renováveis, eficientes e limpas (GREENPEACE, 2007).

Em 2009, ocorreu a Conferência do Clima em Copenhague (COP 15), na qual o Brasil se comprometeu a reduzir suas emissões de gases poluentes entre 36,1 e 38,9\% em relação ao que o país emitiria em 2020 (COP 15).

Uma nova Conferência do Clima, realizada em novembro de 2013, na Polônia, apresentou um estudo afirmando que a acidificação dos oceanos, devido à adição diária de 24 milhões de toneladas de $\mathrm{CO}_{2}$, irá aumentar em $170 \%$ até o ano de 2100 , comprometendo a vida de cerca de 30\% das espécies marinhas (JORNAL A FOLHA DE SÃO PAULO, 2013).

Sendo o $\mathrm{CO}_{2}$ emitido principalmente pelos setores de transportes e industrial, a OMM prevê um desenvolvimento significativo das energias renováveis, e ainda, prediz que este tipo de energia será responsável por 30\% do total consumido até 2035 (JORNAL A FOLHA DE SÃO PAULO, 2013).

Desta forma, torna-se necessária a substituição das fontes fósseis de geração de energia por fontes renováveis, visto que além do impacto ambiental, projeções indicam seu esgotamento nos próximos 50 anos (VIAN, 2006).

Neste âmbito, o Brasil foi pioneiro na implementação do etanol combustível. Além disso, vem pesquisando outras fontes alternativas. Atualmente $81,7 \%$ da energia oferecida no país são geradas a partir de fontes de energia renováveis, Figura 2 (BEN, 2013). 


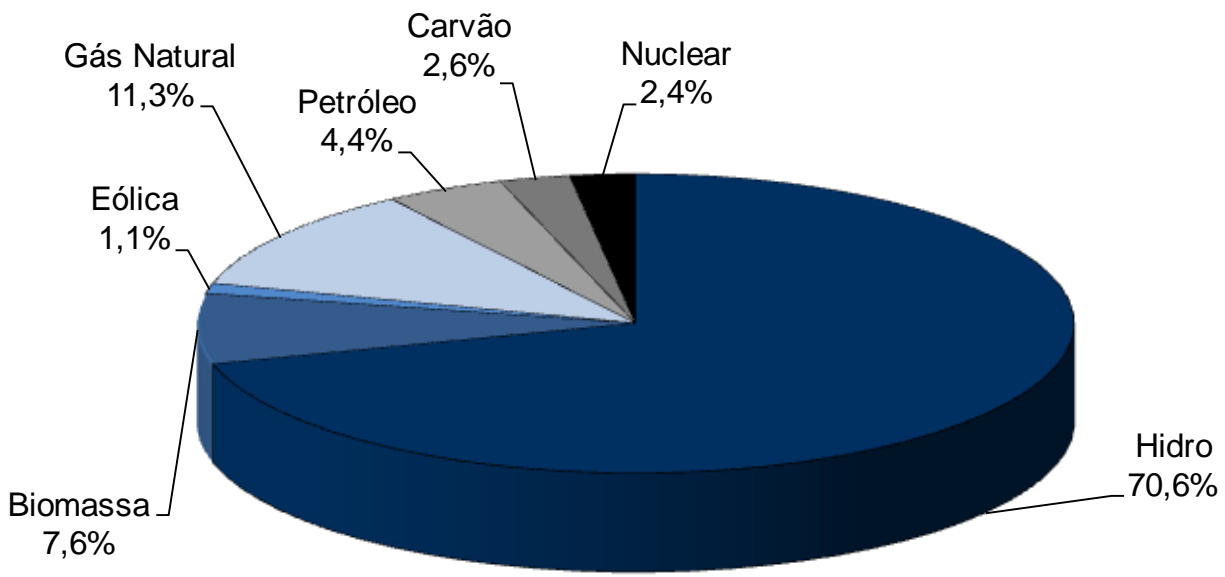

Figura 2: Oferta brasileira de energia.

Dentre as alternativas, pode-se destacar os biocombustíveis produzidos a partir de microalgas (marinhas e de água-doce), que juntamente com outras fontes de energias renováveis serão fundamentais na substituição da era do petróleo.

As microalgas apresentam em sua composição proteínas, carboidratos, além de óleos, que podem ser convertidos a compostos similares aos derivados do petróleo tais como metanol e diesel.

O setor de biocombustíveis tem investido em pesquisas como seleção e melhoramento de linhagens, cultivos em sistemas abertos, utilização de resíduos industriais, desenvolvimento de sistemas em escala industrial, entre outros, que supram as necessidades ambientais e governamentais.

Entretanto, para converter biomassa de microalga em biocombustível ainda há muitos desafios a serem vencidos. Dentre esses desafios, encontram-se desde barreiras com a matéria-prima, como desenvolvimento de banco de dados detalhado e otimização para precursores de biocombustíveis, passando pelos processos de conversão, incluindo adaptação de metodologias de extração e desafios de escalonamento, chegando até a infraestrutura, como otimizar a distribuição de energia e custos de instalação.

Muitos dos principais desafios na utilização de microalgas como fonte biocombustível encontram-se listados na Tabela 2: 
Tabela 2: Principais barreiras encontradas na utilização de microalga como fonte de biocombustível (FISHMAN et al., 2010)

\begin{tabular}{|c|c|c|}
\hline \multicolumn{3}{|c|}{$\begin{array}{c}\text { Superando barreiras para biocombustíveis de algas: Metas } \\
\text { Tecnológicas }\end{array}$} \\
\hline & Etapas & Desafios em Pesquisa e Desenvolvimento \\
\hline \multirow{4}{*}{$\begin{array}{l}\text { M } \\
\mathbf{A} \\
\mathbf{T}\end{array}$} & \multirow{5}{*}{$\begin{array}{l}\text { Biologia da } \\
\quad \text { Alga }\end{array}$} & $\begin{array}{l}\text { Amostras de linhagens de diversos ambientes para uma máxima } \\
\text { diversidade (screening). }\end{array}$ \\
\hline & & Desenvolvimento em escala laboratorial de tecnologias de screening \\
\hline & & $\begin{array}{l}\text { Desenvolvimento de bancos de dados detalhados, com livre acesso, } \\
\text { sobre as coleções microbianas. }\end{array}$ \\
\hline & & $\begin{array}{l}\text { Investigação genética e rotas metabólicas sobre a produção de } \\
\text { precursores de combustível - engenharia metabólica. }\end{array}$ \\
\hline $\mathbf{T}$ & & $\begin{array}{l}\text { Melhoramento de cepas por meio de técnicas de manipulação genética } \\
\text { ou reprodução }\end{array}$ \\
\hline \multirow{5}{*}{$\begin{array}{l}\mathbf{R} \\
\mathbf{I} \\
\mathbf{A} \\
- \\
\mathbf{P} \\
\mathbf{R} \\
\mathbf{I}\end{array}$} & \multirow{5}{*}{$\begin{array}{l}\text { Cultivo de } \\
\text { Algas }\end{array}$} & $\begin{array}{l}\text { Investigar diferentes sistemas de cultivo, tais como abertos, fechado, } \\
\text { crescimento fototrófico, autotrófico e mixotrófico. }\end{array}$ \\
\hline & & Encontrar culturas robustas e estáveis em escala industrial \\
\hline & & $\begin{array}{l}\text { Otimizar sistemas para a produção de precursores de combustíveis por } \\
\text { algas (ex: lipídios) }\end{array}$ \\
\hline & & Gerenciamento sustentável e eficiente da área, água e nutrientes. \\
\hline & & Identificar e gerenciar os riscos e impactos ambientais \\
\hline \multirow[t]{4}{*}{$\begin{array}{l}\mathbf{M} \\
\mathbf{A}\end{array}$} & \multirow{4}{*}{$\begin{array}{l}\text { Colheita e } \\
\text { Secagem }\end{array}$} & $\begin{array}{l}\text { Investigar múltiplas colheitas (ex: sedimentação, floculação, flotação } \\
\text { com ar dissolvido, centrifugação e colheita mecanizada). }\end{array}$ \\
\hline & & Minimizar os gastos energéticos do processo \\
\hline & & Reduzir investimentos e custos operacionais \\
\hline & & $\begin{array}{l}\text { Acessar cada item tecnológico em termos de compatibilidade e } \\
\text { sustentabilidade }\end{array}$ \\
\hline \multirow{13}{*}{$\begin{array}{l}\mathbf{C} \\
\mathbf{O} \\
\mathbf{N} \\
\mathbf{V} \\
\mathbf{E} \\
\mathbf{R} \\
\mathbf{S} \\
\tilde{\mathbf{A}} \\
\mathbf{O}\end{array}$} & \multirow{5}{*}{$\begin{array}{l}\text { Extração e } \\
\text { Fracionamento }\end{array}$} & $\begin{array}{l}\text { Adaptar metodologias (ex: sonicação, micro-ondas, sistemas de } \\
\text { solventes, fluido supercrítico, água subcrítica, extração seletiva). }\end{array}$ \\
\hline & & $\begin{array}{l}\text { Alcançar rendimentos elevados de intermediários desejados, preservar } \\
\text { subprodutos. }\end{array}$ \\
\hline & & Minimizar os gastos energéticos do processo \\
\hline & & Investigar mecanismos de reciclo para minimizar desperdícios \\
\hline & & $\begin{array}{l}\text { Desafios específicos de escalonamento, tais como temperatura de } \\
\text { operação, pressão, logística, reações indesejadas e purificação. }\end{array}$ \\
\hline & \multirow{5}{*}{$\begin{array}{l}\text { Conversão em } \\
\text { combustível }\end{array}$} & $\begin{array}{l}\text { Investigar a logística do transporte de combustíveis líquidos (ex: } \\
\text { produção direta de combustível, conversão termoquímica/catalítica, } \\
\text { conversão bioquímica, e digestão anaeróbica). }\end{array}$ \\
\hline & & Aumentar a especificidade, atividade e durabilidade catalítica. \\
\hline & & Reduzir contaminantes e reações inibidoras \\
\hline & & $\begin{array}{l}\text { Minimizar os gastos energéticos e as emissões do processo durante todo } \\
\text { o ciclo de vida }\end{array}$ \\
\hline & & Alcançar altas taxas de conversão em escalas maiores \\
\hline & \multirow[t]{3}{*}{ Coprodutos } & $\begin{array}{l}\text { Identificar e avaliar a coprodução de produtos químicos de significativo } \\
\text { valor agregado, energia e materiais a partir de restos de algas (Ex: } \\
\text { biogás, alimentação de animais/peixes, fertilizantes, bioplásticos e } \\
\text { surfactantes). }\end{array}$ \\
\hline & & Otimizar a extração e recuperação de coprodutos (downstream) \\
\hline & & Elaborar normas de padronização - ensaios de qualidade e segurança. \\
\hline
\end{tabular}




\begin{tabular}{|c|c|c|}
\hline \multicolumn{3}{|c|}{ Superando barreiras para biocombustílveis de algas: Metas } \\
Tecnológicas
\end{tabular}

Dentre esses desafios, pode-se destacar o desenvolvimento de banco de dados detalhado, que está relacionado à diferenciação de espécies de micro-organismos, como um grande desafio, já que as técnicas atuais são demoradas e dispendiosas.

Desta forma, tem se destacado, no meio científico, o uso da espectrometria de massas para análise de perfil de proteínas de micro-organismos, e posteriormente rápida identificação por comparação com o padrão armazenado no banco de dados. Existem pacotes de bancos de dados para bactérias e fungos, mas ainda não existe para microalgas. 


\section{OBJETIVOS}

\subsection{OBJETIVOS GERAIS}

Tendo como base as buscas por alternativas que reduzam as emissões de poluentes na atmosfera, principalmente o $\mathrm{CO}_{2}$ proveniente de combustíveis de origem fóssil, bem como o potencial das microalgas como fonte alternativa de combustível, foi formado, no ano de 2010, um grupo no Departamento de Engenharia Química da Escola Politécnica da Universidade de São Paulo visando pesquisar o uso potencial de microalgas como fonte alternativa de energia .

Dentre as frentes de estudo estão: produção de biomassa de microalgas em escala de laboratório e escala industrial; pirólise e cinética de pirólise; caracterização; gaseificação e cinética de gaseificação e avaliação econômica e de sustentabilidade, conforme descrito pelo esquema de sinergia mostrado na Figura 3.

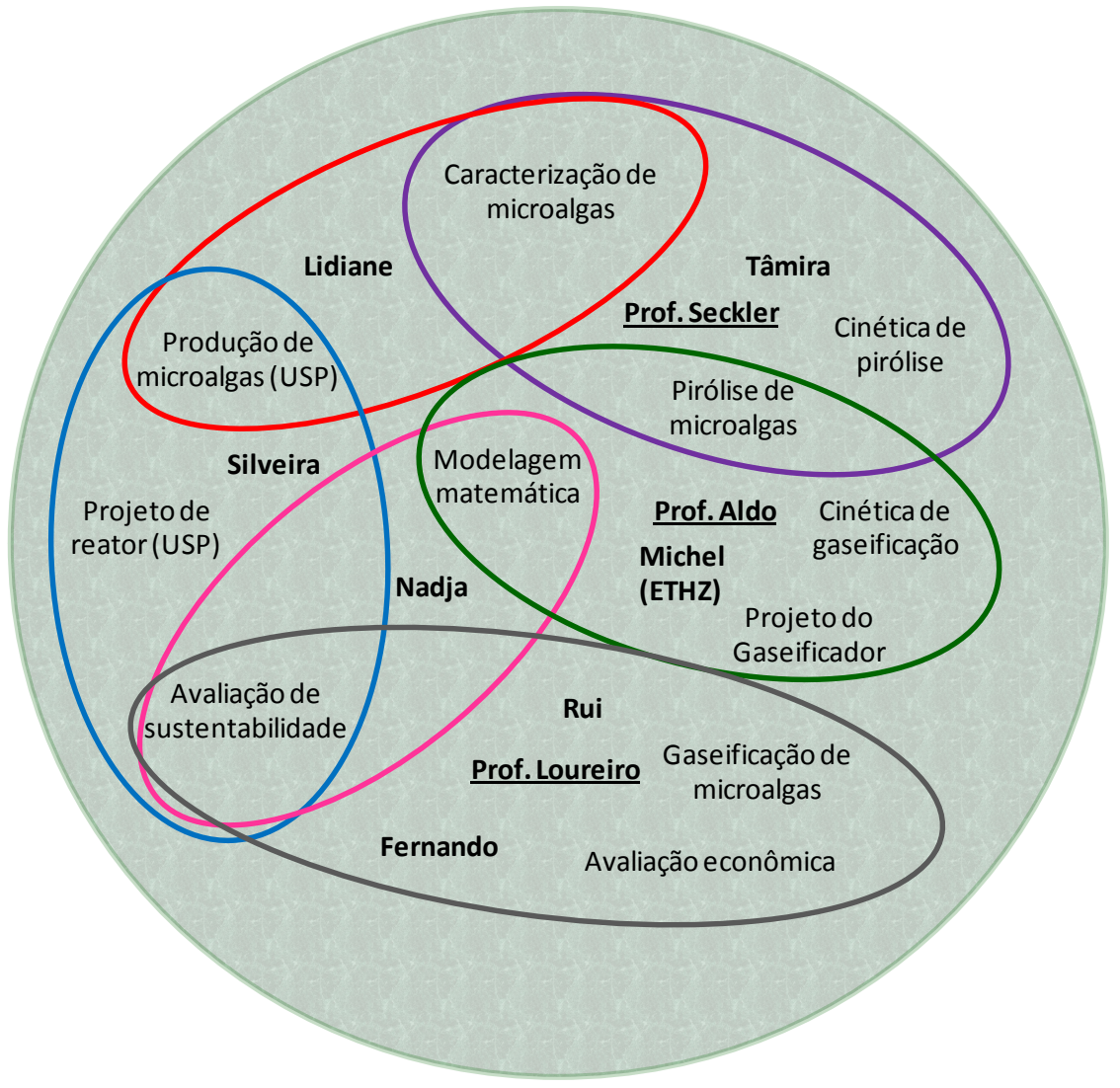

Figura 3: Sinergia do grupo de microalgas

Particularmente, esse estudo tem como objetivos gerais a produção de microalgas e a caracterização das mesmas, utilizando espectrometria de massas. 


\subsection{OBJETIVOS ESPECÍFICOS}

2.2.1 Estudo da cinética microbiana de crescimento das espécies Chlorella vulgaris, Chlorella sp., Desmodesmus sp., Monoraphidium sp. e Oocystis sp..

Determinação das curvas de crescimento, concentração celular máxima e parâmetros cinéticos dos cultivos de microalgas em escala laboratorial, com controle de temperatura, agitação, intensidade luminosa e concentração celular inicial e monitoramento do $\mathrm{pH}$ nas condições de cultivo.

2.2.2 Perfis proteicos de diferentes espécies de microalgas (Chlorella vulgaris, Chlorella sp., Desmodesmus sp., Monoraphidium sp. e Oocystis sp.), utilizando espectrometria de massas.

Utilização da técnica de ionização/dessorção à laser assistida por matriz, com analisador de massas por tempo de vôo (MALDI-TOF-MS) para células de microalgas liofilizadas.

1) As proteínas foram analisadas em diversas fases do crescimento das microalgas, visando avaliar diferenças entre as fases.

2) Otimização da metodologia de preparo de amostra, para obtenção dos melhores espectros de massas.

2.2.3 Identificação dos lipídeos das diferentes espécies de microalgas (Chlorella vulgaris, Chlorella sp., Desmodesmus sp., Monoraphidium sp. e Oocystis sp.), utilizando cromatografia gasosa acoplada à espectrometria de massas.

Extração e identificação dos lipídios das espécies de microalgas estudadas através de cromatografia gasosa acoplada à espectrometria de massas, nas fases estacionária e exponencial. 


\section{REVISÃO BIBLIOGRÁFICA}

\subsection{MICROALGAS}

Microalgas são seres unicelulares de crescimento acelerado e, para serem cultivadas, alguns fatores são de extrema importância, tais como intensidade luminosa, $\mathrm{pH}$, temperatura e fonte de nutrientes (principalmente carbono e alguns sais).

A maioria das espécies de microalgas é fotoautotrófica, ou seja, realiza a fotossíntese utilizando energia luminosa para sua manutenção, desenvolvimento e reprodução celular, através da fixação do carbono, aumentando assim a sua biomassa (GLADUE, 1991).

Microalgas são encontradas principalmente em meio marinho, em água doce e no solo (CHISTI, 2004) e podem ser cultivadas em diversos sistemas (BOROWITZKA, 1999). Recentemente, alguns cultivos têm sido desenvolvidos em equipamentos específicos, denominados fotobioreatores, onde é possível controlar os parâmetros de processo, elevando assim a produtividade (TREDICI, 2004).

Nos últimos anos, as microalgas têm sido bastante estudadas visando a produção de biocombustíveis, e apresentam como vantagens nessa aplicação:

- Crescimento acelerado, quando comparado a culturas atuais (soja, milho, canade-açúcar) para produção de biocombustíveis (GOUVEIA \& OLIVEIRA, 2009).

- Elevada produtividade: 40.000-140.000 litros/hectare/ano em sistemas abertos, podendo ser mais elevada em sistemas fechados (GLADUE, 1991).

- Não competem com a produção de alimentos, já que podem ser cultivadas em terra não fértil (CORNELL).

- Não exigem herbicidas, pesticidas ou fertilizantes (efluentes secundários) (CHISTI, 2004).

- Não afetam as fontes de água - ainda podem ser utilizados para purificar a própria água onde estão sendo cultivadas (CHISTI, 2004).

- Biodegradabilidade.

- Não emitem gases de efeito estufa - sustentável.

- São tolerantes às condições adversas, como desertos e águas salinas e / ou salobras. 
- Apresentam altos teores lipídicos, podendo atingir rendimentos, em forma de óleo, de cerca de $30 \%-70 \%$, como pode ser observado na Tabela 3.

- Elevados teores proteicos, cerca de $63 \%$ da composição total (dependendo da espécie) (BECKER, 2007), motivo pelo qual são amplamente usadas como complemento alimentar.

- Os carboidratos podem ser refinados em gasolina ou fermentados em etanol.

- Podem ser cultivadas utilizando efluentes de estações de tratamento de esgotos ou resíduos agroindustriais.

- O "cake" (resíduos/borra) ou subprodutos podem ser usados como uma fonte orgânica de alimento de alta concentração de proteína ou como matéria-prima na ração ou adubo.

Tabela 3: Comparação de produção de óleo/biodiesel de diversas oleaginosas (MATA,

MARTINS \& CAETANO, 2010).

\begin{tabular}{c|c|c|c|c}
\hline Fonte & $\begin{array}{c}\text { Quantidade de } \\
\text { Óleo } \\
(\% \text { óleo/peso de } \\
\text { biomassa) }\end{array}$ & $\begin{array}{c}\text { Produção de Óleo } \\
\text { (L óleo/hec ano })\end{array}$ & $\begin{array}{c}\text { Área } \\
\text { (m ano/kg } \\
\text { biodiesel) }\end{array}$ & $\begin{array}{c}\text { Produtividade de } \\
\text { Biodiesel } \\
\text { (kg biodiesel/hec.ano) }\end{array}$ \\
\hline Milho (Zea Mays L.) & 44 & 172 & 66 & 152 \\
\hline Cânhamo (Cannabis sativa L.) & 33 & 363 & 31 & 321 \\
\hline Soja (Glycine max L.) & 18 & 636 & 18 & 562 \\
\hline Jatropha (Jatropha curcas L.) & 28 & 741 & 15 & 656 \\
\hline Camelina (Camelina sativa L.) & 42 & 915 & 12 & 809 \\
\hline Canola (Brassica napus L.) & 41 & 974 & 12 & 862 \\
\hline Girassol (Heliathus annuus L.) & 40 & 1.070 & 11 & 946 \\
\hline Mamona (Ricinus communis) & 48 & 1.307 & 9 & 1.156 \\
\hline Dendê (Elaeis guineeansis) & 36 & 5.366 & 2 & 4.747 \\
\hline Microalga (Baixo teor) & 30 & 58.700 & 0,2 & 51.927 \\
\hline Microalga (Médio teor) & 50 & 97.800 & 0,1 & 86.515 \\
\hline Microalga (Alto teor) & 70 & 132.900 & 0,1 & 121.104 \\
\hline
\end{tabular}

Uma das vantagens significativas do uso de microalgas, visando biocombustíveis, é seu potencial de sequestro de carbono, uma vez que as microalgas utilizam, de maneira geral, água, luz solar, $\mathrm{CO}_{2}$ e alguns minerais para metabolizar óleos, biomassa, carboidratos e $\mathrm{O}_{2}$ (CHISTI, 2007). Para cada 1 tonelada de biomassa de microalgas, 1,65 a 1,83 toneladas de $\mathrm{CO}_{2}$ são absorvidas (CHAGAS et al., 2010). Além disso, a possibilidade de utilizar microalgas em sistemas fechados (biorreatores) próximos à termoelétricas e fábricas de produtos químicos, que produzem altas quantidades de emissões atmosféricas de gases, dentre 
eles o $\mathrm{CO}_{2}$, parece ser bastante promissora, já que contrasta com os combustíveis fósseis que são emissores de $\mathrm{CO}_{2}$ (CHAVES \& GOMES, 2014).

Entretanto, a utilização de microalgas visando energia renovável e a produção de biomassa ou biocombustível ainda não é comercialmente viável, devido, em parte, à falta de domínio da tecnologia de cultivo e processamento. A forma de cultivo popular é em lagoa aberta, da qual se obteve em 2008 cerca de $98 \%$ da produção comercial de biomassa de algas. Esse sistema é relativamente barato comparado a cultivos utilizando biorreatores, mas há possibilidades de contaminação de espécies de algas nativas, além de evaporação da água.

Ainda, há estudos em cultivos de cepas de microalgas geneticamente modificadas que são capazes de realizar a fotossíntese com maior eficiência e apresentam maior taxa crescimento que os organismos selvagens, ou seja, aqueles que não sofreram mudanças genéticas (PERRINE, NEGI, \& SAYRE, 2012).

\subsection{ESPÉCIES DE MICROALGAS}

Atualmente,são conhecidas cerca de 40000 espécies de microalgas, sendo que as principais cultivadas comercialmente são Dunaliella salina para a obtenção de caroteno; Haematococcus pluvialis para a obtenção de astaxantina e do gênero Chlorella e Anthospira (Spirulina) para a adição em alimentos naturais, esta última principalmente por apresentar elevadas concentrações de proteína, além de compostos com propriedades de uso farmacêutico, como ácido linoleico e polissacarídeos (BECKER, 2007).

As microalgas mais estudadas de acordo com o teor lipídico, são encontradas na Tabela 4. 
Tabela 4: Teor lipídico e produtividade de diferentes espécies de microalgas (CHISTI, 2007), (HU, et al., 2013), (YU, et al., 2013)

\begin{tabular}{|c|c|c|c|c|}
\hline $\begin{array}{l}\text { Espécies de Microalgas } \\
\text { Marinhas e Água doce }\end{array}$ & $\begin{array}{l}\text { Teor Lipídico } \\
\text { (\% em peso de } \\
\text { biomassa seca) }\end{array}$ & $\begin{array}{l}\text { Produtividade } \\
\text { Lipídica } \\
\text { (mg/L/dia) }\end{array}$ & $\begin{array}{l}\text { Produtividade } \\
\text { Volumétrica de } \\
\text { Biomassa } \\
\text { (g/L/dia) }\end{array}$ & $\begin{array}{c}\text { Produtividade } \\
\text { Areal de } \\
\text { Biomassa } \\
\left(\mathrm{g} / \mathrm{m}^{2} / \mathrm{dia}\right)\end{array}$ \\
\hline Ankistrodesmus sp. & $24,0-31,0$ & - & - & $11,5-17,4$ \\
\hline Botrycoccus braunni & $25,0-75,0$ & - & 0,02 & 3,0 \\
\hline Chaetoceros muelleri & 33,6 & 21,8 & 0,07 & - \\
\hline Chlorella calcitrans & $14,6-16,4 / 39,8$ & 17,6 & 0,04 & - \\
\hline Chlorella emerson ii & $25,0-63,0$ & $10,3-50,0$ & $0,036-0,041$ & $0,91-0,97$ \\
\hline Chlorella protothecoides & $14,6-57,8$ & 1.214 & $2,00-7,70$ & - \\
\hline Chlorella pyrenoidosa & 2,0 & - & $2,9-3,64$ & $72,5 / 130$ \\
\hline Chlorella sorokiniana & $19,0-22,0$ & 44,7 & $0,23-1,47$ & - \\
\hline Chlorella $s p$ & $10,0-48,0$ & 42,1 & $0,02-2,5$ & $1,61-16,47 / 25$ \\
\hline Chlorella vulgaris & $5,0-58,0$ & $11,2-40,0$ & $0,02-0,20$ & $0,57-0,95$ \\
\hline Chlorococcum sp. & 19,3 & 53,7 & 0,28 & - \\
\hline Crypthecodinium cohnii & $20,0-51,1$ & - & 10,0 & - \\
\hline Desmodesmus sp. & 55,0 & 275,0 & 0,5 & - \\
\hline Dunaliella primolecta & 23,1 & - & 0,09 & 14,0 \\
\hline Dunaliella salina & $6,0-25,0$ & 116,0 & $0,22-0,34$ & $1,6-38,0$ \\
\hline Dunaliella sp. & $17,5-67,0$ & 33,5 & - & - \\
\hline Dunaliella tertiolecta & $16,7-71,0$ & - & 0,12 & - \\
\hline Ellipsoidion $s p$. & 27,4 & 47,3 & 0,17 & - \\
\hline Euglena gracilis & $14,0-20,0$ & - & 7,70 & - \\
\hline Haematococcus pluvialis & 25,0 & - & $0,05-0,06$ & $10,2-36,4$ \\
\hline Isochysis galbana. & $7,0-40,0$ & - & $0,32-1,60$ & - \\
\hline Isochysis sp. & $7,1-33,0$ & 37,8 & $0,08-0,17$ & - \\
\hline Monallanthus salina & $20,0-22,0$ & - & 0,08 & 12,0 \\
\hline Monoraphidium sp. & $38,0-57,0$ & $7,0-180,0$ & - & - \\
\hline Nannochloris sp. & $20,0-56,0$ & $60,9-76,5$ & $0,17-0,51$ & - \\
\hline Nannochloropsis oculata. & $22,7-29,7$ & $84,0-142,0$ & $0,37-0,48$ & - \\
\hline Nannochloropsis sp. & $12,0-53,0$ & $37,6-90,0$ & $0,17-1,43$ & $1,9-5,3$ \\
\hline Neochloris oleoabundans & $29,0-65,0$ & $90,0-134,0$ & - & - \\
\hline Nitzschia $s p$ & $16,0-47,0$ & & & $8,8-21,6$ \\
\hline Oocystis pusilla & 10,5 & - & - & $40,6-45,8$ \\
\hline Oocystis $s p$ & - & - & - & - \\
\hline Pavlova lutheri & 35,5 & 40,2 & 0,14 & - \\
\hline Pavlova salina & 30,9 & 49,4 & 0,16 & - \\
\hline Phaeodactlylum tricornutum & $18,0-57,0$ & 44,8 & $0,003-1,90$ & $2,4-21,0$ \\
\hline Porphyridium cruentum & $9,0-18,8 / 60,7$ & 34,8 & $0,36-1,50$ & 25,0 \\
\hline Scenedesmus obliquus & $11,0-55,0$ & - & $0,004-0,74$ & - \\
\hline Scenedesmus quadricauda & $1,9-18,4$ & 35,1 & 0,19 & - \\
\hline Scenedesmus sp. & $19,6-21,1$ & $40,8-53,9$ & $0,03-0,26$ & $2,4-13,5$ \\
\hline Skeletonema costatum & $13,5-51,3$ & 17,4 & 0,08 & - \\
\hline Skeletonema sp. & $13,3-31,8$ & 27,3 & 0,09 & - \\
\hline Spirulina máxima & $4,0-9,0$ & - & $0,21-0,25$ & 25,0 \\
\hline Spirulina platensis & $10-16,6$ & - & $0,06-4,30$ & $1,5-14,5 / 24,0-51,0$ \\
\hline Tetraselmis sp. & $12,6-14,7$ & 43,4 & 0,30 & - \\
\hline Tetraselmis suecica & $8,5-23,0$ & $27,0-36,4$ & $0,13-0,32$ & 19,0 \\
\hline Thalassiosira pseudonama & 20,6 & 17,4 & 0,08 & - \\
\hline
\end{tabular}


No Brasil, não existem coleções de cultivo de grande porte, mas há cerca de 40 laboratórios nos quais microalgas são mantidas, constituindo coleções médias e pequenas (LOURENÇO \& VIEIRA, 2004).

Para esse trabalho, foram estudados 5 gêneros da classe das Clorofíceas, também chamadas algas verdes, o grupo mais numeroso e diversificado de algas, que habita predominantemente (90\%) ambientes de água doce, sendo elas Chlorella vulgaris, Chlorella sp., Desmodesmus sp., Monoraphidium sp. e Oocystis sp..

\subsection{FATORES IMPORTANTES PARA O CRESCIMENTO DAS MICROALGAS}

Uma curva típica de crescimento de micro-organismos engloba, basicamente, 4 fases: Adaptação, Exponencial, Estacionária e Morte, como mostrado na Figura 4 (SCHMIDELL, LIMA, E., \& BORZANI, 2001).

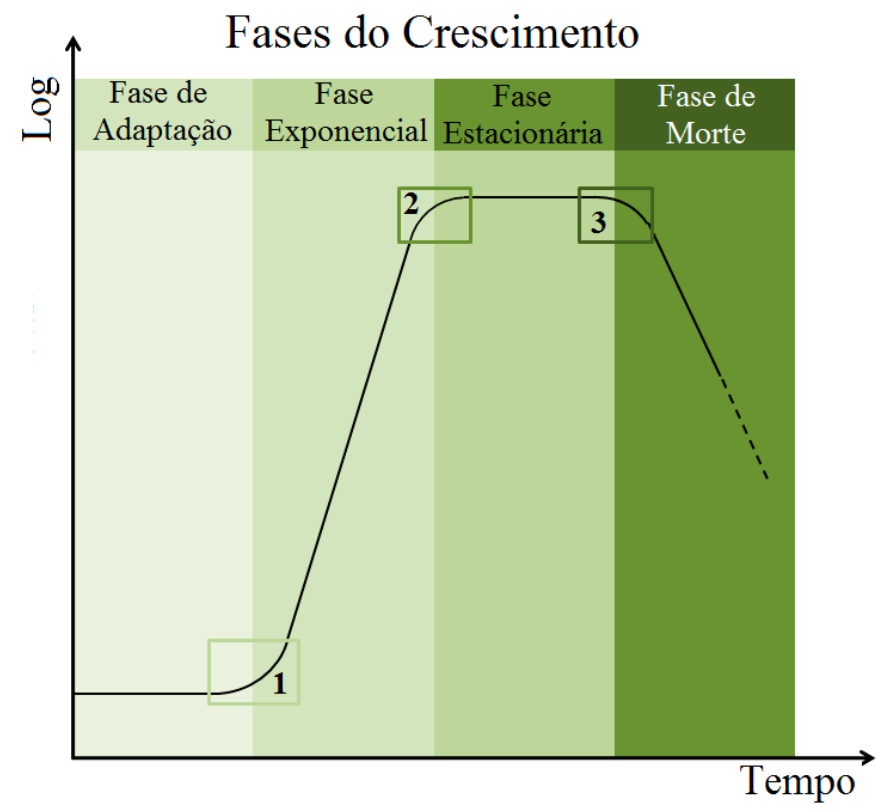

Figura 4: Fases do crescimento de um micro-organismo

No diagrama da Figura 4, tem-se:

- Fase de Adaptação: fase de adaptação metabólica à um novo meio, produção de enzimas para crescimento.

- Ponto 1: período em que há tanto células em crescimento quanto em desenvolvimento. 
- Fase Exponencial: a velocidade de crescimento é máxima e constante. As células se duplicam após um determinado intervalo de tempo.

- Ponto 2: redução da velocidade específica máxima de crescimento, devido à limitação nutricional

- Fase Estacionária: interrupção da divisão celular. A taxa de morte se iguala à taxa de crescimento.

Ponto 3: taxa de morte está aumentando enquanto a fase de crescimento está diminuindo ou cessou.

- Fase de Morte: perda irreversível da capacidade de divisão celular.

Para o crescimento das microalgas, são necessários, principalmente, luz, pH adequado, macronutrientes (C, N, P, O, H, Ca, Mg, S, K) e micronutrientes ( $\mathrm{Mn}, \mathrm{Mo}, \mathrm{Fe}, \mathrm{Cu}, \mathrm{Zn}$ ).

\subsubsection{Fonte de carbono}

O carbono é considerado o macronutriente mais importante, já que contribui com, aproximadamente, $50 \%$ da biomassa microalgal (proteínas, carboidratos, vitaminas e lipídios, entre outros) (LOURENÇO, 2006). Geralmente, a fonte de carbono é o $\mathrm{CO}_{2}$, e a principal rota de fixação do carbono pela microalga é através da fotossíntese, por meio da assimilação fotoautotrófica (equação 1) (SASI, 2009).

$$
12 \mathrm{H}_{2} \mathrm{O}+6 \mathrm{CO}_{2} \rightarrow 6 \mathrm{O}_{2}+6 \mathrm{H}_{2} \mathrm{O}+\mathrm{C}_{6} \mathrm{H}_{12} \mathrm{O}_{6}
$$

Entretanto, algumas espécies, como a Spirulina e a Chlorella vulgaris, permitem a combinação entre a fotossíntese e a assimilação heterotrófica ${ }^{1}$ de compostos orgânicos (mixotrofia) (LIANG, SARKANY, \& CUI, 2009).

Assimilação heterotrófica ocorre nos seres que não sintetizam matéria orgânica ( seres heterotróficos), mas utilizam a matéria orgânica por meio de reações que decorrem no organismo (digestão, respiração, etc.) 


\subsubsection{Luminosidade}

A luz é o fator mais importante que influencia no crescimento de organismos fotossintéticos, representando a principal fonte de energia (SOLETTO et al., 2005).

No entanto, exposição a alta densidade de fluxo de fótons fotossintéticos (photosynthetic photon flux density - PPFD) pode aumentar a produção de espécies de oxigênio reativas prejudiciais, como $\mathrm{H}_{2} \mathrm{O}_{2}$, danificando a estrutura celular, ou originando o fenômeno da fotoinibição, ou seja, a redução da capacidade de fotossíntese da microalga causando branqueamento e morte (SOLETTO et al., 2005), (MULLER, Li, \& NIYOGI, 2001), (MEHLITZ, 2009).

Dentre os trabalhos encontrados na literatura, visando avaliar a intensidade luminosa no crescimento de microalgas, Soletto e colaboradores (2005) estudaram o comportamento de Spirulina platensis, usando diferentes densidades de fluxo de fótons fotossintéticos. Usando um reator com volume de $4 \mathrm{~L}$, obtiveram máxima eficiência fotossintética com 125 $\mu$ molfotons. $\mathrm{m}^{-2} \cdot \mathrm{s}^{-1}$. O fenômeno de fotoinibiação para baixos PPFD e excesso de $\mathrm{CO}_{2}$ inibiram o crescimento.

Redaelli e colaboradores (2011) também estudaram a influência da intensidade luminosa $(2200,10000,17000,24500$ lux) sobre a biofixação do carbono em Chlorella minutíssima, utilizando um fotobiorreator de 2,2 L, e observaram que os melhores resultados foram obtidos para intensidade 17000 lux, atingido uma biomassa de 0,38 g/L e velocidade específica de crescimento de $0,61 \mathrm{dia}^{-1}$.

\subsubsection{Temperatura}

A temperatura ótima é uma importante variável no crescimento das microalgas. Uma elevação da temperatura pode causar um aumento na biomassa até certo nível, no qual o crescimento pode ser inibido devido à inativação por choque térmico das proteínas (MAHBOOB, et al., 2012).

Chinnasamy e colaboradores (2009) estudaram a produção de biomassa a temperaturas de 30,40 e $50^{\circ} \mathrm{C}$, e verificaram que, para um crescimento elevado a temperatura ótima para a microalga Chlorella vulgaris é $30^{\circ} \mathrm{C}$.

Segundo Kerby e Stewart (1989) a temperatura ideal para um rápido crescimento, especialmente das espécies Chlorella, deve estar entre 20 e $32^{\circ} \mathrm{C}$. 


\subsubsection{Agitação}

A agitação é uma variável importante por proporcionar uma exposição mais homogênea à luz; aumentar a disponibilidade de nutrientes, os quais, em agitação constante, não cristalizam (ficam suspensos); evitar a sedimentação das microalgas, o que acarretaria exposição em excesso das camadas superiores e subexposição das camadas inferiores (COUTTEAU \& SORGELOOS, 1992), (MONTEIRO, LUCHESE, \& ABSHER, 2010).

\subsection{5 pH}

A faixa de $\mathrm{pH}$ ideal para a maioria das espécies de alga está entre 5 e 9.

Entretanto, Marinho e colaboradores (2009) verificaram que, em pH 5, a produtividade da microalga Chlorella vulgaris aumenta consideravelmente. Após 9 dias, a concentração, em $\mathrm{pH} 5$ foi de $9,5 \times 10^{7} \mathrm{cel} / \mathrm{mL}$, em $\mathrm{pH} 7$ foi de $4,5 \times 10^{7} \mathrm{cel} / \mathrm{mL}$ e em $\mathrm{pH} 9$ foi de $1,5 \times 10^{7} \mathrm{cel} / \mathrm{mL}$ nas seguintes condições: densidade inicial de $100 \times 10^{4} \mathrm{cel} / \mathrm{mL}$, temperatura de $24{ }^{\circ} \mathrm{C}$, fotoperíodo de 24:0 (claro/escuro) e luminosidade $97 \mu$ molfoton $/ \mathrm{m}^{2}$.s.

Segundo Becker (2004), o pH influencia a solubilidade do $\mathrm{CO}_{2}$ e dos minerais, interferindo direta ou indiretamente no metabolismo das algas.

Segundo Esteves (1998), em meio aquoso, o carbono inorgânico pode estar na forma $\mathrm{CO}_{2}, \mathrm{H}_{2} \mathrm{CO}_{3}, \mathrm{HCO}_{3}^{-}$(bicarbonato) ou $\mathrm{CO}_{3}^{-}$(carbonato) e suas proporções dependem do $\mathrm{pH}$. Em pHs altos (básicos), as proporções de $\mathrm{HCO}_{3}{ }^{-}$ou $\mathrm{CO}_{3}{ }^{-}$aumentam. Assim, em uma cultura com pH ácido, a disponibilidade de $\mathrm{CO}_{2}$ aumenta, já que esta é a fonte de carbono usada pelas algas.

A elevação gradativa do $\mathrm{pH}$ no meio de cultura é indicativa do crescimento microalgal. $\mathrm{O}$ incremento do $\mathrm{pH}$ ocorre devido à atividade biológica das células, o que produz uma redução no conteúdo de carbono inorgânico dissolvido através do consumo necessário ao crescimento celular, forçando um deslocamento do equilíbrio carbonato-bicarbonato no sistema tampão (BERENGUEL et al., 2004). Devido à baixa solubilidade do $\mathrm{CO}_{2}$ em soluções aquosas, ocorre a necessidade de seu fornecimento ao longo de todo o processo (KLASSON, CLAUSEN, \& GADDY, 1991).

Mayo e Noike (1994) estudaram o efeito da concentração de íons de hidrogênio no crescimento de Chlorella vulgaris entre pHs 3,0 e 11,5 e mostraram que essa espécie apresenta maior crescimento na faixa de $\mathrm{pH} 5,5$ a 8,0. 


\subsubsection{Fonte de nutrientes}

Além do carbono, outros nutrientes são fundamentais para o cultivo de microalgas, como pode ser observado na Tabela 5.

Tabela 5: Macronutrientes para cultivos de microalgas

\begin{tabular}{|c|c|c|}
\hline Elemento & $\begin{array}{c}\text { Forma usual encontrada na } \\
\text { natureza }\end{array}$ & $\begin{array}{c}\text { Forma química fornecida em meio de } \\
\text { cultura }\end{array}$ \\
\hline Carbono $(\mathrm{C})$ & $\mathrm{CO}_{2}$, compostos orgânicos & Glicose, malato, acetato, entre outros \\
\hline Hidrogênio $(\mathrm{H})$ & $\mathrm{H}_{2} \mathrm{O}$, compostos orgânicos & $\mathrm{H}_{2} \mathrm{O}$, compostos orgânicos \\
\hline Oxigênio $(\mathrm{O})$ & $\mathrm{H}_{2} \mathrm{O}, \mathrm{O}_{2}$, compostos orgânicos & $\mathrm{H}_{2} \mathrm{O}, \mathrm{O}_{2}$, compostos orgânicos \\
\hline Nitrogênio (N) & $\begin{array}{l}\mathrm{NH}_{3}, \mathrm{NO}_{3}^{-}, \quad \mathrm{N}_{2}, \quad \text { compostos } \\
\text { orgânicos nitrogenados }\end{array}$ & $\begin{array}{l}\mathrm{NH}_{4} \mathrm{Cl},\left(\mathrm{NH}_{4}\right)_{2} \mathrm{SO}_{4}, \mathrm{KNO}_{3}, \mathrm{~N}_{2} \text {, aminoácidos, } \\
\text { entre outros. }\end{array}$ \\
\hline Fósforo (P) & $\mathrm{PO}_{4}^{3-}$ & $\mathrm{KH}_{2} \mathrm{PO}_{4}, \mathrm{Na}_{2} \mathrm{HPO}_{4}$ \\
\hline Enxofre (S) & $\mathrm{H}_{2} \mathrm{~S}, \mathrm{SO}_{4}{ }^{2-}$ & $\mathrm{Na}_{2} \mathrm{SO}_{4}, \mathrm{Na}_{2} \mathrm{~S}_{2} \mathrm{O}_{3}, \mathrm{Na}_{2} \mathrm{~S}$, entre outros \\
\hline Potássio (K) & $\mathrm{K}^{+}$em solução ou sais de $\mathrm{K}$ & $\mathrm{KCl}, \mathrm{KH}_{2} \mathrm{PO}_{4}$ \\
\hline Magnésio $(\mathrm{Mg})$ & $\mathrm{Mg}^{2+}$ em solução ou sais de $\mathrm{Mg}$ & $\mathrm{MgCl}_{2}, \mathrm{MgSO}_{4}$ \\
\hline Sódio $(\mathrm{Na})$ & $\mathrm{Na}^{+}$em solução ou sais de $\mathrm{Na}$ & $\mathrm{NaCl}$ \\
\hline Cálcio (Ca) & $\mathrm{Ca}^{2+}$ em solução ou sais de $\mathrm{Ca}$ & $\mathrm{CaCl}_{2}$ \\
\hline Ferro $(\mathrm{Fe})$ & $\mathrm{Fe}^{2+}, \mathrm{Fe}^{3+}$ ou sais de $\mathrm{Fe}$ & $\mathrm{FeCl}_{3}, \mathrm{FeSO}_{4}, \mathrm{Fe}^{3+} \mathrm{EDTA}$ \\
\hline
\end{tabular}

De acordo com Richmond (2004), os principais macronutrientes, com exceção do carbono, são:

- Nitrogênio: um interessante efeito deste macronutriente é que, em ambientes pobres em $\mathrm{N}$, as microalgas desviam o fluxo de carbono da formação de proteínas para a produção de carboidratos e lipídios. Em algumas espécies, a falta de $\mathrm{N}$ conduz à formação de outros compostos, como betacaroteno (Dunaliella) ou astaxantina (Haematococcus pluvialis). Geralmente, o $\mathrm{N}$ é fornecido na forma de nitratos, amônia, sais de amônio e uréia.

- Fósforo: a deficiência deste macronutriente provoca o aumento de betacaroteno e astaxantina, mas não de forma tão marcante como no caso do nitrogênio.

- Ferro: excesso de Fe pode levar ao estresse oxidativo devido à reação com água oxigenada (produzida pelas células), via reação de Fenton.

Ainda, são necessários alguns micronutrientes, também chamados elementos traços, utilizados em quantidade bastante reduzidas, sendo os principais cobalto $(\mathrm{Co})$, cobre $(\mathrm{Cu})$, manganês (Mn), molibdênio (Mo), zinco ( $\mathrm{Zn})$ e ferro $(\mathrm{Fe})$. 
Os ensaios de adição de nutrientes, em que são detectadas mudanças sutis nas concentrações dos elementos de um meio de cultivo, fornecem informações importantes sobre o efeito de cada nutriente, tanto na cinética de crescimento quanto na composição da biomassa (CAMACHO \& WIT, 2003). Muitos estudos têm utilizado, como nutrientes, resíduos agroindustriais.

\subsection{LIPÍDIOS DAS MICROALGAS}

Lipídios são biomoléculas compostas por carbono $(\mathrm{C})$, hidrogênio $(\mathrm{H})$ e oxigênio $(\mathrm{O})$, insolúveis em água e solúveis em solventes orgânicos (TINDALE, 1988).

Microalgas são consideradas um dos melhores candidatos para produção de biocombustíveis, devido ao seu alto teor de lipídios e, por esse motivo, a identificação e quantificação precisa desses lipídios nas microalgas são fundamentais.

O biodiesel é, comumente, produzido por meio de uma reação química denominada transesterificação, Equação 2 . No caso específico para a reação abaixo, os trigliceróis (óleos ou gorduras de origem animal/vegetal) reagem com metanol, na presença de um catalisador, produzindo glicerina (subproduto) e éster metílico de ácido (biodiesel). A reação de transesterificação pode ser catalisada por ácido ou base, dependendo das características do óleo e/ou gordura utilizados (CHISTI, 2007).
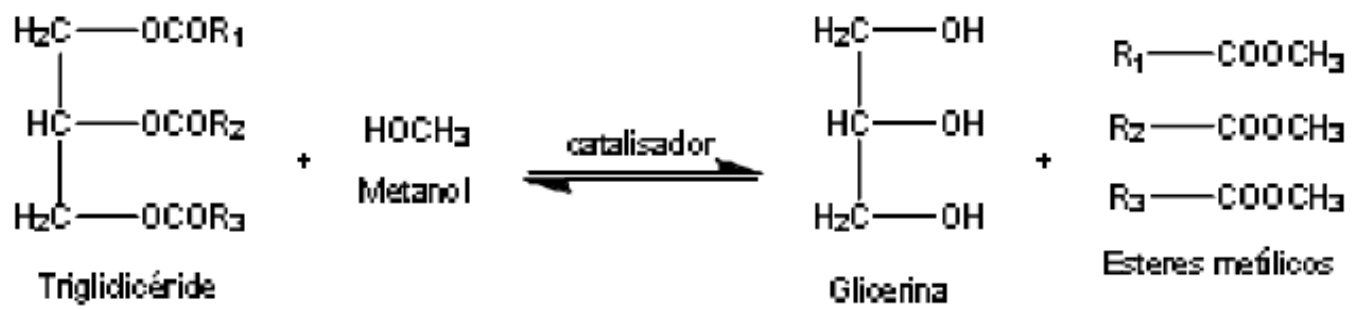

(equação 2)

Equação 2: Reação de esterificação metanólica (CHISTI, 2007).

A composição lipídica das microalgas é formada, principalmente, por ácidos graxos de cadeia longa, como os exemplificados na Tabela 6. A maioria deles é da família ômega (ácido oleico, ácido linoleico, ácido linolênico, ácido araquidônico, ácido eicosapentaenoico (EPA) e ácido docosahexaenóico (DHA), estes três últimos de alto valor agregado), motivo pelo qual vêm sendo muito utilizados como complemento alimentar. 
Tabela 6: Principais ácidos graxos presentes em microalgas.

\begin{tabular}{|c|c|c|c|c|c|}
\hline $\begin{array}{c}\text { Nome } \\
\text { descritivo }\end{array}$ & Nome sistemático & $\begin{array}{c}\text { Átomos de } \\
\text { Carbono }\end{array}$ & $\begin{array}{c}\text { Duplas } \\
\text { Ligações }\end{array}$ & $\begin{array}{c}\text { Posição da Dupla } \\
\text { Ligação }\end{array}$ & Família \\
\hline Láurico & Dodecanóico & 12 & 0 & - & - \\
\hline Mirístico & Tetradecanóico & 14 & 0 & - & - \\
\hline Palmítico & Hexadecanóico & 16 & 0 & - & - \\
\hline Palmitoléico & Hecadecenóico & 16 & 1 & 9 & $\omega 7$ \\
\hline Esteárico & Octadecanóico & 18 & 0 & - & - \\
\hline Oleico & Octadecenóico & 18 & 1 & 9 & $\omega 9$ \\
\hline Linoleico & Octadecadienóico & 18 & 2 & 9,12 & $\omega 6$ \\
\hline $\begin{array}{c}\text { Alfa- } \\
\text { Linolênico }\end{array}$ & Octadecatrienóico & 18 & 3 & $9,12,15$ & $\omega 3$ \\
\hline $\begin{array}{c}\text { Gama- } \\
\text { Linolênico }\end{array}$ & Octadecatrienóico & 18 & 3 & $6,9,12$ & $\omega 6$ \\
\hline $\begin{array}{l}\text { Homo Gama- } \\
\text { Linolênico }\end{array}$ & Eicosatrienóico & 20 & 3 & $5,11,14$ & $\omega 6$ \\
\hline Araquidônico & Eicosatetraenóico & 20 & 4 & $5,8,11,14$ & $\omega 6$ \\
\hline EPA & Eicosapentaenóico & 20 & 5 & $5,8,11,14,17$ & $\omega 3$ \\
\hline DHA & Docosahexaenóico & 22 & 6 & $4,7,10,13,16,19$ & $\omega 3$ \\
\hline
\end{tabular}

Dentre os trabalhos encontrados na literatura, Costa e colaboradores (2006) estudaram o perfil de ácidos graxos em microalgas do genero Chlorella, e observaram a predominância dos ácidos palmitoléico (C16:1) e araquídico (C20:0) além de outros ácidos graxos em menor quantidade, como ácido mirístico (C14:0); ácido palmítico (C16:0); ácido esteárico (C18:0); ácido oleico (C18:1); ácido linoleico (C18:2) e ácido linolênico (C18:3) variando entre 0,06 e $27,08 \%$

Fidalgo e colaboradores (1998) em cultivos de Isochrysis galbana, utilizando meios com diferentes fontes de nitrogênio (nitrito, nitrato e uréia), concluíram que a concentração das principais biomoléculas na célula é mais afetada pela idade da cultura do que pela fonte de nitrogênio. Verificaram ainda uma maior concentração de proteínas na fase exponencial de crescimento, enquanto os lipídios e carboidratos foram acumulados durante a fase estacionária.

Lv e colaboradores (2010) estudaram a melhora da produção de lipídios da microalga Chlorella vulgaris por ajustes nas condições de cultivo como, por exemplo, o tempo exato de coleta, e corroboraram com os resultados obtidos por Fidalgo e colaboradores (1998), concluindo que o início da fase estacionária é a melhor fase para se alcançar maior produtividade lipídica.

A faixa de produção de lipídios pelas microalgas pode variar entre 1 e 70\%, dependendo das condições de cultivo e da espécie. Existem vários trabalhos na literatura 
visando aumentar a produtividade de lipídios, como, por exemplo, o de Cunha (2011) que estudou a adição de glicose no meio de cultivo e observou que a adição de glicose favoreceu a produção de lipídios totais.

Chagas e colaboradores (2010) estudaram a otimização da produção de lipídios pela microalga Isochrysis galbana, sob condições de estresse nutricional, induzido pela escassez de nitrogênio. Em condições de estresse, as células param de se dividir e passam a sintetizar carboidratos e lipídios como reservas energéticas. Eles concluíram que a falta de nitrogênio compromete a produtividade em biomassa (a produção de proteínas), e favorece a produção de lipídios.

Os processos de extração de óleo são simples, mas também podem inferir sobre a produtividade de lipídios das microalgas e muitos estudos tem se dirigido a aumentar a eficiência e o rendimento à baixos custos.

Os métodos mais tradicionais de extração de lipídios são através de processos químicos utilizando solventes como benzeno, clorofórmio, éter e hexano. Ainda é possível a utilização de enzimas que auxiliam na extração.

Pode-se também usar processos físicos, como choque osmótico.

A extração com fluido supercrítico têm se mostrado um processo de extração lipídica melhor que os processos convencionais utilizando extração com solvente (CRAMPON, BOUTIN, \& BADENS, 2011).

Dantas e colaboradores (2010) estudaram a extração de óleo de microalga Scenedesmus subpicatus utilizando ultrassom com diferentes solventes, como água, metanol, etanol, tetrahidrofurano e hexano, e concluíram que o uso de metanol apresentou o melhor resultado. A mesma conclusão com respeito ao solvente utilizado na extração foi encontrada por D'oca e colaboradores (2008), utilizando a microalga Chlorella pyrenoidosa.

\subsection{PROTEÍNAS DAS MICROALGAS}

Proteínas são compostos orgânicos de alto peso molecular, formados por um ou mais polipeptídeos (20 ou mais aminoácidos ligados entre si) através de ligações peptídicas (ligação covalente entre C e N) e constituem cerca de 50 a $80 \%$ do peso seco dos microorganismos (TINDALE, 1988).

Koichi Tanaka, vencedor do Prêmio Nobel de Química em 2002, foi o pioneiro a utilizar a técnica de espectrometria de massas com Ionização/Dessorção à Laser Assistida por 
Matriz acoplada a analisador por tempo de vôo (MALDI-TOF-MS) para análise de proteínas de micro-organismos. Assim, MALDI-TOF-MS tem demonstrado ser uma ferramenta eficiente para rápida identificação de micro-organismos (BIZZINI et al., 2010), tendo em vista que a diferenciação de espécies de micro-organismos é um grande desafio e as técnicas atuais são demoradas, dispendiosas e muitas vezes duvidosas (MURUGAIYAN et al., 2012).

As células intactas de micro-organismos produzem um espectro de proteínas conservadas geneticamente típicas de cada espécie, que são como uma impressão digital (“fingerprinting"). Estes espectros podem ser comparados à espectros previamente identificados e armazenados em banco de dados. Assim, o micro-organismo com a informação genômica disponível pode ser identificado através das suas proteínas comparando-a com as impressões digitais do banco de dados proteico (MURUGAIYAN, et al., 2012).

Dentre os banco de dados comerciais destacam-se o Samaris da Shimadzu, MicrobeLynx da Waters e o BioTyper da Bruker. Esse último apresenta uma biblioteca de micro-organismos com cerca de 5627 espécies para fungos, bactérias e leveduras (MURUGAIYAN, et al., 2012).

Murugayian e colaboradores (2012) estabeleceram e validaram uma metodologia para identificação do gênero Prototheca, a única microalga infecciosa conhecida, gerando uma biblioteca de espectros principais para 6 espécies Prototheca, visando facilitar a rápida identificação através do MALDI-TOF-MS.

Paz e colaboradores (2011) fizeram estudos preliminares para rápida identificação de ficotoxinas em microalgas, usando MALDI-TOF-MS. Utilizando diversas matrizes e solventes, encontraram como melhor resultado a solução de DHB $10 \mu \mathrm{g} / \mu \mathrm{L}$ em $0,1 \%$ de TFA/ACN $(3: 7 \mathrm{v} / \mathrm{v})$.

Vieler e colaboradores (2007) utilizaram a técnica MALDI-TOF-MS combinada com cromatografia de camada delgada para a identificação de lipídios das microalgas Chamydomonas reinhardt e Cyclotella meneghiniana. Eles observaram que as microalgas estudadas diferem na classe de lipídios, na contribuição relativa individual de cada lipídio e diferentes composições acila. 


\subsection{ESPECTROMETRIA DE MASSAS MALDI-TOF-MS}

A espectrometria de massas oferece alta sensibilidade para identificar proteínas através da comparação com banco de dados, sendo este trabalho o ponto chave na caracterização de uma grande quantidade de proteínas, tecidos e organismos bioquímicos (SHIMADZU).

A técnica de espectrometria de massas é composta por uma fonte de ionização, um analisador de massas, um detector e um sistema de aquisição de dados.

\subsubsection{Fonte de ionização}

Dentre as várias formas de ionização, equipamentos com fonte de ionização do tipo MALDI são equipamentos de última geração que possibilitam avanços na área biológica, especialmente na rápida identificação de micro-organismos tais como bactérias e fungos (SHIMADZU).

MALDI - Ionização por Dessorção a Laser Assistida por Matriz (do inglês MatrixAssisted Laser Desorption/Ionization) - é um método que possibilita a ionização de macromoléculas biológicas, que geralmente são difíceis de serem ionizadas. A ionização é permitida através da irradiação de uma matriz (geralmente um composto orgânico de baixo peso molecular que absorve no comprimento de onda do laser utilizado) misturada à amostra a ser analisada. A matriz absorve os feixes de laser de nitrogênio (luz ultravioleta, $337 \mathrm{~nm}$ ) e converte em energia térmica (SHIMADZU). Essa energia térmica aquece rapidamente a amostra, vaporizando-a e ionizando-a através da transferência de próton da matriz, Figura 5.

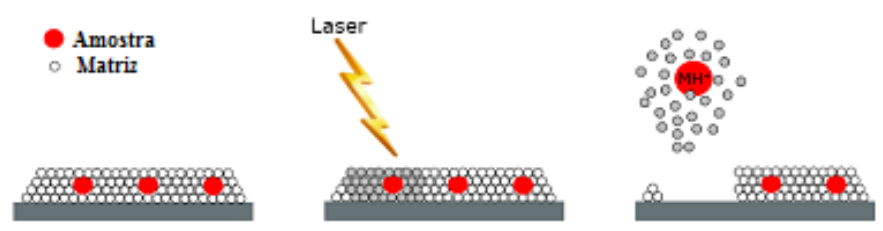

Figura 5: Ionização da mistura amostra/matriz (BRUKER, 2013a).

\subsubsection{Analisador de massas}

Os diferentes íons, tanto positivos quanto negativos, são extraídos da amostra devido à diferença de potencial entre o suporte da amostra e o eletrodo. Após a dessorção, todos os 
íons com carga q e número de carga $\mathrm{z}$, tem energia potencial $\mathrm{E}_{\mathrm{p}}$ proporcional a voltagem de aceleração U (equação 3).

$$
\mathrm{E}_{\mathrm{p}}=\mathrm{zeU}
$$

Após a ionização e vaporização da amostra, os íons são acelerados para dentro do analisador de massas, que terá a função de separar os íons com diferentes valores de massa/carga.

Nos analisadores do tipo TOF (tempo de vôo, do inglês time-of-flight) os íons são acelerados dentro do tubo de voo e sua energia potencial é convertida em energia cinética $\left(E_{k}\right)$, (equação 4).

$$
\mathrm{E}_{\mathrm{k}}=1 / 2 \mathrm{mv} v^{2}
$$

De acordo com a primeira lei da termodinâmica, a energia deve ser conservada, então tem-se que a energia potência $E_{p}$ igual a energia cinética $E_{k}$ (equação 5):

$$
1 / 2 \mathrm{mv} v^{2}=\mathrm{zeU}
$$

A velocidade $\mathrm{v}$ dos íons é igual a distância, que é o comprimento do tubo de vôo dado por L, dividido pelo tempo, que é o tempo que o íon leva para ir da fonte ao detector. Substituindo a velocidade por L/t tem-se as seguintes equações (equações 6 e 7):

$$
\begin{aligned}
& 1 / 2 \mathrm{~m}(\mathrm{~L} / \mathrm{t})^{2}=\mathrm{zeU} \\
& \mathrm{m} / \mathrm{z}=\left(2 \mathrm{eU} / \mathrm{L}^{2}\right) \mathrm{t}^{2}
\end{aligned}
$$

Sabendo que o termo $2 \mathrm{eU} / \mathrm{L}^{2}$ é uma constante, tem-se, (equação 8 e 9):

$$
\begin{aligned}
& m / z=\text { const } t^{2} \\
& t=\text { const } \sqrt{m / z}
\end{aligned}
$$

Como a diferença de potencial é constante, os íons adquirem velocidades diferentes (tempo de vôo) de acordo com a sua massa, ou seja, íons mais leves alcançam maiores 
velocidades. A diferença de velocidade e consequentemente no tempo de chegada ao detector (entre íons de massa diferente) possibilita a separação dos íons, Figura 6.

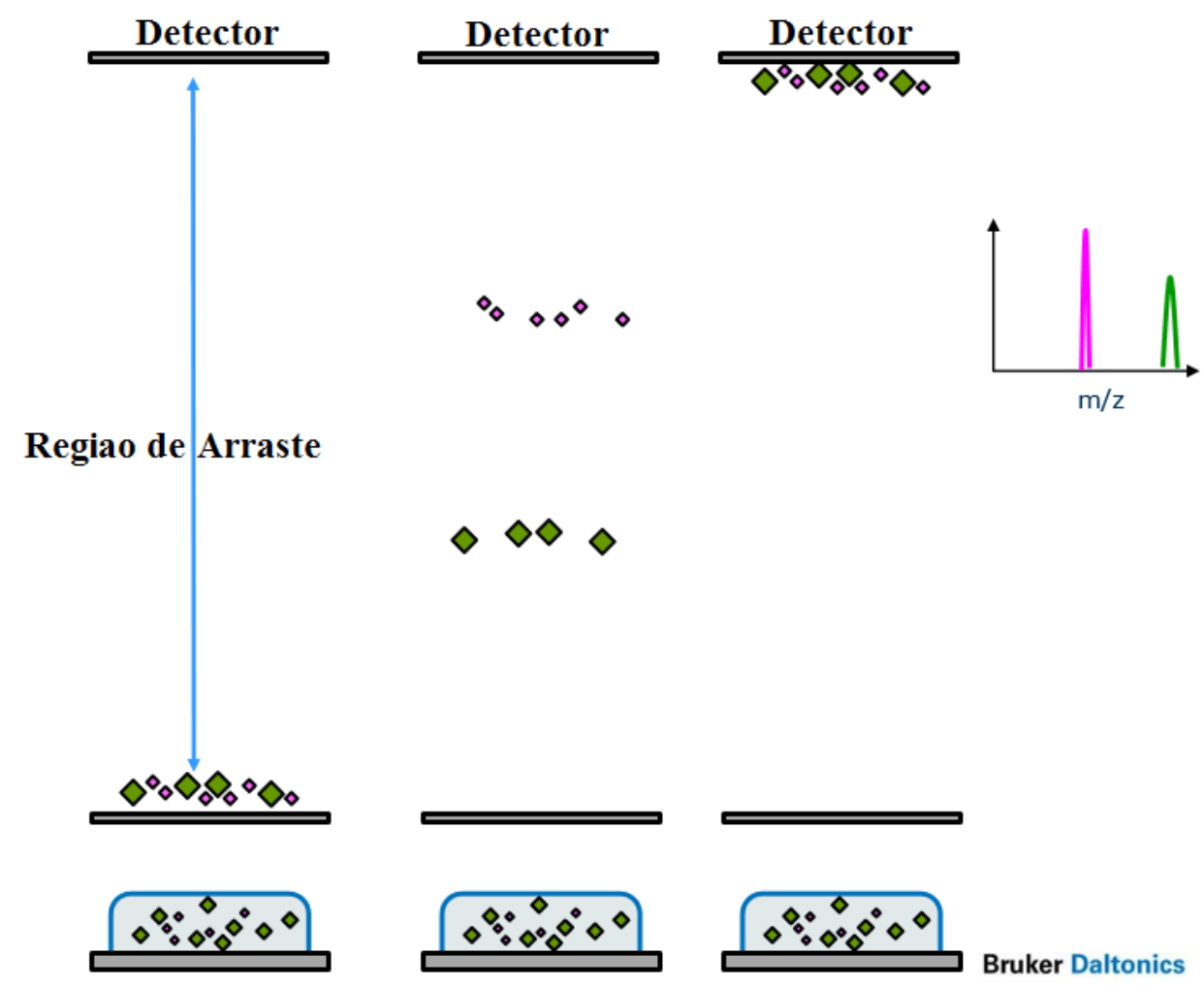

Figura 6: Ionização da amostra/matriz, aceleração pelo tubo de vôo e detecção dos íons (BRUKER, 2013a).

A Figura 7 representa o diagrama do tubo de tempo de vôo e os componentes usados na técnica MALDI-TOF-MS.

1. Um feixe de laser pulsado é direcionado a amostra;

2. A energia do feixe de laser dessorve e ioniza a amostra;

3. Um campo elétrico de alta voltagem acelera as amostras através do tub;

4. Os íons são concentrados e orientados. Um portão de íons (íon gate) permite:

a. exclusão de íons de massa baixa (por exemplo, derivados da matriz), ou

b. seleção de uma faixa de massa de íons da amostra;

5. Os íons são separados na região de arraste;

6. Placas defletoras para correção dos íons que desviaram o caminho do detector;

7. No modo linear, o detector linear detecta os íons diretamente da amostra (íons de baixo peso molecular seguido de íons de alto peso molecular); 
8. No modo refletor, um campo elétrico de alta voltagem (ligeiramente inclinado) desacelera os íons e os acelera novamente no sentido contrário.

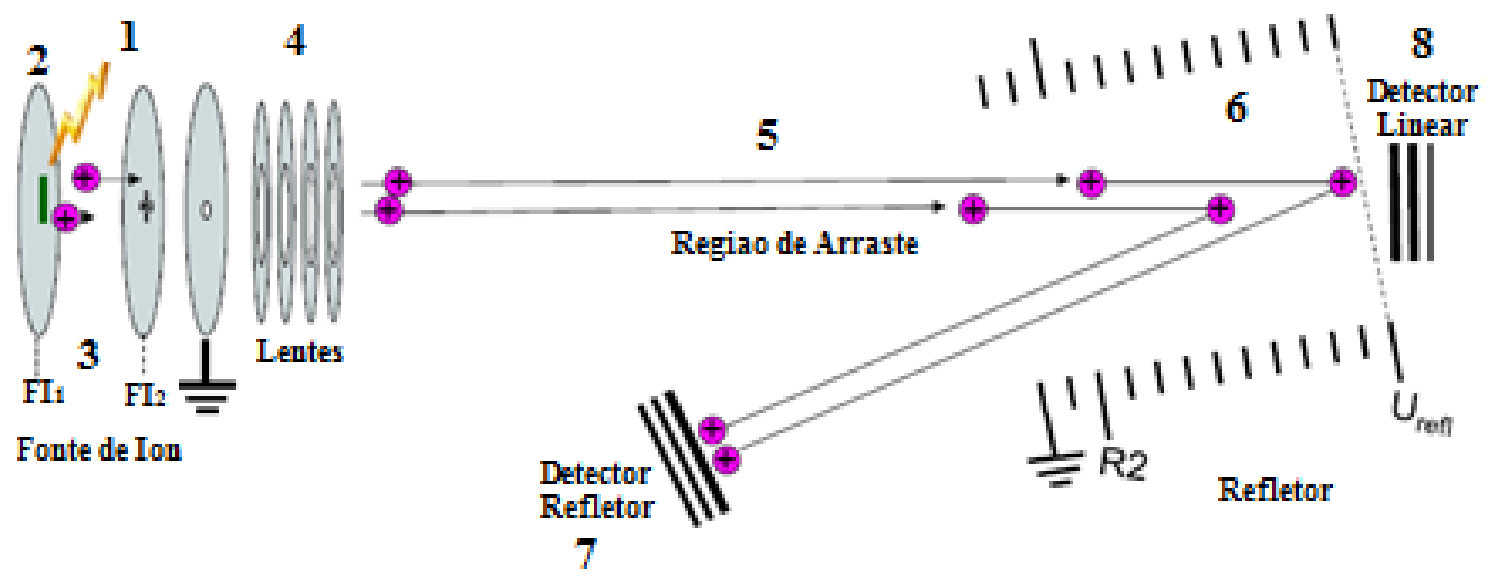

Figura 7: Diagrama de um espectrômetro de massas do tipo MALDI-TOF-MS (BRUKER, 2013a).

\subsubsection{Detectores}

Os íons que chegam ao detector geram um sinal elétrico que é registrado e processado pelo software do espectrômetro de massas e apresentado como um espectro de intensidade de sinal de íons versus razão massa/carga $(\mathrm{m} / \mathrm{z})$.

O detector é um componente de placas de microcanais, em que o impacto de partículas gera um sinal cuja intensidade está relacionada com a energia de colisão. Se Ek é constante e determinada pela força da carga iônica e do campo elétrico, então se a massa é maior, a velocidade torna-se menor. Em algum ponto, a velocidade cai abaixo do fundamental para a geração de sinais (para fins práticos, de 200-300 kDa, mas os sinais foram observados até 1 MDa).

Uma vez familiarizado com o espectrômetro de massas, pode-se otimizar os parâmetros de acordo com as necessidades.

\subsubsection{Placas "anchorchip" e "polished"}

As placas "polished", cujos "spots" (porta amostras) apresentam $800 \mu \mathrm{m}$, são as mais comuns e são praticamente livres de qualquer estrutura em sua superfície, proporcionando o máximo de nivelamento das finas camadas de amostras para MALDI. 
As placas "anchorchip" para técnica MALDI são fabricadas com pontos hidrofílicos ("anchors") cercadas por um ambiente hidrofóbico, fazendo com que a gotícula fique centralizada no "spot" (porta amostra) e concentrada sobre esses pontos hidrofílicos, os quais têm diâmetro de $400 \mu \mathrm{m}$, aumentando então a sensibilidade, principalmente para amostras muito diluídas, Figura 8.

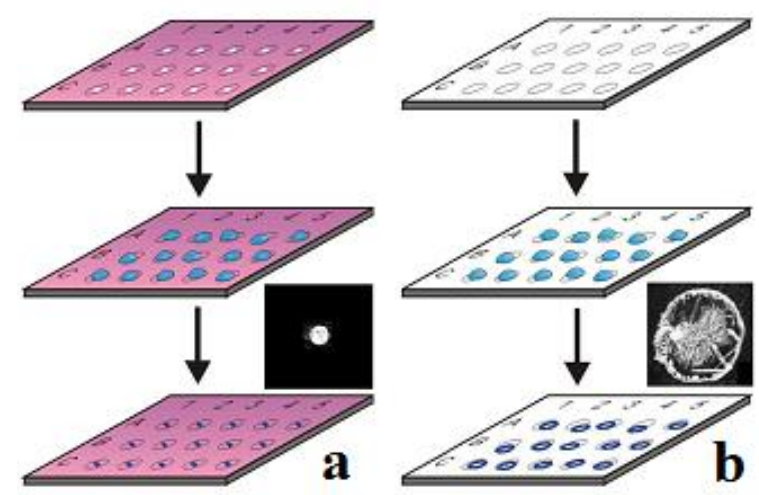

Figura 8: Princípios básicos das placas "anchorchip" (a) e a tradicional "polished" (b) utilizadas na técnica de MALDI (BRUKER, 2013b).

Após o ajuste adequado da placa na fonte de íons, o alinhamento exato garante que cada tiro ("shot") de laser disparado durante a corrida automática atingirá pontos individuais a serem analisados, sendo esse, o grande benefício no processo de aquisição de MALDI. O revestimento hidrofóbico anchorchip ${ }^{\mathrm{TM}}$ não é apenas "fobia" contra a água, mas também contra quase todos os solventes orgânicos como álcool, acetonitrila e acetona, por exemplo (BRUKER, 2013b).

\subsubsection{Modos linear e refletor}

Existem dois modos de operação no analisador de massas por tempo de vôo, o modo refletor e o modo linear. O modo refletor tem como objetivo a focalização dos íons simultaneamente no tempo e espaço, por compensação dos íons de diferentes energias. Consiste em uma série de pratos onde são aplicados um aumento das voltagens. Esta diferença de voltagem acelera os íons e redireciona o caminho de vôo dos íons para o detector refletor, melhorando a acurácia da massa e a resolução do pico, como pode ser visto na Figura 9 


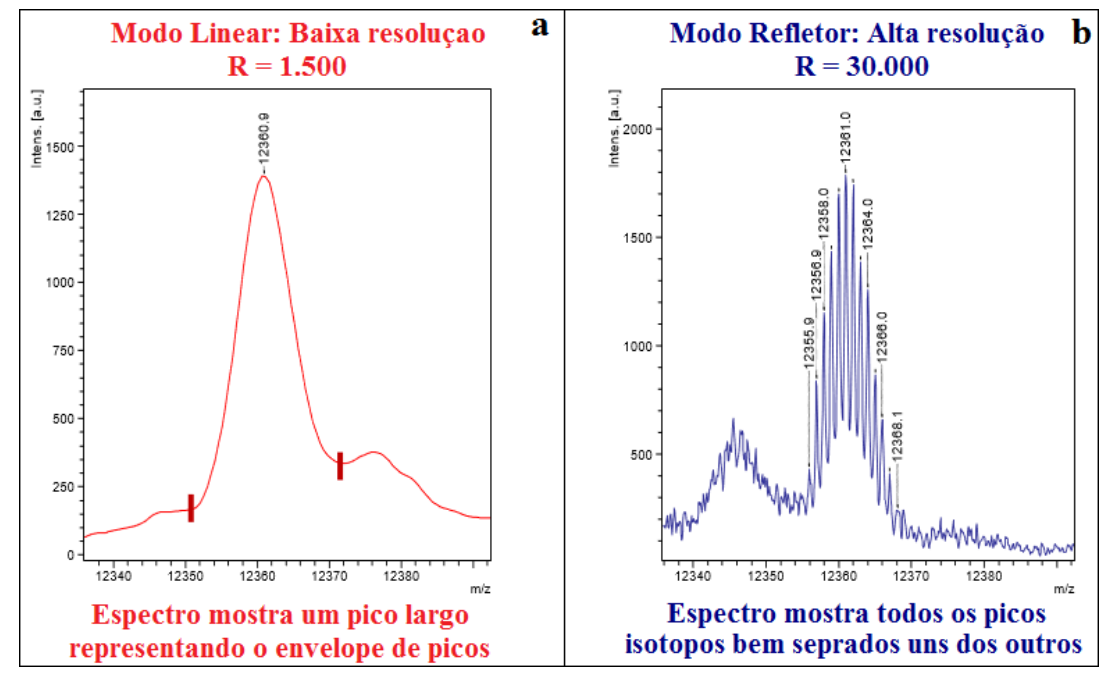

Figura 9: Diferença na resolução dos espectros adquiridos utilizando analisador de massas TOF nos modo linear (a) e refletor (b) (BRUKER, 2013a).

O modo linear é usado sempre que analitos não são estáveis o suficiente para sobreviver ao estresse energético que é inerente ao passar pelo refletor (íons são desacelerados/reacelerados no refletor por um campo elétrico de alta voltagem em nanosegundos). Moléculas maiores, como proteínas intactas, apresentam estabilidade limitada ao passar pelo campo refletor, e podem sofrer forte fragmentação, resultando em espectros mal resolvidos e /ou perda drástica na sensibilidade (fragmentos de baixa massa vão se perder no refletor) (BRUKER, 2013a).

\subsubsection{Matrizes}

São compostos orgânicos de baixo peso molecular utilizados para auxiliar na ionização das amostras. Elas são escolhidas de acordo com os tipos de compostos que serão analisados.

Para análise de proteínas e peptídeos, as matrizes mais comumente utilizadas são ácido a-ciano-4-hidroxicinamico (HCCA), Ácido Sinapínico (SA) e Ácido Dihidroxibenzóico (DHB). As matrizes devem apresentar alto grau de pureza. Todas as matrizes apresentam pros e contras, citados a seguir:

- $\alpha$-ciano-4-hidroxicinamico (HCCA): Essa matriz com cristais de coloração amarelo claro é comumente usada para peptídeos em faixa de massa baixa. Essa matriz não é solúvel em água e solubiliza bem em solventes orgânicos. É considerada uma matriz forte, pois o analito adquire bastante energia interna durante os processos de dessorção 
e ionização, levando a uma quantidade considerável de íons fragmentados no tubo analisador de massa - drift (post source decay). A principal vantagem no uso de HCCA para peptídeos é a possibilidade desta matriz formar pequenos cristais homogêneos, já que a homogeneidade geométrica está diretamente relacionada ao aumento da resolução da análise .

- Ácido Sinapínico (SA): Essa matriz é mais comumente utilizada em análises de proteínas de massa alta. Não é solúvel em água, mas é bastante solúvel em solventes orgânicos. É uma matriz mais suave se comparada a matriz HCCA. Os íons do analito recebem menos energia interna proveniente do SA e portanto a fragmentação é menor, tornando essa matriz mais adequada para análises de proteínas. SA também forma pequenos cristais. Entretanto, o SA tende a formar produtos de adição com os íons do analito, os quais podem ser vistos no espectro de massas até $40 \mathrm{kDa}$.

- Ácido 2,5-Dihidroxibenzóico (DHB): Essa matriz é geralmente usada em análises de glicoproteínas, glicanos e peptídeos. Ao contrário das outras matrizes citadas anteriormente, DHB é solúvel em água e solventes orgânicos. A principal desvantagem do DHB é o fato deste formar grandes cristais e dispersar-se na placa em forma de anel, implicando em mudanças na geometria da amostra de spot para spot. Se os espectros são somados de diferentes pontos de preparação da amostra, a resolução é consideravelmente menor do que os espectros obtidos com HCCA, por exemplo. A grande vantagem no uso dessa matriz é sua alta tolerância a contaminações como sais ou detergentes, quando comparada as outras matrizes.

- Super DHB (sDHB): É uma mistura contendo 90\% de DHB com 10\% de ácido 2hidroxi-5-metoxibenzóico, recomendada para análises de proteínas de massa alta e glicoproteínas. sDHB é também adequada para análises de ISD (do inglês in-source decay) de proteínas intactas, onde a fragmentação ocorre ainda na fonte de ionização.

A escolha da matriz é crucial para a obtenção de bons resultados quando se usa a técnica de MALDI.

\subsubsection{Tensão de aceleração $-I_{1}$}

O valor da tensão de aceleração (IS 1 ) na placa de MALDI é de grande importância para alcançar alta resolução em um espectrômetro de massas MALDI-TOF. Isso se deve à 
diferença absoluta em energia observada para os íons de diferentes massas com o aumento da voltagem aplicada para a aceleração inicial dos íons formados. No entanto, IS $_{1}$ não é considerado um parâmetro isolado, e assim, não é um parâmetro escolhido livremente pelo usuário.

\subsubsection{Potência do laser}

A quantidade de energia de laser fornecida à mistura matriz/amostra sempre influencia na qualidade do espectro gerado, especialmente se trabalhado logo acima do limite de absorção da matriz. A quantidade de energia do laser depende:

- da substância a ser analisada,

- da sensibilidade do analito,

- da razão molar matriz:analito, e

- da técnica de preparo

Quando a energia do laser é excedida, podem ocorrer processos secundários levando a diminuição da resolução, como observado na Figura 10.

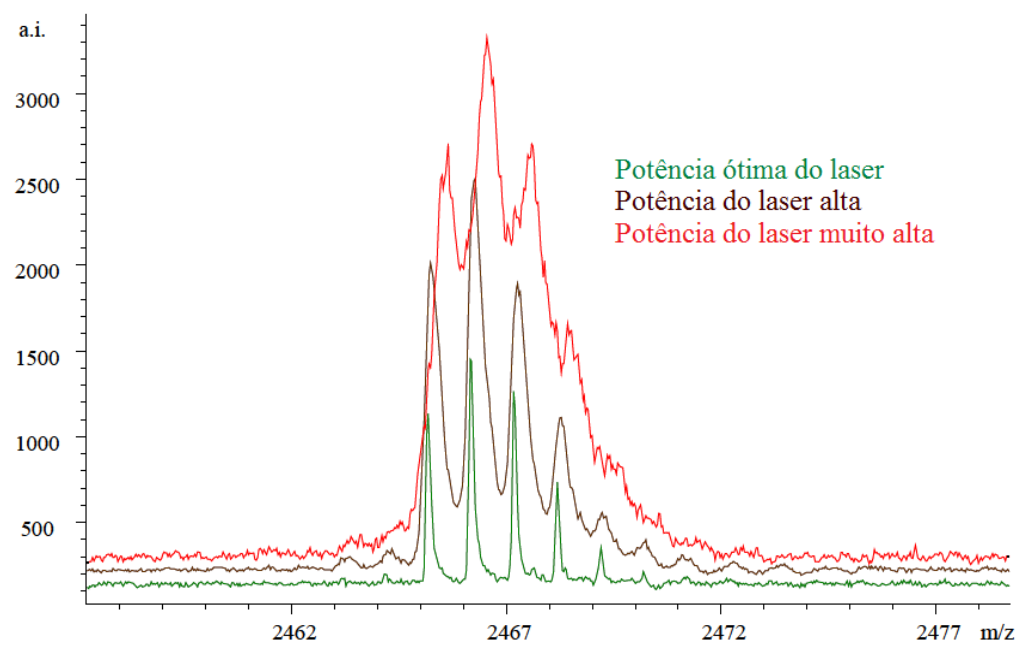

Figura 10: Influência da potência do laser aplicada sobre a qualidade dos espectros (BRUKER).

\subsubsection{PIE (extração pulsada de íons) e tensão de aceleração - IS $S_{2}$}

Inicialmente não há diferença de voltagem $(\mathrm{dV})$ entre a fonte 1 - placa $\left(\mathrm{IS}_{1}\right)$ e a fonte 2 - eletrodo $\left(\mathrm{IS}_{2}\right)$. Após a incidência do laser, os analitos são ionizados e viajam de $\mathrm{IS}_{1}$ para 
IS $_{2}$. Nesse momento, as amostras são ionizadas ainda sem diferença de potencial, pois $\mathrm{IS}_{1}=\mathrm{IS}_{2}$, e a velocidade inicial dos íons é somente resultado do processo de MALDI. Íons maiores apresentam uma velocidade mais lenta, enquanto íons menores tem uma velocidade mais rápida. Íons de mesma massa, que apresentam velocidades espalhadas, criam uma resolução ruim no espectro de massas, especialmente no modo linear. Ao final do tempo de "delay" (PIE) a voltagem da fonte $\mathrm{IS}_{2}$ é reduzida, provocando uma diferença de potencial entre $\mathrm{IS}_{1}$ e IS $\mathrm{IS}_{2}$, fornecendo maior energia cinética aos íons menores, acelerando os íons e fazendo os íons de mesma massa chegarem mais rapidamente ao detector, diminuindo o efeito de espalhamento e deixando os picos mais estreitos e mais bem resolvidos (BRUKER).

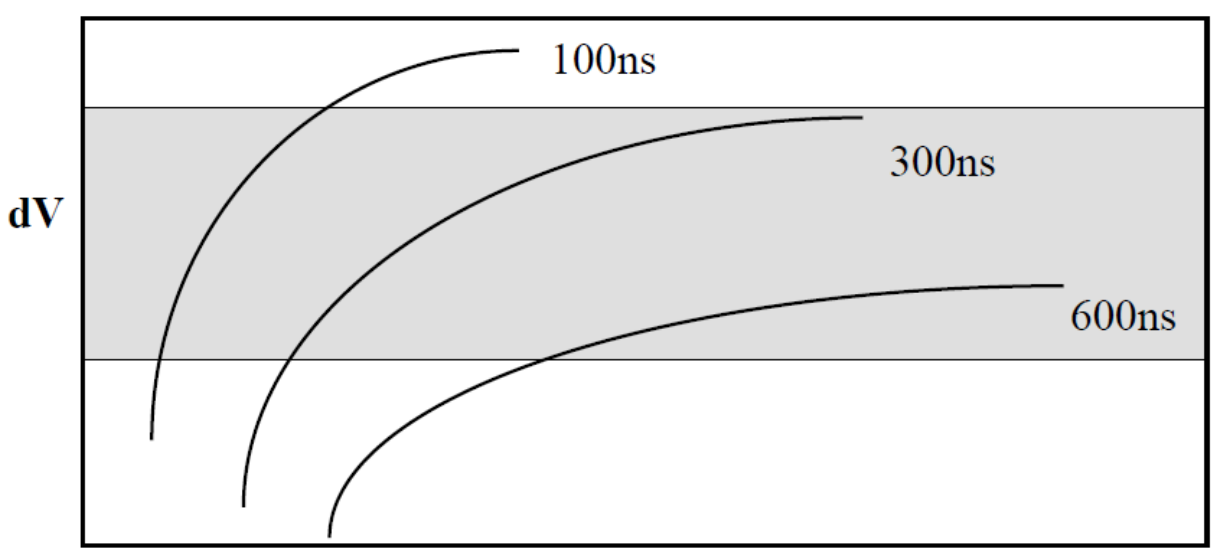

Massa

Figura 11: Relação entre a diferença de potência (dV) e a massa do íon em vários PIE (BRUKER).

Como observado na Figura 11, se o PIE for constante, quanto maior a massa dos íons, maior deve ser a diferença de potencial entre IS $_{1}$ e $I_{2}$ e se $I_{2}$ é mantido constante, quanto maior a massa dos íons maior deve ser o tempo de "delay". Ou seja, a distribuição das velocidades dos íons mais rápidos e mais lentos, com mesma $\mathrm{m} / \mathrm{z}$ é bastante ampla, e para compensar essa distribuição, uma maior diferença de potencial entre $\mathrm{IS}_{1}$ e $\mathrm{IS}_{2}$ é requerida para que todos os íons de mesma massa cheguem ao mesmo tempo no detector (BRUKER).

Assim, os parâmetros PIE (Pulsed Ion Extraction) e IS $_{2}$ (tensão de aceleração 2) influenciam drasticamente na resolução de um espectro de massas MALDI-TOF e a variação desses parâmetros torna-se de grande importância no procedimento de otimização (BRUKER).

É essencial saber como a PIE trabalha para ajustar esse parâmetro de maneira correta e, consequentemente, obter melhores resultados. 


\section{MATERIAIS E MÉTODOS}

\subsection{MATERIAIS E INSTRUMENTOS}

Os reagentes químicos utilizados nesse trabalho são de grau analítico e sua marca e grau de pureza estão descritos no Anexo I. Já os equipamentos bem como seus modelos e marcas estão descritos no Anexo II.

\subsection{MÉTODOS}

\subsubsection{Cultivos de microalgas}

\subsubsection{Espécies de microalgas estudadas}

Para a otimização do sistema de cultivo, especialmente com respeito à luminosidade, foi escolhida a cepa da microalga Chlorella vulgaris, gentilmente cedida pelo Departamento de Ecologia e Biologia Evolutiva da Universidade Federal de São Carlos, através do professor Armando Augusto Henriques Vieira.

Já para as caracterizações dos perfis de proteínas, foram utilizadas, além da microalga Chlorella vulgaris, as cepas Chlorella sp., Desmodesmus sp., Monoraphiudium sp. e Oocystis $s p$. cedidas gentilmente pela empresa Algae Biotecnologia Ltda, através do gerente técnico Sérgio Goldemberg.

\subsubsection{Repiques}

A manutenção das microalgas em tubos de ensaio e erlenmeyers se deu através de procedimentos de repique, realizados a cada 20 dias, em média. Todo o material, vidrarias e meio de cultivo foram autoclavados (esterilizados) à $121{ }^{\circ} \mathrm{C}$ por 20 minutos, para posterior manipulação em fluxo laminar. Um pequeno volume de inóculo foi coletado (cerca de $2 \mathrm{~mL}$ ) e colocado nos tubos de ensaio (Figura 12) contendo $15 \mathrm{~mL}$ de um meio de cultura novo visando manutenção (sobrevivência) da cultura.

As culturas são mantidas à temperatura de $23{ }^{\circ} \mathrm{C}$ sob intensidade luminosa de $9 \mu \mathrm{mol}_{\text {fotons. }} \mathrm{m}^{-2} \cdot \mathrm{s}^{-1}$ e fotoperíodo de $12 / 12 \mathrm{~h}$ claro/escuro. 


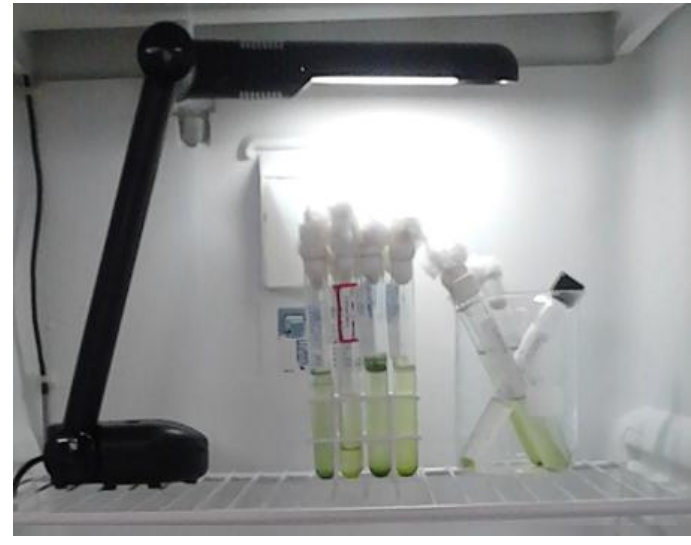

Figura 12: Banco de culturas das microalgas estudadas.

Um volume maior de cultura (erlenmeyers contendo $100 \mathrm{~mL}$ de meio de cultura), com células provenientes dos tubos de ensaios, também é mantido à temperatura de $23{ }^{\circ} \mathrm{C}$, sob intensidade luminosa de $9 \mu$ molfotons. $\mathrm{m}^{-2} \mathrm{~s}^{-1}$ e fotoperíodo de 12/12 h claro/escuro, para realização dos experimentos posteriores, Figura 13.

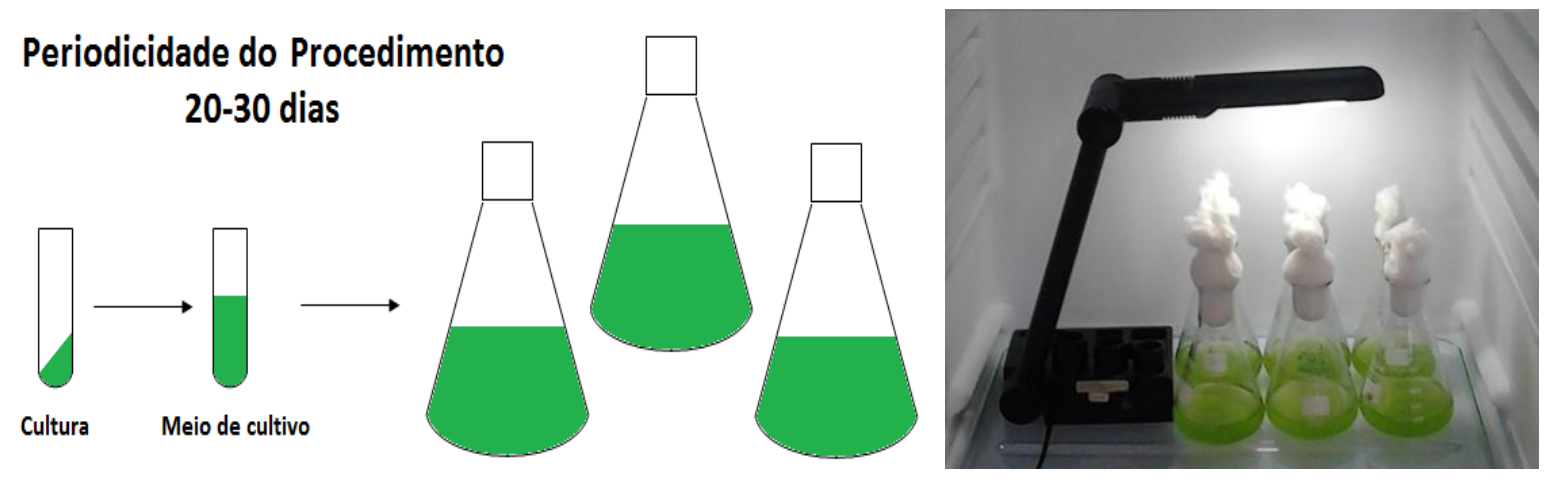

Figura 13: Banco de culturas para realização dos experimentos.

\subsubsection{Meio de cultivo sintético $\mathrm{WC}^{2}$}

Como meio de cultivo sintético, foi utilizado o meio WC (ANDERSEN, 2005) adaptado, cuja formulação é apresentada na Tabela 7:

\footnotetext{
${ }^{2}$ A sigla WC é proveniente do inglês "Wright's cryptophyte", meio utilizado por Wright para crescimento de algas criptoficeas.
} 
Tabela 7: Composição do meio sintético WC (ANDERSEN, 2005).

\begin{tabular}{|c|c|c|c|}
\hline \multicolumn{4}{|c|}{ Meio Sintético WC } \\
\hline Componente & $\begin{array}{l}\text { Soluçãa Estoque } \\
\left(\text { g.L.L } \mathbf{L}^{-1} \cdot \mathbf{d H}_{\mathbf{2}} \mathbf{O}\right)\end{array}$ & Volume & $\begin{array}{c}\text { Concentração Final } \\
\text { no Meio (M) }\end{array}$ \\
\hline $\mathrm{NaNO}_{3}$ & 85,01 & $1 \mathrm{~mL}$ & $1,00 \times 10^{-3}$ \\
\hline $\mathrm{CaCl}_{2} \cdot 2 \mathrm{H}_{2} \mathrm{O}$ & 36,76 & $1 \mathrm{~mL}$ & $2,50 \times 10^{-4}$ \\
\hline $\mathrm{MgSO}_{4} \cdot 7 \mathrm{H}_{2} \mathrm{O}$ & 36,97 & $1 \mathrm{~mL}$ & $1,50 \times 10^{-4}$ \\
\hline $\mathrm{NaHCO}_{3}$ & 12,60 & $1 \mathrm{~mL}$ & $1,50 \times 10^{-4}$ \\
\hline $\mathrm{Na}_{2} \mathrm{SiO}_{3} \cdot 9 \mathrm{H}_{2} \mathrm{O}$ & 28,42 & $1 \mathrm{~mL}$ & $1,00 \times 10^{-4}$ \\
\hline $\mathrm{K}_{2} \mathrm{HPO}_{2}$ & 8,71 & $1 \mathrm{~mL}$ & $5,00 \times 10^{-5}$ \\
\hline Traços de Metais & - & $1 \mathrm{~mL}$ & $5,00 \times 10^{-5}$ \\
\hline \multicolumn{4}{|c|}{ Solução Traços de Metais } \\
\hline Componente & $\begin{array}{l}1^{\text {a }} \text { Solução Estoque } \\
\left(\text { g.L }{ }^{-1} \cdot \mathbf{d H}_{2} \mathrm{O}\right)\end{array}$ & $\begin{array}{c}\text { Quantidade } \\
\text { Usada }\end{array}$ & $\begin{array}{c}\text { Concentração Final } \\
\text { no Meio (M) }\end{array}$ \\
\hline NaEDTA . 2H $2 \mathrm{O}$ & - & $4,36 \mathrm{~g}$ & $1,17 \times 10^{-5}$ \\
\hline $\mathrm{FeCl}_{3} \cdot 6 \mathrm{H}_{2} \mathrm{O}$ & - & $3,15 \mathrm{~g}$ & $1,17 \times 10^{-5}$ \\
\hline $\mathrm{CuSO}_{4} \cdot 5 \mathrm{H}_{2} \mathrm{O}$ & 10,0 & $1 \mathrm{~mL}$ & $4,01 \times 10^{-8}$ \\
\hline $\mathrm{ZnSO}_{4} \cdot 7 \mathrm{H}_{2} \mathrm{O}$ & 22,0 & $1 \mathrm{~mL}$ & $7,65 \times 10^{-8}$ \\
\hline $\mathrm{CoCl}_{2} \cdot 6 \mathrm{H}_{2} \mathrm{O}$ & 10,0 & $1 \mathrm{~mL}$ & $4,20 \times 10^{-8}$ \\
\hline $\mathrm{MnCl}_{2} \cdot \mathbf{4 \mathrm { H } _ { 2 } \mathrm { O }}$ & 180,0 & $1 \mathrm{~mL}$ & $9,10 \times 10^{-7}$ \\
\hline $\mathrm{Na}_{2} \mathrm{MoO}_{4} \cdot 2 \mathrm{H}_{2} \mathrm{O}$ & 6,0 & $1 \mathrm{~mL}$ & $2,48 \times 10^{-8}$ \\
\hline $\mathrm{MgSO}_{4}$ & - & $1,0 \mathrm{~g}$ & $1,62 \times 10^{-5}$ \\
\hline
\end{tabular}

\subsubsection{Avaliação do crescimento}

Visando a padronização dos experimentos, as microalgas foram previamente aclimatadas às condições de cultivo, procedimento chamado de pré-inóculo. Assim, antes do início dos experimentos, as microalgas foram cultivadas em erlenmeyers de $250 \mathrm{~mL}$ colocadas em um agitador orbital com rotação de $150 \mathrm{rpm}$ e submetidas à condições específicas, ou seja, volume de meio WC $100 \mathrm{~mL}$, temperatura de $30^{\circ} \mathrm{C}$, intensidade luminosa de 23-24 $\mu$ molfotons. $\mathrm{m}^{-2} \cdot \mathrm{s}^{-1}$, ideal para cultivos em erlenmeyers (COUTTEAU, 1996) e concentração inicial de $\mathrm{DO}_{750 \mathrm{~nm}}=0,1$. Após a fase de adaptação, as microalgas foram empregadas como inóculo, sempre na fase exponencial de crescimento, tomando como padronização o $4^{\mathrm{o}}$ dia (após 96 horas, $\mathrm{DO}_{750 \mathrm{~nm}}$ superior a 0,4), para diminuir a fase de adaptação durante os cultivos (LAVENS \& SORGELOOS, 1996).

Para as curvas de crescimento, as amostras foram coletadas e analisadas em um espectrofotômetro UV2600, da marca Shimadzu. As leituras foram realizadas com comprimento de onda de $750 \mathrm{~nm}$, e como branco foi usado o meio de cultivo WC. 


\subsubsection{Quantificação da concentração celular - Densidade Óptica x Massa Seca}

Membranas da marca Whatman 1, com porosidade de 0,45 $\mu \mathrm{m}$ foram colocadas em placa de Petri, e levadas ao forno de micro-ondas à $150 \mathrm{~W}$ por 15 minutos para remover toda a água presente. As membranas foram colocadas em dessecador por 10 minutos para resfriar e foram então pesadas (OLSSOM \& NIELSEN, 1997).

A suspensão de células foi filtrada à vácuo, utilizando uma das membranas previamente seca e pesada e as células foram lavadas com água deionizada.

A membrana contendo as células foi novamente levada ao forno de micro-ondas à $150 \mathrm{~W}$ por 15 minutos para secagem.

A membrana, agora contendo as células, foi colocada em dessecador para resfriamento e, posteriormente, pesada. A massa de células foi obtida pela diferença de peso da membrana e da membrana com as células de microalgas.

\subsubsection{Extração e identificação de lipídios}

\subsubsection{Extração de lipídios}

Os lipídios foram extraídos utilizando o procedimento utilizado por Vieler e colaboradores (VIELER, et al., 2007) adaptado conforme descrito a seguir:

Ao final da curva de crescimento as soluções de microalga em suspensão foram centrifugadas a $5000 \mathrm{rpm}$ por 5 minutos e o sobrenadante foi descartado. As amostras foram liofilizadas para completa remoção do meio de cultura. Após a liofilização, as amostras foram pesadas para padronização do método, obtendo-se massas equivalentes a 0,002 g. Foram adicionados 0,25 mL de metanol e 0,5 mL de clorofórmio ( proporção 1:2 v/v). A fase orgânica contendo os lipídios esterificados solubilizados na mistura metanol e clorofórmio foi então analisada.

\subsubsection{Identificação de lipídios}

Após a extração e esterificação, as amostras foram analisadas em um cromatógrafo gasoso acoplado a um espectrômetro de massas (modelo CG MS QP 2010 Plus, Shimadzu), com fonte de ionização do tipo ionização por elétrons $(\mathrm{EI})(70 \mathrm{eV})$ e analisador quadrupolo. 
A coluna utilizada foi a DB1MS (5\% difenil and 95\% dimetil-polisiloxano - 30m de comprimento, 0,25 $\mathrm{mm}$ de diâmetro interno e $0,25 \mu \mathrm{m}$ de espessura do filme), com injeções de $3 \mu \mathrm{L}$. As amostras foram analisadas utilizando as seguintes condições de análise (Tabela 8).

Tabela 8: Condições da análise cromatográfica.

\begin{tabular}{c|c}
\hline Temperatura do injetor & $280{ }^{\circ} \mathrm{C}$ \\
\hline Temperatura da Interface & $300^{\circ} \mathrm{C}$ \\
\hline Temperatura inicial da coluna & $50{ }^{\circ} \mathrm{C}$ \\
\hline Temperatura final da coluna & $300^{\circ} \mathrm{C}$ \\
\hline Taxa de aquecimento & $5^{\circ} \mathrm{C} / \mathrm{min}$ \\
\hline Tempo total de análise & $60 \mathrm{~min}$ \\
\hline
\end{tabular}

\subsubsection{Perfil proteico}

As proteínas foram analisadas utilizando diferentes métodos, onde foram avaliados os solventes, matrizes, placas e parâmetros do equipamento.

\subsubsection{Preparo dos solventes}

O preparo das soluções de solventes utilizados nesse trabalho está descritos a seguir:

- TA30 - solvente composto por 30\% em volume de acetonitrila (ACN) e 70\% em volume de uma solução aquosa $0,1 \%$ ácido trifluoracético (TFA) - ACN:0.1\%TFA $(30: 70 \mathrm{v} / \mathrm{v})$.

- TA50 - solvente composto por 50\% em volume de ACN e 50\% em volume de uma solução aquosa $0,1 \%$ TFA - ACN:0.1\% TFA (50:50 v/v).

- 1 TA50 - solvente composto por $50 \%$ em volume de ACN e $50 \%$ em volume de uma solução aquosa 1\% TFA - ACN:1.0\% TFA (50:50 v/v).

- 2,5TA50 - solvente composto por 50\% em volume de ACN e 50\% em volume de uma solução aquosa 2,5\% TFA - ACN:2,5\% TFA (50:50 v/v).

- ISOTA50 - solvente composto por 50\% em volume de ACN, 35\% em volume de uma solução aquosa 0,1\% TFA e 15\% de Isopropanol (ISO) - ACN:0.1\%TFA:ISO $(50: 35: 15 \mathrm{v} / \mathrm{v})$.

- ISO1TA50 - solvente composto por 50\% em volume de ACN, 35\% em volume de uma solução aquosa 1\% TFA e 15\% de ISO - ACN:1.0\%TFA:ISO (50:35:15 v/v) 
- ISO2,5TA50 - solvente composto por 50\% em volume de ACN, 35\% em volume de uma solução aquosa 2,5\% TFA e 15\% de ISO - ACN:2.5\%TFA:ISO (50:35:15 $\mathrm{v} / \mathrm{v})$.

\subsubsection{Limpeza das placas "anchorchip" e "polished"}

Primeiramente, foi feita a limpeza das placas (porta amostra) de MALDI, segundo o procedimento padrão descrito pela Bruker Corporation (BRUKER, 2012a).

Usando luvas, a placa foi limpa com o auxílio de um pano umedecido primeiramente com isopropanol e posteriormente com água, para remoções de resquícios amostras visíveis. A placa foi colocada em isopropanol e levada ao ultrassom de banho por 10 minutos. A placa foi, então, colocada em uma solução de TA30 levada ao ultrassom de banho por mais 10 minutos. Por fim a placa foi seca em temperatura ambiente para então ser utilizada.

\subsubsection{Preparo do calibrante}

O uso do calibrante, ou seja, uma mistura de proteínas (Protein Standard I), permitiu a calibração e testes em faixas de massas entre 4 e $20 \mathrm{kDa}$. Os compostos presentes nesse calibrante e seus respectivos pesos moleculares são listados na Tabela 9.

Tabela 9: Composição da mistura de calibrantes de proteínas padrão (BRUKER, 2012b).

\begin{tabular}{l|c}
\hline \multicolumn{1}{c|}{ Proteínas } & Média (Da) \\
\hline Insulina $[\mathrm{M}+\mathrm{H}]^{+}$ & 5734,51 \\
\hline${\text { Citocromo C }[\mathrm{M}+2 \mathrm{H}]^{2+}}^{2+}$ & 6180,99 \\
\hline Mioglobina $[\mathrm{M}+2 \mathrm{H}]^{2+}$ & 8476,65 \\
\hline${\text { Ubiquitina I }[\mathrm{M}+\mathrm{H}]^{+}}^{+}$ & 8565,76 \\
\hline Citocromo C $[\mathrm{M}+\mathrm{H}]^{+}$ & 12360,97 \\
\hline Mioglobina $[\mathrm{M}+\mathrm{H}]^{+}$ & 16952,30 \\
\hline
\end{tabular}

Foram adicionados $125 \mu \mathrm{l}$ de solvente TA50 ao tubo contendo o calibrante e agitado utilizando um vortex por 5 segundos.

$\mathrm{Na}$ placa de amostragem foi colocado $1 \mu \mathrm{l}$ da solução contendo a mistura de calibrantes, e, após completa secagem, foi adicionado sobre o calibrante $1 \mu \mathrm{l}$ da solução de matriz, de acordo com os procedimentos descritos a seguir. Após a completa secagem em temperatura ambiente, a calibração foi realizada e as amostras analisadas (BRUKER, 2012b). 


\subsubsection{Preparo das matrizes}

Nesse trabalho foram testadas 4 diferentes matrizes, ácido sinapínico (SA), ácido $\alpha$ ciano-4-hidroxicinamico (HCCA), ácido 2,5-dihidroxibenzóico (DHB) e ácido 2,5dihidroxibenzóico + ácido 2-hidroxi-5-methoxibezóico (90:10) (sDHB). As concentrações e solventes utilizados para cada uma delas estão descritos a seguir:

- $\mathrm{SA}$ - Ácido Sinapínico - (PM=225,08 Da) - Essa matriz foi dissolvida em TA50 até saturação à temperatura ambiente. Utilizando uma mini centrifuga, o excesso de matriz foi separado ( 5 min a $10,000 \mathrm{~g}$ ) e foi usado somente a fase homogênea (BRUKER, 2012a).

- HCCA - Ácido $\alpha$-ciano-4-hidroxicinamico - (PM=189,17 Da) - Essa matriz foi dissolvida em TA50 até saturação à temperatura ambiente. O excesso foi separado com o auxílio de uma mini centrifuga ( 5 min a $10,000 \mathrm{~g}$ ) e somente foi utilizada a fase homogênea (BRUKER, 2012a).

- DHB - Ácido 2,5-dihidroxibenzóico - $(\mathrm{PM}=154,12 \mathrm{Da})$ - Essa matriz foi dissolvida em TA50 a uma concentração de $20 \mathrm{mg} / \mathrm{ml}$ à temperatura ambiente (BRUKER, 2012a).

- DHB - Ácido 2,5-dihidroxibenzóico - $(\mathrm{PM}=154,12 \mathrm{Da})$ - Essa matriz foi dissolvida em TA50 a uma concentração de $45 \mathrm{mg} / \mathrm{mL}$ em temperatura ambiente (BRUKER, 2012a).

- $\quad$ sDHB - Ácido 2,5-dihidroxibenzóico + Ácido 2-hidroxi-5-methoxibezóico (90:10) - $(\mathrm{PM}=168,15 \mathrm{Da})$ - Essa matriz, a uma concentração de $50 \mathrm{mg} / \mathrm{mL}$ à temperatura ambiente foi dissolvida nos solventes TA50; 1TA50; 2,5TA50; ISOTA50; ISO1TA50 e ISO2,5TA50 (BRUKER, 2012a).

\subsubsection{Preparo das amostras e análise}

Foi colocado na placa de amostragem $1 \mu \mathrm{L}$ da amostra solubilizado em solvente. Após completa secagem à temperatura ambiente, adicionou-se sobre a amostra $1 \mu \mathrm{L}$ da matriz a ser estudada.

Novamente, após completa secagem da amostra, a placa foi inserida no equipamento para a análise do perfil proteico correspondente à fase de crescimento das microalgas. 
O equipamento utilizado foi um espectrômetro de massas Ultraflextreme (Bruker) que conta com fonte de ionização do tipo MALDI (laser "smartbeam" gerando íons positivos ou negativos) e analisador do tipo TOF (tempo de vôo). As análises foram conduzidas em modo linear com frequência de $2000 \mathrm{~Hz}$, voltagem de aceleração de $25 \mathrm{kV}$ para a primeira fonte de íons, na placa, e 23,6 kV para a segunda fonte de íons, no eletrodo. Cada espectro foi coletado manualmente em modo íon positivo com uma média de 10000 "shots", e o intervalo de massas analisado foi de m/z 4-20 kDa (razão massa/carga). 


\section{RESULTADOS E DISCUSSÃO}

\subsection{CULTIVO DE MICROALGAS}

\subsubsection{Espécies de microalgas estudadas}

As cepas de microalgas foram selecionadas visando explorar a classe das clorofíceas com relação a ordem, família, gênero e espécie, sendo esse o primeiro trabalho experimental com microalga no nosso grupo. As classificações taxonômicas das microalgas usadas nesse trabalho são mostradas na Tabela 10.

Tabela 10: Classificação das diferentes espécies de microalgas usadas nesse trabalho

\begin{tabular}{l|c|c|c|c|c}
\hline & $\begin{array}{c}\text { Chlorella } \\
\text { vulgaris }\end{array}$ & $\begin{array}{c}\text { Chlorella } \\
\boldsymbol{s p}\end{array}$ & $\begin{array}{c}\text { Desmodesmus } \\
\boldsymbol{s p}\end{array}$ & $\begin{array}{c}\text { Monoraphidium } \\
\boldsymbol{s p}\end{array}$ & $\begin{array}{c}\text { Oocystis } \\
\boldsymbol{s} \boldsymbol{p}\end{array}$ \\
\hline Abreviação & $\mathbf{C v}$ & $\mathbf{C s p}$ & $\mathbf{D s p}$ & Msp & Osp \\
\hline Reino & Protista & Protista & Protista & Protista & Protista \\
\hline Filo & Clorófitas & Clorófitas & Clorófitas & Clorófitas & Clorófitas \\
\hline Classe & Clorofíceas & Clorofíceas & Clorofíceas & Clorofíceas & Clorofíceas \\
\hline Ordem & Chlorococcales & Chlorococcales & Sphaeropleales & Sphaeropleales & Chlorococcales \\
\hline Família & Oocystaceae & Oocystaceae & Scenedesmaceae & Selenastraceae & Oocystaceae \\
\hline Gênero & Chlorella & Chlorella & Desmodesmus & Monoraphidium & Oocystis \\
\hline Espécie & C. vulgaris & C. $\mathrm{sp}$ & D. $\mathrm{sp}$ & M. sp & O. sp \\
\hline
\end{tabular}

As suspensões das espécies estudadas foram dispostas em lâminas comuns para microscopia, e utilizando um microscópio óptico da marca Olympus, modelo BX 60, com aumento de 400 vezes, as imagens obtidas são mostradas nas Figuras 14A , B, C, D e E, respectivamente para as espécies Cv, Csp, Dsp, Msp e Osp. 


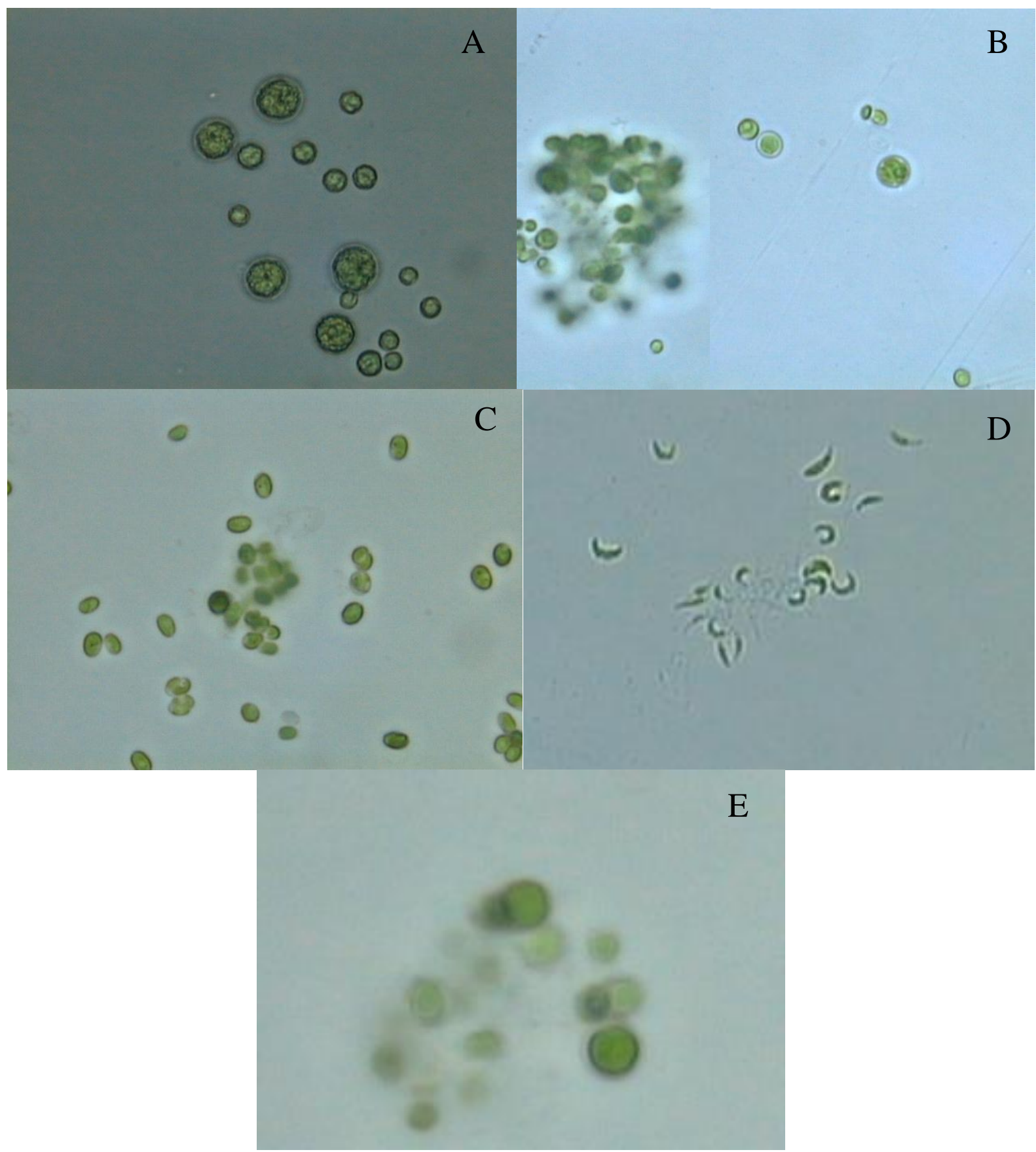

Figura 14: Imagens adquiridas em microscópio das espécies Chlorella vulgaris, Chlorella sp., Desmodesmus sp., Monoraphidium sp. e Oocystis sp., respectivamente A, B, C, D e E, utilizadas nesse trabalho.

\subsubsection{Mapeamento do agitador orbital (Shaker)}

O primeiro experimento consistiu em fazer o mapeamento do agitador orbital, modelo 109/1TC da marca Ethik Technology utilizado para montagem da curva de crescimento, e verificação da homogeneidade do sistema para os parâmetros utilizados. Um desenho 
esquemático das posições (Figura 15) dos 12 erlenmeyers utilizados descreve como a intensidade luminosa atinge cada uma das posições.

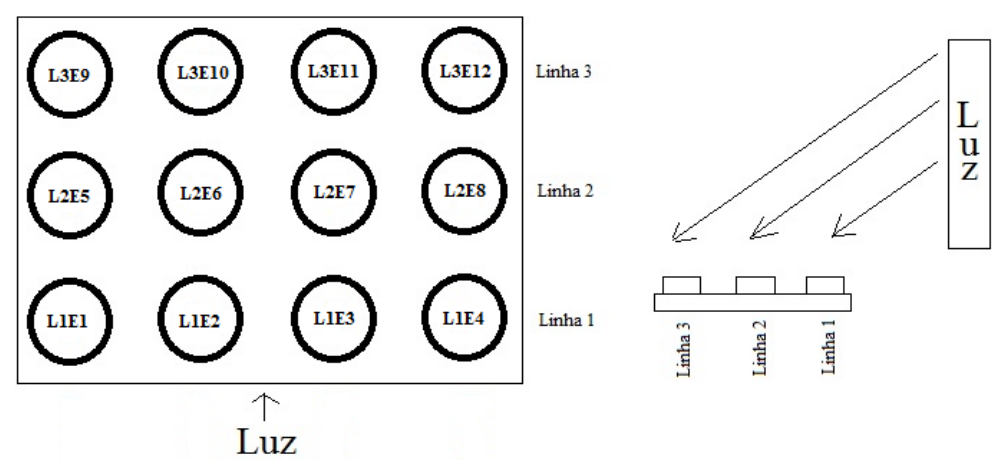

Figura 15: Esquema da incidência da intensidade luminosa nas posições do agitador orbital

A intensidade luminosa foi medida em triplicata em cada uma das posições indicadas na Figura 15, utilizando um luxímetro ${ }^{3}$, sem a presença dos erlenmeyers.

Os valores de intensidade luminosa médio para cada posição, convertidos para $\mu$ molfotons. $\mathrm{m}^{-2} \cdot \mathrm{s}^{-1}\left(1000 \mathrm{lux}=51,2 \mu\right.$ molfotons. $\left.\mathrm{m}^{-2} \cdot \mathrm{s}^{-1}\right)$ encontram-se na Tabela 11:

Tabela 11: Medidas de intensidade luminosa em cada posição do agitador orbital sem a presença de erlenmeyers

\begin{tabular}{|c|c|c|}
\hline Posição & $\begin{array}{c}\text { Média } \\
\left(\mu \text { molfótons. } \mathrm{m}^{-2} \cdot \mathrm{s}^{-1}\right)\end{array}$ & $\begin{array}{l}\text { Média da } \\
\text { Linha }\end{array}$ \\
\hline L1E1 & 24,21 & \multirow{4}{*}{$24,63 \pm 0,28$} \\
\hline L1E2 & 24,84 & \\
\hline L1E3 & 24,71 & \\
\hline L1E4 & 24,75 & \\
\hline L2E5 & 23,85 & \multirow{4}{*}{$23,84 \pm 0,05$} \\
\hline L2E6 & 23,81 & \\
\hline L2E7 & 23,80 & \\
\hline L2E8 & 23,91 & \\
\hline L3E9 & 23,20 & \multirow{4}{*}{$23,09 \pm 0,08$} \\
\hline L3E10 & 23,02 & \\
\hline L3E11 & 23,10 & \\
\hline L3E12 & 23,05 & \\
\hline Média & $23,85 \pm 0,67$ & $23,85 \pm 0,77$ \\
\hline
\end{tabular}

Com o objetivo de avaliar a equivalência entre as linhas do agitador orbital, foi realizada uma análise estatística levando-se em consideração que as 4 posições em cada linha

${ }^{3}$ Medidor de intensidade luminosa, medida dada em lux (1000 lux $=51,2 \mu$ molfótons. $\left.\mathrm{m}^{-2} \mathrm{~s}^{-1}\right)$ 
eram homogêneas. Verificou-se, através do teste $\mathrm{F}$ que há diferença significativa ao nível de $5 \%$ de probabilidade, entre as linhas $\left(\mathrm{F}_{\text {calculado }} 90,66\right.$ e $\left.\mathrm{F}_{\text {tabelado }} 3,29\right)$. A comparação de médias através do teste Tukey também mostrou que as todas linhas diferem entre si.

\subsubsection{Curva de crescimento para análise estatística}

Para a curva de crescimento e posterior análise estatística da mesma, foi adotado um sistema de cultivo em agitador orbital (shaker) disposto dentro um fotoperíodo, Figura 16, e isto permitiu o controle dos parâmetros de cultivo utilizados.

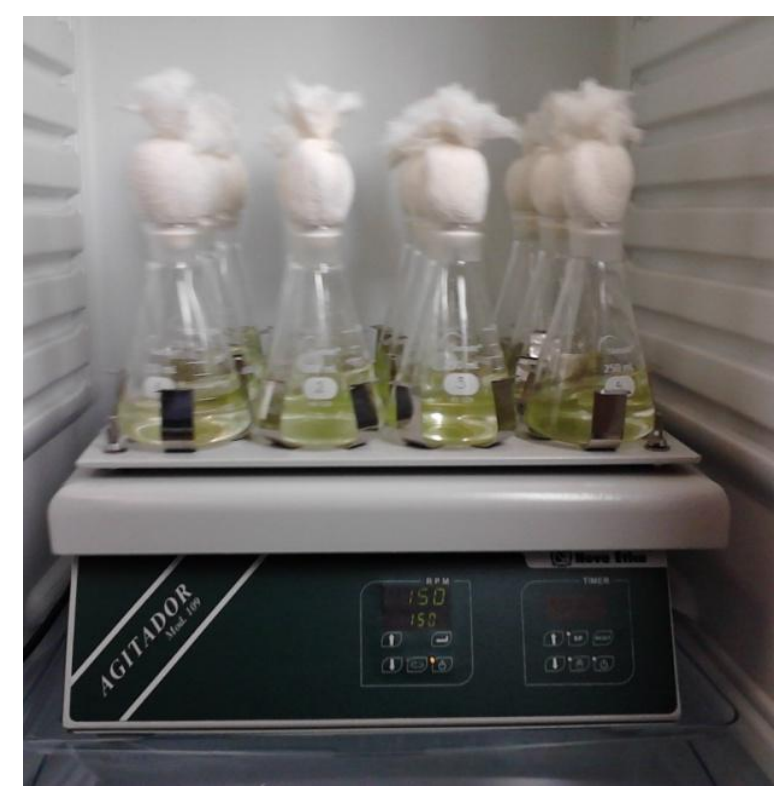

Figura 16: Agitador orbital para cultivo das microalgas

Visando verificar a distribuição da intensidade luminosa no sistema a ser utilizado para cultivo de microalgas ("shaker" agitador orbital mecânico), foi analisada a curva de crescimento da microalga Chlorella vulgaris (Figura 17) à temperatura de $23{ }^{\circ} \mathrm{C}$, luminosidade de 23-24 $\mu$ molfótons. $\mathrm{m}^{-2} \cdot \mathrm{s}^{1}$ fotoperíodo de 12/12 horas claro/escuro, rotação de $150 \mathrm{rpm}, 100 \mathrm{~mL}$ de meio de cultivo WC (meio de cultivo sintético) em erlenmeyers de $250 \mathrm{~mL}$ e inóculo inicial de $\mathrm{DO}_{750 \mathrm{~nm}}=0,1$ em cada posição do shaker. 


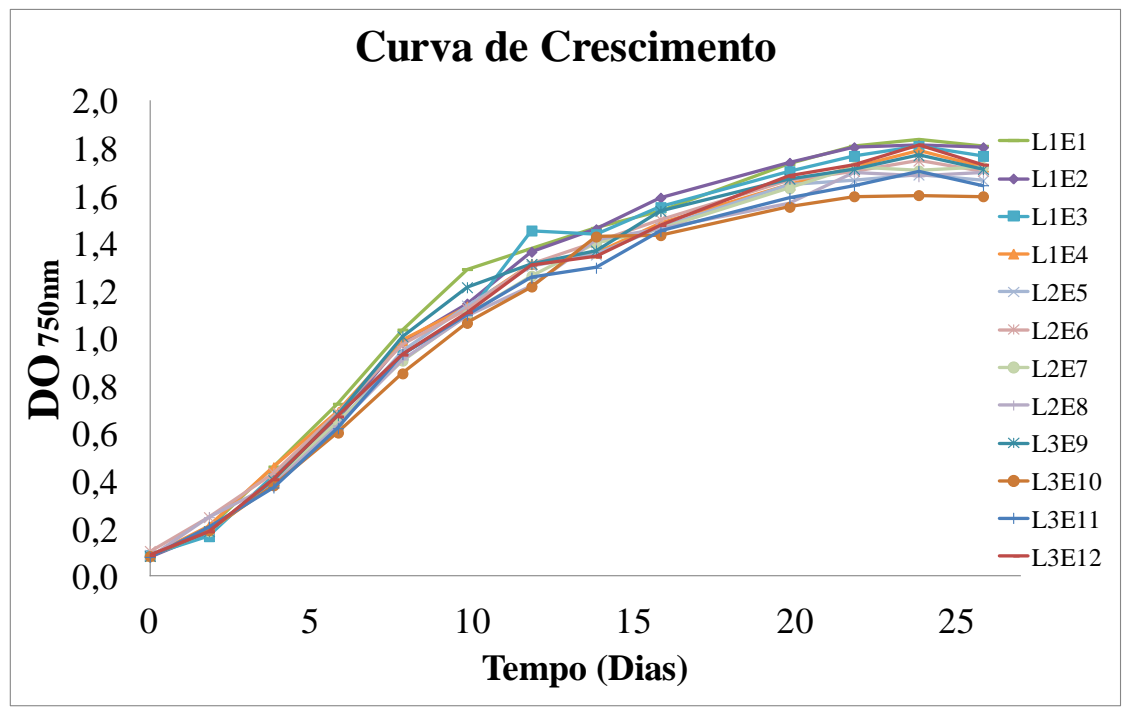

Figura 17: Curva de Crescimento para todas as posições do agitador orbital ao longo de 26 dias

Para a construção da curva de crescimento, foram realizadas coletas de $2,5 \mathrm{~mL}$ de amostra a cada 2 dias, e as mesmas foram analisadas em espectrofotômetro UV em comprimento de onda de $750 \mathrm{~nm}$.

O crescimento celular foi avaliado através da determinação da velocidade específica máxima de crescimento $(\mu \max )$, sendo que a velocidade específica é dada pela seguinte equação:

$$
\mu_{\max }=(1 / \mathrm{X}) \cdot \Delta \mathrm{X} / \Delta \mathrm{t}
$$

onde: $\mathrm{X}=$ Concentração celular $(\mathrm{g} / \mathrm{L})$

$\Delta X=$ Variação da concentração celular $(\mathrm{g} / \mathrm{L})$

$\Delta \mathrm{t}=$ Tempo de cultivo

O tempo de duplicação $t_{d}$, ou seja, o tempo necessário para que uma célula forme outras duas (fase exponencial $\left(2 \mathrm{X}_{0}=\mathrm{X}\right)$ ), é dado por:

$$
\begin{array}{r}
X=X_{0 .} e^{\mu t d} \text { ou seja } \\
L n 2=\mu_{\max } \cdot t_{d}
\end{array}
$$

onde: $\mathrm{X}_{0}=$ concentração inicial celular $(\mathrm{g} / \mathrm{L})$ 
A curva de crescimento para todas as posições do agitador orbital apresenta comportamento semelhante, sendo que a fase exponencial termina após 8 dias, como pode ser observado na posição L1E1, Figura 18.

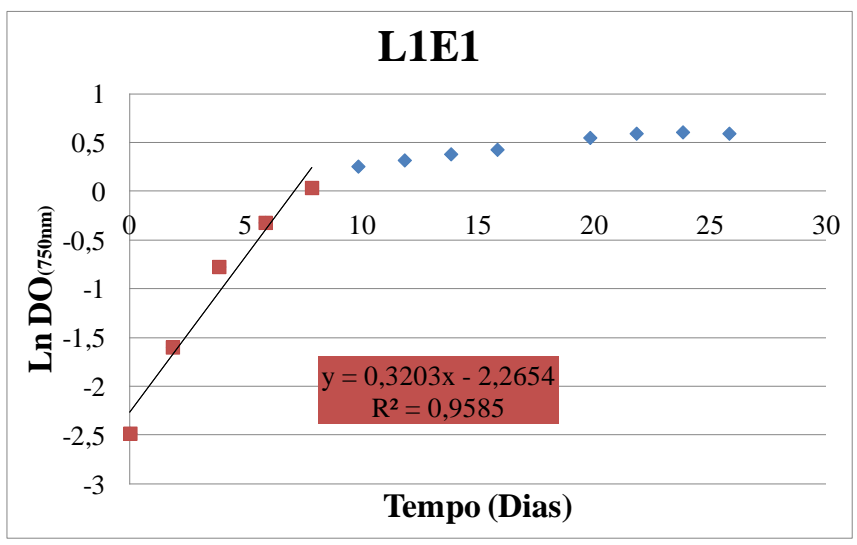

Figura 18: Curva cinética da fase exponencial na posição L1E1

Os dados de velocidade específica máxima de crescimento $(\mu \max )$ e tempo de duplicação $\left(t_{d}\right)$, para todas as posições do agitador orbital estão mostrados na Tabela 12, onde observou-se que em média o $\mu$ max é $0,3203 \mathrm{dia}^{-1}$, valor similar ao obtido por Ruiz e colaboradores (2010) que obtiveram $\mu$ max de $0,377 \mathrm{dia}^{-1}$ em seu estudo, com a mesma espécie de microalga e tempo de duplicação $\left(t_{d}\right)$, para todos os frascos é aproximadamente de 2 dias . Os gráficos da cinética para cada posição do agitador encontram-se no Anexo III.

Tabela 12: Valores de $\mu_{\max }$ e $t_{d}$ para a curva de crescimento em cada posição do agitador orbital.

\begin{tabular}{|c|c|c|c|c|}
\hline Posição & $\mu_{\text {máx }}\left(\operatorname{dia}^{-1}\right)$ & $\begin{array}{c}\text { Desvio Padrão } \\
\left(\text { dia }^{-1}\right)\end{array}$ & $\mathbf{t}_{d}(\operatorname{dias})$ & $\begin{array}{c}\text { Desvio Padrão } \\
\text { (dias) }\end{array}$ \\
\hline L1E1 & 0,3203 & \multirow{4}{*}{$0,3145 \pm 0,0006$} & 2,16 & \multirow{4}{*}{$2,21 \pm 0,04$} \\
\hline L1E2 & 0,3195 & & 2,17 & \\
\hline L1E3 & 0,3100 & & 2,24 & \\
\hline L1E4 & 0,3083 & & 2,25 & \\
\hline L2E5 & 0,3010 & \multirow{4}{*}{$0,2933 \pm 0,0127$} & 2,30 & \multirow{4}{*}{$2,37 \pm 0,10$} \\
\hline L2E6 & 0,2765 & & 2,51 & \\
\hline L2E7 & 0,3048 & & 2,27 & \\
\hline L2E8 & 0,2908 & & 2,38 & \\
\hline L3E9 & 0,3161 & \multirow{4}{*}{$0,3038 \pm 0,0098$} & 2,19 & \multirow{4}{*}{$2,28 \pm 0,07$} \\
\hline L3E10 & 0,2921 & & 2,37 & \\
\hline L3E11 & 0,3035 & & 2,28 & \\
\hline L3E12 & 0,3033 & & 2,29 & \\
\hline Média & $0,3039 \pm 0,0128$ & $0,3039 \pm 0,0128$ & $2,29 \pm 0,10$ & $2,29 \pm 0,10$ \\
\hline
\end{tabular}


A análise de variância (ANOVA) com 95\% de confiança foi realizada com os dados da curva de crescimento (medidas de $\mathrm{DO}_{750 \mathrm{~nm}}$ ), já que, provavelmente, as diferentes posições do agitador orbital recebem diferentes valores de intensidade luminosa, o que pode resultar em um efeito significante sobre o desenvolvimento das microalgas.

Esta análise teve o objetivo de identificar a diferença no crescimento microbiano entre as linhas 1, 2 e 3 (tratamentos), em cada dia de coleta de amostra (0, 2, 4, etc), separadamente.

Para exemplificar, serão mostrado somente os dados de absorbância obtidos para o dia 0, Tabela 13. Os dados obtidos para os outros dias estão apresentados no Anexo IV.

Tabela 13: Medidas de absorbância para as 3 linhas do agitador orbital utilizadas para análise estatística do dia 0 .

\begin{tabular}{c|c|ccc|c|c}
\hline Linhas & Posições & $\begin{array}{c}\text { Medida } \\
\mathbf{1}\end{array}$ & $\begin{array}{c}\text { Medida } \\
\mathbf{2}\end{array}$ & $\begin{array}{c}\text { Medida } \\
\mathbf{3}\end{array}$ & Média & $\begin{array}{c}\text { Média da } \\
\text { Linha }\end{array}$ \\
\hline \multirow{4}{*}{$\mathbf{1}$} & 1 & 0,0837 & 0,0837 & 0,0833 & 0,0836 & \\
& 2 & 0,0815 & 0,0807 & 0,0799 & 0,0807 & \multirow{2}{*}{0,0846} \\
& 3 & 0,0874 & 0,0889 & 0,0885 & 0,0883 & \\
& 4 & 0,0846 & 0,0874 & 0,0854 & 0,0858 & \\
$\mathbf{2}$ & 5 & 0,0896 & 0,0898 & 0,0900 & 0,0898 & \\
& 6 & 0,0923 & 0,0936 & 0,0933 & 0,0931 & \multirow{2}{*}{0,0872} \\
& 7 & 0,0836 & 0,0839 & 0,0829 & 0,0835 & \\
$\mathbf{3}$ & 8 & 0,0860 & 0,0813 & 0,0805 & 0,0826 & \\
& 9 & 0,0838 & 0,0852 & 0,0858 & 0,0849 & \\
& 10 & 0,0829 & 0,0852 & 0,0860 & 0,0847 & \multirow{2}{*}{0,0849} \\
& 11 & 0,0814 & 0,0812 & 0,0810 & 0,0812 & \\
& 12 & 0,0887 & 0,0897 & 0,0875 & 0,0886 & \\
\hline
\end{tabular}

Através da análise ANOVA, para cada linha do agitador orbital, foram calculados os valores de $\mathrm{F}_{\text {calculado }}$ para todos os dias da curva de crescimento, Tabela 14. $\mathrm{O} \mathrm{F}_{\text {tabelado }}$ obtido foi 3,29 (BOX, HUNTER, \& HUNTER, 2005), de acordo com a tabela de distribuição F de Snedecor a 5\% ( $\mathrm{p}=0,05)$, Anexo V. Para avaliação estatística dos dados, tem-se que:

- se $\mathrm{F}_{\text {calculado }}>\mathrm{F}_{\text {tabelado }}=$ há diferença estatística,

- se $\mathrm{F}_{\text {calculado }}<\mathrm{F}_{\text {tabelado }}=$ não há diferença estatística. 
Tabela 14: Análise de variância (ANOVA) para as 3 linhas do agitador orbital.

\begin{tabular}{|c|c|c|c|}
\hline Dia & F calculado & Dia & F calculado \\
\hline 0 & 1,90 & 14 & 9,14 \\
\hline 2 & 8,35 & 16 & 15,28 \\
\hline 4 & 13,74 & 20 & 12,15 \\
\hline 6 & 8,98 & 22 & 14,63 \\
\hline 8 & 5,93 & 24 & 14,31 \\
\hline 10 & 5,04 & 26 & 14,63 \\
\hline 12 & 20,88 & & \\
\hline
\end{tabular}

$\mathrm{O}$ teste $\mathrm{F}$, para probabilidade $5 \%$, mostrou evidências que a iluminação possui influência significativa no crescimento celular das linhas analisadas nos diferentes dias de cultivo. A comparação das médias através do teste Tukey mostrou que o crescimento das linhas 2 e 3 não diferem entre si, sendo que a linha 1 é a única que difere das demais. A Figura 18 mostra o comportamento das linhas do agitador orbital de acordo com as coletas realizadas, comprovando o que foi encontrado pela análise estatística. Assim, devido a proximidade com a fonte de luz (Figura 19), as posições da linha 1 apresentaram um favorecimento estatisticamente significativo ao crescimento microbiano.

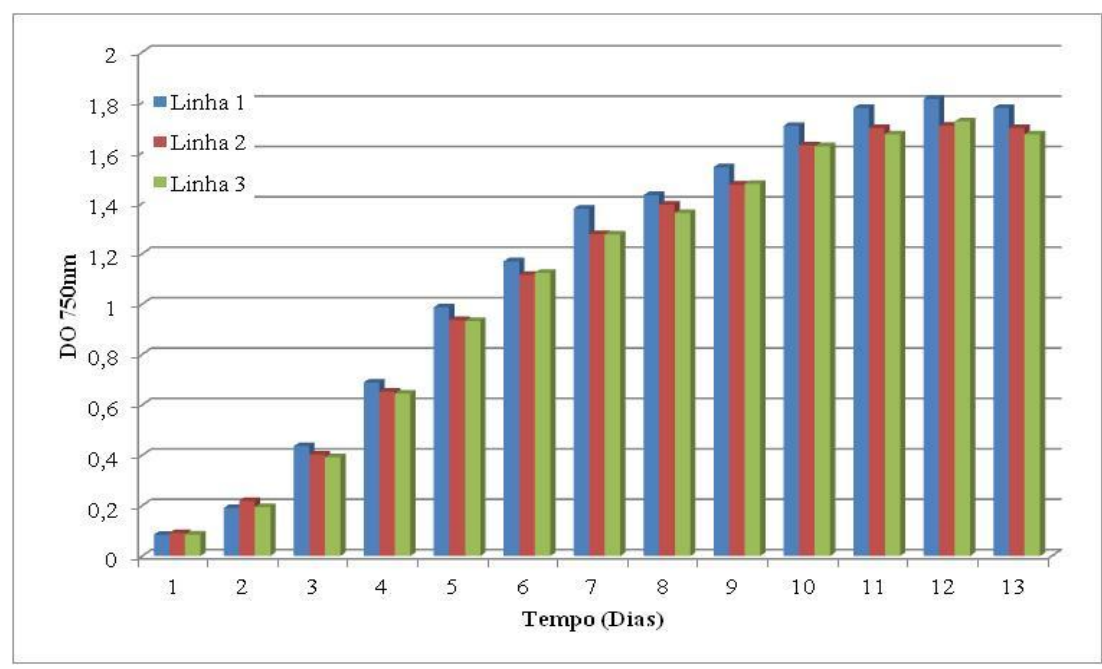

Figura 19: Gráfico comparativo das linhas do agitador orbital de acordo com o crescimento celular.

Ao final do experimento para obtenção da curva de crescimento para mapeamento do agitador orbital, ou seja, após 26 dias, foram realizadas as análises Carbono Total (CT), Carbono Inorgânico Total (CIT) e Carbono Orgânico Total (COT). Os dados são apresentados na Tabela 15. 
Tabela 15: Dados de carbono total (CT), carbono inorgânico total (CIT) e carbono orgânico Total (COT) da amostra de Chlorella vulgaris após 26 dias.

\begin{tabular}{|c|c|c|c|c|}
\hline Amostra & $\begin{array}{c}\mathbf{C T} \\
(\mathbf{p p m})\end{array}$ & $\begin{array}{c}\text { CIT } \\
(\mathbf{p p m})\end{array}$ & $\begin{array}{l}\text { COT } \\
\text { (ppm) }\end{array}$ & $\begin{array}{l}\text { COT Médio } \\
\text { (ppm) }\end{array}$ \\
\hline Meio WC & 5,837 & 3,88 & 1,958 & 1,958 \\
\hline L1E1 & 463,2 & 13,76 & 449,4 & \multirow{4}{*}{$442,9 \pm 14,0$} \\
\hline L1E2 & 467,6 & 13,00 & 457,4 & \\
\hline L1E3 & 470,2 & 12,86 & 439,8 & \\
\hline L1E4 & 452,4 & 12,66 & 424,8 & \\
\hline L2E5 & 438,0 & 13,26 & 430,2 & \multirow{4}{*}{$430,1 \pm 4,1$} \\
\hline L2E6 & 443,4 & 13,21 & 428,6 & \\
\hline L2E7 & 441,4 & 12,81 & 426,0 & \\
\hline L2E8 & 439,2 & 13,14 & 435,6 & \\
\hline L3E9 & 449,4 & 13,72 & 435,6 & \multirow{4}{*}{$430,0 \pm 5,5$} \\
\hline L3E10 & 438,0 & 13,31 & 424,6 & \\
\hline L3E11 & 448,4 & 14,46 & 433,8 & \\
\hline L3E12 & 439,4 & 13,56 & 426,0 & \\
\hline
\end{tabular}

Pode-se observar que o valor de carbono inorgânico total (CIT) para todas as amostras é muito semelhante, já que este carbono é proveniente somente do meio de cultivo e do $\mathrm{CO}_{2}$ dissolvido no meio, mostrando que os sistemas são bastante homogêneos. Já os valores de carbono orgânico total (COT) apresentam valores superiores para a linha 1, mostrando que o $\mathrm{CO}_{2}$ foi mais assimilado pelas microalgas, e consequentemente houve maior crescimento das mesmas, condizendo com o observado na análise estatística.

Assim, em função da conclusão da ANOVA, onde verificou-se que a diferença de luminosidade entre as linhas interferiu significativamente no crescimento das microalgas, decidiu-se avaliar se havia diferença de luminosidade entre as posições de cada linha.

Ainda utilizando a análise de variância ANOVA, foram avaliadas as equivalências entre todas as posições do agitador orbital através das medidas de $\mathrm{DO}_{750 \mathrm{~nm}}$ (Anexo IV) ao longo da curva de crescimento, e os valores de $\mathrm{F}_{\text {calculado }}$ obtidos para cada posição do agitador são observados na Tabela 16.

O $\mathrm{F}_{\text {tabelado }}$ obtido foi 2,22 (BOX, HUNTER, \& HUNTER, 2005), de acordo com a distribuição F de Snedecor a 5\% (p=0,05), Anexo V. 
Tabela 16: Análise de variância (ANOVA) para as 12 posições do agitador orbital.

\begin{tabular}{|c|c|c|c|}
\hline Dia & F calculado & Dia & F calculado \\
\hline $\mathbf{0}$ & 27,84 & 14 & 856,95 \\
\hline 2 & 258,90 & 16 & 620,21 \\
\hline 4 & 996,39 & 20 & 570,92 \\
\hline 6 & 2343,73 & 22 & 10,07 \\
\hline 8 & 1525,84 & 24 & 343,58 \\
\hline 10 & 130,97 & 26 & 10,07 \\
\hline 12 & 1271,98 & & \\
\hline
\end{tabular}

$\mathrm{O}$ teste $\mathrm{F}$, para probabilidade $5 \%$, mostrou evidências que a iluminação possui influência significativa no crescimento celular com relação à posição no agitador orbital, para todos os dias analisados ao longo da curva de crescimento.

\subsubsection{Otimização do sistema de cultivo}

Com o objetivo de otimizar o agitador orbital, para realização de experimentos com maior reprodutibilidade das condições, foi desenvolvido um sistema, no qual, cada posição do agitador orbital pode ser considerado como um reator. Desta forma, é possível realizar experimentos em triplicata (usando as colunas do agitador orbital, conforme descrito na Figura 20) com 4 variáveis (usando as linhas do agitador orbital) de uma só vez.

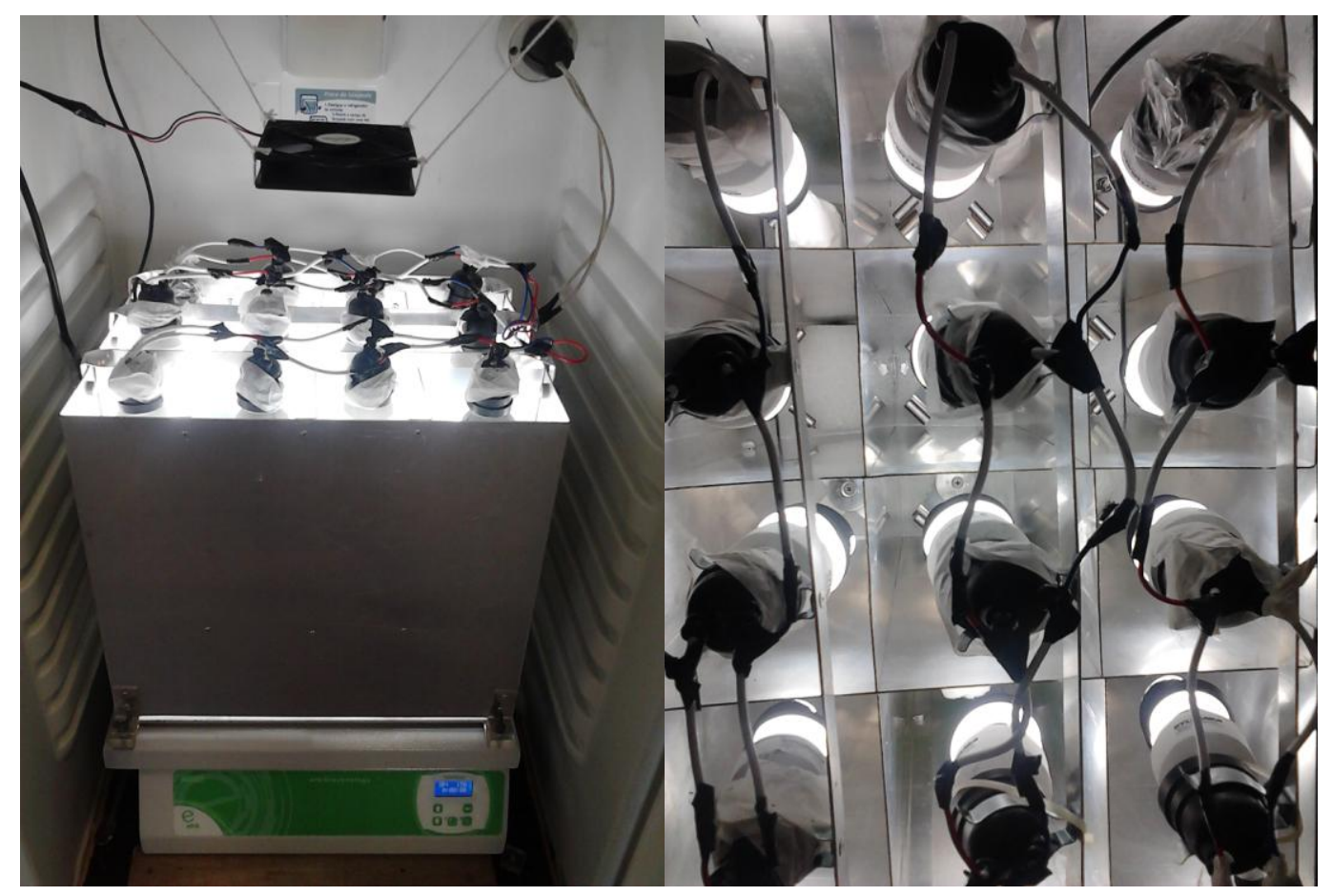

Figura 20: Sistema otimizado de cultivos de microalgas 
Primeiramente as 12 lâmpadas fluorescentes mini-Lynxs espiral branca fria da marca Sylvania, com potência de $11 \mathrm{~W}$ e intensidade luminosa inicial de $137 \mu$ molfótons. $\mathrm{m}^{-1} . \mathrm{s}^{2}$ foram ajustadas utilizando tinta preta para intensidades similares, na faixa de 23-24 $\mu$ molfótons.m-1.s ${ }^{2}$. As intensidades luminosas de cada posição foram medidas em triplicata e as médias se encontram na Tabela 17.

Tabela 17: Medidas médias de intensidades luminosas para cada posição do agitador orbital.

\begin{tabular}{|c|c|c|}
\hline Posição & $\begin{array}{l}\text { Média da Intensidade } \\
\text { Luminosa } \\
\left(\mu \mathrm{molfotons} . \mathrm{m}^{-2} \cdot \mathrm{s}^{-1}\right)\end{array}$ & $\begin{array}{l}\text { Média de Intensidade } \\
\text { Luminosa } \\
\left(\mu \text { molfotons. } \mathbf{m}^{-2} \cdot \mathrm{s}^{-1}\right)\end{array}$ \\
\hline L1E1 & 22,85 & \multirow{4}{*}{$22,90 \pm 0,25$} \\
\hline L1E2 & 22,85 & \\
\hline L1E3 & 23,24 & \\
\hline L1E4 & 22,66 & \\
\hline L2E5 & 23,05 & \multirow{4}{*}{$23,63 \pm 0,48$} \\
\hline L2E6 & 23,63 & \\
\hline L2E7 & 23,63 & \\
\hline L2E8 & 24,22 & \\
\hline L3E9 & 24,41 & \multirow{4}{*}{$23,73 \pm 0,67$} \\
\hline L3E10 & 23,63 & \\
\hline L3E11 & 22,85 & \\
\hline L3E12 & 24,02 & \\
\hline Média & $23,42 \pm 0,59$ & $23,42 \pm 0,45$ \\
\hline
\end{tabular}

Visando a homogeneidade do sistema, um sensor de temperatura foi colocado o mais próximo possível dos erlenmeyers para diminuir as diferenças de temperatura causadas pelo aquecimento das lâmpadas. Além disso, foi adaptado um "cooler" na parte superior da caixa de lâmpadas, como pode ser visto na Figura 20, com a função de sugar o ar quente gerado pelas lâmpadas, auxiliando na circulação de ar e trocas térmicas.

Após otimização do sistema, foi feito um pré-inóculo antes de iniciar o experimento, para garantir que as microalgas inoculadas estivessem na mesma fase, na fase exponencial.

Para determinação do dia em que o pré-inóculo seria utilizado, foi realizada uma curva de crescimento utilizando a microalga Chlorella vulgaris, sob as seguintes condições: temperatura de $30^{\circ} \mathrm{C}$, rotação de $150 \mathrm{rpm}, 100 \mathrm{~mL}$ de meio de cultivo WC em erlenmeyers de $250 \mathrm{~mL}, \mathrm{pH}$ inicial de 6 , intensidade luminosa média de $23-24 \mu$ molfótons. $\mathrm{m}^{-2} \cdot \mathrm{s}^{-1}$ e densidade óptica inicial de $\mathrm{DO}_{750 \mathrm{~nm}}=0,1$. O pré-inóculo foi realizado em duplicata e as coletas de $2 \mathrm{~mL}$ das suspensões de microalgas foram feitas diariamente, respeitando o horário inicial de inóculo, e os dados se encontram na Tabela 18: 
Tabela 18: Medidas de densidade óptica para determinação do pré-inóculo.

\begin{tabular}{|c|c|c|c|c|}
\hline & Curva 1 & Curva 2 & Média & Desvio \\
\hline Dia & \multicolumn{3}{|c|}{ DO $_{750 \mathrm{~nm}}$} & \\
\hline 0 & 0,1023 & 0,0991 & 0,1007 & 0,0023 \\
\hline 1 & 0,1876 & 0,1827 & 0,1852 & 0,0035 \\
\hline 2 & 0,2788 & 0,2713 & 0,2751 & 0,0053 \\
\hline 3 & 0,3474 & 0,3480 & 0,3477 & 0,0004 \\
\hline 4 & 0,4349 & 0,4337 & 0,4343 & 0,0008 \\
\hline 5 & 0,5361 & 0,5498 & 0,5430 & 0,0097 \\
\hline 6 & 0,6580 & 0,6878 & 0,6729 & 0,0211 \\
\hline 7 & 0,7996 & 0,7700 & 0,7848 & 0,0209 \\
\hline 8 & 0,9200 & 0,9146 & 0,9173 & 0,0038 \\
\hline 9 & 0,9434 & 0,9402 & 0,9418 & 0,0023 \\
\hline 10 & 1,0668 & 1,0674 & 1,0671 & 0,0004 \\
\hline
\end{tabular}

A Figura 21A mostra a média das duas curvas de crescimento, onde cada ponto foi medido em triplicata, no espectrofotômetro UV (750nm). Também pode ser observado, na Figura 21B, a cinética dos dois experimentos, com os respectivos desvios padrões de cada medida.
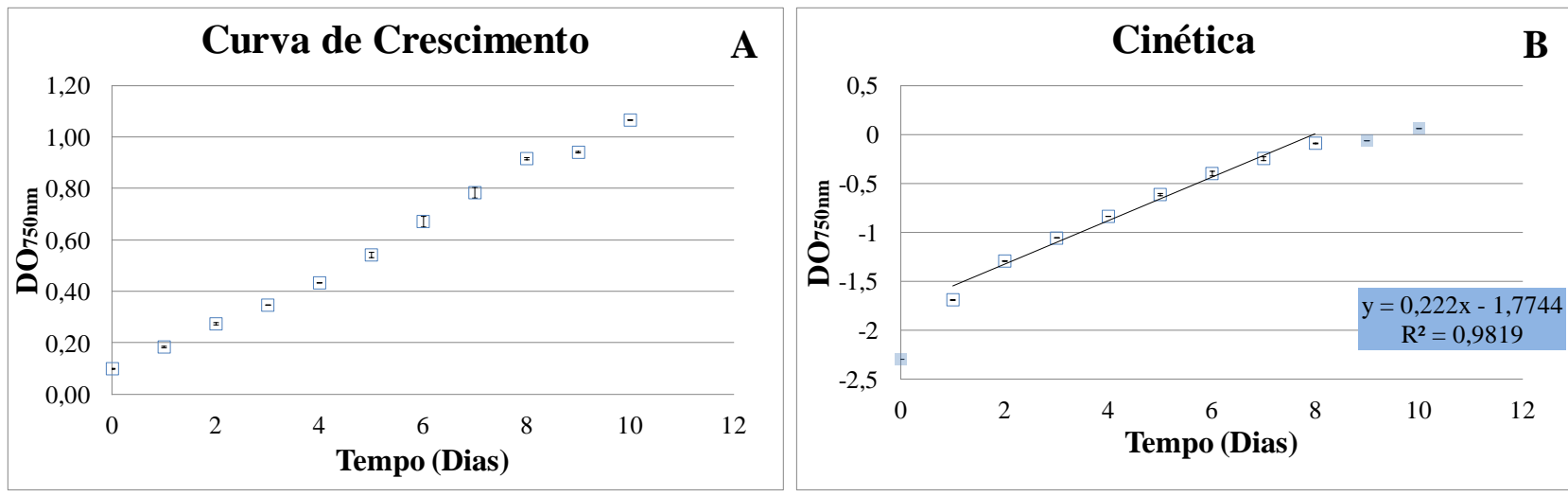

Figura 21: Curva de crescimento (A) e cinética (B) para caracterização do pré-inóculo

Nota-se que o crescimento deixa a fase exponencial a partir do $8^{\circ}$ dia e o valor de $\mu_{\max }$ médio encontrado foi $0,2220 \mathrm{dia}^{-1}$ com desvios próximos a zero, mostrando uma maior reprodutividade do sistema otimizado, quando comparado ao experimento com a incidência de luz heterogênea. Com base neste experimento, $o t_{d}$ médio foi determinado como sendo 3,12 dias.

Dessa forma, foi adotado o dia 4 como concentração inicial para todos os experimentos. Nesse dia, a microalga se encontra na fase exponencial e a $\mathrm{DO}_{750 \mathrm{~nm}}$ na faixa de 0,4 permite que um volume de cerca de $25 \mathrm{~mL}$ de inóculo seja adicionado aos $100 \mathrm{~mL}$ de 
meio de cultivo (corroborando com os inóculos comumente usados na faixa de 15 a $20 \%$ do novo volume) (MORETTI, et al., 1999).

\subsubsection{Curva de calibração para quantificação celular - Densidade Óptica $\left(\right.$ DO $\left._{750 \mathrm{~nm}}\right) \times$ Concentração de Massa Seca $(\mathrm{g} / \mathrm{L})$}

Foram construídas curvas de calibração para quantificação celular para todas as espécies estudadas. Partindo de um pré-inóculo conforme descrito anteriormente, as condições de cultivo foram: temperatura de $30^{\circ} \mathrm{C}$, rotação de $150 \mathrm{rpm}, 100 \mathrm{~mL}$ de meio de cultivo WC em erlenmeyers de $250 \mathrm{~mL}, \mathrm{pH}$ inicial de 6 , intensidade luminosa média de 23-24 $\mu$ molfótons. $\mathrm{m}^{-1} \cdot \mathrm{s}^{-2}$ e densidade óptica inicial de $\mathrm{DO}_{750 \mathrm{~nm}}=0,1$. Cada espécie foi cultivada em duplicata e a cada dois dias, intercalando os erlenmeyers da mesma espécie, foram realizadas coletas de dois volumes das suspensões de microalgas, sendo $2 \mathrm{~mL}$ para leitura no espectrofotômetro e $5 \mathrm{~mL}$ para massa seca, visando não ultrapassar a retirada de mais de $10 \%$ do volume total de cultivo, Tabela 19.

Tabela 19: Coletas realizadas nos respectivos dias e posições do "shaker"

\begin{tabular}{c|c|c}
\hline \multirow{2}{*}{ Dias } & $\mathbf{0 , 4}$ e 8 & $\mathbf{2 , 6}$ e 10 \\
\cline { 2 - 3 } Espécie & \multicolumn{2}{|c}{ Posição } \\
\hline Cv & L1E1 & L2E7 \\
\hline Csp & L1E2 & L2E8 \\
\hline Dsp & L1E4 & L3E10 \\
\hline Msp & L2E5 & L3E11 \\
\hline Osp & L2E6 & L3E12 \\
\hline
\end{tabular}

As leituras foram realizadas nos seguintes comprimentos de onda $750 \mathrm{~nm}$ para leitura de turbidez e $665 \mathrm{~nm}$ para leitura da clorofila. Os dados para cada uma das espécies se encontram na Tabela 20. 
Tabela 20: Leituras de densidade óptica a 750 e $665 \mathrm{~nm}$ para quantificação celular.

\begin{tabular}{|c|c|c|c|c|c|c|c|c|}
\hline & Espécie & DO $_{750 \mathrm{~nm}}$ & $\mathrm{DO}_{665 \mathrm{~nm}}$ & $\begin{array}{c}\text { Membrana } \\
\text { (g) }\end{array}$ & \begin{tabular}{|c} 
Membrana \\
+ Microalga \\
(g)
\end{tabular} & $\begin{array}{c}\text { Microalga } \\
\text { (g) }\end{array}$ & $\begin{array}{c}\text { Volume } \\
\text { (ml) }\end{array}$ & $\begin{array}{c}\text { Concentração } \\
(\mathrm{g} / \mathrm{L})\end{array}$ \\
\hline \multirow{5}{*}{ Dia 0} & $\mathrm{Cv}$ & 0,1030 & 0,0930 & 0,07564 & 0,07578 & 0,00014 & 5 & 0,0280 \\
\hline & Csp & 0,0983 & 0,0960 & 0,07568 & $\mathbf{0 , 0 7 5 8 1}$ & 0,00013 & 5 & 0,0260 \\
\hline & Dsp & 0,1030 & 0,0900 & $\mathbf{0 , 0 7 5 7 7}$ & 0,0759 & 0,00013 & 5 & 0,0260 \\
\hline & Msp & 0,0880 & 0,0920 & 0,07575 & 0,07586 & 0,00011 & 5 & 0,0220 \\
\hline & Osp & 0,0920 & 0,0930 & 0,07563 & 0,07575 & 0,00012 & 5 & 0,0240 \\
\hline \multirow{5}{*}{ Dia 2} & $\mathbf{C v}$ & 0,2190 & 0,2066 & 0,07574 & 0,07596 & 0,00022 & 5 & 0,0440 \\
\hline & Csp & 0,1810 & 0,1680 & 0,07576 & 0,07595 & 0,00019 & 5 & 0,0380 \\
\hline & Dsp & 0,1830 & 0,1780 & 0,07578 & 0,07596 & 0,00018 & 5 & 0,0360 \\
\hline & Msp & 0,1250 & 0,1410 & $\mathbf{0 , 0 7 5 7 3}$ & 0,07589 & 0,00016 & 5 & 0,0320 \\
\hline & Osp & 0,1440 & 0,1500 & 0,07567 & 0,07584 & 0,00017 & 5 & 0,0340 \\
\hline \multirow{5}{*}{ Dia 4} & $\mathrm{Cv}$ & 0,3730 & 0,3530 & 0,07624 & 0,07658 & 0,00034 & 5 & 0,0680 \\
\hline & Csp & 0,3850 & 0,3830 & 0,07902 & 0,0794 & 0,00038 & 5 & 0,0760 \\
\hline & Dsp & 0,4190 & 0,4260 & 0,0788 & 0,07915 & 0,00035 & 5 & 0,0700 \\
\hline & Msp & 0,3284 & 0,3310 & 0,07884 & 0,07912 & 0,00028 & 5 & 0,0560 \\
\hline & Osp & 0,3710 & 0,4060 & 0,07889 & $\mathbf{0 , 0 7 9 1 7}$ & 0,00028 & 5 & 0,0560 \\
\hline \multirow{5}{*}{ Dia 6} & $\mathrm{Cv}$ & 0,6099 & 0,6188 & $\mathbf{0 , 0 7 8 8 1}$ & 0,07935 & 0,00054 & 5 & 0,1080 \\
\hline & Csp & 0,6440 & 0,6260 & 0,07859 & 0,07913 & 0,00054 & 5 & 0,1080 \\
\hline & Dsp & 0,7540 & 0,7380 & 0,07866 & $\mathbf{0 , 0 7 9 2 3}$ & 0,00057 & 5 & 0,1140 \\
\hline & Msp & 0,4600 & 0,5250 & $\mathbf{0 , 0 7 5 8 7}$ & 0,0762 & 0,00033 & 5 & 0,0660 \\
\hline & Osp & 0,4920 & 0,5140 & 0,07838 & 0,07876 & 0,00038 & 5 & 0,0760 \\
\hline \multirow{5}{*}{ Dia 8} & $\mathrm{Cv}$ & 0,9519 & 1,0080 & 0,07866 & 0,07946 & 0,0008 & 5 & 0,1600 \\
\hline & Csp & 0,9160 & 0,9150 & 0,07862 & $\mathbf{0 , 0 7 9 3 4}$ & 0,00072 & 5 & 0,1440 \\
\hline & Dsp & 0,9200 & 0,8880 & $\mathbf{0 , 0 7 8 3 9}$ & 0,07906 & 0,00067 & 5 & 0,1340 \\
\hline & Msp & 0,6400 & 0,6240 & $\mathbf{0 , 0 7 8 4 3}$ & 0,07894 & 0,00051 & 5 & 0,1020 \\
\hline & Osp & 0,6150 & 0,6440 & 0,07842 & 0,07892 & 0,0005 & 5 & 0,1000 \\
\hline \multirow{5}{*}{ Dia 10} & $\mathrm{Cv}$ & 1,0919 & 1,1280 & $\mathbf{0 , 0 7 8 5 1}$ & $\mathbf{0 , 0 7 9 3 5}$ & 0,00084 & 5 & 0,1680 \\
\hline & Csp & 0,9940 & 0,9610 & 0,07856 & 0,07933 & 0,00077 & 5 & 0,1540 \\
\hline & Dsp & 0,9820 & 0,9400 & 0,0787 & 0,07948 & 0,00078 & 5 & 0,1560 \\
\hline & Msp & 0,8760 & 0,8310 & 0,07839 & 0,07901 & 0,00062 & 5 & 0,1240 \\
\hline & Osp & $\mathbf{0 , 7 8 2 0}$ & $\mathbf{0 , 8 1 4 0}$ & $\mathbf{0 , 0 7 8 3 6}$ & $\mathbf{0 , 0 7 8 9 6}$ & 0,0006 & 5 & 0,1200 \\
\hline
\end{tabular}


As curvas de crescimento e as cinéticas para cada uma das espécies encontram-se nas Figuras 22-26.

\subsubsection{Chlorella vulgaris $(\mathrm{Cv})$}

Após 10 dias, foi possível quantificar a concentração de massa seca (MS) de células de $\mathrm{Cv}$ e determinar as relações entre MS e as leituras de DO. Essa correlação foi obtida através dos gráficos de MS versus $\mathrm{DO}_{750 \mathrm{~nm}}$ (Figura 22A) e $\mathrm{DO}_{665 \mathrm{~nm}}$ (Figura 22B), e foi dada pelo coeficiente angular da reta, sendo considerado que para MS igual a 0, a DO é igualmente nula. As correlações obtidas para a $\mathrm{DO}_{750 \mathrm{~nm}}$ e $\mathrm{DO}_{665 \mathrm{~nm}}$ são observadas nas equações 13 e 14, respectivamente.

$$
\begin{aligned}
\mathrm{MS}_{\mathrm{Cv}} & =0,1647 \quad \mathrm{DO}_{750 \mathrm{~nm}} \\
\mathrm{MS}_{\mathrm{Cv}} & =0,1592 \mathrm{DO}_{665 \mathrm{~nm}}
\end{aligned}
$$$$
\text { (equação 13) }
$$
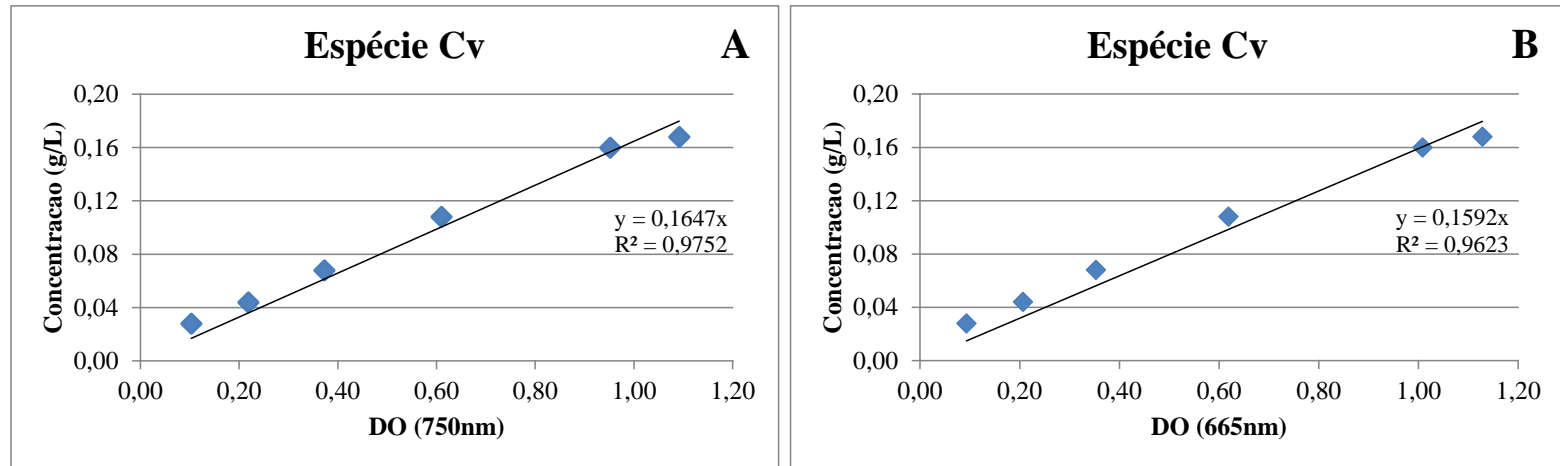

Figura 22: Relação MS (g/L) e $\mathrm{DO}_{750 \mathrm{~nm}}(\mathrm{~A})$ e $\mathrm{DO}_{665 \mathrm{~nm}}(\mathrm{~B})$ para $\mathrm{Cv}$.

Pode-se observar que para os dois valores de DO estudados são apresentados valores de $\mathrm{R}^{2}$ superiores a 0,96 , mostrando uma correlação linear entre os valores de MS e DO.

\subsubsection{Chlorella sp. (Csp)}

A quantificação de MS de células, após 10 dias, realizada para a microalga Csp e as leituras da $\mathrm{DO}_{750 \mathrm{~nm}}$ e $\mathrm{DO}_{665 \mathrm{~nm}}$ forneceram as correlações observadas nas equações 15 e 16, respectivamente.

$$
\begin{aligned}
& \mathrm{MS}_{\mathrm{Csp}}=0,1617 \mathrm{DO}_{750 \mathrm{~nm}} \\
& \mathrm{MS}_{\mathrm{Csp}}=0,1649 \mathrm{DO}_{665 \mathrm{~nm}}
\end{aligned}
$$


Os gráficos obtidos para a aquisição das equações anteriores são mostrados na Figura 23 , e novamente foram observados valores de $\mathrm{R}^{2}$ superiores a 0,96 , mostrando a linearidade dos dados.
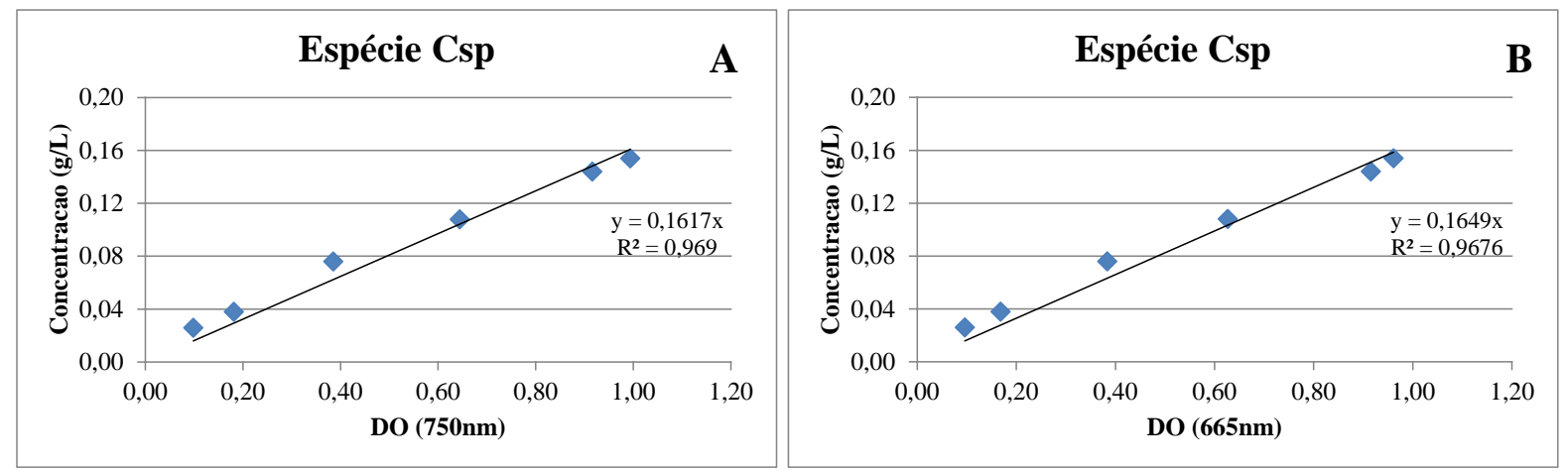

Figura 23: Relação MS (g/L) e $\mathrm{DO}_{750 \mathrm{~nm}}(\mathrm{~A})$ e $\mathrm{DO}_{665 \mathrm{~nm}}$ (B) para Csp.

\subsubsection{Desmodesmus sp. (Dsp)}

Para a microalga Dsp, após 10 dias, a quantificação através da MS de células e a leitura da $\mathrm{DO}_{750 \mathrm{~nm}}$ e $\mathrm{DO}_{665 \mathrm{~nm}}$ forneceu as correlações observadas nas equações 17 e 18, respectivamente.

$$
\begin{aligned}
& \mathrm{MS}_{\text {Dsp }}=0,1543 \mathrm{DO}_{750 \mathrm{~nm}} \\
& \mathrm{MS}_{\mathrm{Dsp}}=0,1593 \mathrm{DO}_{665 \mathrm{~nm}}
\end{aligned}
$$

Os gráficos obtidos para a aquisição das equações 17 e 18 são mostrados na Figura $24 \mathrm{~A}$ e $24 \mathrm{~B}$, respectivamente, e novamente foram observados valores de $\mathrm{R}^{2}$ superiores a 0,97 , mostrando a linearidade dos dados.
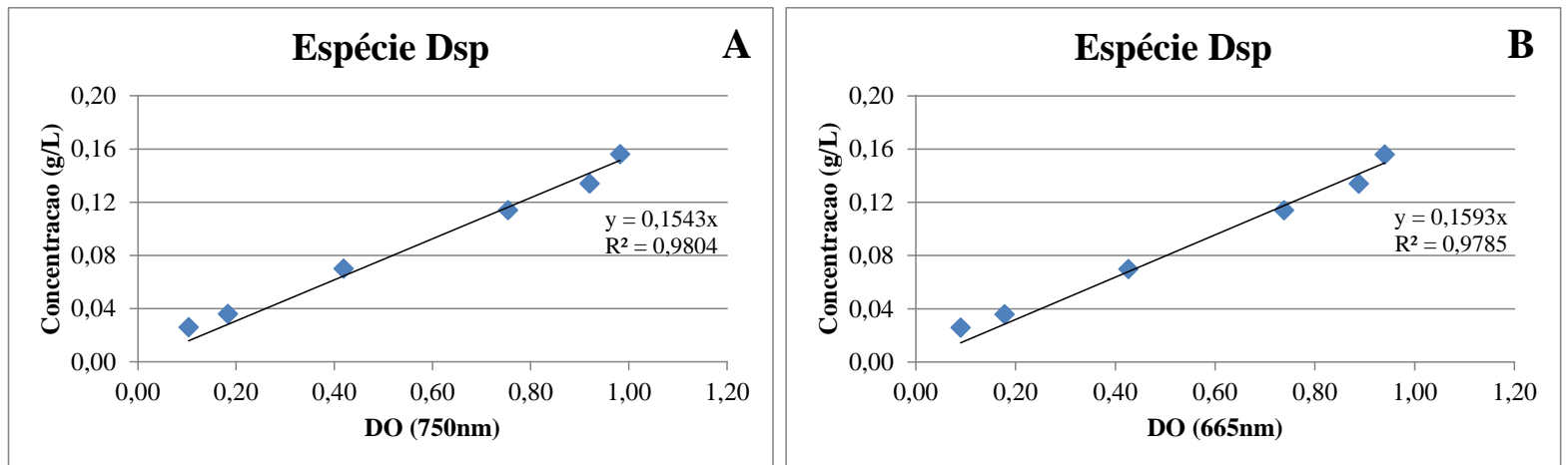

Figura 24: Relação MS (g/L) e $\mathrm{DO}_{750 \mathrm{~nm}}(\mathrm{~A})$ e $\mathrm{DO}_{665 \mathrm{~nm}}$ (B) para Dsp. 


\subsubsection{Monoraphidium sp. (Msp)}

Após 10 dias, para a microalga Msp, a quantificação da MS de células e a leitura da $\mathrm{DO}_{750 \mathrm{~nm}}$ e $\mathrm{DO}_{665 \mathrm{~nm}}$ forneceram as correlações observadas nas equações 19 e 20, respectivamente.

$$
\begin{aligned}
& \mathrm{MS}_{\text {Dsp }}=0,1504 \mathrm{DO}_{750 \mathrm{~nm}} \\
& \mathrm{MS}_{\text {Dsp }}=0,1516 \mathrm{DO}_{665 \mathrm{~nm}}
\end{aligned}
$$

Pode-se observar, Figura 25, que para os dois valores de DO estudados foram obtidos valores de $\mathrm{R}^{2}$ superiores a 0,94 , uma vez mais mostrando a linearidade entre os valores de MS e DO.
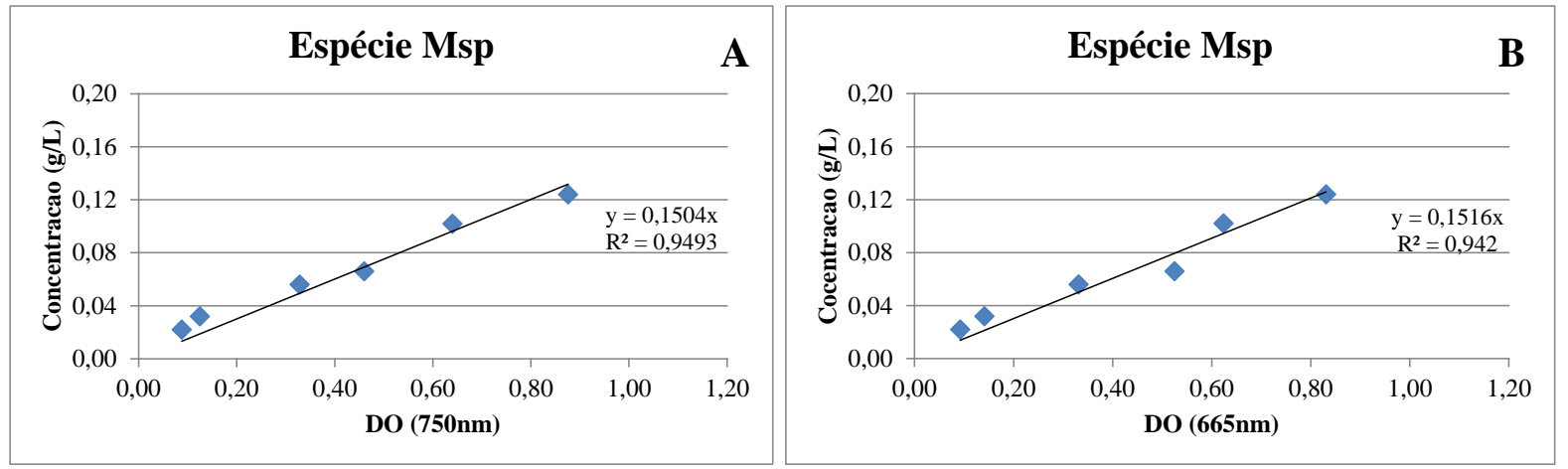

Figura 25: Relação MS (g/L) e $\mathrm{DO}_{750 \mathrm{~nm}}(\mathrm{~A})$ e $\mathrm{DO}_{665 \mathrm{~nm}}$ (B) para Msp.

\subsubsection{Oocystis sp. (Osp)}

Para a espécie Osp, após 10 dias, foi possível correlacionar a concentração de massa seca (MS) de células com as leituras de DO. Essas correlações, obtidas através dos gráficos de MS versus DO $_{750 \mathrm{~nm}}$ (Figura 26A) e DO $_{665 \mathrm{~nm}}$ (Figura 26B) são observadas nas equações 21 e 22 , respectivamente.

$$
\begin{aligned}
\mathrm{MS}_{\text {Dsp }} & =0,1577 \mathrm{DO}_{750 \mathrm{~nm}} \\
\mathrm{MS}_{\text {Dsp }} & =0,1504 \mathrm{DO}_{665 \mathrm{~nm}}
\end{aligned}
$$


Pode-se observar, Figura 26, que para os dois valores de DO estudados foram obtidos valores de $\mathrm{R}^{2}$ superiores a 0,96, novamente mostrando a linearidade entre os valores de MS e DO.
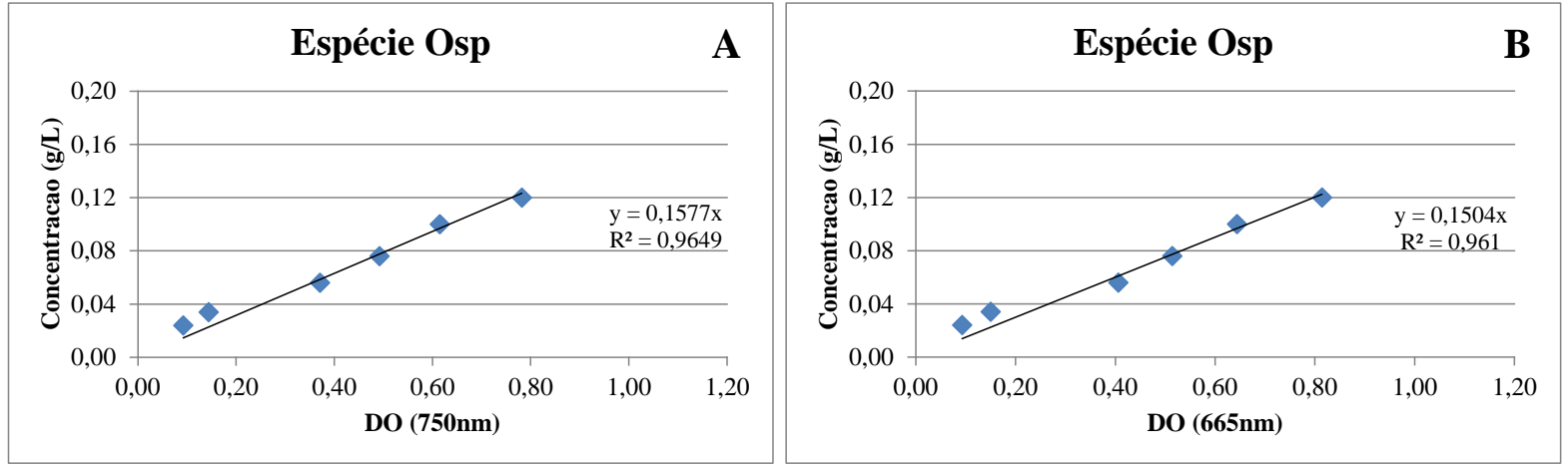

Figura 26: Relação MS (g/L) e $\mathrm{DO}_{750 \mathrm{~nm}}(\mathrm{~A})$ e $\mathrm{DO}_{665 \mathrm{~nm}}$ (B) para Osp.

\subsubsection{Curvas de crescimento e cinética das espécies estudadas}

Foram realizadas 2 curvas de crescimento para cada espécie de microalga, experimento I e II, partindo-se de um pré-inóculo (descrito anteriormente). As condições de cultivo utilizadas foram: temperatura de $30^{\circ} \mathrm{C}$, rotação de $150 \mathrm{rpm}, 100 \mathrm{~mL}$ meio de cultivo WC em erlenmeyers de $250 \mathrm{~mL}, \mathrm{pH}$ inicial de 6 , intensidade luminosa média de 23-24 $\mu$ molfótons $/ \mathrm{m} . \mathrm{s}^{2}$ e densidade óptica inicial de $\mathrm{DO}_{750 \mathrm{~nm}}=0,1$. Cada espécie foi cultivada em duplicata e a cada dois dias foram coletados $2 \mathrm{~mL}$ de amostra para leitura em triplicata no espectrofotômetro UV, a $750 \mathrm{~nm}$. As curvas de crescimento e cinéticas de cada espécie do experimento I são apresentadas nas Figuras 27 e 28, respectivamente. E as curvas de crescimento e cinéticas de cada espécie do experimento II são apresentadas nas Figuras 29 e 30 , respectivamente.

\subsubsection{Curvas de crescimento - Experimento I}

Pode-se observar que as microalgas do gênero Chlorella e do gênero Desmodesmus apresentaram maiores concentrações após 12 dias, quando comparadas aos gêneros Monoraphidium e Oocystis. As produtividades obtidas para cada uma das espécies nas condições de crescimento utilizadas foram $\mathrm{Cv}$ 0,018 $\mathrm{g} / \mathrm{L} / \mathrm{dia}, \quad \mathrm{Csp}$ 0,017 $\mathrm{g} / \mathrm{L} / \mathrm{dia}$, Dsp 0,018 g/L/dia, Msp 0,011 g/L/dia e Osp 0,013 g/L/dia, Figura 27A-E, respectivamente. 
Chen e colaboradores (2011) obtiveram produtividade entre 0,02 e $0,18 \mathrm{~g} / \mathrm{L} /$ dia para a espécie Cv e Mata e colaboradores (2010) obtiveram produtividades entre 0,02-0,25 g/L/dia, mostrando assim que os valores de produtividade obtidos nesse estudo estão próximos aos mínimos encontrados na literatura para as espécies Cv e Csp. Não foram encontrados dados de produtividade para as espécies Dsp, Msp e Osp.

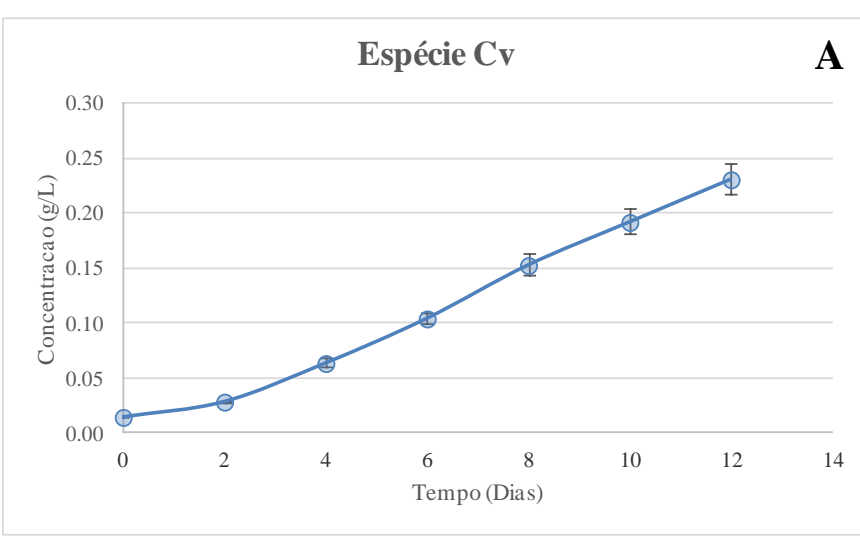

Espécie Dsp

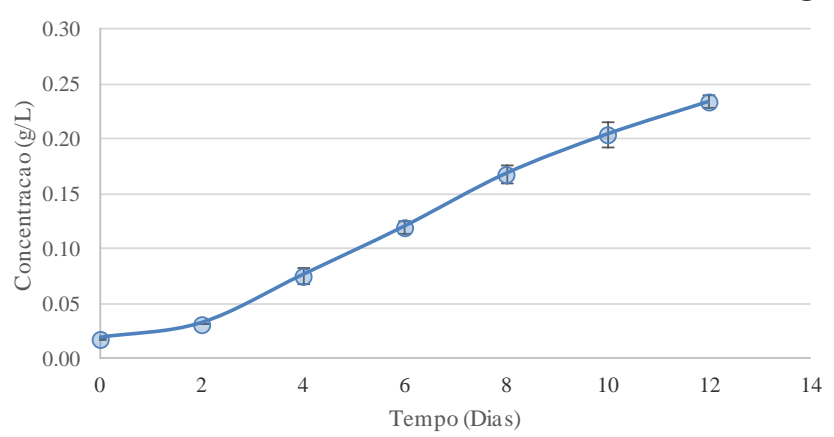

A

$\mathrm{C}$
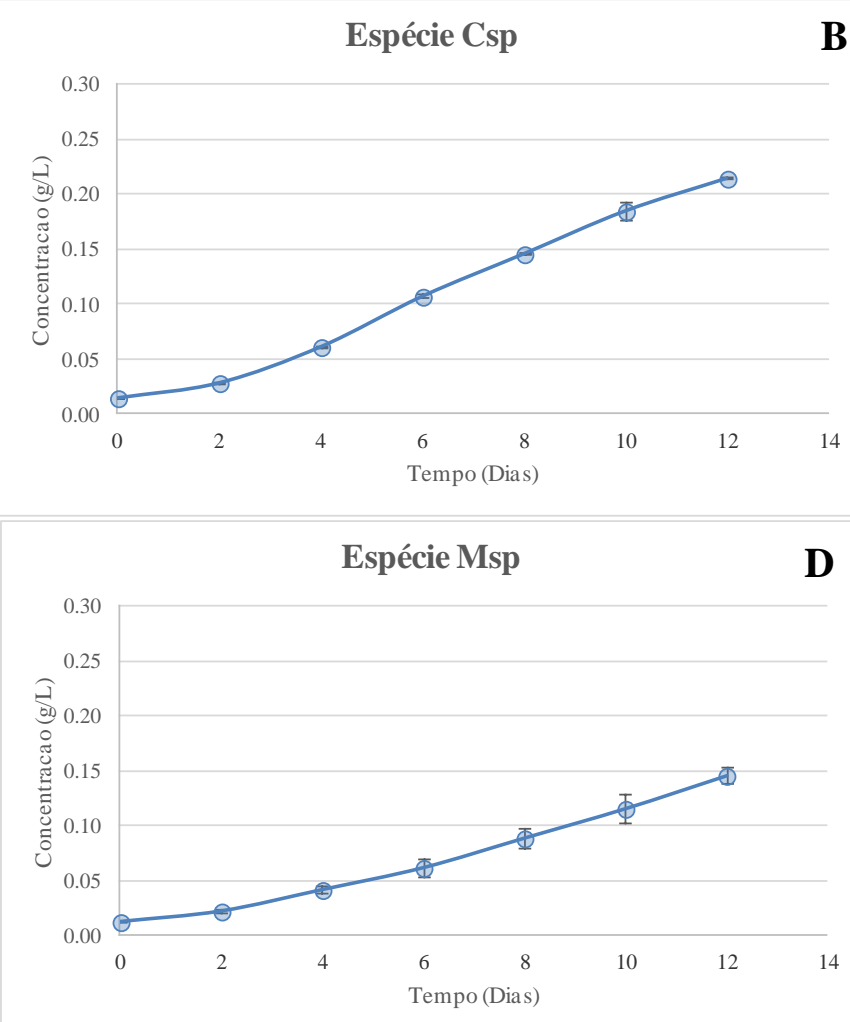

Espécie Osp

E

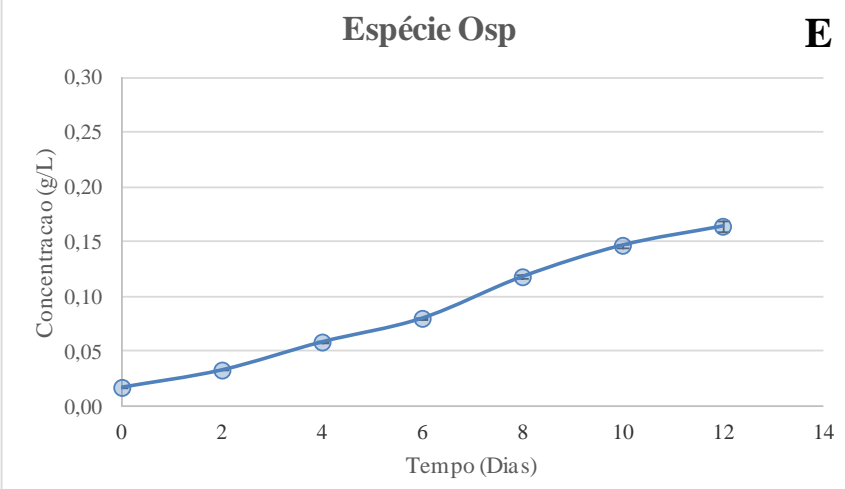

Figura 27: Curvas de crescimento das espécies Cv (A), Csp (B), Dsp (C), Msp (D) e Osp (E)

- experimento I 


\subsection{Cinéticas de crescimento - Experimento I}

Novamente pode-se observar um alto valor de $\mathrm{R}$ para as curvas cinéticas de todas as espécies, quando considerada a fase exponencial até o $8^{\circ}$ dia, Figura 28. Foram obtidos valores de velocidade de crescimento máximo específico $\left(\mu_{\max }\right)$ de 0,$2987 ; 0,2976 ; 0,2891$; 0,2468 e 0,2397 dia $^{-1}$, para as espécies Cv, Csp, Dsp, Msp e Osp, respectivamente.

Foi observado que as microalgas do gênero Chlorella e do gênero Desmodesmus apresentaram maiores valores para $\mu_{\max }$ se comparadas aos gêneros Monoraphidium e Oocystis.
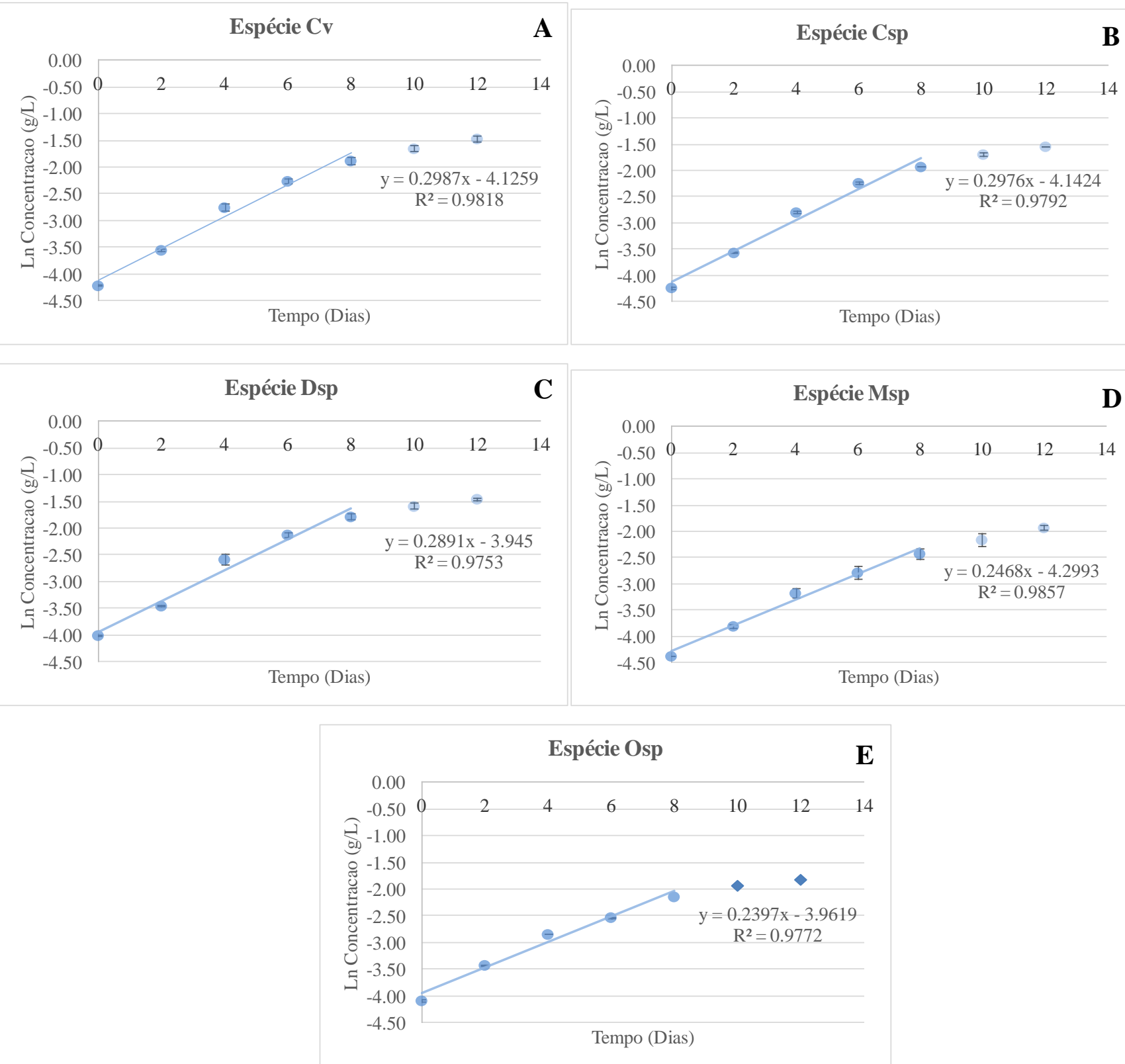

Figura 28: Cinéticas de crescimento das espécies Cv (A), Csp (B), Dsp (C), Msp (D) e Osp (E) do experimento I 


\subsubsection{Curvas de crescimento - Experimento II}

A segunda curva de crescimento, realizada até o $8^{\circ}$ dia (final da fase exponencial) mostra grande reprodutibilidade do sistema de cultivo utilizado. Novamente as microalgas do gênero Chlorella e do gênero Desmodesmus apresentaram maiores concentrações ao final do experimento, quando comparadas aos gêneros Monoraphidium e Oocystis. As produtividades obtidas nessa segunda curva de crescimento, para cada uma das espécies foram Cv 0,019 g/L/dia, Csp 0,016 g/L/dia, Dsp 0,017 g/L/dia e Msp 0,009 g/L/dia e Osp 0,011 g/L/dia, Figuras 29A-E, respectivamente.
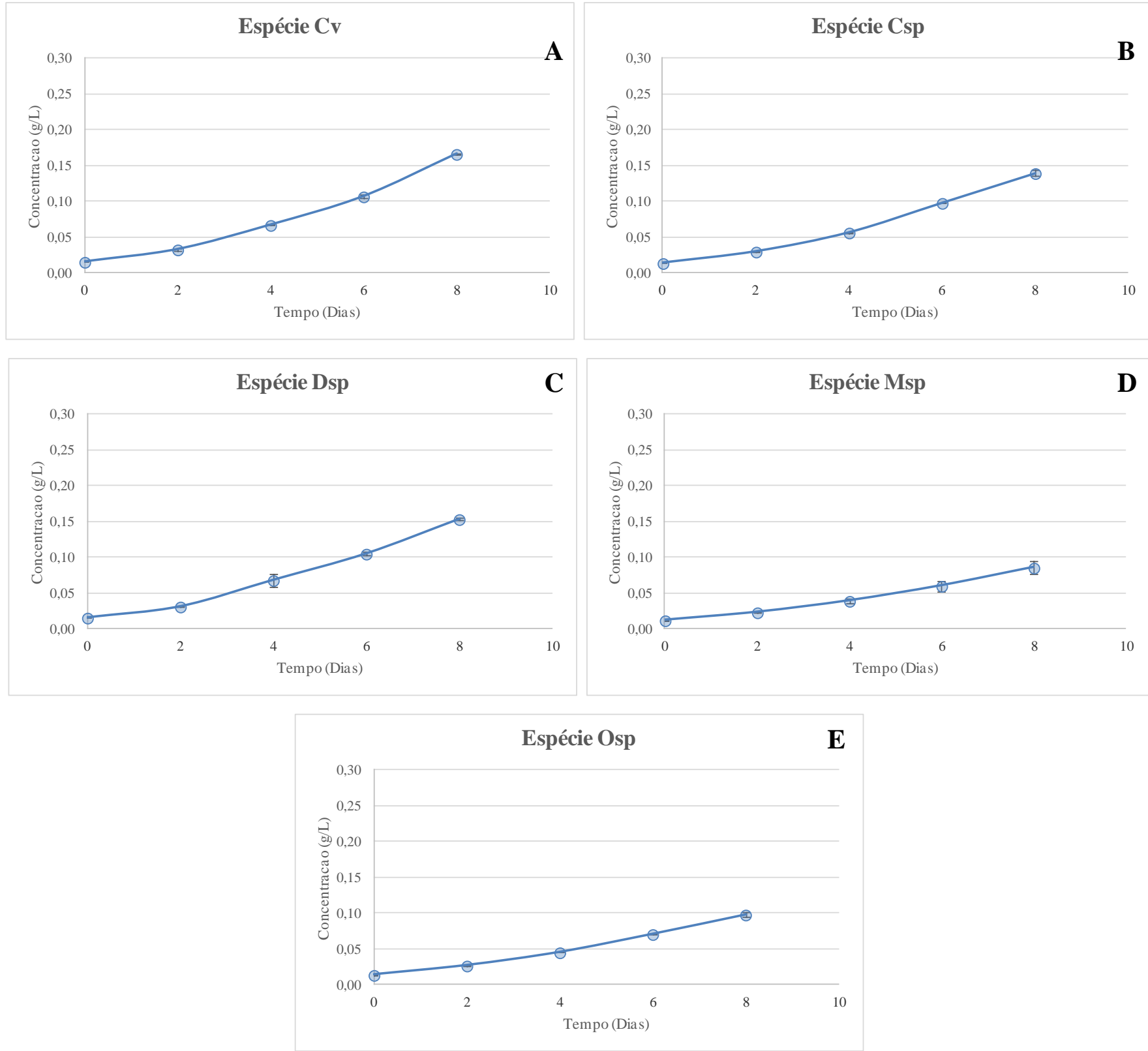

Figura 29: Curvas de crescimento das espécies Cv (A), Csp (B), Dsp (C), Msp (D) e Osp (E) - experimento II 


\subsection{Cinéticas de crescimento - Experimento II}

Novamente pode-se observar um alto valor de $\mathrm{R}$ para as curvas cinéticas de todas as espécies quando considerada a fase exponencial até o $8^{\circ}$ dia, Figura 30. Foram obtidos valores de velocidade de crescimento máximo específico $\left(\mu_{\max }\right)$ de 0,$2976 ; 0,2925 ; 0,2900 ; 0,2459$ e 0,2482 $\mathrm{dia}^{-1}$, para as espécies Cv, Csp, Dsp, Msp e Osp, respectivamente.

As microalgas do gênero Chlorella e Desmodesmus apresentaram maiores valores para $\mu_{\max }$ se comparadas aos gêneros Monoraphidium e Oocystis. Os valores obtidos nesse segundo experimento estão próximos dos valores obtidos no experimento I, mostrando a reprodutibilidade do sistema.
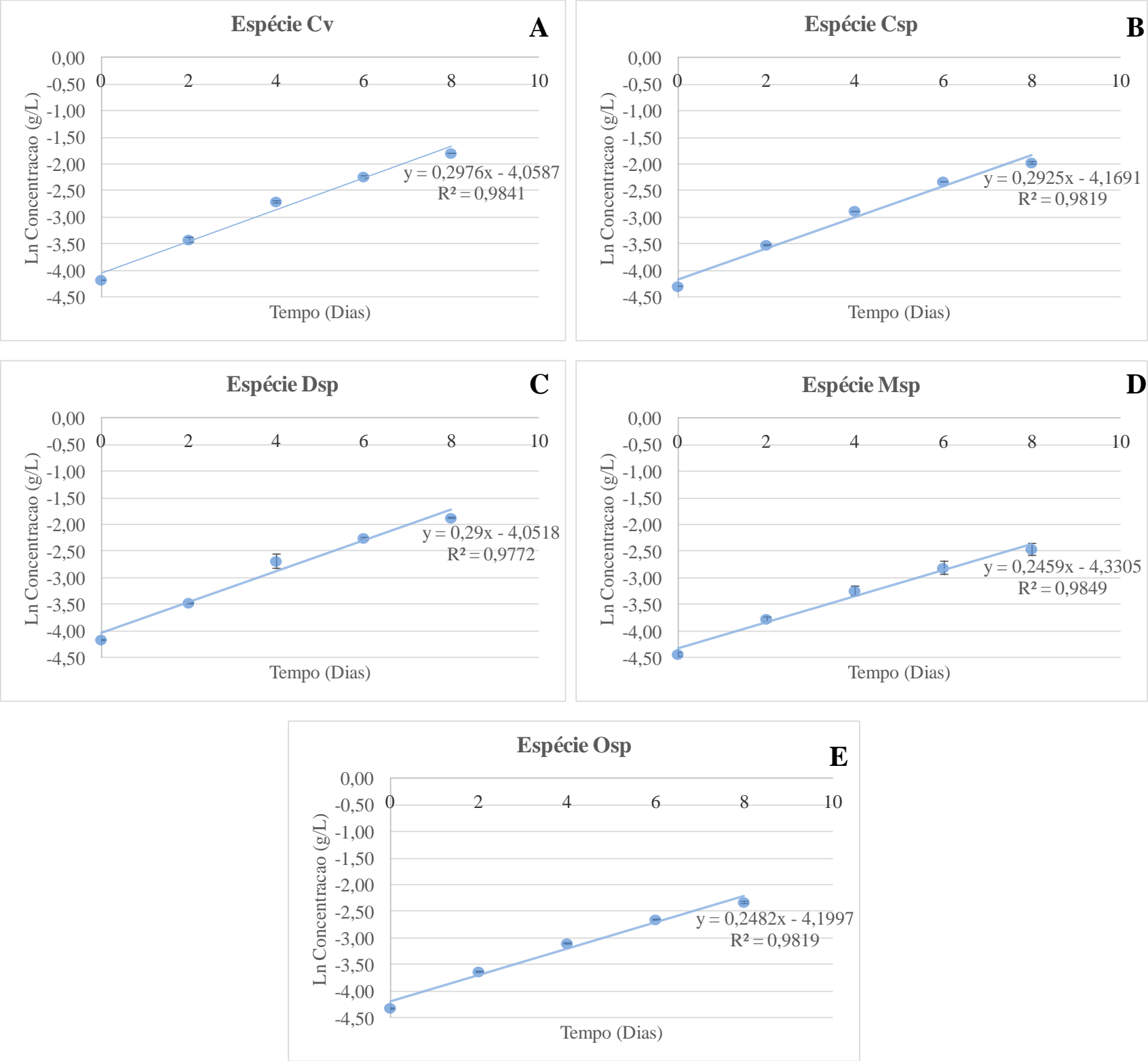

Figura 30: Cinéticas de crescimento das espécies Cv (A), Csp (B), Dsp (C), Msp (D) e Osp (E) do experimento II. 


\subsection{PERFIL PROTEICO AO LONGO DA CURVA DE CRESCIMENTO}

O objetivo desse estudo foi verificar se existe diferença no perfil proteico das espécies de microalgas estudadas em suas várias fases de crescimento.

Durante o crescimento das microalgas foi coletado $1 \mathrm{~mL}$ de suspensão de microalgas a cada dois dias, o qual foi centrifugado e seco, utilizando um concentrador modelo "centrivap concentrator" da marca LabConco.

Ao "pellet" seco foram adicionados $12 \mu \mathrm{L}$ do solvente TA50, seguido de agitação em vortex por 5 segundos. O volume de $0,6 \mu \mathrm{L}$ da amostra foi colocado na placa "anchorchip", e esperou-se até a secagem completa da amostra à temperatura ambiente. Após completa secagem, foram adicionados $0,6 \mu \mathrm{L}$ de solução de matriz HCCA e esperou-se até a secagem completa à temperatura ambiente.

As amostras foram analisadas utilizando o equipamento MALDI Ultraflextreme (Bruker) equipado com um laser "smartbeam" operando em modo linear. Cada espectro foi coletado manualmente, em modo íon positivo, e varredura com faixa de razão massa carga entre 4-20 kDa.

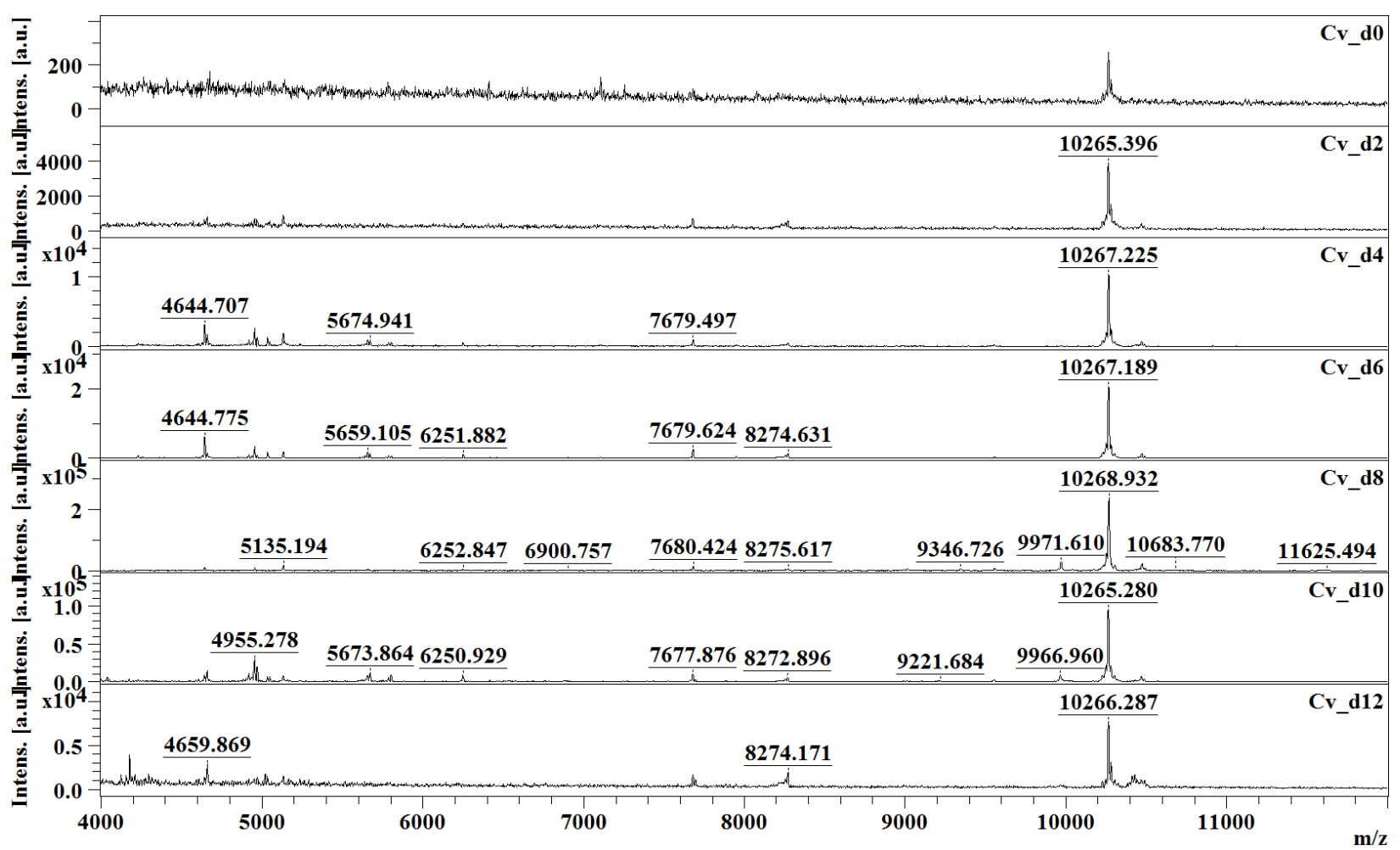

Figura 31: Perfis dos espectros de massa do tipo MALDI-TOF de proteínas ao longo do crescimento do dia 0 ao dia 12 (coletas a cada 2 dias) da espécie $\mathrm{Cv}$. 


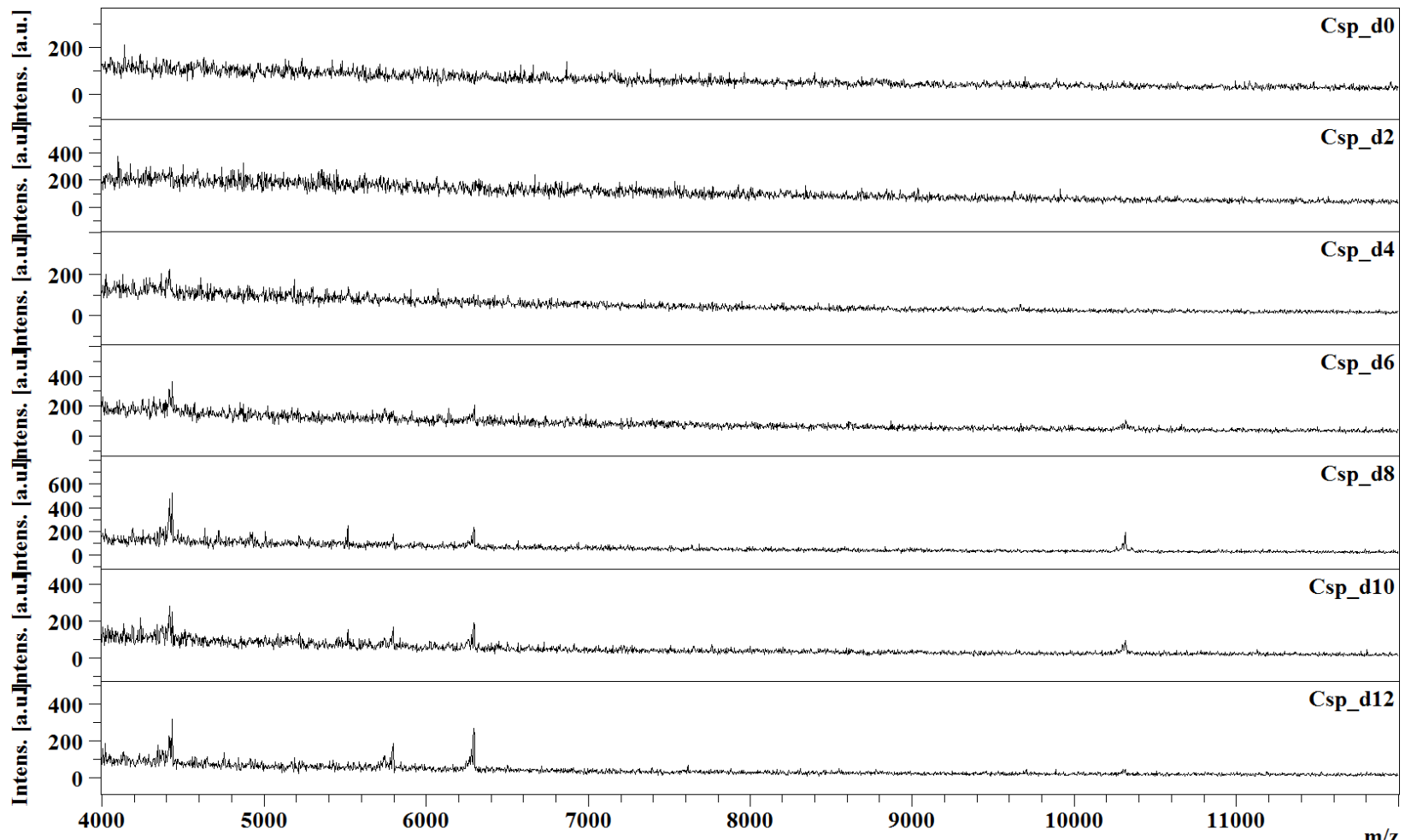

Figura 32: Perfis dos espectros de massa do tipo MALDI-TOF de proteínas ao longo do crescimento do dia 0 ao dia 12 (coletas a cada 2 dias) da espécie Csp.

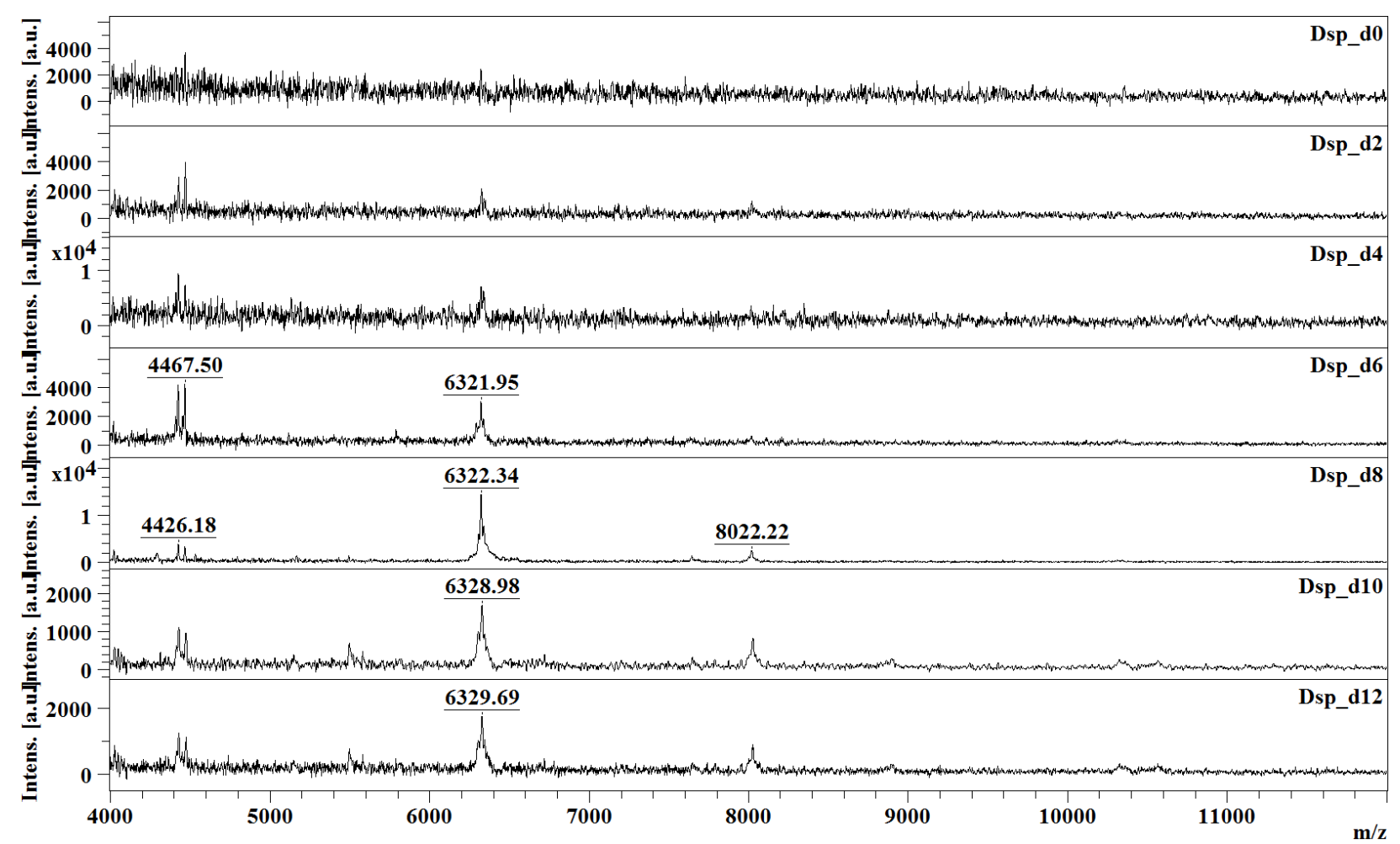

Figura 33: Perfis dos espectros de massa do tipo MALDI-TOF de proteínas ao longo do crescimento do dia 0 ao dia 12 (coletas a cada 2 dias) da espécie Dsp. 


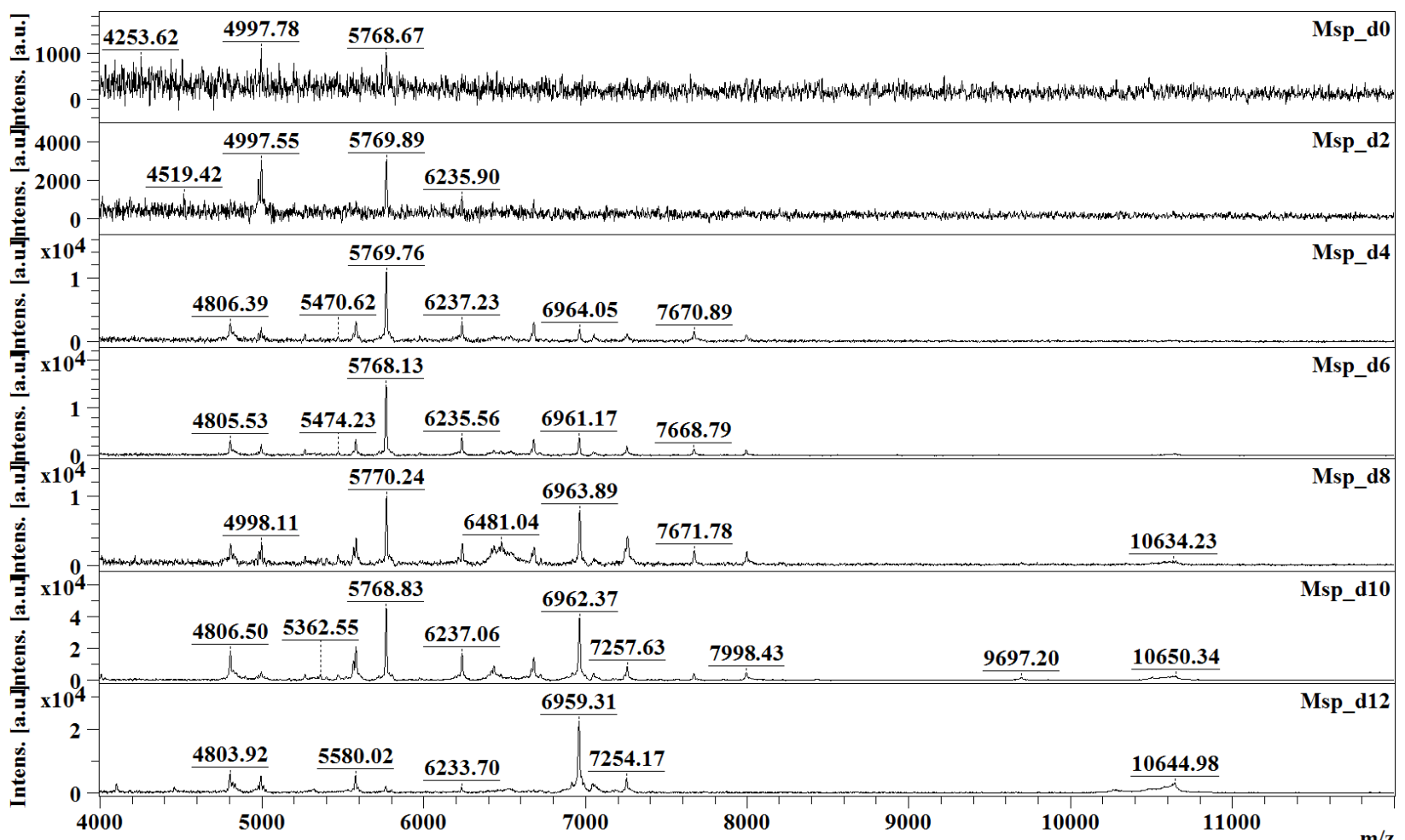

Figura 34: Perfis do espectro de massa do tipo MALDI-TOF de proteínas ao longo do crescimento do dia 0 ao dia 12 (coletas a cada 2 dias) da espécie Msp.

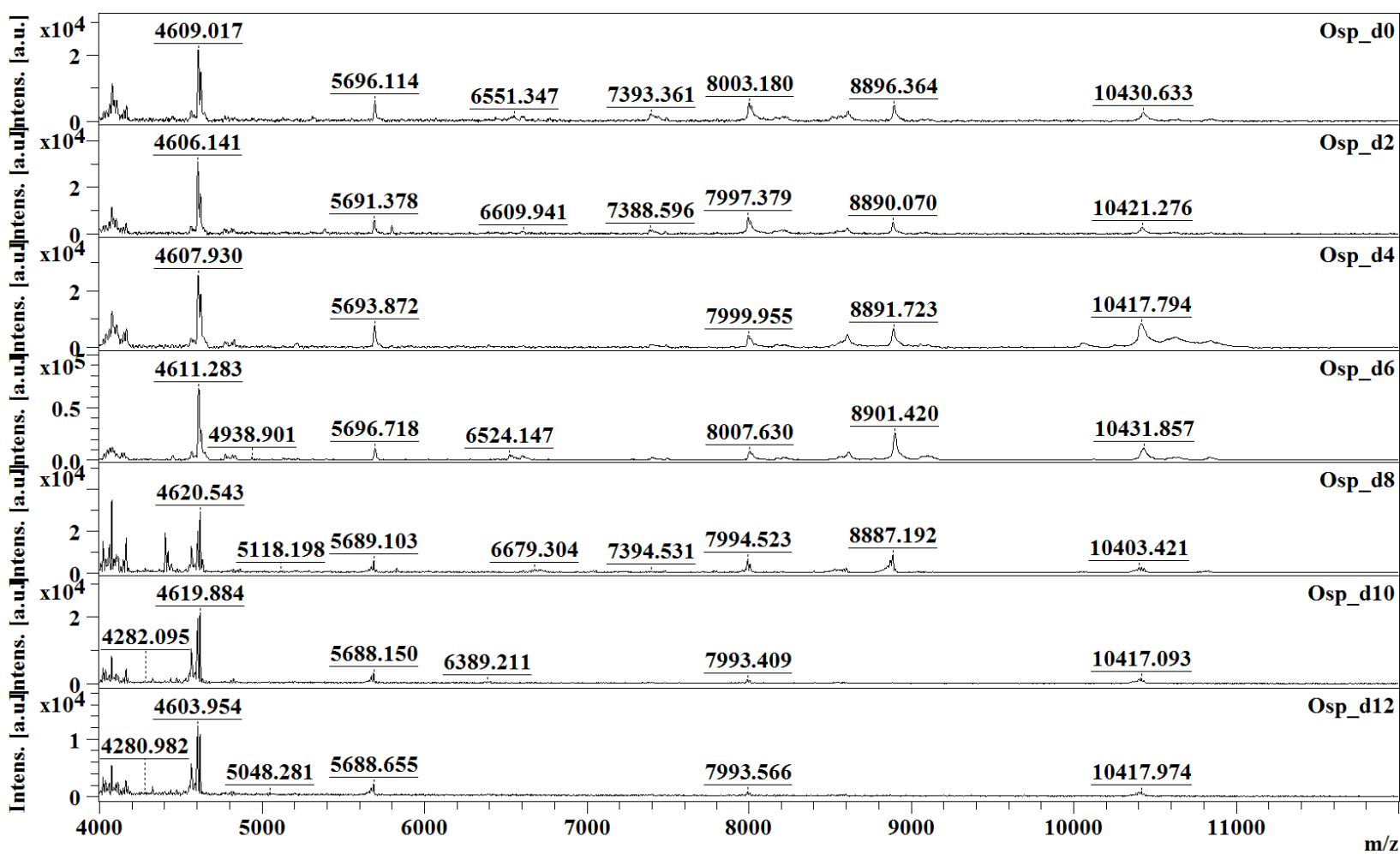

Figura 35: Perfis dos espectros de massa do tipo MALDI-TOF de proteínas ao longo do crescimento do dia 0 ao dia 12 (coletas a cada 2 dias) da espécie Osp. 
Pode-se observar que desde o dia 0 até o dia 12 as microalgas apresentaram praticamente o mesmo perfil de proteínas, mostrando que a composição proteica é bastante semelhante, independente da fase de crescimento em que a microalga se encontra. Entretanto, devido à grande dificuldade na aquisição de espectro bem resolvidos, Figuras 31-35, foram realizados diversos testes, visando a otimização da metodologia de preparo de amostra e aquisição de dados, já que o sucesso da análise de amostras reais é largamente dependente da preparação das mesmas. A literatura mostra que um grande número de matrizes, placas, métodos de preparação, entre outros, tem sido estudado (KELLER \& LI, 2006).

\subsection{OTIMIZAÇÃO DA METODOLOGIA}

Sabendo-se que o perfil proteico independe da fase de crescimento em que a microalga se encontra, ao final dos experimentos, de 12 dias, as amostras foram secas utilizando um "speed vac" e armazenadas em forma de pó, para posterior otimização da metodologia de preparo de amostra e análise via espectrometria de massas MALDI-TOF.

Para análise estatística dos melhores espectros obtidos, foram considerados 3 parâmetros: número de íons (P1), relação sinal/ruído do pico base (P2) e intensidade do pico base (P3). Esses parâmetros foram classificados em ordem crescente e avaliados para cada um dos estudos realizados. Foram respeitados os parâmetros recomendados pela Bruker, tais como relação sinal ruído superior a 2 e resolução do pico superior a 400. Todos esses dados foram obtidos através do processamento dos espectros utilizando o algoritmo fornecido pelo equipamento. O sinal “+”, nas Tabelas 21 a 29, significa a espécie de microalga a ser analisada e o parâmetro a ser avaliado.

\subsubsection{Comparação dos tipos de placas}

As placas "anchorchip" e "polished" foram testadas com relação ao seu desempenho para a análise de microalgas. A "anchorchip" já havia sido utilizada anteriormente. A "polished" constitui-se de uma placa padrão feita em aço inox isenta de qualquer estrutura em sua superfície e que proporciona o máximo de nivelamento para camadas finas, sendo usada para qualquer tipo de amostra. Para esses testes foi usada a matriz HCCA. 


\subsubsection{Calibração}

A calibração do equipamento, cujos calibrantes foram preparados de acordo com o item 4.2.3.3, foi conduzida de acordo com os seguintes parâmetros: PIE $250 \mathrm{~ns}, \mathrm{IS}_{1} 25 \mathrm{kV}, \mathrm{IS}_{2}$ 23,55 kV, abertura das lentes de $7 \mathrm{kV}$, número de "shots" de 10000 e potência do laser de $95 \%$.

Os desvios padrões da qualidade da calibração observados para as placas "anchorchip" e "polished" foram 90,405 e 60,163 ppm, respectivamente. Como pode ser observado a placa "polished" mostrou melhor desempenho para a solução de calibrantes.

\subsubsection{Análises das amostras de microalgas}

As análises das amostras utilizando as placas "anchorchip" e "polished" foram conduzidas de acordo com os seguintes parâmetros padrões do equipamento operando no modo linear: PIE $250 \mathrm{~ns}, \mathrm{IS}_{1} 25 \mathrm{kV}$, IS $23,55 \mathrm{kV}$, abertura das lentes de $7 \mathrm{kV}$, número de "shots" de 10000 e potência do laser de $95 \%$.

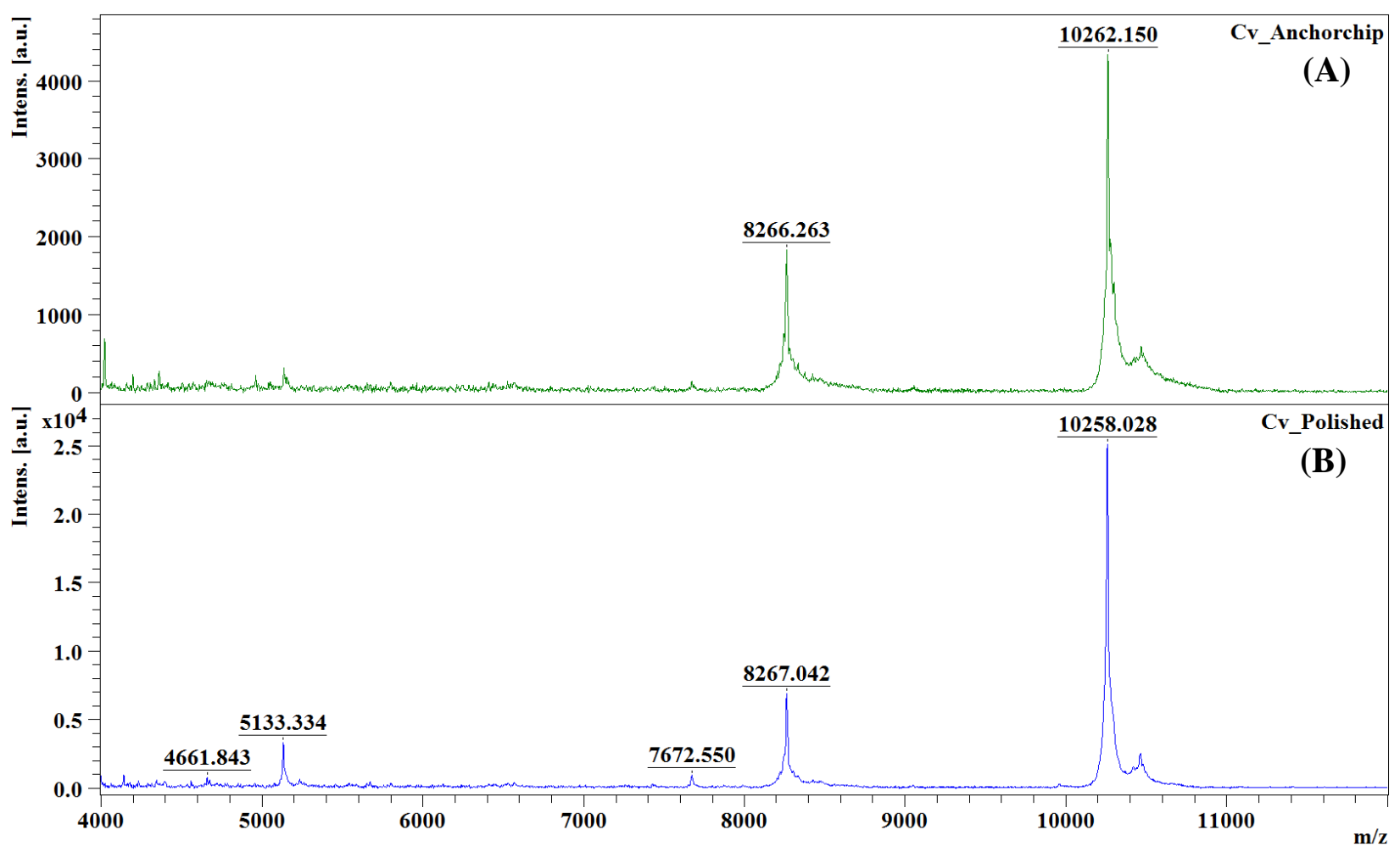

Figura 36: Comparação dos perfis dos espectros de massas do tipo MALDI-TOF produzidos utilizando as placas "anchorchip" (A) e "polished" (B) no estudo da microalga Cv. 


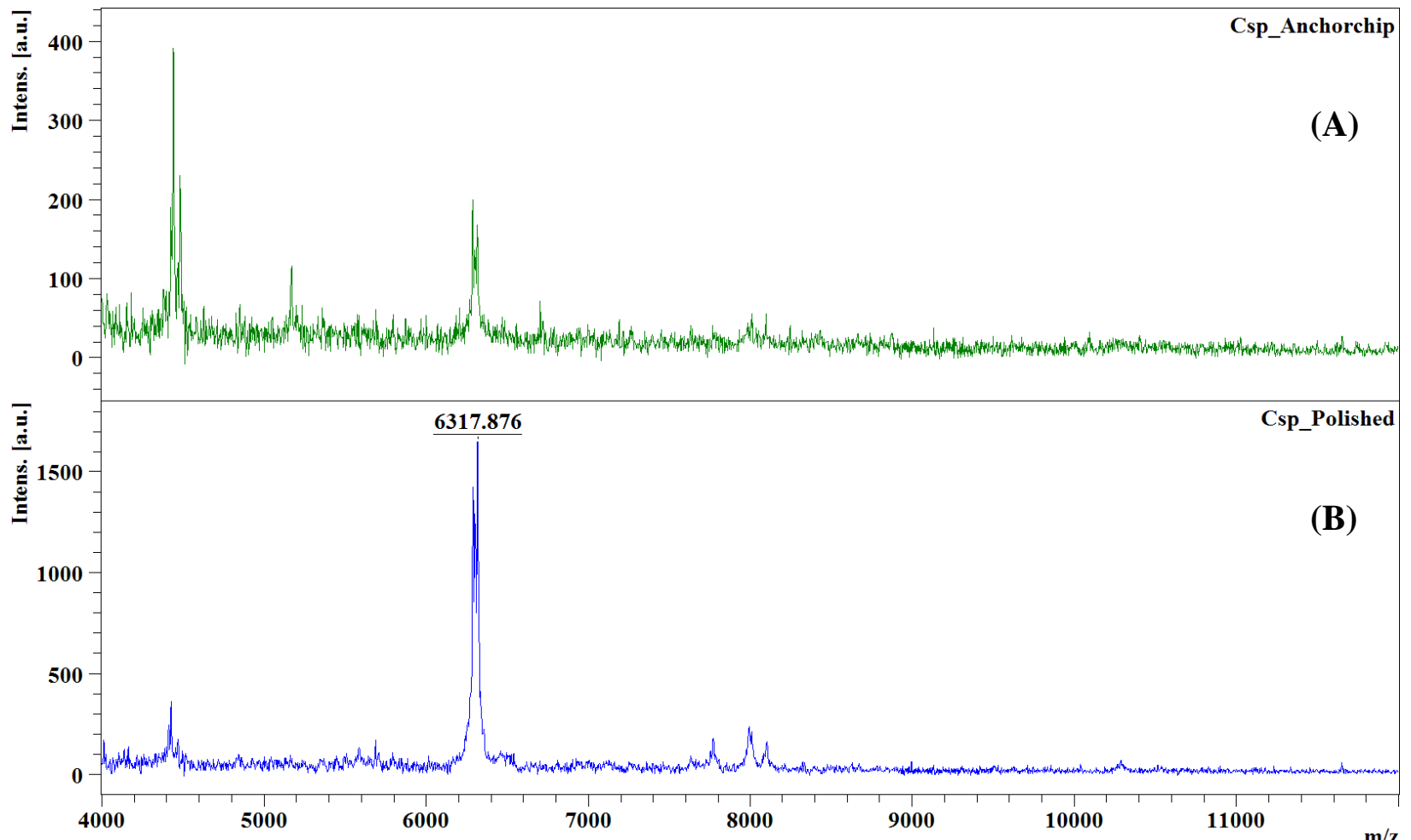

Figura 37: Comparação dos perfis dos espectros de massas do tipo MALDI-TOF produzidos

utilizando as placas "anchorchip" (A) e "polished" (B) no estudo da microalga Csp.

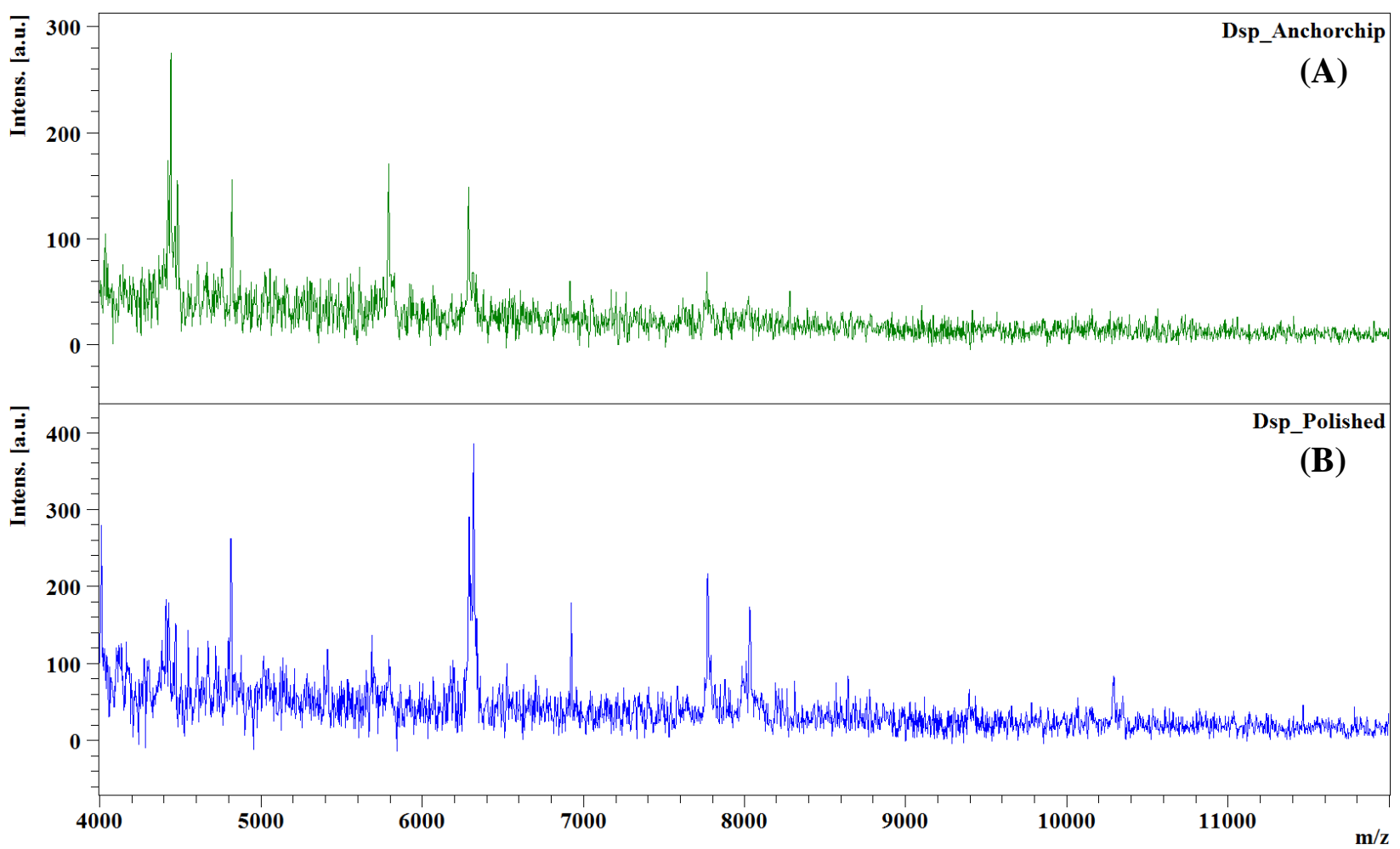

Figura 38: Comparação dos perfis dos espectros de massas do tipo MALDI-TOF produzidos utilizando as placas "anchorchip" (A) e "polished" (B) no estudo da microalga Dsp. 


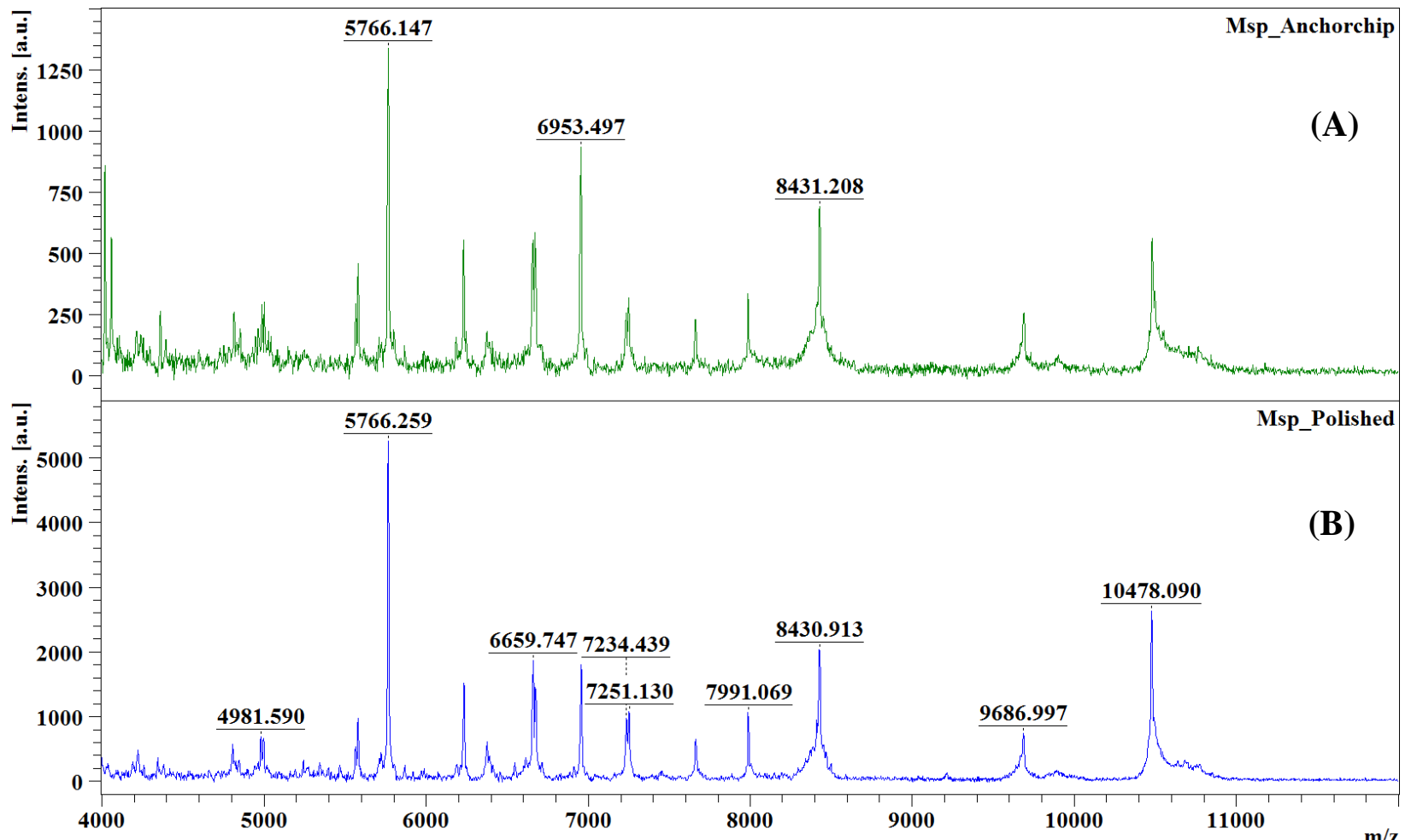

Figura 39: Comparação dos perfis dos espectros de massas do tipo MALDI-TOF produzidos

utilizando as placas "anchorchip" (A) e "polished" (B) no estudo da microalga Msp.

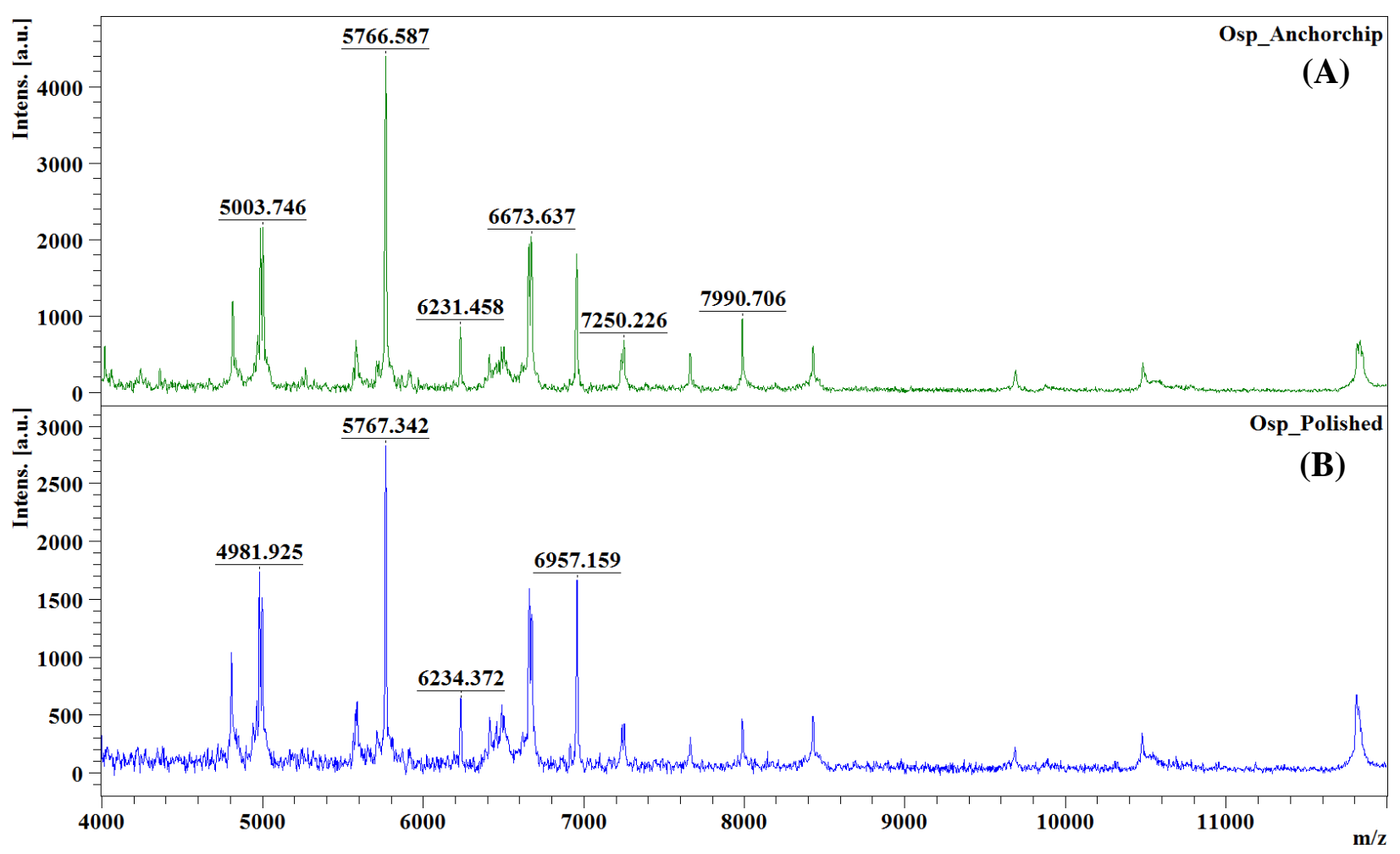

Figura 40: Comparação dos perfis dos espectros de massas do tipo MALDI-TOF produzidos utilizando as placas "anchorchip" (A) e "polished" (B) no estudo da microalga Osp. 
Como pode ser observado nas Figuras 36-40, respectivamente para as espécies $\mathrm{Cv}$, Csp, Dsp, Msp e Osp, para a maioria das amostras, o uso da placa "polished" se mostrou mais efetivo, apresentando espectros com picos mais intensos e mais bem definidos. A Tabela 21 confirma tais observações, sendo que o valor 2 foi atribuído ao melhor desempenho dos parâmetros P1, P2 e P3 e o valor 1 ao pior desempenho. Para as amostras Cv, Csp e Msp, o uso da placa "polished" se mostrou mais efetivo, pois foi possível observar melhor relação $\mathrm{S} / \mathrm{R}$, número de íons e intensidade de sinal. Entretanto, para a microalga Osp, verificou-se um melhor desempenho da placa "anchorchip". Contudo, essa pequena melhora não justifica a troca da placa. Para a espécie Dsp não foram observados íons, respeitando os parâmetros fornecidos pela Bruker, para nenhuma das placas. Entretanto, ao observar o espectro de massas, Figura 38, verificou-se um discreto aumento na intensidade de sinal e no número de íons quando se usa a placa "polished".

Tabela 21: Comparação dos resultados no uso das placas "polished" e "anchorchip".

\begin{tabular}{c|cc|c|c|c|c|c|c|c}
\hline \multirow{2}{*}{$\begin{array}{c}\text { Espécie de } \\
\text { Microalga }\end{array}$} & \multicolumn{2}{|c|}{ Tipo de Placa } & \multicolumn{2}{c|}{ S/R (+Int) } & \multicolumn{2}{c|}{$\begin{array}{c}\text { Intensidade } \\
\text { (+Int) }\end{array}$} & \multicolumn{2}{c|}{$\begin{array}{c}\text { Número de } \\
\text { Íons }\end{array}$} & Soma \\
\cline { 2 - 10 } & Polished Anchorchip & P1 & Classif. & \multicolumn{2}{c}{ P2 } & \multicolumn{1}{c}{ Classif. } & P3 & Classif. & \\
\hline \multirow{2}{*}{ Cv } & + & 0 & 330 & 2 & 25156 & 2 & 52 & 2 & 6 \\
& 0 & + & 131 & 1 & 4337 & 1 & 10 & 1 & 3 \\
\hline \multirow{2}{*}{ Csp } & + & 0 & 30 & 2 & 1649 & 2 & 3 & 2 & 6 \\
& 0 & + & 0 & 0 & 0 & 0 & 0 & 0 & 0 \\
\hline \multirow{2}{*}{ Dsp } & + & 0 & 0 & 0 & 0 & 0 & 0 & 0 & 0 \\
& 0 & + & 0 & 0 & 0 & 0 & 0 & 0 & 0 \\
\hline \multirow{2}{*}{ Msp } & + & 0 & 47 & 2 & 5273 & 2 & 20 & 2 & 6 \\
& 0 & + & 19 & 1 & 1338 & 1 & 4 & 1 & 3 \\
\hline \multirow{2}{*}{ Osp } & + & 0 & 24 & 1 & 2833 & 1 & 11 & 1 & 3 \\
& 0 & + & 43 & 2 & 4403 & 2 & 17 & 2 & 6 \\
\hline
\end{tabular}

Os melhores resultados alcançados pela placa "polished" podem ser explicados pelo fato de que a concentração da amostra promovida pela placa "anchorchip" torna a ionização mais difícil e diminui a sensibilidade dos sinais observados, corroborando desta forma com o trabalho de Wilkinson e colaboradores (1996), que afirma que com o aumento da massa do analito, a conversão de íons em elétrons torna-se menos eficiente, resultando em sinais mais fracos.

Gantt e colaboradores (1999) estudaram diferentes concentrações (alta, baixa e ótima) de células de bactérias intactas utilizando SA como matriz e observaram que acima e abaixo da concentração ótima (entre $7 \times 10^{-5}$ e $2 \times 10^{-7}$ células $/ \mu \mathrm{L}$ ), a intensidade do sinal diminui, 
eventualmente mostrando somente ruídos. Quando a amostra é muito diluída não há íons suficientes alcançando o detector, acima da linha do ruído. Por outro lado, se a amostra está muito concentrada e não há matriz suficiente, a energia transferida para cada analito será insuficiente para dessorvê-lo e ionizá-lo. Com base nos resultados obtidos e corroborados pela literatura, foi adotado o uso da placa "polished" para todos os estudos posteriores.

\subsubsection{Variável modo de análise: linear e refletor}

O espectrômetro de massas com analisador do tipo TOF permite que sejam realizadas análises em modo linear e o modo refletor. Desta forma, foram realizados testes para verificar qual seria o mais adequado para as análises de amostras de microalgas.

\subsubsection{Calibração}

O calibrante foi preparado da mesma forma conforme descrito no item 4.2.3.3. Nesse caso, as calibrações foram feitas utilizando dois diferentes modos de análise, linear e refletor, sob os seguintes parâmetros: placa "polished", HCCA como matriz, número de "shots" de 10000 e potência do laser de $95 \%$.

As condições originais do modo refletor são IS $_{1} 25 \mathrm{kV}$, IS $22,45 \mathrm{kV}$, abertura das lentes de 8,25 kV, PIE $120 \mathrm{~ns}$ e do modo linear são IS $_{1} 25 \mathrm{kV}$, IS $23,55 \mathrm{kV}$, abertura das lentes de 8,7 kV e PIE 250 ns. Os desvios padrões da qualidade da calibração observados para o modo refletor e modo linear foram 4,926 e 72,429 ppm; respectivamente. Pode-se observar que para a análise do calibrante, o modo refletor apresentou um menor erro de calibração.

\subsubsection{Análises das amostras de microalgas}

Neste estudo as amostras de microalgas foram analisadas juntamente no modo linear e refletor, com o objetivo de se determinar qual o melhor método de análise. As análises foram realizadas utilizando HCCA como matriz e a placa "polished", e conduzidas sob os seguintes parâmetros padrões para o modo refletor $\mathrm{IS}_{1} 25 \mathrm{kV}$, IS $22,45 \mathrm{kV}$, abertura das lentes de 8,25 $\mathrm{kV}$, PIE 120 ns e para o modo linear IS $125 \mathrm{kV}, \mathrm{IS}_{2} 23,55 \mathrm{kV}$, abertura das lentes de $8,7 \mathrm{kV}$ e PIE 250 ns. Os espectros podem ser visto nas Figuras 41-45, respectivamente para as espécies Cv, Csp, Dsp, Msp e Osp,. 


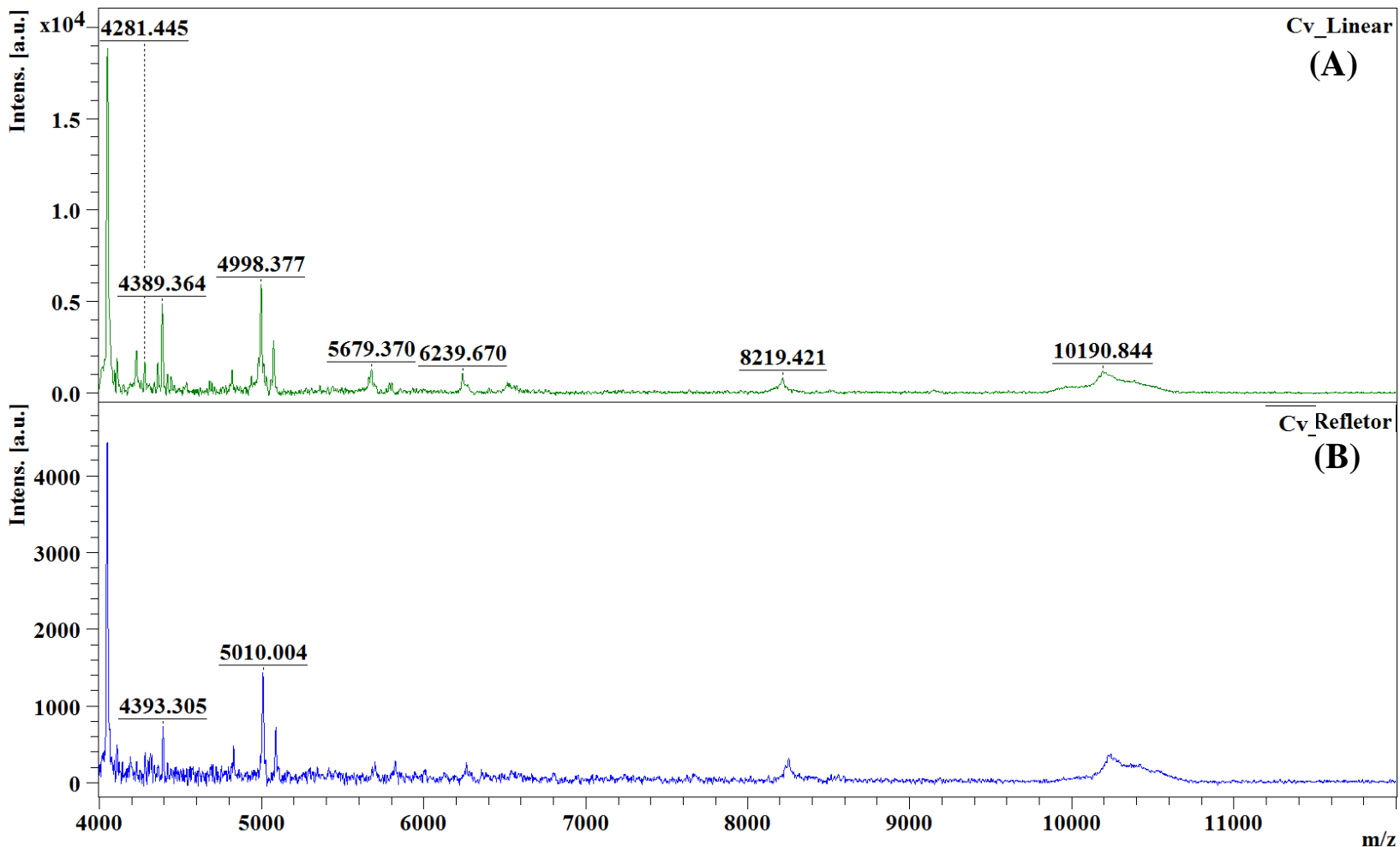

Figura 41: Comparação dos perfis dos espectros de massas do tipo MALDI-TOF nos diferentes modos de análise linear (A) e refletor (B) utilizados no estudo da microalga $\mathrm{Cv}$.

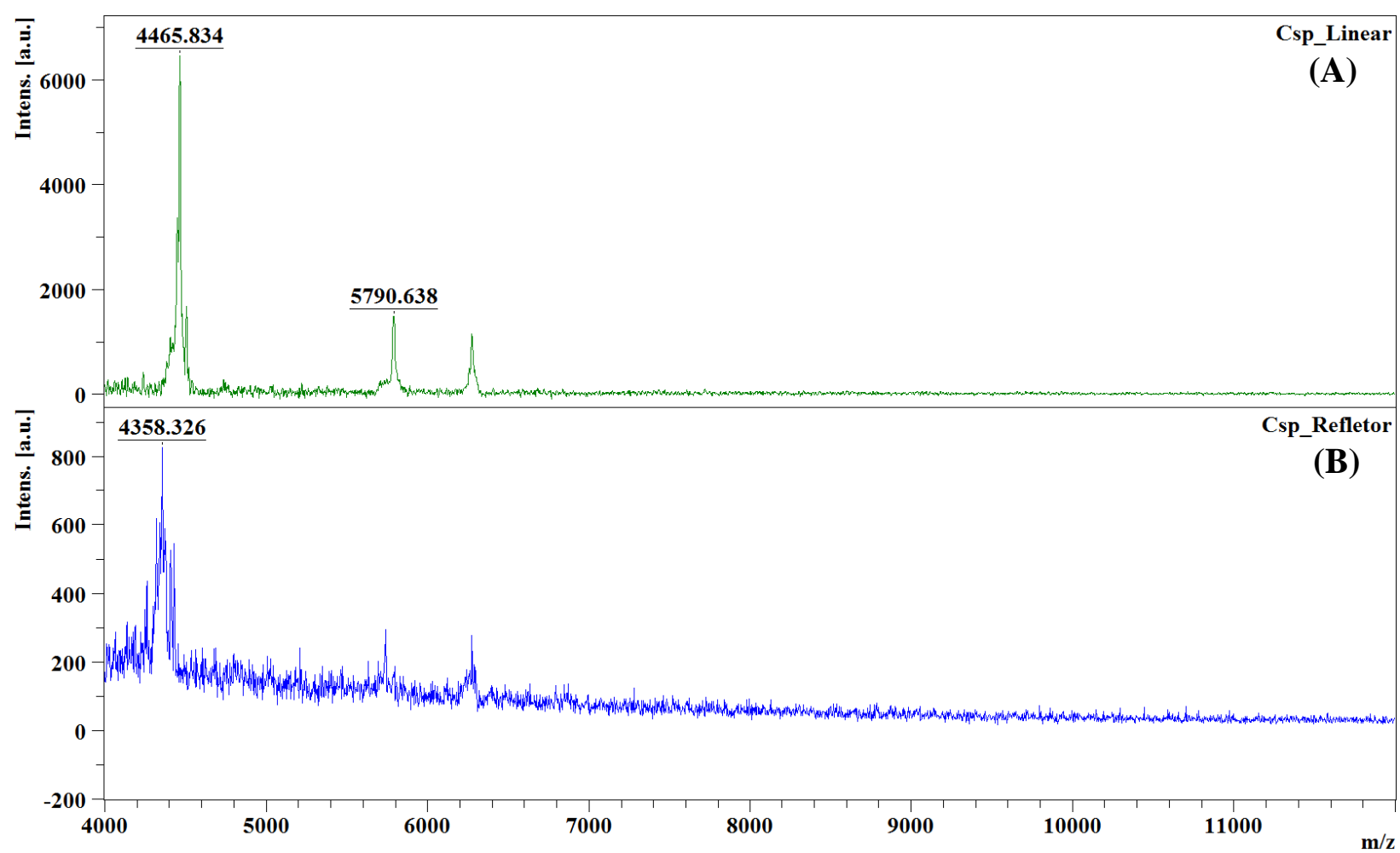

Figura 42: Comparação dos perfis dos espectros de massas do tipo MALDI-TOF nos diferentes modos de análise linear (A) e refletor (B) utilizados no estudo da microalga Csp. 


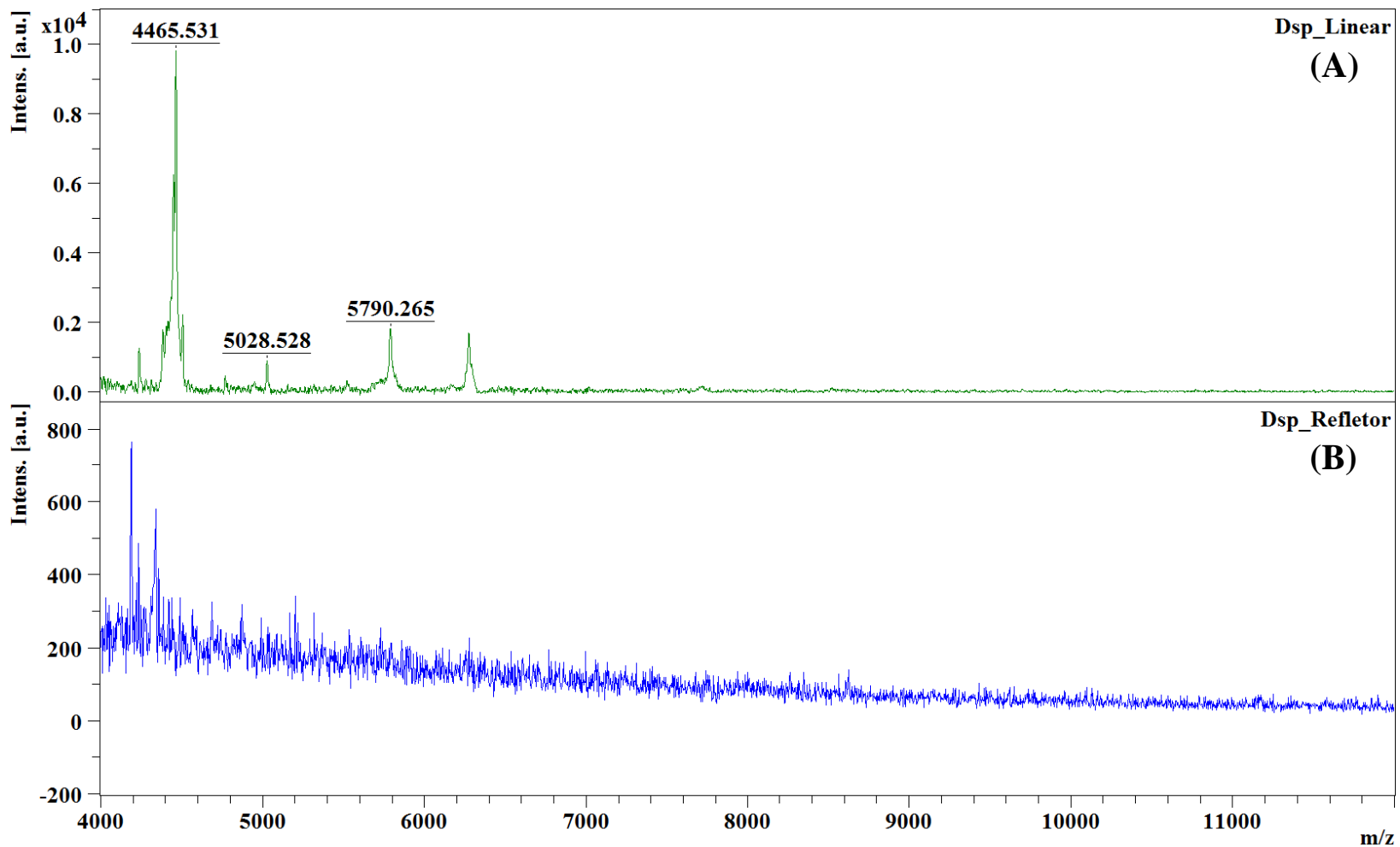

Figura 43: Comparação dos perfis dos espectros de massas do tipo MALDI-TOF nos diferentes modos de análise linear (A) e refletor (B) utilizados no estudo da microalga Dsp.

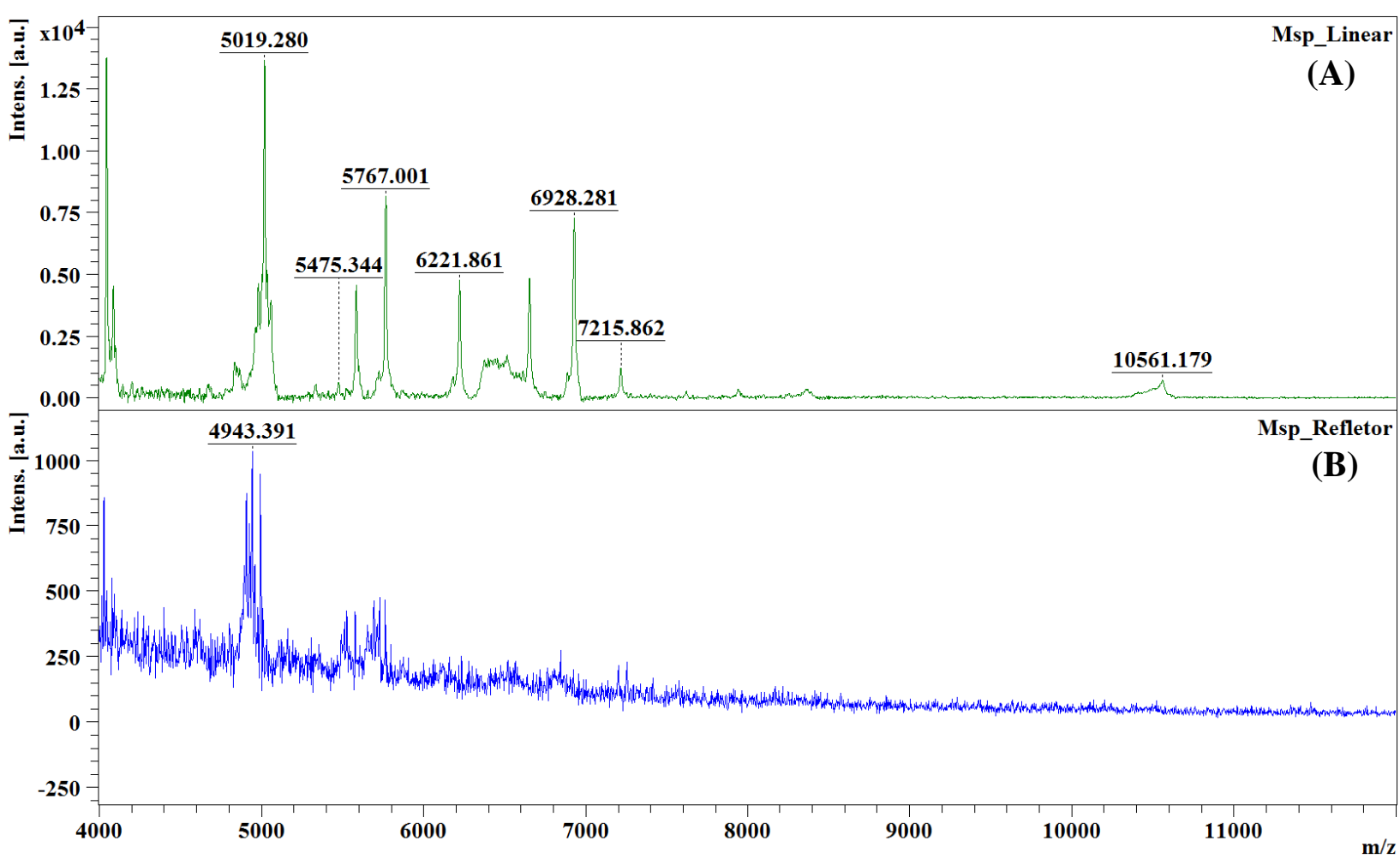

Figura 44: Comparação do perfil dos espectros de massas do tipo MALDI-TOF nos diferentes modos de análise linear (A) e refletor (B) utilizados no estudo da microalga Msp. 


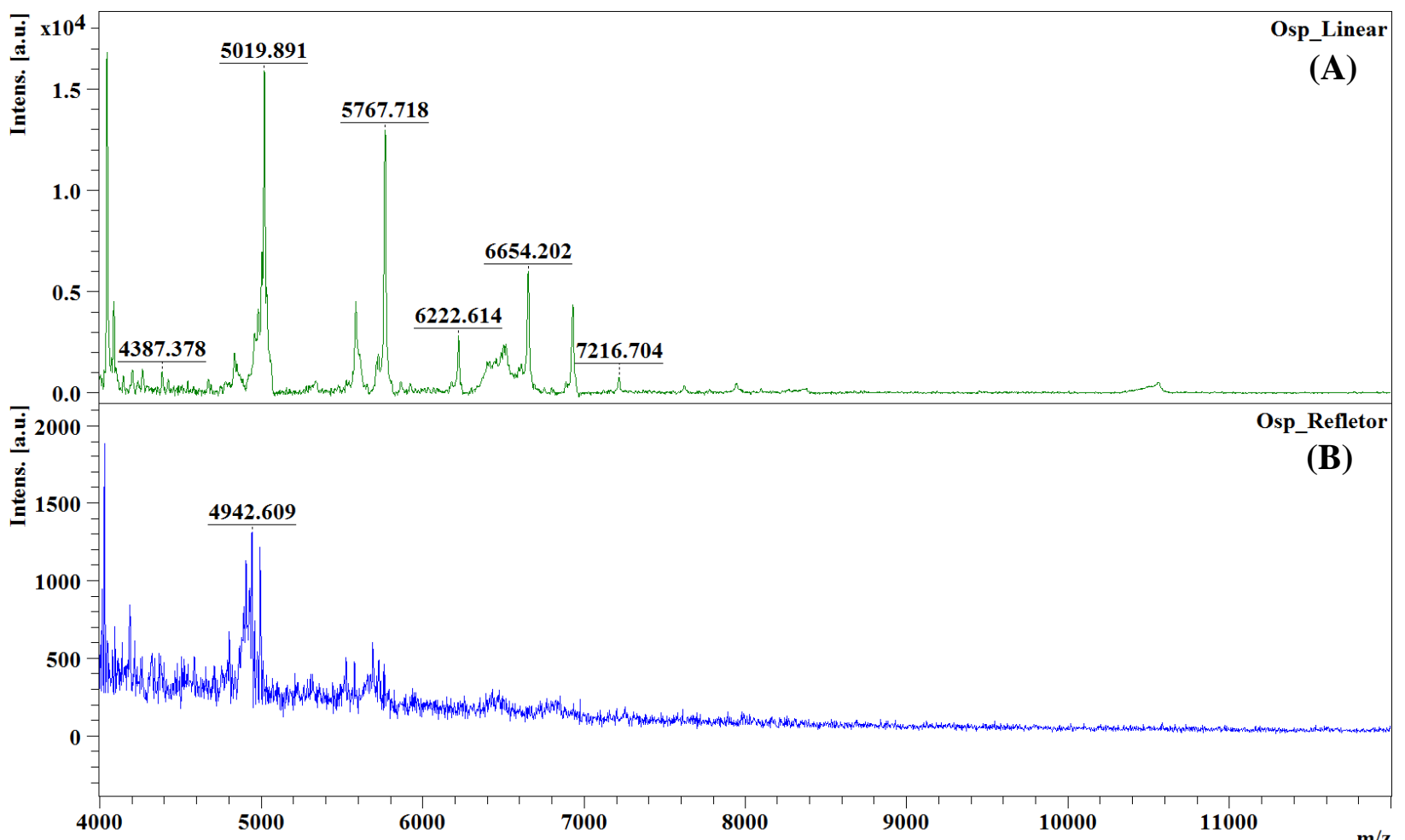

Figura 45: Comparação dos perfis dos espectros de massas do tipo MALDI-TOF nos diferentes modos de análise linear (A) e refletor (B) utilizados no estudo da microalga Osp.

Para todas as espécies de microalgas verificou-se que o modo linear apresenta picos mais bem resolvidos, quando comparado com o modo refletor. Os parâmetros P1, P2 e P3 podem ser observados na Tabela 22.

Tabela 22: Estudo comparativo de diferentes modos de análise.

\begin{tabular}{c|cc|c|c|c|c|c|c|c}
\hline \multirow{2}{*}{$\begin{array}{c}\text { Espécie de } \\
\text { Microalga }\end{array}$} & \multicolumn{2}{|c|}{ Modo } & \multicolumn{2}{c|}{ S/R (+Int) } & \multicolumn{2}{c|}{$\begin{array}{c}\text { Intensidade } \\
\text { (+Int) }\end{array}$} & \multicolumn{2}{c|}{$\begin{array}{c}\text { Número de } \\
\text { Íons }\end{array}$} & Soma \\
\cline { 2 - 10 } & Linear & Refletor & P1 & Classif. & P2 & Classif. & P3 & Classif. & \\
\hline \multirow{2}{*}{ Cv } & + & 0 & 44 & 2 & 18833 & 2 & 40 & 2 & 6 \\
& 0 & + & 23 & 1 & 4443 & 1 & 5 & 1 & 3 \\
\hline \multirow{2}{*}{ Csp } & + & 0 & 29 & 2 & 6468 & 2 & 14 & 2 & 6 \\
& 0 & + & 6 & 1 & 829 & 1 & 4 & 1 & 3 \\
\hline \multirow{2}{*}{ Dsp } & + & 0 & 35 & 2 & 9814 & 2 & 16 & 2 & 6 \\
& 0 & + & 5 & 1 & 723 & 1 & 1 & 1 & 3 \\
\hline \multirow{2}{*}{ Msp } & + & 0 & 35 & 2 & 13763 & 2 & 54 & 2 & 6 \\
& 0 & + & 6 & 1 & 1037 & 1 & 7 & 1 & 3 \\
\hline \multirow{2}{*}{ Osp } & + & 0 & 34 & 2 & 16837 & 2 & 46 & 2 & 6 \\
& 0 & + & 7 & 1 & 1786 & 1 & 17 & 1 & 3 \\
\hline
\end{tabular}


$\mathrm{Na}$ avaliação dos parâmetros $\mathrm{P} 1, \mathrm{P} 2$ e $\mathrm{P} 3$, novamente o número 1 foi atribuído ao pior desempenho, o número 2 ao melhor desempenho, e 0 quando não foram observados íons. A Tabela 22 confirma as observações anteriores, de que o modo linear se mostrou muito mais efetivo, obtendo somatória máxima para os parâmetros analisados.

O caminho percorrido pelo íon no modo refletor é maior que o caminho percorrido no modo linear (Figura 7), pois no modo refletor os íons são totalmente desacelerados e acelerados novamente no sentido contrário. Esta força de reaceleração não é suficiente para que os íons das microalgas atinjam o detector refletor, resultando na diminuição da detecção de íons, bem como na relação sinal/ruído e na intensidade. Dessa forma, para as próximas análises, foi adotado o modo de análise linear.

\subsubsection{Parâmetro PIE - Extração Pulsada de Íons (Pulsed Ion Extraction)}

Nesse estudo foi verificada a influência do parâmetro PIE (do inglês "pulsed ion extraction"), que é o tempo em nanosegundos entre os pulsos de laser, com o objetivo de aumentar a resolução dos espectros de massas para amostras de microalgas liofilizadas.

\subsubsection{Calibração}

O calibrante foi preparado conforme descrito no item 4.2.3.3. As calibrações foram feitas utilizando diferentes valores de PIEs (100 ns, $250 \mathrm{~ns}$ e $450 \mathrm{~ns}$ ), a placa "polished" e HCCA como matriz sob os seguintes parâmetros: $\mathrm{IS}_{1} 25 \mathrm{kV}, \mathrm{IS}_{2} 23,55 \mathrm{kV}$, abertura das lentes de 7,0 kV, número de "shots" de 10000 e potência do laser de 95\%. Os desvios padrões da qualidade da calibração observados para PIEs 100 ns, 250 ns e 450 ns foram 144,47; 260,23 e $350,54 \mathrm{ppm}$; respectivamente. Pode-se observar que os desvios da calibração são diretamente proporcionais ao aumento do valor de PIE.

\subsubsection{Análises das amostras de microalgas}

Nesse estudo as amostras de microalgas foram utilizadas juntamente com a matriz HCCA, cuja preparação foi feita de acordo com o descrito no item 4.2.3.4, utilizando a placa "polished" e os espectros obtidos no modo linear com parâmetros de análise sendo IS $_{1} 25$ $\mathrm{kV}, \mathrm{IS}_{2} 23,55 \mathrm{kV}$, abertura das lentes de $7 \mathrm{kV}$, com variações nos valores de PIE (100 ns, 250 ns e 450ns), conforme pode ser visto nas Figuras 46-50, respectivamente para as espécies $\mathrm{Cv}$, Csp, Dsp, Msp e Osp. 


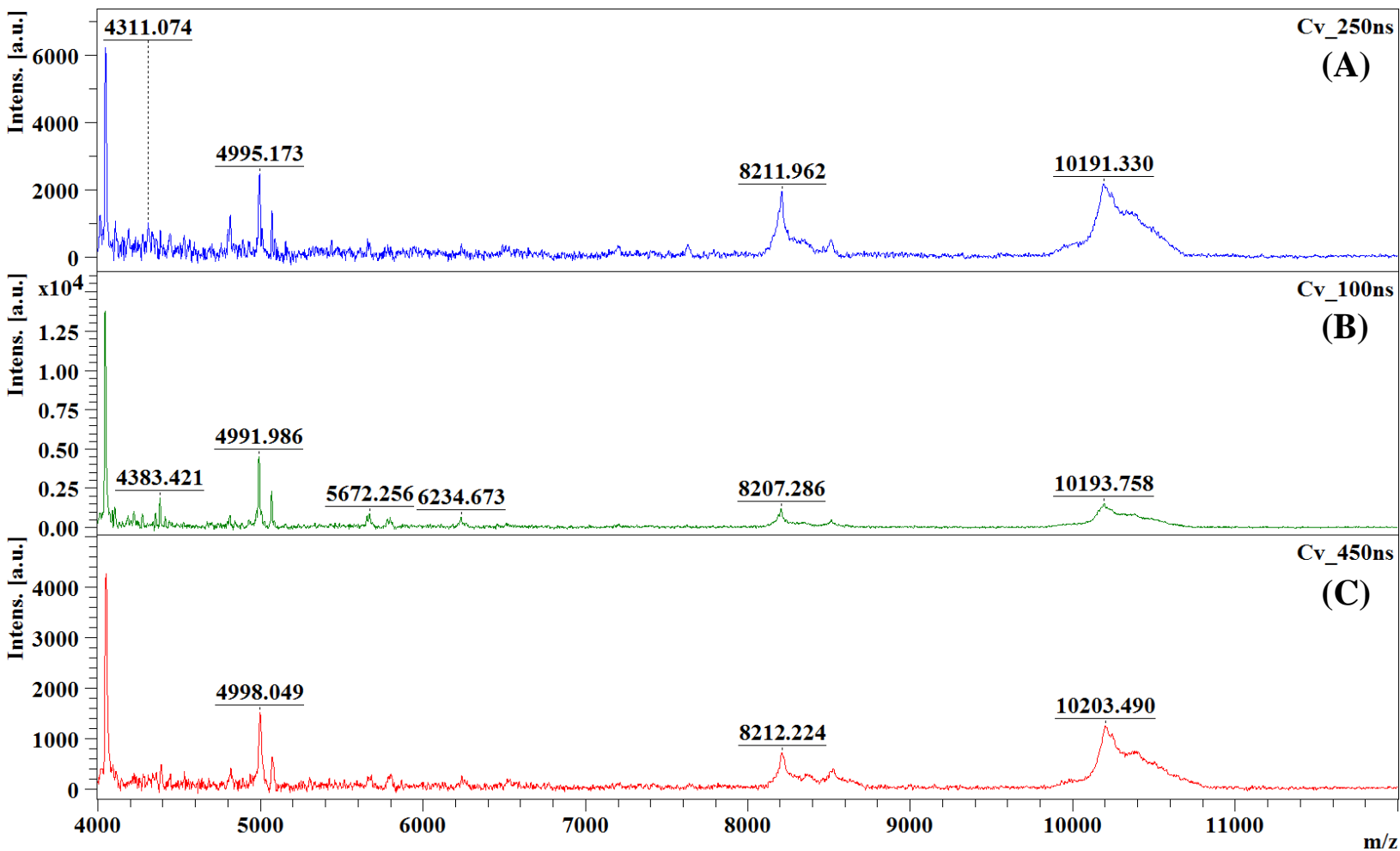

Figura 46: Comparação dos perfis dos espectros de massas do tipo MALDI-TOF obtidos nos diferentes valores de PIEs, 100 ns (A), 250 ns (B) e 450 ns (C) no estudo da microalga Cv.

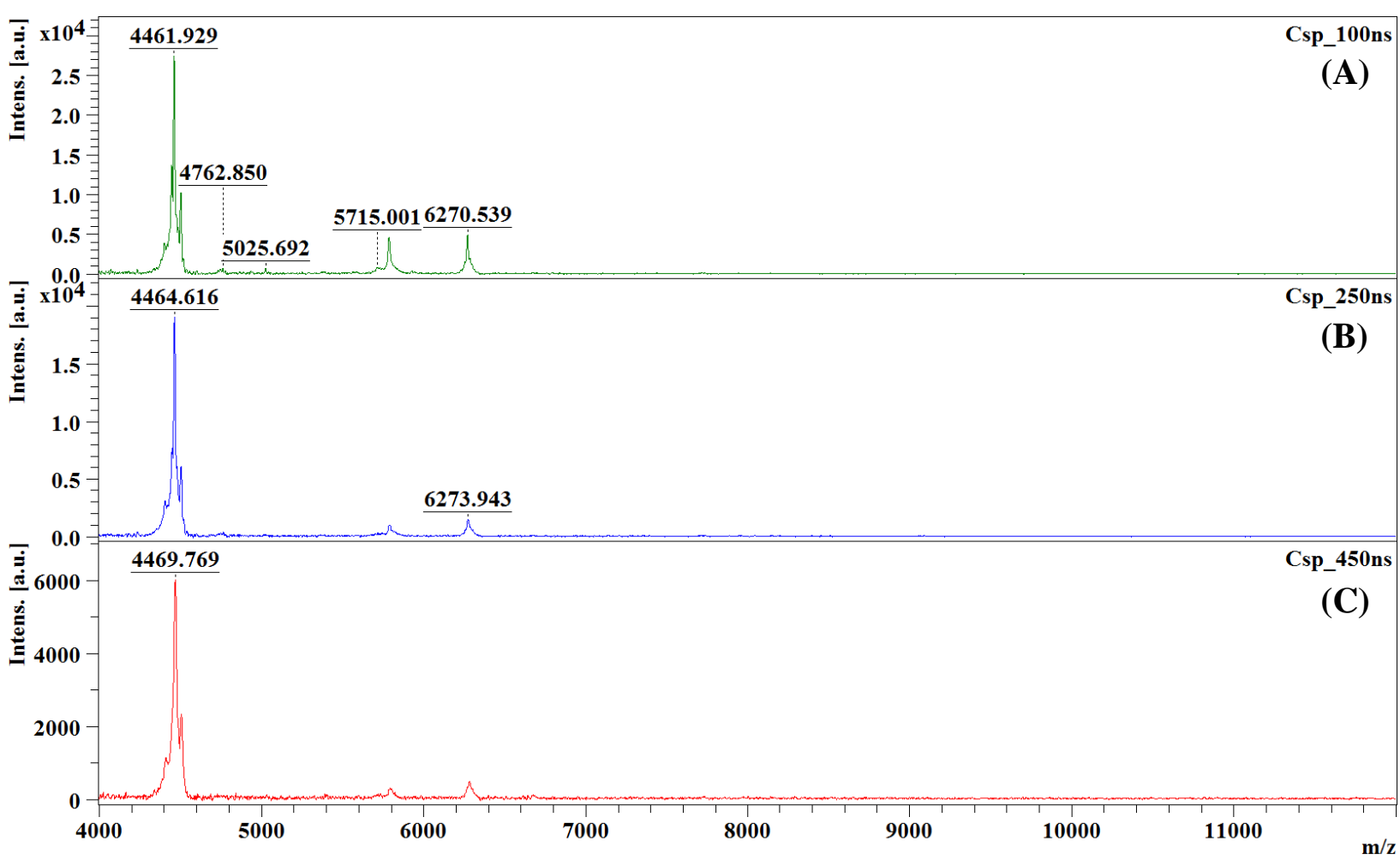

Figura 47: Comparação dos perfis dos espectros de massas do tipo MALDI-TOF obtidos nos diferentes valores de PIEs, $100 \mathrm{~ns}$ (A), $250 \mathrm{~ns}$ (B) e $450 \mathrm{~ns}$ (C) no estudo da microalga Csp. 


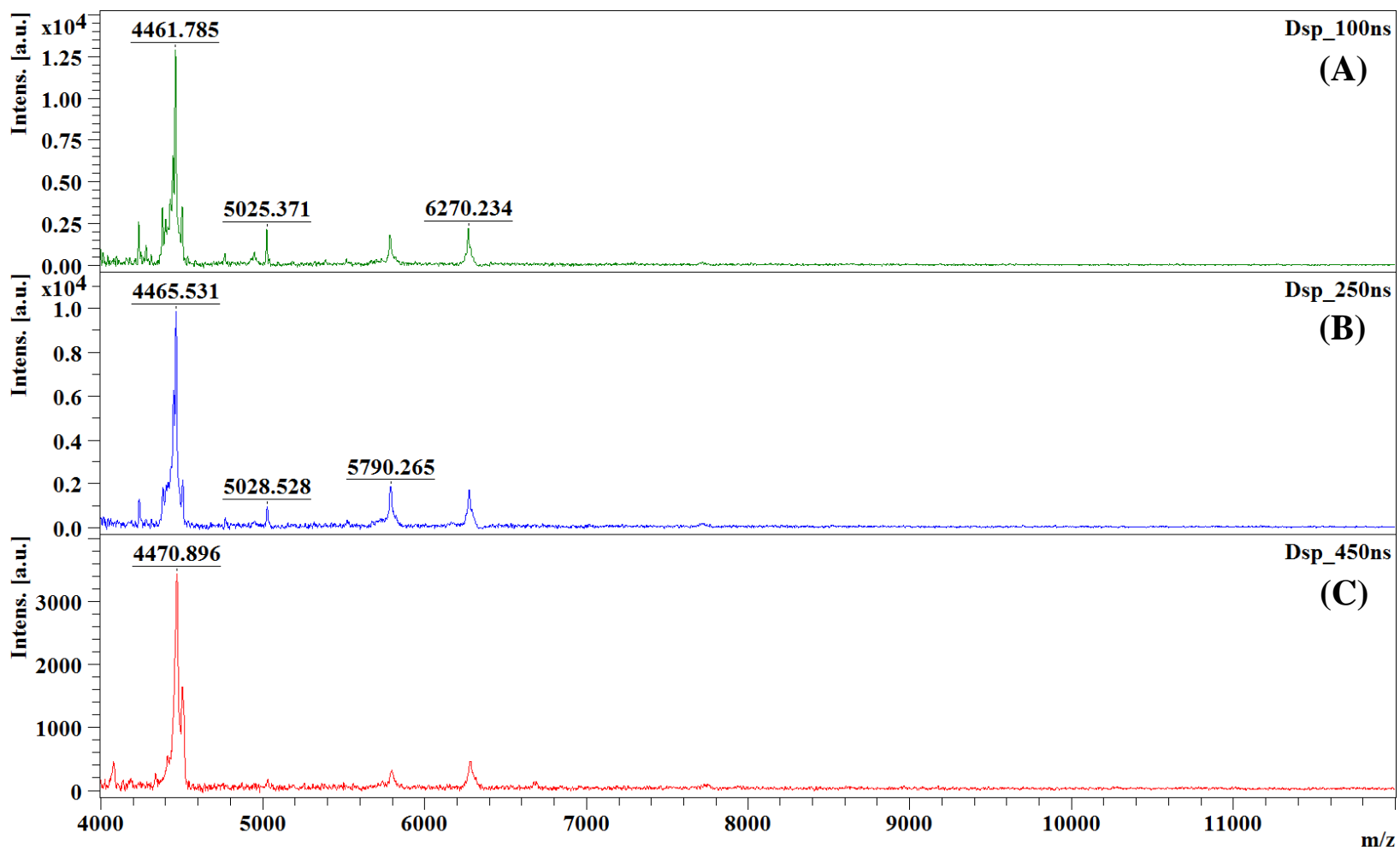

Figura 48: Comparação dos perfis dos espectros de massas do tipo MALDI-TOF obtidos nos diferentes valores de PIEs, 100 ns (A), 250 ns (B) e 450 ns (C) no estudo da microalga Dsp.

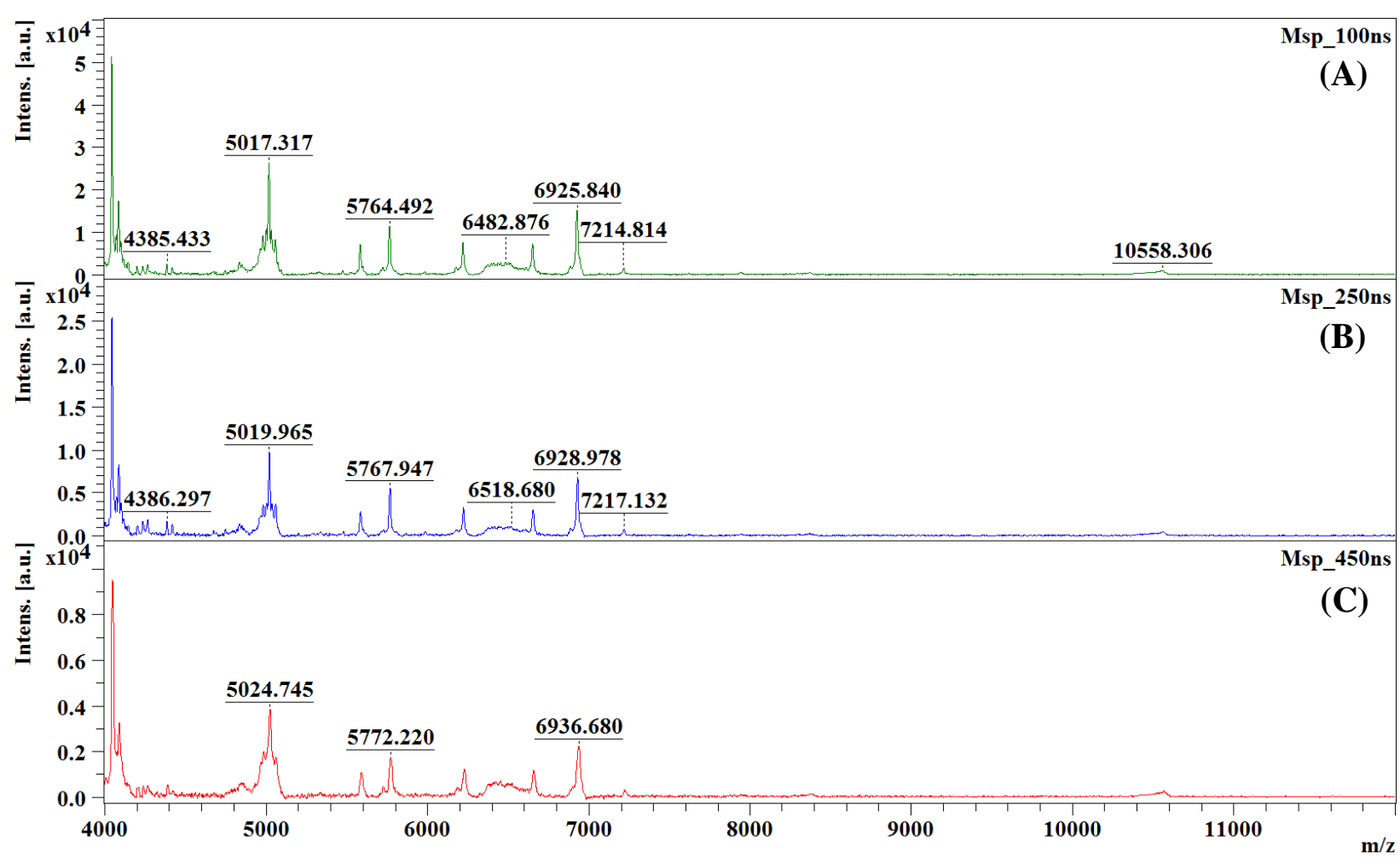

Figura 49: Comparação dos perfis dos espectros de massas do tipo MALDI-TOF obtidos nos diferentes valores de PIEs, 100 ns (A), 250 ns (B) e 450 ns (C) no estudo da microalga Msp. 


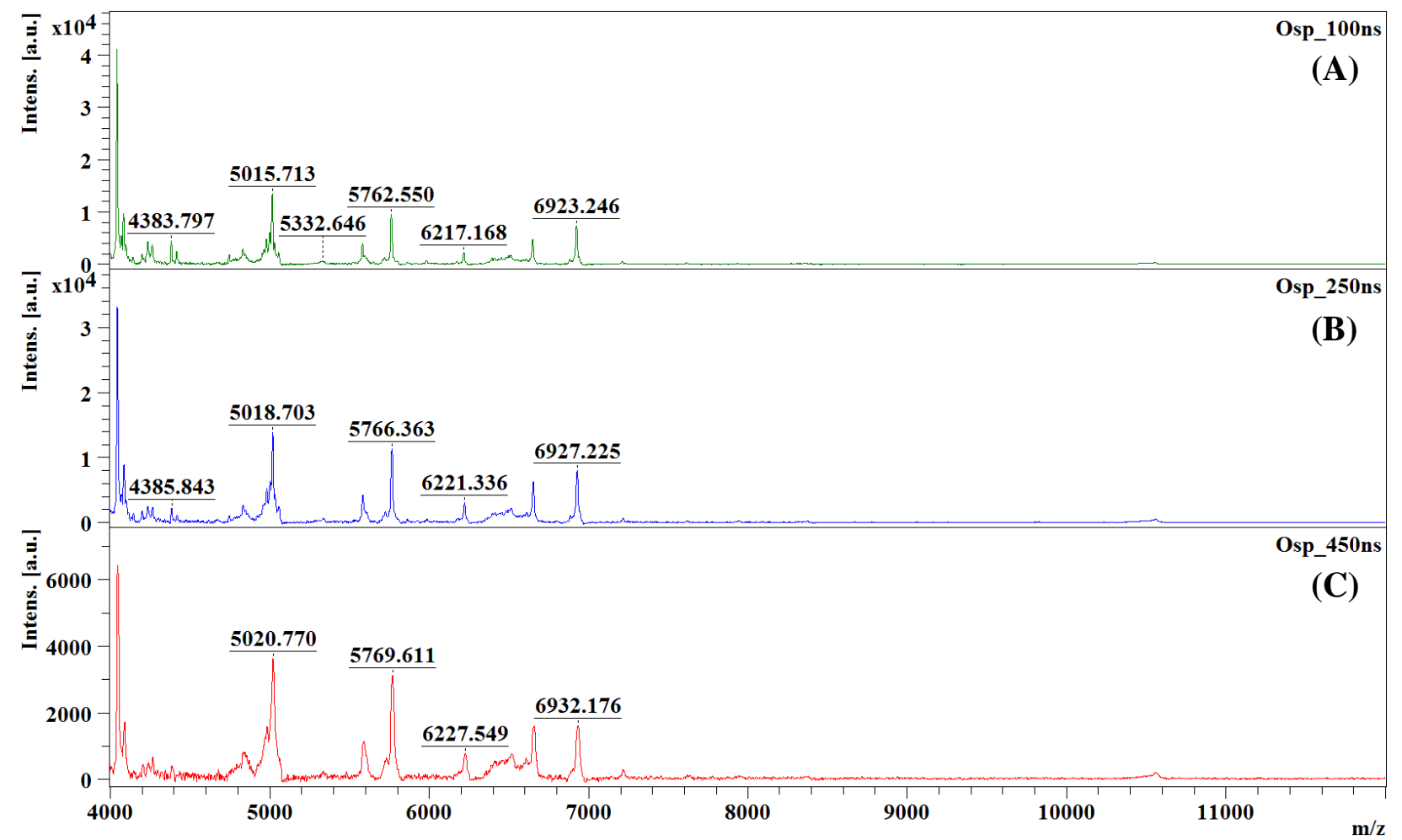

Figura 50: Comparação dos perfis dos espectros de massas do tipo MALDI-TOF obtidos nos diferentes valores de PIEs, 100 ns (A), 250 ns (B) e 450 ns (C) no estudo da microalga Osp.

Para todas as espécies de microalgas pode-se observar um perfil semelhante para os três valores de PIE utilizados, porém quando usado um valor de PIE de 100 ns foi observada uma maior intensidade do sinal, maior relação sinal/ruído e maior número de íons. Os parâmetros P1, P2 e P3 podem ser observados na Tabela 23. 
Tabela 23: Estudo comparativo de diferentes valores de PIEs.

\begin{tabular}{c|ccc|c|c|c|c|c|c|c}
\hline \multirow{2}{*}{$\begin{array}{c}\text { Espécie de } \\
\text { Microalga }\end{array}$} & \multicolumn{3}{|c|}{ PIE (ns) } & \multicolumn{2}{c|}{ S/R (+Int) } & \multicolumn{2}{c|}{$\begin{array}{c}\text { Intensidade } \\
\text { (+Int) }\end{array}$} & \multicolumn{2}{c|}{$\begin{array}{c}\text { Número de } \\
\text { Íons }\end{array}$} & Soma \\
\cline { 2 - 11 } & $\mathbf{1 0 0}$ & $\mathbf{2 5 0}$ & $\mathbf{4 5 0}$ & P1 & Classif. & P2 & Classif. & P3 & Classif. & \\
\hline \multirow{3}{*}{ Cv } & + & 0 & 0 & 43 & 3 & 13570 & 3 & 47 & 3 & 9 \\
& 0 & + & 0 & 28 & 2 & 6237 & 2 & 45 & 2 & 6 \\
& 0 & 0 & + & 21 & 1 & 4256 & 1 & 21 & 1 & 3 \\
\hline \multirow{3}{*}{ Csp } & + & 0 & 0 & 110 & 2 & 27482 & 3 & 26 & 3 & 8 \\
& 0 & + & 0 & 115 & 3 & 19026 & 2 & 16 & 2 & 7 \\
& 0 & 0 & + & 62 & 1 & 6009 & 1 & 4 & 1 & 3 \\
\hline \multirow{3}{*}{ Dsp } & + & 0 & 0 & 46 & 3 & 12907 & 3 & 23 & 3 & 9 \\
& 0 & + & 0 & 37 & 2 & 9857 & 2 & 17 & 2 & 6 \\
& 0 & 0 & + & 35 & 1 & 3442 & 1 & 3 & 1 & 3 \\
\hline \multirow{3}{*}{ Msp } & + & 0 & 0 & 108 & 3 & 51365 & 3 & 81 & 3 & 9 \\
& 0 & + & 0 & 81 & 2 & 25382 & 2 & 66 & 2 & 6 \\
& 0 & 0 & + & 48 & 1 & 9508 & 1 & 27 & 1 & 3 \\
\hline \multirow{3}{*}{ Osp } & + & 0 & 0 & 99 & 3 & 41130 & 3 & 66 & 3 & 9 \\
& 0 & + & 0 & 67 & 2 & 33096 & 2 & 60 & 2 & 6 \\
& 0 & 0 & + & 28 & 1 & 6431 & 1 & 24 & 1 & 3 \\
\hline
\end{tabular}

$\mathrm{Na}$ avaliação dos parâmetros $\mathrm{P} 1, \mathrm{P} 2$ e P3, novamente o número 1 foi atribuído ao pior desempenho e o número 3 ao melhor desempenho. A Tabela 23 confirma as observações anteriores, sendo o valor de 100 ns de PIE o mais efetivo, obtendo somatória máxima para os parâmetros analisados.

A diminuição no valor do PIE auxilia na compensação da distribuição das velocidades iniciais fazendo com que os íons com mesma razão $\mathrm{m} / \mathrm{z}$ cheguem simultaneamente no detector, melhorando a resolução e intensidade dos picos. Dessa forma, para as próximas análises foi adotado o uso do valor de PIE de 100 ns para todas as amostras.

\subsubsection{Parâmetro $\mathrm{IS}_{2}$}

Assim como o valor do PIE, o valor de $\mathrm{IS}_{2}$ (tensão de aceleração) influencia bastante na resolução dos espectros. Por isso, foram realizados testes com 3 diferentes valores de $\mathrm{IS}_{2}$, $23 ; 23,55$ e $24 \mathrm{kV}$, para verificar a influência deste parâmetro no perfil dos espectros de proteínas das microalgas. O valor 23,55 kV é o valor utilizado método padrão da Bruker. 


\subsubsection{Calibração}

A padronização do método começou com a calibração do equipamento. O calibrante foi preparado conforme descrito no item 4.2.3.3. Nesse caso, as calibrações foram realizadas utilizando o calibrante com a placa "polished" e utilizando HCCA como matriz. Os parâmetros do equipamento foram mantidos constantes com os seguintes valores: $\mathrm{IS}_{1} 25 \mathrm{kV}$, PIE 100ns, abertura das lentes de 7,0 kV, número de "shots" de 10000 e potência do laser de $95 \%$.

Os desvios padrões da qualidade da calibração observados para $\mathrm{IS}_{2}$ igual a 23; $24 \mathrm{e}$ $23,55 \mathrm{kV}$ foram 28,033; 173,96 e 108,684 ppm, respectivamente. Pode-se observar que o menor desvio na calibração foi obtido para o menor valor de $\mathrm{IS}_{2}$.

\subsubsection{Análises das amostras de microalgas}

As amostras de microalgas foram analisadas utilizando HCCA como matriz (método de preparação descrito no item 4.2.3.4), na placa "polished". As análises foram conduzidas em modo linear sob os seguintes parâmetros de análise $\mathrm{IS}_{1} 25 \mathrm{kV}$, abertura das lentes de $7 \mathrm{kV}$, PIE $100 \mathrm{~ns}$ e diferentes valores para $\mathrm{IS}_{2}(23 ; 23,55$ e $24 \mathrm{kV})$. Os espectros podem ser visto nas Figuras 51 a 55, respectivamente para as espécies Cv, Csp, Dsp, Msp e Osp. 


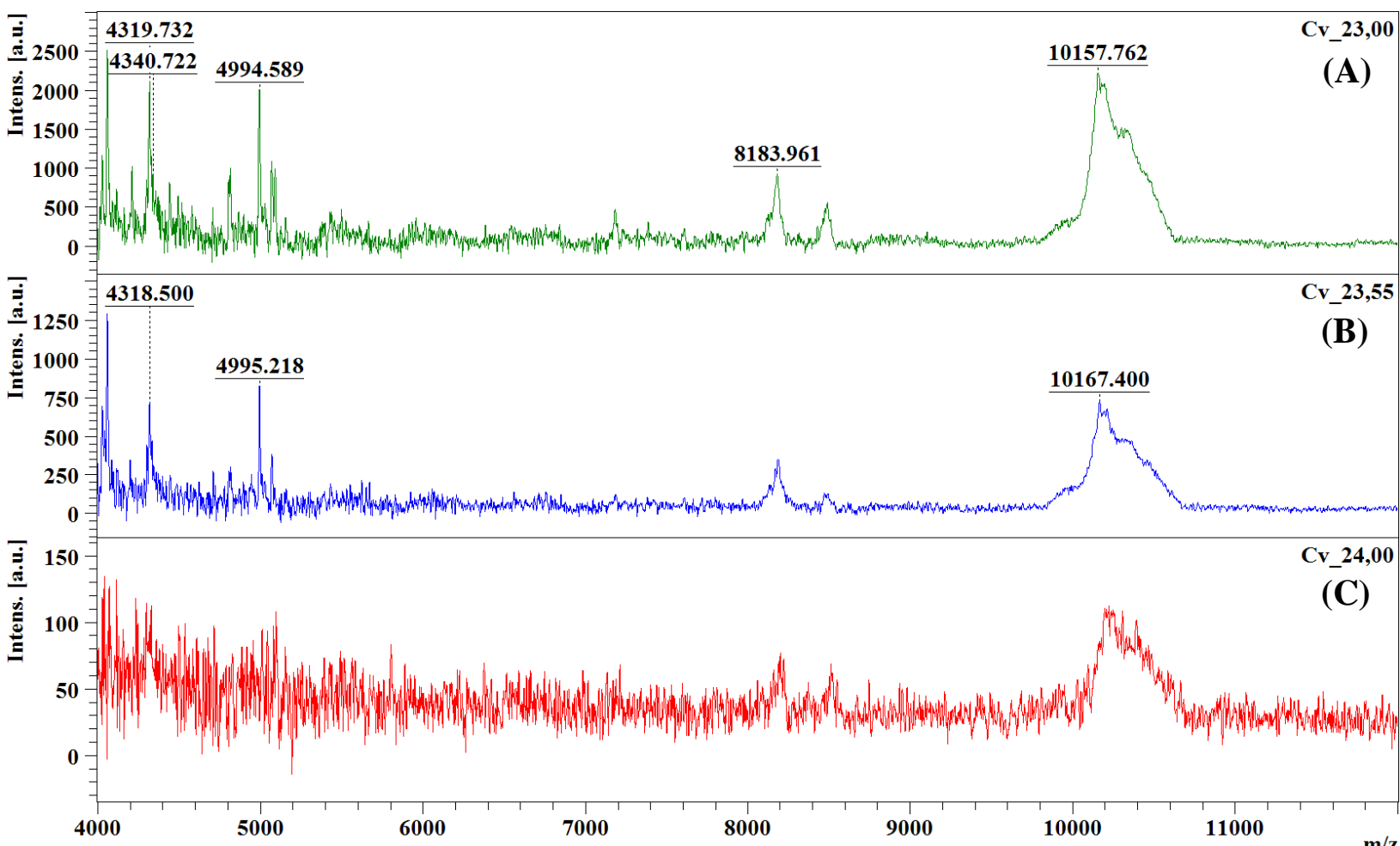

Figura 51: Comparação dos perfis dos espectros de massas do tipo MALDI-TOF de proteínas da microalga $\mathrm{Cv}$, obtidos com diferentes valores de $\mathrm{IS}_{2}, 23 \mathrm{kV}$ (A); 23,55 kV (B) e $24 \mathrm{kV}$ (C).

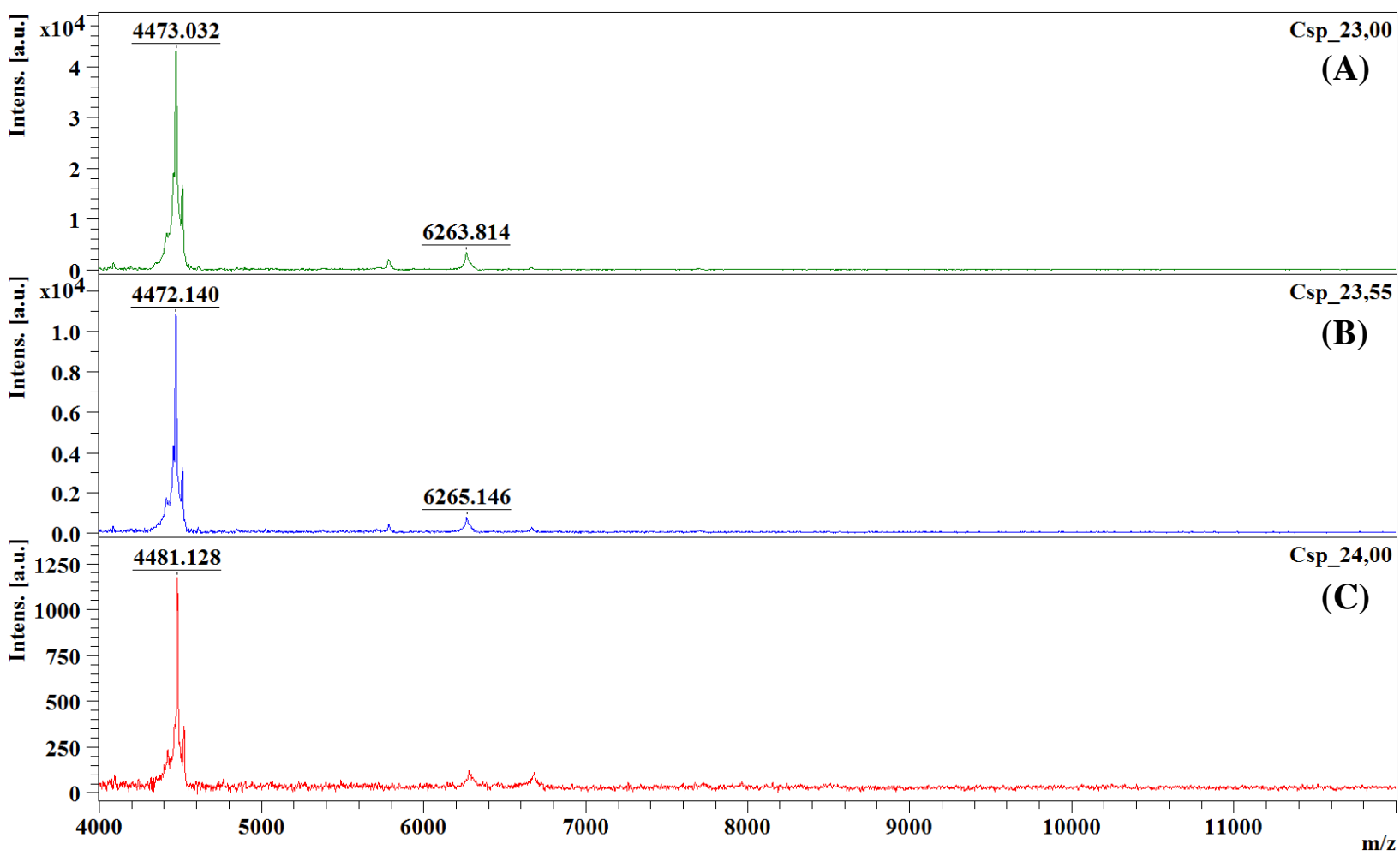

Figura 52: Comparação dos perfis dos espectros de massas do tipo MALDI-TOF de proteínas da microalga Csp, obtidos com diferentes valores de IS $2,23 \mathrm{kV}$ (A); 23,55 kV (B) e $24 \mathrm{kV}$ (C). 


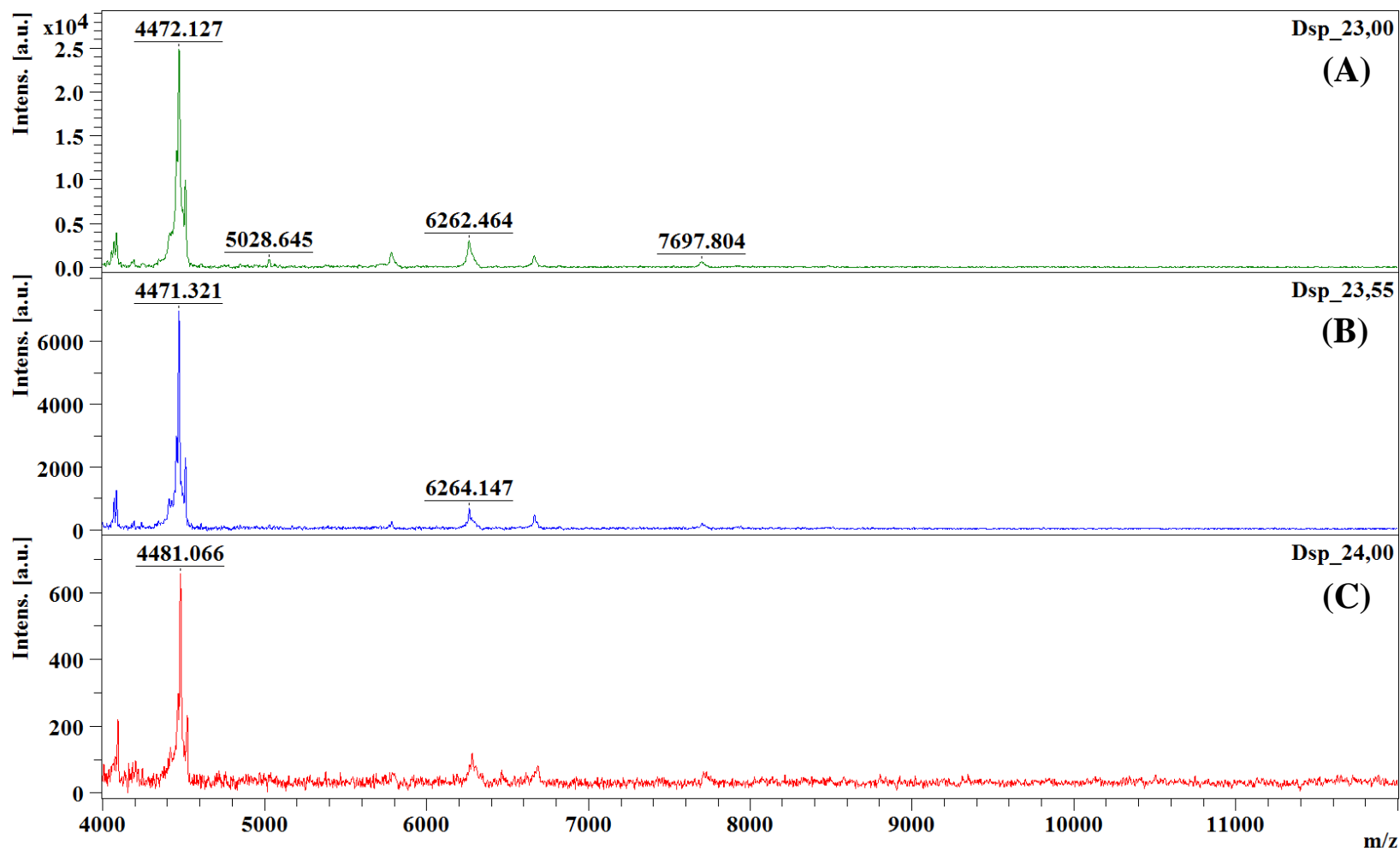

Figura 53: Comparação dos perfis dos espectros de massas do tipo MALDI-TOF de proteínas da microalga Dsp, obtidos com diferentes valores de $\mathrm{IS}_{2}, 23 \mathrm{kV}$ (A); 23,55 kV (B) e $24 \mathrm{kV}$ (C).

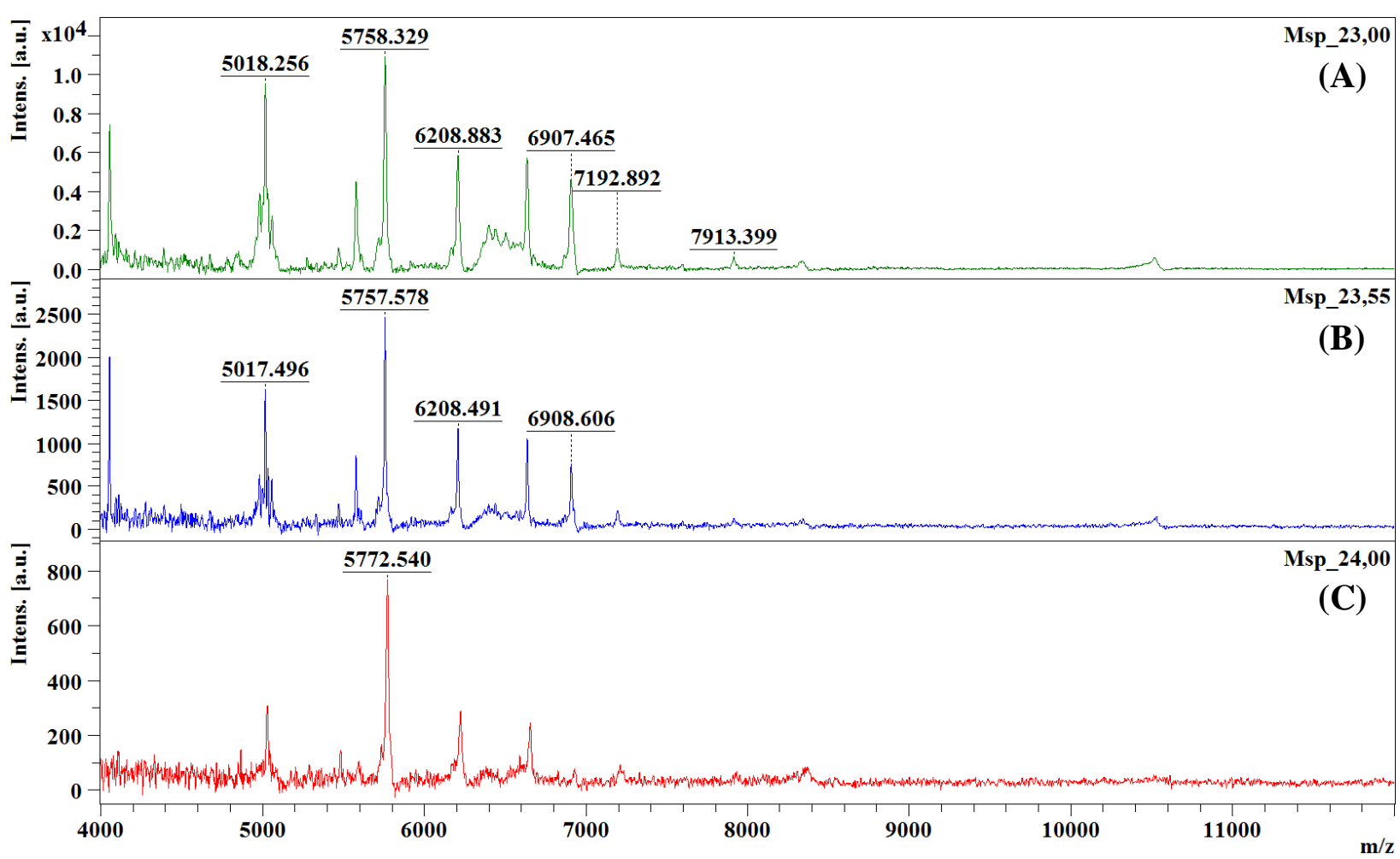

Figura 54: Comparação dos perfis dos espectros de massas do tipo MALDI-TOF de proteínas da microalga Msp, obtidos com diferentes valores de $\mathrm{IS}_{2}, 23 \mathrm{kV}$ (A); 23,55 kV (B) e $24 \mathrm{kV}$ (C). 


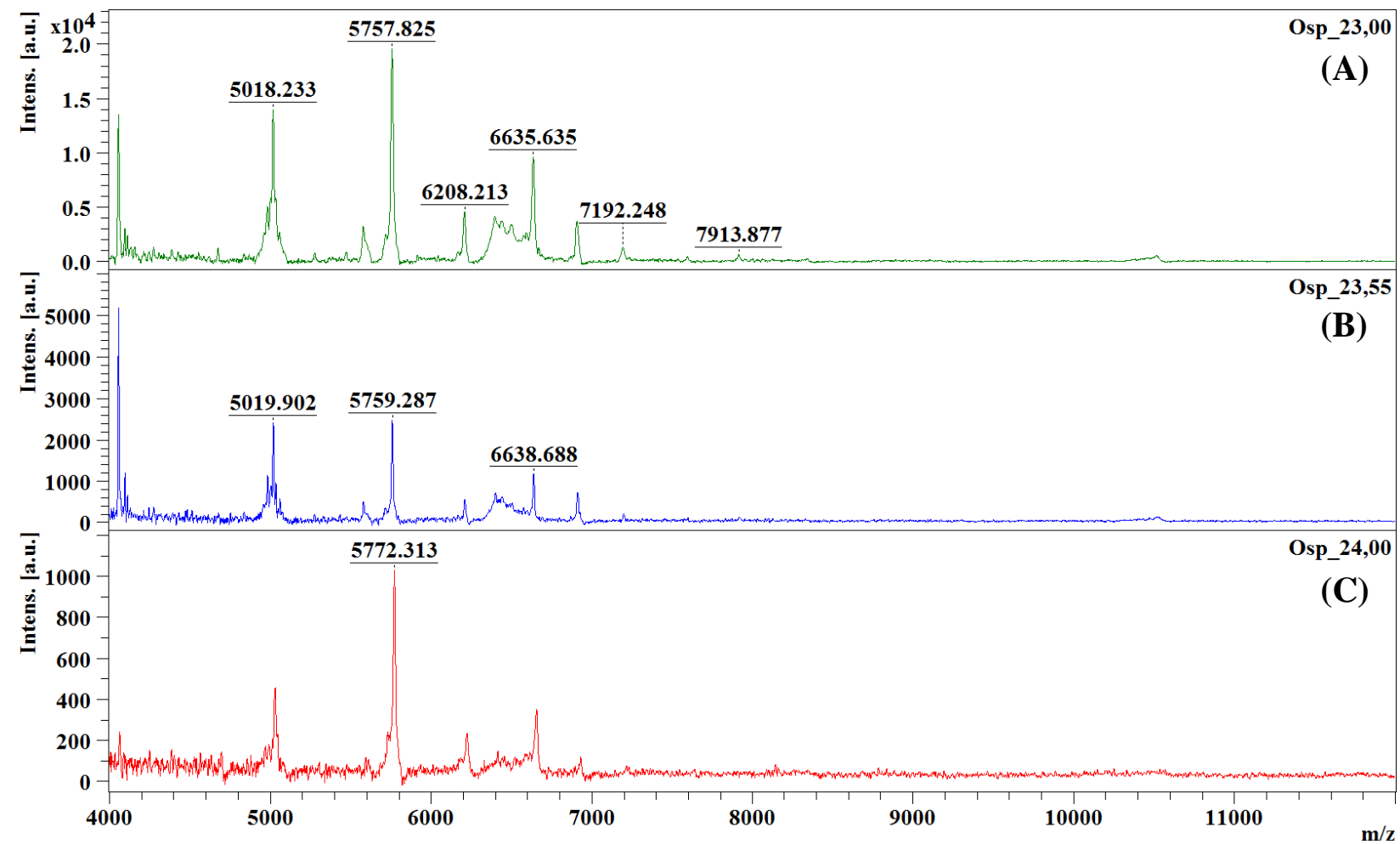

Figura 55: Comparação dos perfis dos espectros de massas do tipo MALDI-TOF de proteínas da microalga Osp, obtidos com diferentes valores de $\mathrm{IS}_{2}, 23 \mathrm{kV}$ (A); 23,55 kV (B) e $24 \mathrm{kV}$ (C).

Para todas as espécies de microalgas, pode-se observar um perfil semelhante para os três valores de $\mathrm{IS}_{2}$ utilizados. Entretanto, a diferença de potencial $\left(\mathrm{IS}_{1}-\mathrm{IS}_{2}\right)$ que produziu o melhor espectro foi de $2 \mathrm{kV}$, ou seja, com o valor de $\mathrm{IS}_{2}$ de $23 \mathrm{kV}$. Para confirmar tais informações, os parâmetros P1, P2 e P3, observados na Tabela 24, foram novamente analisados. 
Tabela 24: Estudo comparativo de diferentes valores para $\mathrm{IS}_{2}$.

\begin{tabular}{|c|c|c|c|c|c|c|c|c|c|c|}
\hline \multirow{2}{*}{$\begin{array}{l}\text { Espécie de } \\
\text { Microalga }\end{array}$} & \multicolumn{3}{|c|}{$\mathbf{I S}_{\mathbf{2}}(\mathbf{k V})$} & \multicolumn{2}{|c|}{ S/R (+Int) } & \multicolumn{2}{|c|}{$\begin{array}{c}\text { Intensidade } \\
\text { (+Int) }\end{array}$} & \multicolumn{2}{|c|}{$\begin{array}{c}\text { Número de } \\
\text { Ílons }\end{array}$} & \multirow[t]{2}{*}{ Soma } \\
\hline & 23,00 & 23,55 & 24,00 & P1 & Classif. & P2 & Classif. & $\mathbf{P 3}$ & Classif. & \\
\hline \multirow{3}{*}{$\mathrm{Cv}$} & + & 0 & 0 & 10 & 3 & 2509 & 3 & 40 & 3 & 9 \\
\hline & 0 & + & 0 & 7 & 2 & 1292 & 2 & 7 & 2 & 6 \\
\hline & 0 & 0 & + & 0 & 0 & 0 & 0 & 0 & 0 & 0 \\
\hline \multirow{3}{*}{ Csp } & + & 0 & 0 & 142 & 3 & 43090 & 3 & 14 & 3 & 9 \\
\hline & 0 & + & 0 & 90 & 2 & 10853 & 2 & 8 & 2 & 6 \\
\hline & 0 & 0 & + & 26 & 1 & 1176 & 1 & 1 & 1 & 3 \\
\hline \multirow{3}{*}{ Dsp } & + & 0 & 0 & 86 & 3 & 24867 & 3 & 22 & 3 & 9 \\
\hline & 0 & + & 0 & 65 & 2 & 6964 & 2 & 11 & 2 & 6 \\
\hline & 0 & 0 & + & 16 & 1 & 656 & 1 & 1 & 1 & 3 \\
\hline \multirow{3}{*}{ Msp } & + & 0 & 0 & 30 & 3 & 10921 & 3 & 29 & 3 & 9 \\
\hline & 0 & + & 0 & 21 & 2 & 2462 & 2 & 9 & 2 & 6 \\
\hline & 0 & 0 & + & 14 & 1 & 767 & 1 & 1 & 1 & 3 \\
\hline \multirow{3}{*}{ Osp } & + & 0 & 0 & 44 & 3 & 19581 & 3 & 30 & 3 & 9 \\
\hline & 0 & + & 0 & 26 & 2 & 5183 & 2 & 12 & 2 & 6 \\
\hline & 0 & 0 & + & 18 & 1 & 1030 & 1 & 1 & 1 & 3 \\
\hline
\end{tabular}

Novamente o valor 1 foi atribuído ao pior desempenho e o valor 3 ao melhor desempenho, na avaliação dos parâmetros $\mathrm{P} 1, \mathrm{P} 2$ e P3. O valor de $23 \mathrm{kV}$ para $\mathrm{IS}_{2}$ foi o mais efetivo, obtendo somatória máxima para os parâmetros analisados, conforme observado na Tabela 24. Esse resultado corrobora com o menor desvio na calibração obtido para a utilização do menor valor de $\mathrm{IS}_{2}$, ou seja $23 \mathrm{kV}$.

O fornecimento de energia cinética, derivado da diferença de potencial entre a fonte $\mathrm{IS}_{1}$ e IS 2 faz com que os íons de mesma massa cheguem ao detector ao mesmo tempo, e tendo o valor de PIE constante em $100 \mathrm{~ns}$, a diferença de potencial entre $\mathrm{IS}_{1}$ e $\mathrm{IS}_{2}$ deve ser maior para compensar a distribuição das velocidades dos íons de mesma massa.

Desta forma, ficou determinado que o valor de $\mathrm{IS}_{2}$ que gera o melhor perfil de espectro para amostras de microalgas é de $23 \mathrm{kV}$.

\subsubsection{Estudo de comparação dos diferentes tipos matrizes}

\subsubsection{Calibração}

O calibrante foi preparado conforme descrito no item 4.2.3.3. Nesse experimento, as calibrações foram feitas utilizando o calibrante cristalizado com as diferentes matrizes (SA, 
HCCA, DHB e sDHB) colocados na placa "polished". Os parâmetros de análise foram mantidos constantes nos seguintes valores: PIE $100 \mathrm{~ns}, \mathrm{IS}_{1} 25 \mathrm{kV}, \mathrm{IS}_{2} 23 \mathrm{kV}$, abertura das lentes de $7 \mathrm{kV}$, número de "shots" de 10000 e potência do laser de $95 \%$.

Os desvios padrões da qualidade da calibração observados para as matrizes SA, HCCA, DHB e sDHB foram 72,429; 149,846; 37,985 e 35,236 ppm; respectivamente. Podese observar que os menores desvios foram obtidos com a utilização de matrizes contendo DHB em sua composição.

\subsubsection{Análises das amostras de microalgas}

Para a realização deste experimento, as amostras de microalgas foram cristalizadas com as matrizes SA, HCCA, DHB e sDHB, conforme descrito no item 4.2.3.4.

Foram preparados 12 "spots" sendo 3 para cada tipo de matriz. Levando-se em consideração que a concentração da microalga da mesma espécie foi mantida constante, a matriz utilizada foi a única variável. As avaliações da influência das matrizes para cada espécie de microalga foram conduzidas separadamente. As Figuras 56-60 mostram os perfis dos espectros de massas do tipo MALDI-TOF para cada espécie de microalga, respectivamente para $\mathrm{Cv}$, Csp, Dsp, Msp e Osp, cristalizadas com as diferentes matrizes estudadas.

\subsection{Chlorella vulgaris $(\mathrm{Cv})$}

Para a espécie de microalga $\mathrm{Cv}$ as matrizes contendo DHB em sua composição (DHB pura ou sDHB) produziram espectros de massas com melhor resolução e intensidade de sinal para todo o intervalo de massa analisado (4-20 kDa) como pode ser observado nas Figuras 56C e 56D. A Figura 56A mostra o perfil do espectro de massas para a Cv utilizando a matriz SA. Esta matriz produziu um espectro de massas com picos bem resolvidos na faixa de massa alta $(\mathrm{m} / \mathrm{z} 10-11 \mathrm{kDa})$ porém com baixa intensidade. Por outro lado, não foram observados picos na região de massa baixa $(4-4,5 \mathrm{kDa})$, sendo essa a única matriz a não apresentar picos nesta região. A matriz HCCA (Figura 56B) apesar de apresentar espectros com picos intensos em todo intervalo de massa analisado, foi a que apresentou pior resultado em termos de resolução. Nenhuma das matrizes utilizadas apresentaram picos com relação m/z superior a 12 $\mathrm{kDa}$. 


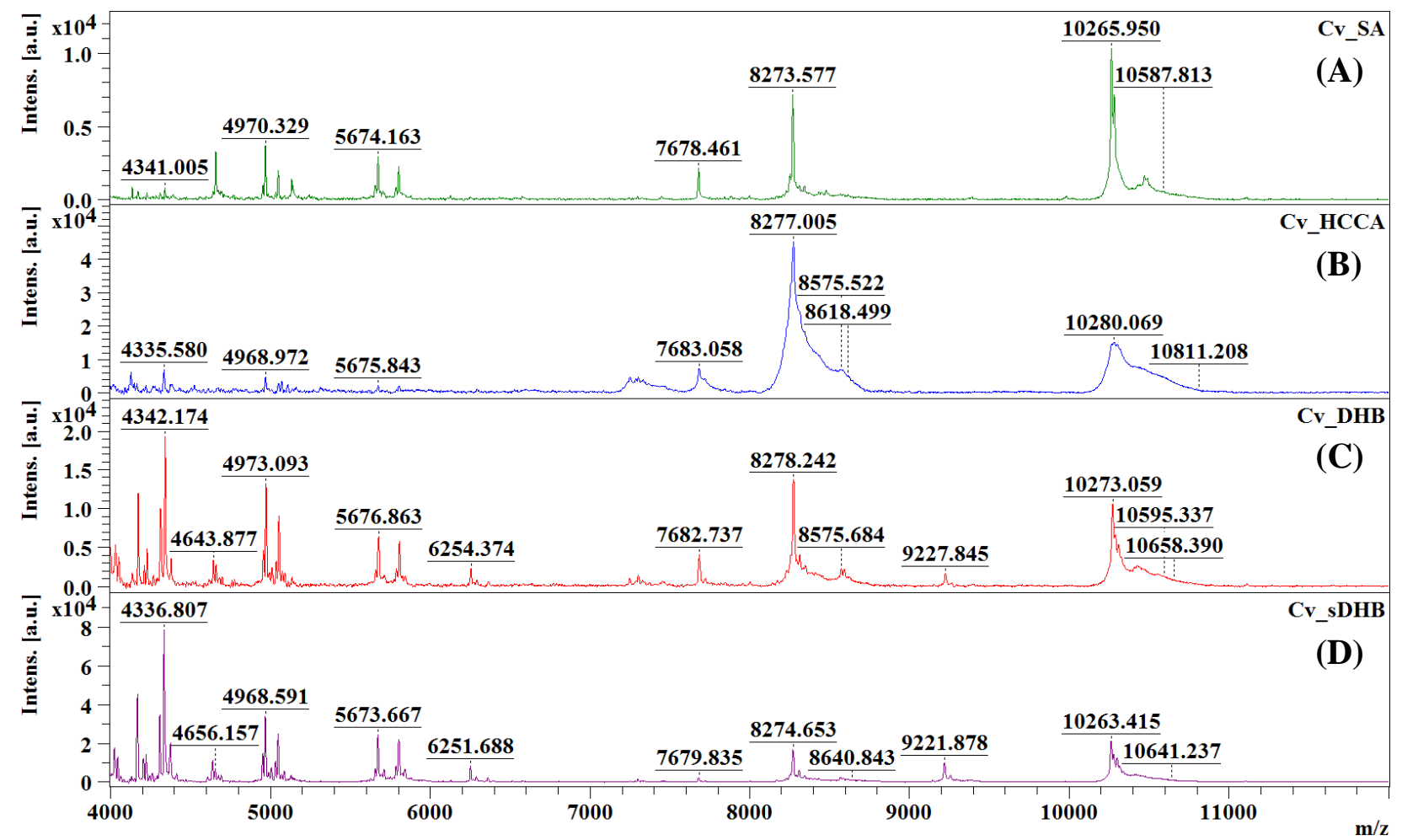

Figura 56: Perfis de espectros de massas do tipo MALDI-TOF obtidos para a microalga Cv no estudo com as diferentes matrizes SA (A), HCCA (B), DHB (C) e sDHB (D).

\subsection{Chlorella sp. (Csp)}

Para a espécie Csp, como pode ser observado na Figura 57, novamente as matrizes DHB e sDHB apresentaram espectros de massas com picos mais intensos e bem resolvidos. O uso da matriz SA apresentou os picos menos intensos, sendo a intensidade máxima alcançada em 3000 a.u., ao contrário das outras matrizes onde as intensidades alcançaram a ordem de grandeza de $10^{4}$. 


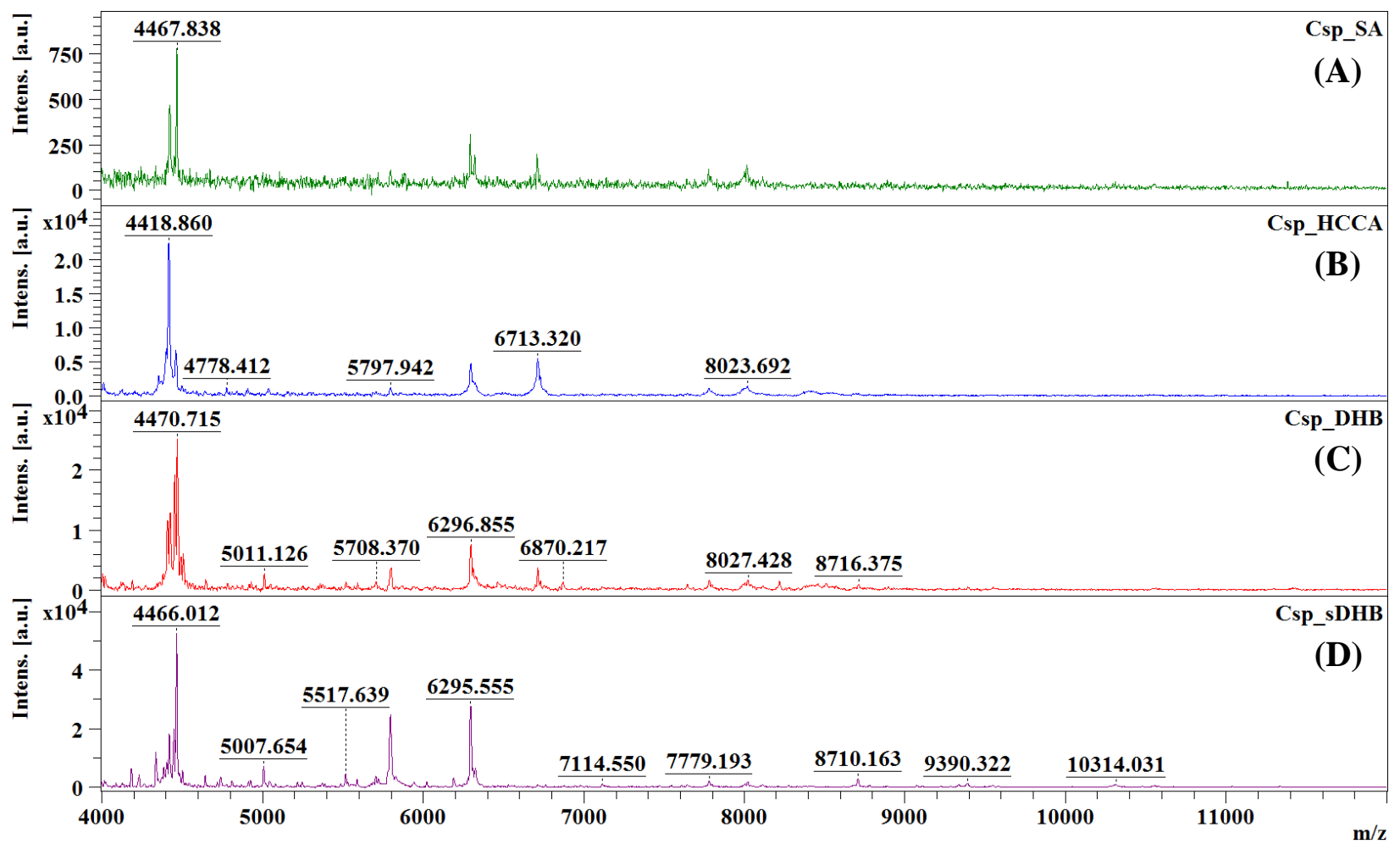

Figura 57: Perfis de espectros de massas do tipo MALDI-TOF obtidos para a microalga Csp no estudo com as diferentes matrizes SA (A), HCCA (B), DHB (C) e sDHB (D).

\subsection{Desmodesmus sp. (Dsp)}

Para a espécie Dsp, o uso da matriz SA mais uma vez mostrou picos com baixas intensidades, alcançando o máximo em 800 a.u, resultado bem inferior quando comparados à utilização da matriz HCCA, com máxima intensidade de 3000 a.u e com e as matrizes contendo DHB em sua composição com intensidades em ordem de grandeza de $10^{4}$, Figura 58A-D. Os espectros de massas da microalga Dsp não apresentaram picos de massas acima da razão $\mathrm{m} / \mathrm{z} 9 \mathrm{kDa}$ para nenhuma das 4 matrizes utilizadas. A utilização da matriz sDHB apresentou picos bastante intensos na faixa de massa 4-5 $\mathrm{kDa}$, além de dois picos também bastante intensos na faixa de massa de 5,7-6,4 kDa. Estes últimos não foram observados com o uso das outras matrizes. 


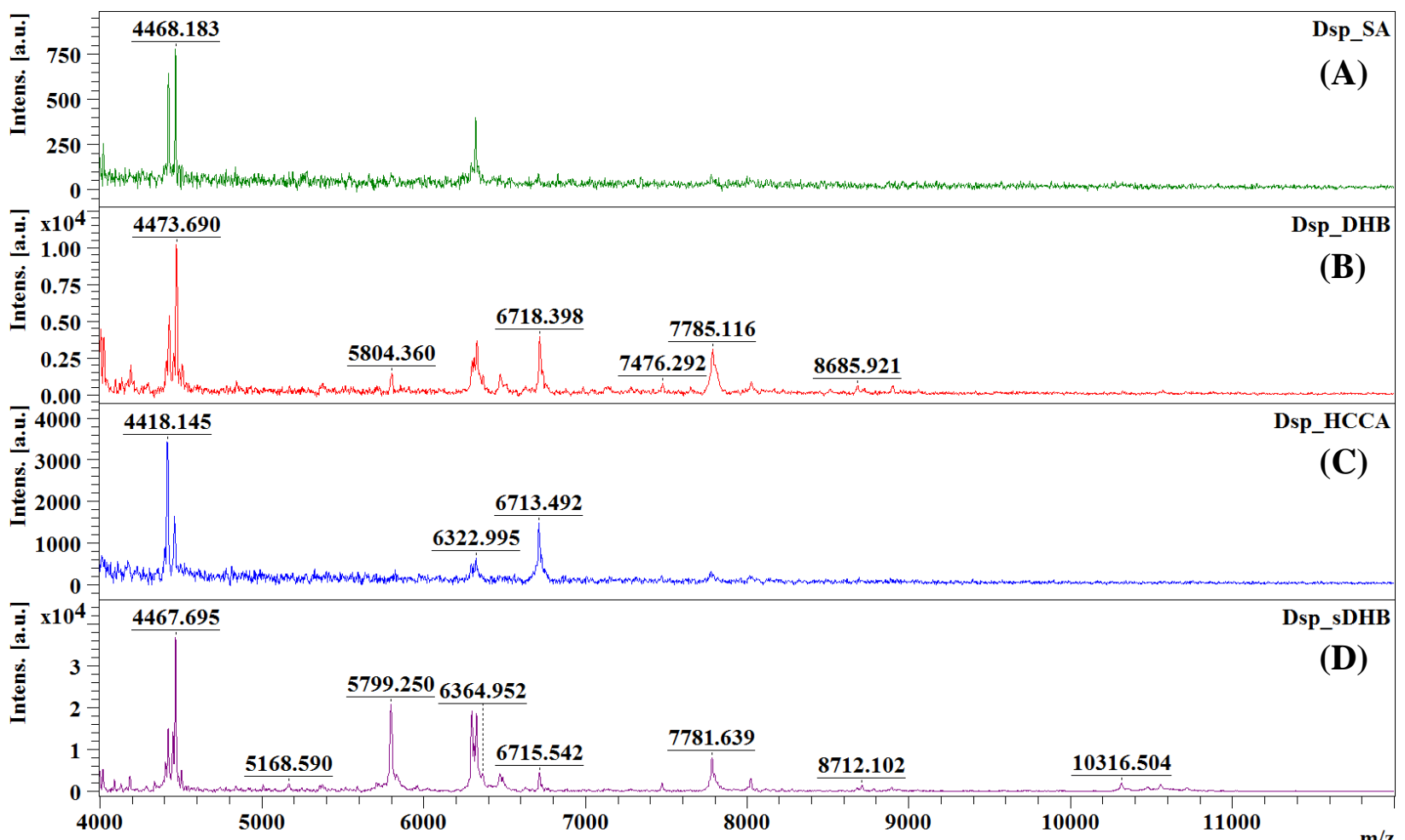

Figura 58: Perfis de espectros de massas do tipo MALDI-TOF obtidos para a microalga Dsp no estudo com as diferentes matrizes SA (A), HCCA (B), DHB (C) e sDHB (D).

\subsection{Monoraphidium sp. (Msp)}

Para a espécie Msp, o uso da matriz SA mais uma vez mostrou picos com as menores intensidades, Figura 59A. O espectro de massas observado para a matriz HCCA (Figura 59B) apresentou picos bem intensos, entretanto, de baixa resolução. Novamente, análises realizadas com as matrizes DHB e sDHB (Figuras 59C-D) mostraram espectros com boa resolução e intensidade de sinal. Além disso, estas matrizes foram as únicas que apresentaram picos na faixa de massa de 4-5 kDa. 


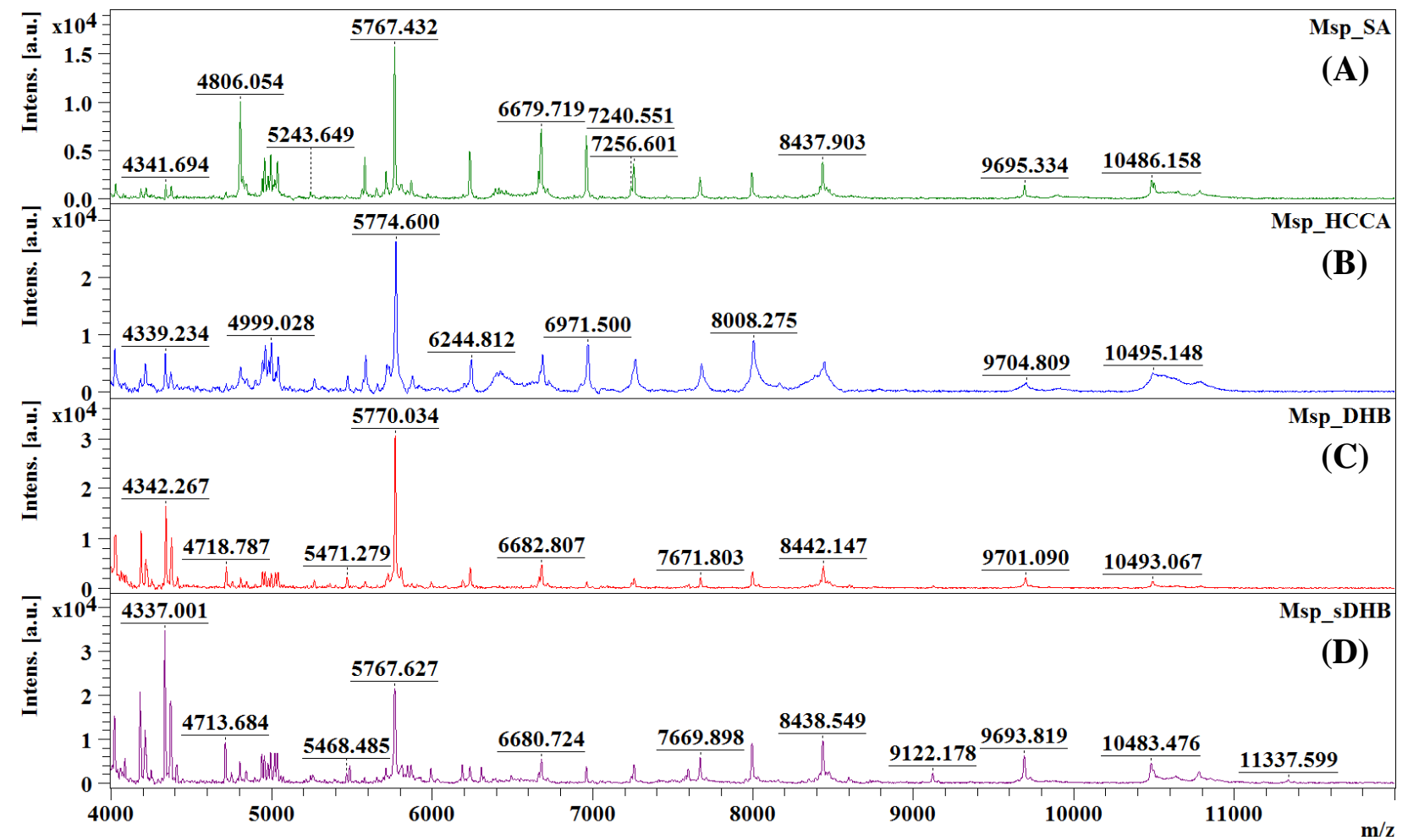

Figura 59: Perfis de espectros de massas do tipo MALDI-TOF obtidos para a microalga Msp no estudo com as diferentes matrizes SA (A), HCCA (B), DHB (C) e sDHB (D).

\subsection{Oocystis sp. (Osp)}

Para a espécie Osp, como pode ser observado na Figura 59A, novamente, o uso da matriz SA mostrou picos com baixas intensidades, sendo o máximo em 3000 a.u., bem inferiores quando comparados à utilização de outras matrizes cujas intensidades alcançaram ordem de grandeza entre $10^{4}$ e $10^{5}$. Analisando ainda os espectros de massas para esta espécie de microalga, chegam-se aos mesmos resultados obtidos para as anteriores. A matriz HCCA produz espectros de picos intensos, porém de baixa resolução, Figura 60B. Enquanto que as matrizes DHB e sDHB produzem espectros com picos intensos e mais bem resolvidos, Figuras 60C e 60D. Novamente, estas matrizes foram as únicas a apresentar picos na região de massa abaixo de 4,5 kDa. 


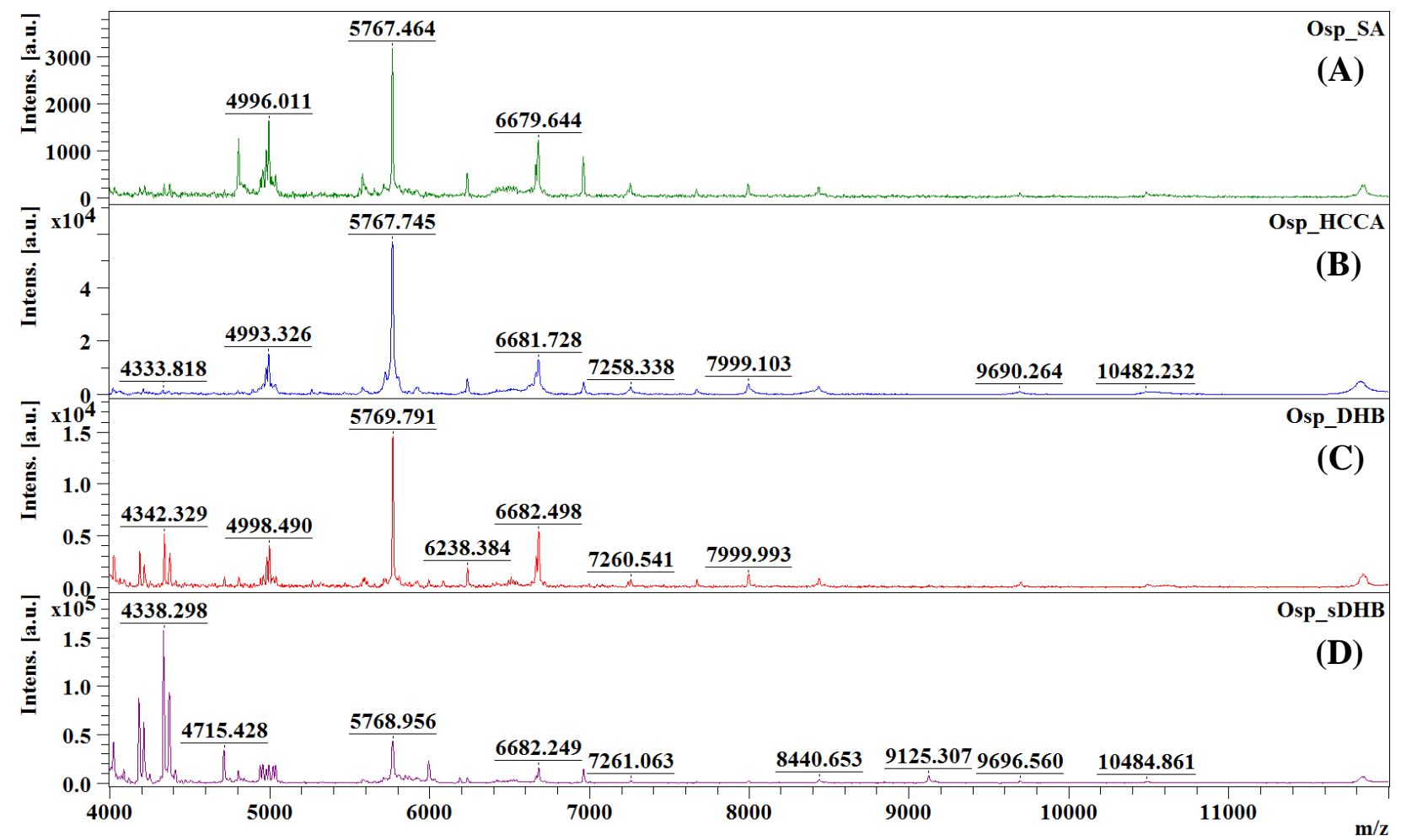

Figura 60: Perfis de espectros de massas do tipo MALDI-TOF obtidos para a microalga Osp no estudo com as diferentes matrizes SA (A), HCCA (B), DHB (C) e sDHB (D).

Nesse estudo, como foram avaliadas 4 variáveis, os parâmetros P1, P2 e P3 foram classificados com os valores de 1 a 4 , sendo o valor 4 atribuído ao melhor desempenho e o valor 1 atribuído ao pior desempenho.

A Tabela 25 confirma as observações anteriores, sendo que para as amostras $\mathrm{Cv}, \mathrm{Csp}$, Dsp e Msp, o uso da matriz sDHB se mostrou mais efetivo, obtendo somatória máxima para os parâmetros analisados. Somente para a amostra Osp, a maior somatória foi alcançada para o uso da matriz HCCA, entretanto estes valores de somatória não foram muito superiores ao obtido para o uso das matrizes DHB e sDHB. 
Tabela 25: Estudo comparativo de diferentes matrizes

\begin{tabular}{|c|c|c|c|c|c|c|c|c|c|c|c|}
\hline \multirow{2}{*}{$\begin{array}{l}\text { Espécie de } \\
\text { Microalga }\end{array}$} & \multicolumn{4}{|c|}{ Matriz } & \multicolumn{2}{|c|}{ S/R (+Int) } & \multicolumn{2}{|c|}{$\begin{array}{c}\text { Intensidade } \\
\quad(+ \text { Int })\end{array}$} & \multicolumn{2}{|c|}{$\begin{array}{c}\text { Número de } \\
\text { Íons }\end{array}$} & \multirow[t]{2}{*}{ Soma } \\
\hline & $\mathbf{S A}$ & HCCA & DHB & sDHB & P1 & Classif. & P2 & Classif. & $\mathbf{P 3}$ & Classif. & \\
\hline \multirow{4}{*}{$\mathrm{Cv}$} & + & 0 & 0 & 0 & 175 & 4 & 10321 & 1 & 52 & 1 & 6 \\
\hline & 0 & + & 0 & 0 & 37 & 1 & 45246 & 3 & 166 & 2 & 7 \\
\hline & 0 & 0 & + & 0 & 42 & 2 & 19377 & 2 & 173 & 3 & 7 \\
\hline & 0 & 0 & 0 & + & 159 & 3 & 78600 & 4 & 246 & 4 & 11 \\
\hline \multirow{4}{*}{ Csp } & + & 0 & 0 & 0 & 11 & 1 & 738 & 1 & 1 & 1 & 3 \\
\hline & 0 & + & 0 & 0 & 43 & 3 & 22400 & 2 & 61 & 2 & 7 \\
\hline & 0 & 0 & + & 0 & 30 & 2 & 25349 & 3 & 64 & 3 & 8 \\
\hline & 0 & 0 & 0 & + & 71 & 4 & 52428 & 4 & 80 & 4 & 12 \\
\hline \multirow{4}{*}{ Dsp } & + & 0 & 0 & 0 & 10 & 2 & 780 & 1 & 2 & 1 & 4 \\
\hline & 0 & + & 0 & 0 & 10 & 2 & 3448 & 2 & 9 & 2 & 6 \\
\hline & 0 & 0 & + & 0 & 16 & 3 & 10191 & 3 & 39 & 3 & 9 \\
\hline & 0 & 0 & 0 & + & 37 & 4 & 36667 & 4 & 84 & 4 & 12 \\
\hline \multirow{4}{*}{ Msp } & + & 0 & 0 & 0 & 60 & 4 & 15693 & 1 & 96 & 1 & 6 \\
\hline & 0 & + & 0 & 0 & 29 & 1 & 26262 & 2 & 192 & 4 & 7 \\
\hline & 0 & 0 & + & 0 & 46 & 2 & 30534 & 3 & 186 & 2 & 7 \\
\hline & 0 & 0 & 0 & + & 52 & 3 & 34722 & 4 & 153 & 3 & 10 \\
\hline \multirow{4}{*}{ Osp } & + & 0 & 0 & 0 & 42 & 1 & 3175 & 1 & 8 & 1 & 3 \\
\hline & 0 & + & 0 & 0 & 97 & 4 & 57156 & 3 & 161 & 4 & 11 \\
\hline & 0 & 0 & + & 0 & 64 & 3 & 14646 & 2 & 61 & 2 & 7 \\
\hline & 0 & 0 & 0 & + & 171 & 2 & 157590 & 4 & 155 & 3 & 9 \\
\hline
\end{tabular}

O único trabalho analisando proteínas de microalga com a técnica MALDI encontrado na literatura é o de Murugaiyan e colaboradores (2012) que utilizaram a matriz HCCA para analisar proteínas extraídas com AF 70\% e ACN (50:50, v/v) das microalgas dos gêneros Prototheca e Chlorella. Para as duas espécies de Chlorella estudadas (Chlorella protethocoides e Chlorella ellipsoidea), não foram obtidos íons com razão massa/carga superiores a $14 \mathrm{kDa}$, resultados semelhantes aos obtidos nos nossos estudos.

McDaniel e Bullman (2013) estudaram a utilização de diferentes matrizes como SA, HCCA, DHB, sDHB, MSA (ácido 5-Metoxisalicílico), DHAP (5-Dihidroxiacetofenona) e DAN (1,5-Diaminonaftaleno), além da combinação de sDHB e DAN em diversas amostras comerciais de proteínas. As matrizes que se mostraram mais efetivas foram sDHB, DHB e MSA, sendo que a matriz sDHB apresentou resultado superior. Este resultado também corrobora com os resultados obtidos nesse trabalho.

A grande desvantagem no uso de matrizes contendo DHB em sua composição é que ela leva a formação de um anel de cristais nas bordas do "spot", Figura 61C-D, fazendo com 
que a coleta de dados seja dificultada, especialmente em modos automatizados de aquisição de espectros. Já para o uso das matrizes SA e HCCA (Figuras 61A e 61B), é observada uma distribuição mais homogênea em todo o "spot".
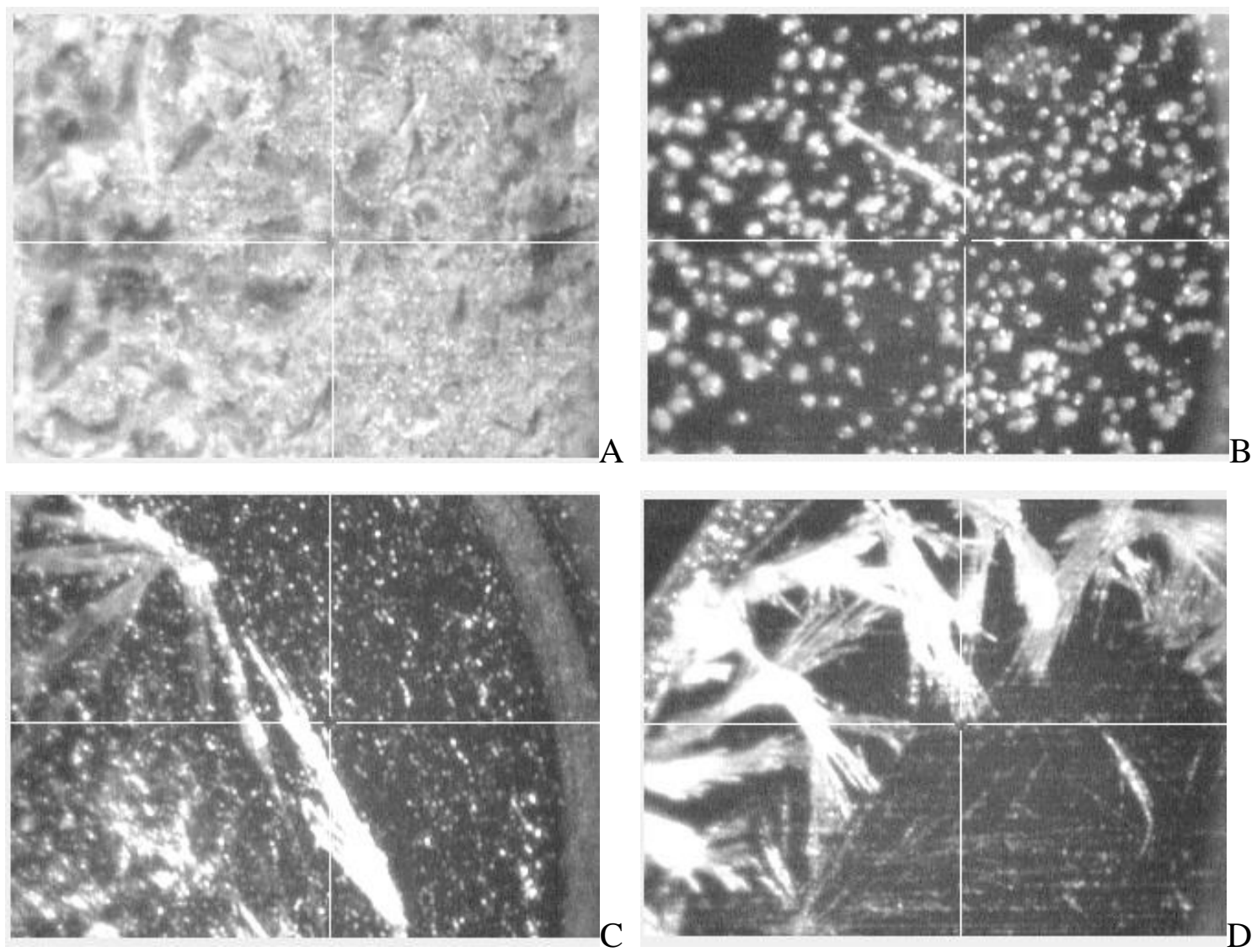

Figura 61: Distribuição das matrizes SA (A), HCCA (B), DHB (C) e sDHB (D) nos "spots".

Mesmo apresentando essa dificuldade devido à heterogeneidade em sua distribuição no "spot", a matriz sDHB apresentou os melhores resultados. Entretanto, segundo protocolo da Bruker, a matriz DHB é preparada com concentração de $20 \mathrm{mg} / \mathrm{mL}$ e a matriz sDHB, que contém 90\% de DHB em sua composição é preparada com concentração de $45 \mathrm{mg} / \mathrm{mL}$ de DHB, gerando então a dúvida se a sDHB foi mais efetiva pela maior concentração de DHB ou se a mistura é a melhor para as amostras de microalgas. Dessa forma, foi realizado um teste com as concentrações padrões de DHB (20 mg/mL), sDHB (50 mg/mL) e uma solução de DHB concentrada a $45 \mathrm{mg} / \mathrm{mL}$. 


\subsubsection{Estudo da concentração da matriz DHB}

\subsubsection{Calibração}

O calibrante foi preparado conforme descrito no item 4.2.3.3. As calibrações foram feitas utilizando o calibrante e a placa "polished". Os parâmetros de análise foram mantidos constantes nos seguintes valores: modo linear, IS $125 \mathrm{kV}$, IS $23 \mathrm{kV}$, PIE 100ns, abertura das lentes de $7 \mathrm{kV}$, número de "shots" de 10000, potência do laser de 95\%. E as matrizes utilizadas foram DHB20, DHB45 e sDHB.

Os desvios padrões da qualidade da calibração observados para DHB20, DHB45 e sDHB foram 137,51; 90,73 e 65,48 ppm; respectivamente. Pode-se observar que o menor desvio foi obtido utilizando a matriz sDHB.

\subsubsection{Análises das amostras de microalgas}

As amostras de microalgas foram analisadas utilizando as matrizes sDHB, DHB20 e DHB45, preparadas conforme item 4.2.3.4. Os espectros foram obtidos utilizando a placa "polished", e os parâmetros de análise foram: modo linear, $\mathrm{IS}_{1} 25 \mathrm{kV}, \mathrm{IS}_{2} 23 \mathrm{kV}$, PIE 100ns, abertura das lentes de $7 \mathrm{kV}$, número de "shots" de 10000, potência do laser de 95\%. Os espectros podem ser visto na Figura 62-66, respectivamente para as espécies Cv, Csp, Dsp, Msp e Osp. 


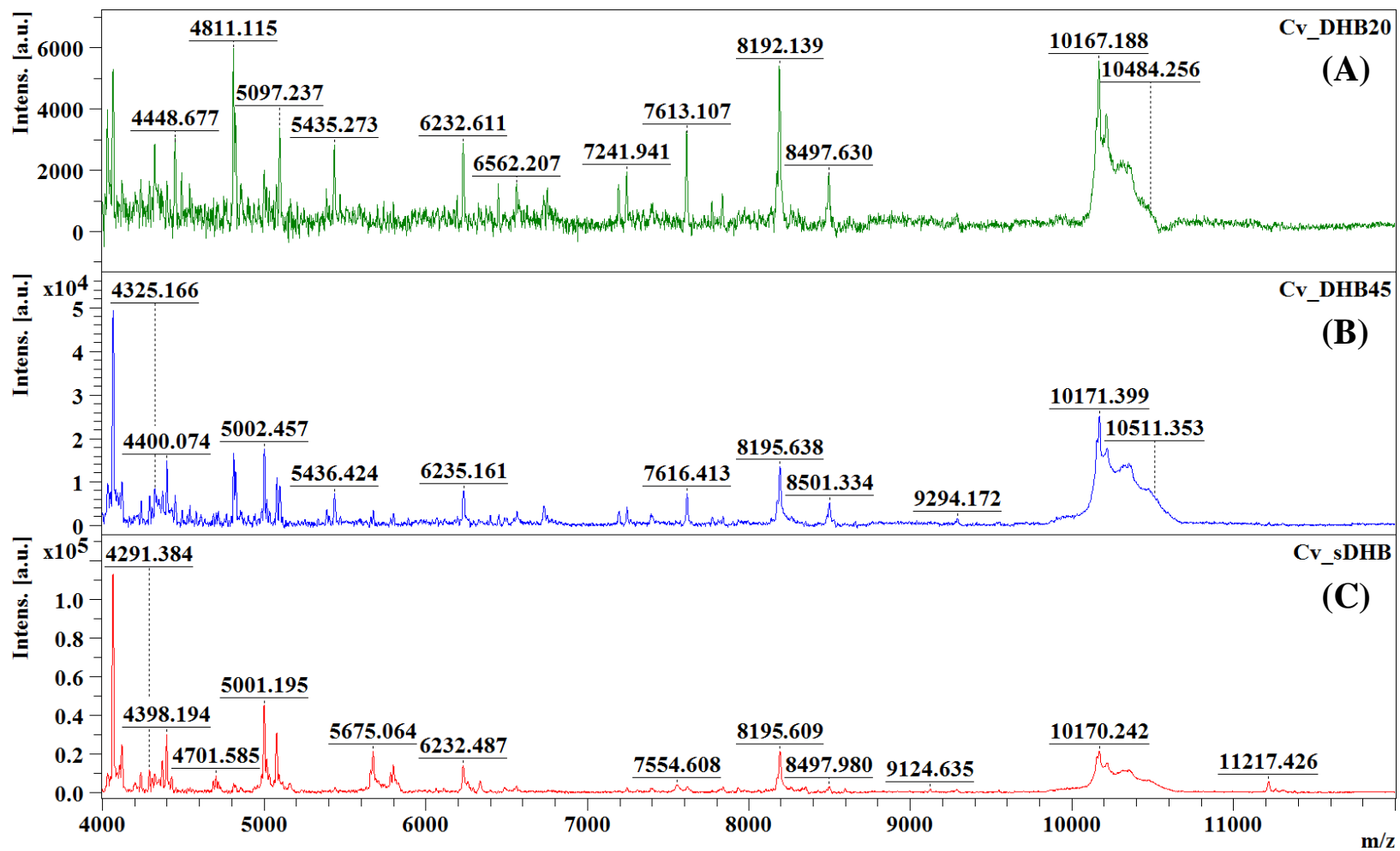

Figura 62: Perfis de espectros de massas do tipo MALDI-TOF obtidos no estudo dos diferentes teores de DHB em diferentes matrizes DHB20 (A), DHB45 (B) e sDHB (C) para a microalga Cv.

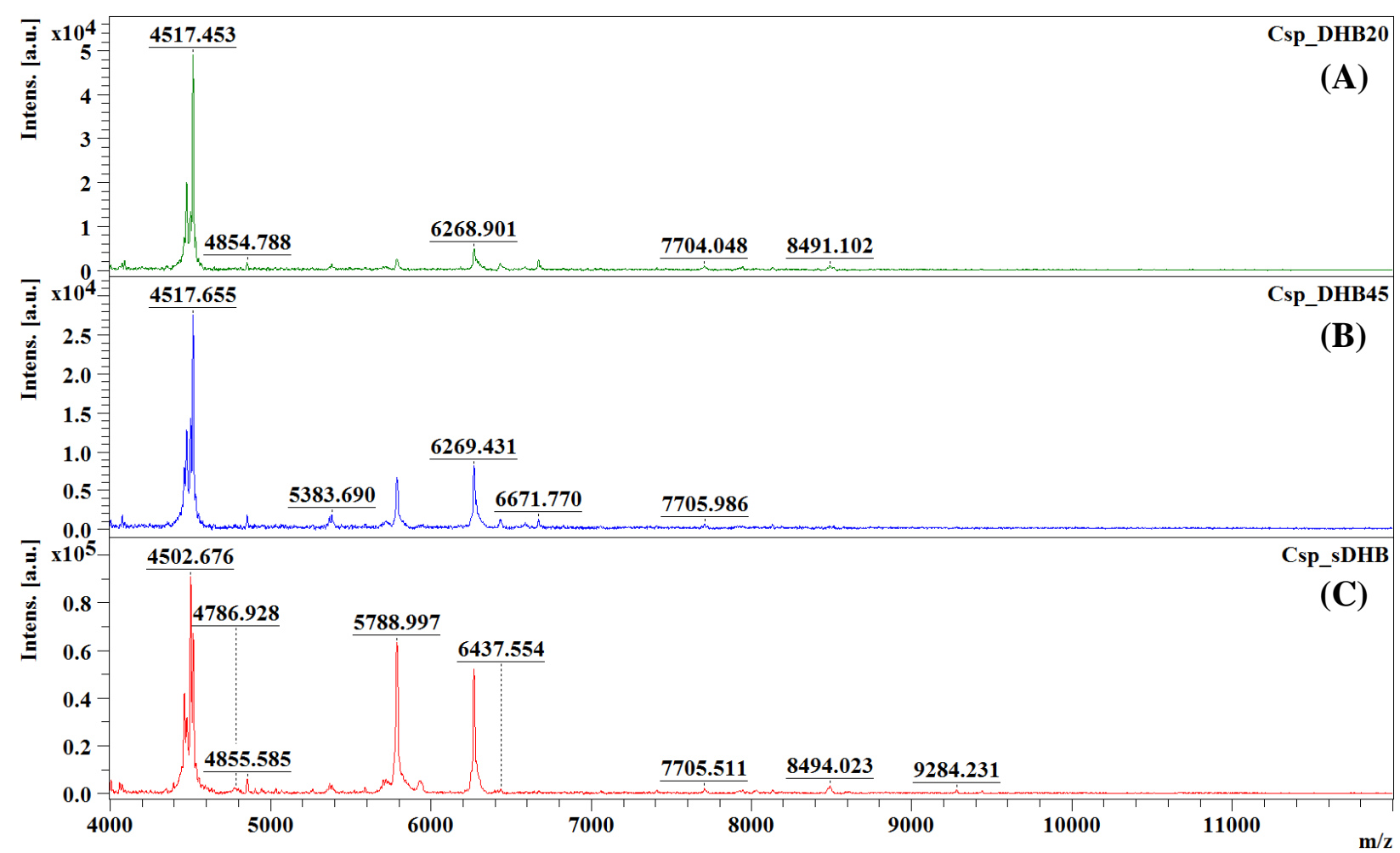

Figura 63: Perfis de espectros de massas do tipo MALDI-TOF obtidos no estudo dos diferentes teores de DHB em diferentes matrizes DHB20 (A), DHB45 (B) e sDHB (C) para a microalga Csp. 


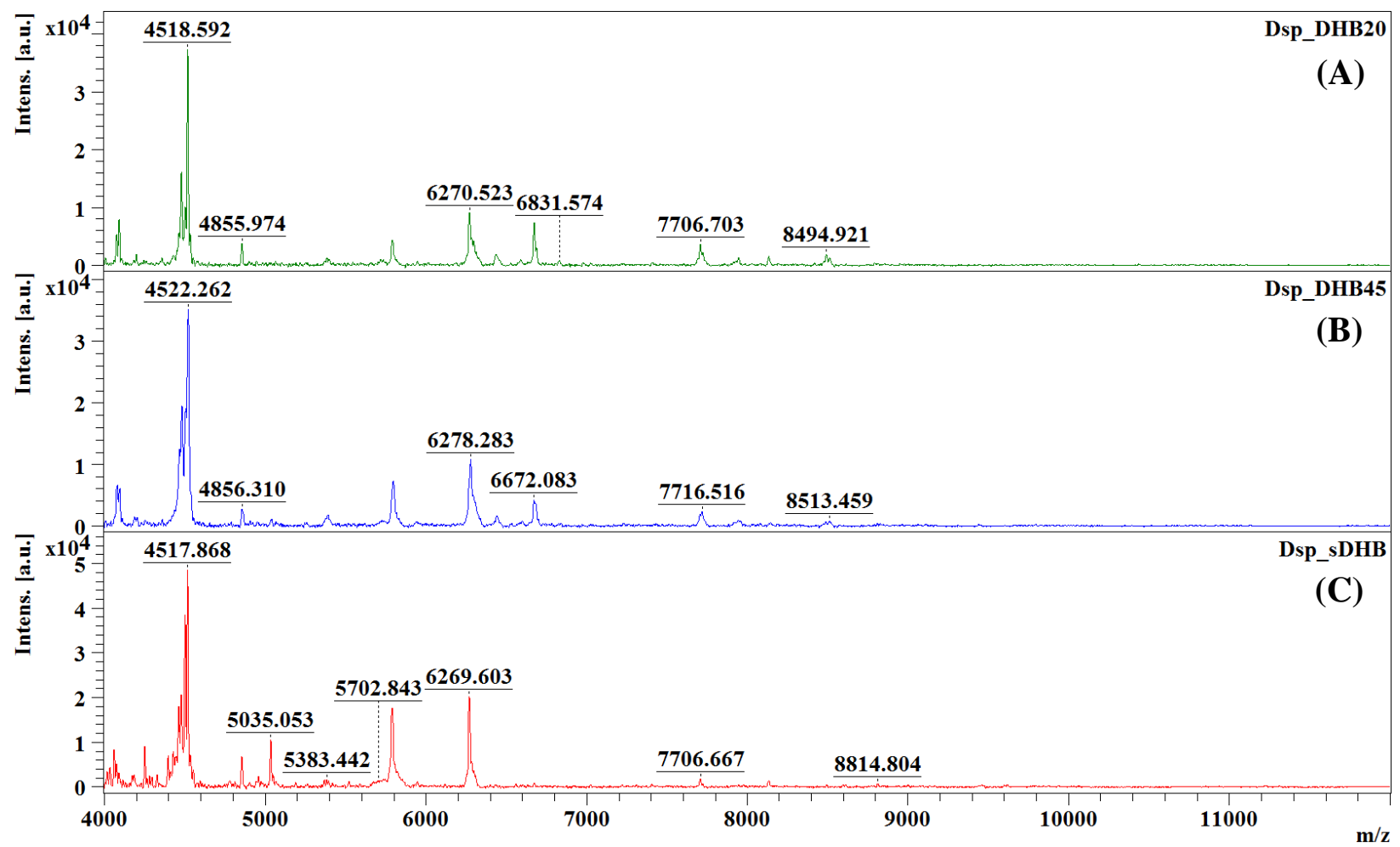

Figura 64: Perfis de espectros de massas do tipo MALDI-TOF obtidos no estudo dos diferentes teores de DHB em diferentes matrizes DHB20 (A), DHB45 (B) e sDHB (C) para a microalga Dsp.

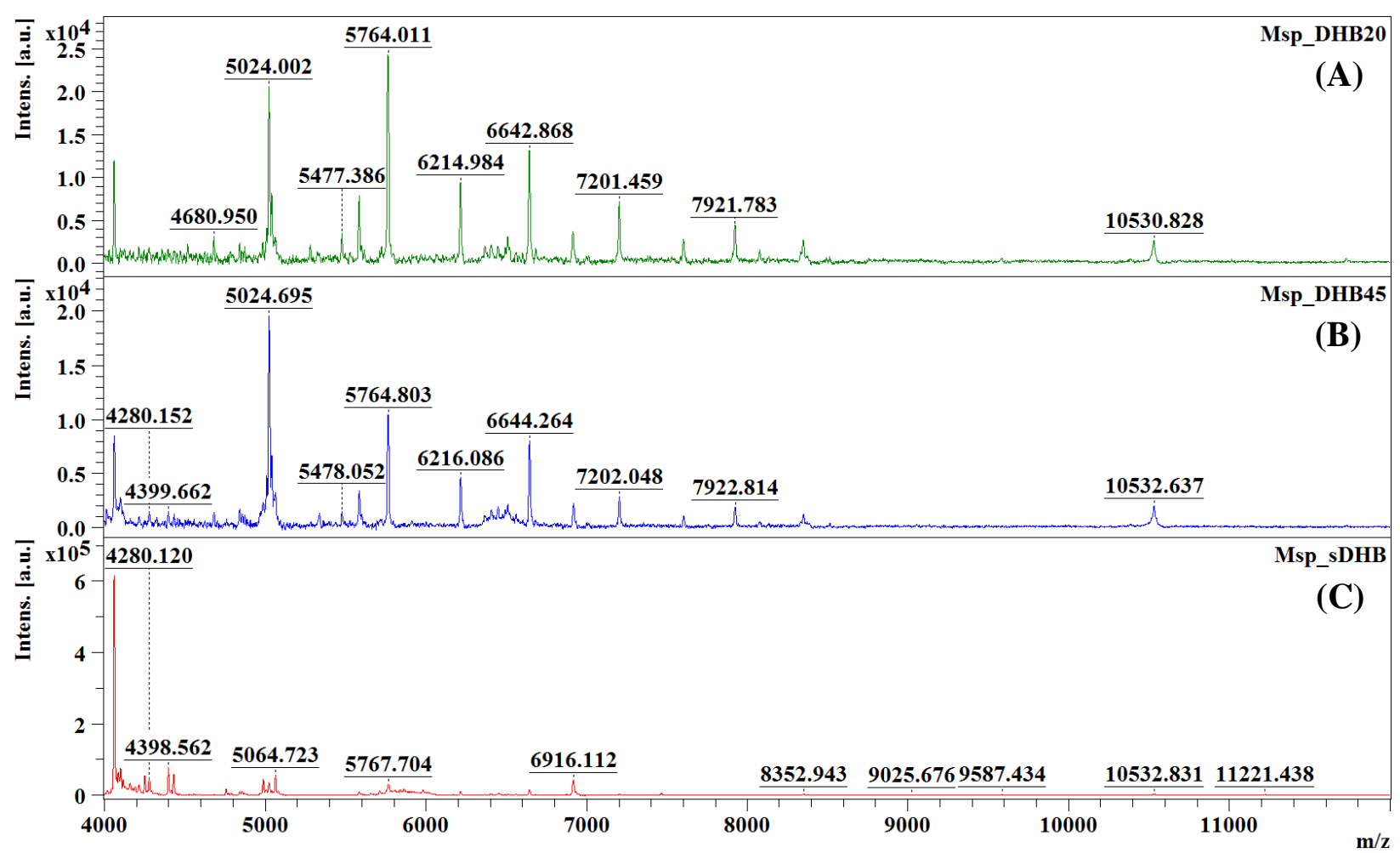

Figura 65: Perfis de espectros de massas do tipo MALDI-TOF obtidos no estudo dos diferentes teores de DHB em diferentes matrizes DHB20 (A), DHB45 (B) e sDHB (C) para a microalga Msp. 


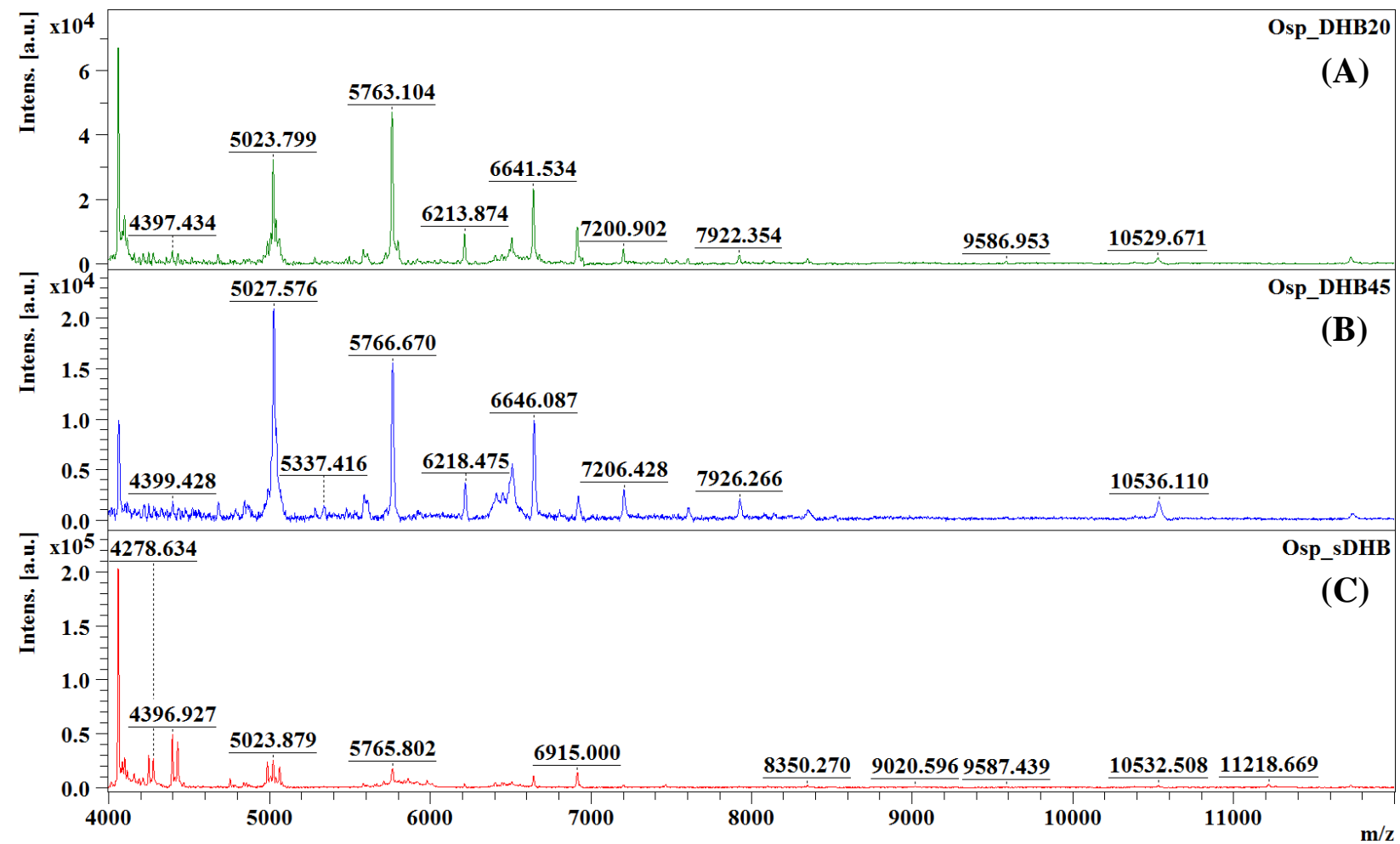

Figura 66: Perfis de espectros de massas do tipo MALDI-TOF obtidos no estudo dos diferentes teores de DHB em diferentes matrizes DHB20 (A), DHB45 (B) e sDHB (C) para a microalga Osp.

Após a análise detalhada dos espectros de massas obtidos com o uso das 3 matrizes, para todas as espécies de microalgas, Figura 61 a 66, foi possível observar, visualmente, que a matriz sDHB ainda produziu os melhores resultados, ou seja, picos mais intensos e bem resolvidos. Para uma análise mais detalhada, os parâmetros P1, P2 e P3, observados na Tabela 26, foram analisados. 
Tabela 26: Estudo comparativo da concentração de DHB na matriz.

\begin{tabular}{|c|c|c|c|c|c|c|c|c|c|c|}
\hline \multirow{2}{*}{$\begin{array}{l}\text { Espécie de } \\
\text { Microalga }\end{array}$} & \multicolumn{3}{|c|}{ Matriz } & \multicolumn{2}{|c|}{$\mathrm{S} / \mathrm{R}$ (+Int) } & \multicolumn{2}{|c|}{$\begin{array}{c}\text { Intensidade } \\
(+ \text { Int })\end{array}$} & \multicolumn{2}{|c|}{$\begin{array}{c}\text { Número de } \\
\text { Íons } \\
\end{array}$} & \multirow[t]{2}{*}{ Soma } \\
\hline & DHB20 & DHB45 & SDHB & $\mathbf{P 1}$ & Classif. & $\mathbf{P 2}$ & Classif. & P3 & Classif. & \\
\hline \multirow{3}{*}{$\mathrm{Cv}$} & + & 0 & 0 & 9 & 1 & 5522 & 1 & 35 & 1 & 3 \\
\hline & 0 & + & 0 & 26 & 2 & 48376 & 2 & 57 & 2 & 6 \\
\hline & 0 & 0 & + & 100 & 3 & 110337 & 3 & 88 & 3 & 9 \\
\hline \multirow{3}{*}{ Csp } & + & 0 & 0 & 114 & 3 & 47889 & 2 & 36 & 2 & 7 \\
\hline & 0 & + & 0 & 79 & 1 & 26775 & 1 & 30 & 1 & 3 \\
\hline & 0 & 0 & + & 110 & 2 & 88980 & 3 & 49 & 3 & 8 \\
\hline \multirow{3}{*}{ Dsp } & + & 0 & 0 & 47 & 1 & 52367 & 3 & 17 & 1 & 5 \\
\hline & 0 & + & 0 & 58 & 2 & 34928 & 1 & 25 & 2 & 5 \\
\hline & 0 & 0 & + & 75 & 3 & 47926 & 2 & 47 & 3 & 8 \\
\hline \multirow{3}{*}{ Msp } & + & 0 & 0 & 23 & 1 & 23798 & 2 & 32 & 1 & 4 \\
\hline & 0 & + & 0 & 54 & 2 & 19071 & 1 & 46 & 2 & 5 \\
\hline & 0 & 0 & + & 581 & 3 & 595427 & 3 & 103 & 3 & 9 \\
\hline \multirow{3}{*}{ Osp } & + & 0 & 0 & 135 & 2 & 167794 & 2 & 77 & 2 & 6 \\
\hline & 0 & + & 0 & 26 & 1 & 15744 & 1 & 39 & 1 & 3 \\
\hline & 0 & 0 & + & 333 & 3 & 197283 & 3 & 104 & 3 & 9 \\
\hline
\end{tabular}

Uma vez mais o valor 1 foi atribuído ao pior desempenho e o valor 3 ao melhor desempenho, na avaliação dos parâmetros P1, P2 e P3. Para todas as espécies, a maior somatória dos parâmetros analisados foi obtida para a matriz sDHB, conforme observado na Tabela 26, mostrando que não é somente a concentração de DHB que influencia na aquisição dos espectros. Desta forma, determinou-se que a melhor matriz para o estudo das amostras de microalgas é a sDHB. Assim, as análises seguintes foram realizadas utilizando a matriz sDHB.

Sabendo-se da heterogeneidade da distribuição da matriz na amostra, o estudo seguinte foi verificar a influência da concentração de ácido trifluoracético (TFA) no solvente da matriz, visando melhorar o perfil dos espectros de massas.

\subsubsection{Influência da concentração de TFA no solvente da matriz SDHB}

Neste estudo foi realizado um teste com o objetivo de verificar a influência do aumento da concentração de TFA no solvente da matriz sDHB para análise de proteínas de amostras de microalgas liofilizadas. Foram usados como solvente TA50, 1TA50 e 2,5TA50, contendo 0,$1 ; 1$ e $2,5 \%$ de TFA respectivamente, preparados conforme descrito no item 
4.2.3.1. As análises do uso de cada um dos diferentes solventes da matriz foram feitas separadamente para garantir que a condição inicial das amostras fosse a mesma.

\subsubsection{Calibração}

A calibração, preparada de acordo com o item 4.2.3.3, foi conduzida sob as seguintes condições: PIE 100ns, IS $125 \mathrm{kV}, \mathrm{IS}_{2} 23 \mathrm{kV}$, abertura das lentes de $7 \mathrm{kV}$, número de "shots" de 10000, potência do laser de 95\% e modo linear.

Os desvios padrões da qualidade da calibração observados para os solventes contendo 0,1; 1 e 2,5\% de TFA (TA50, 1TA50 e 2,5TA50) foram 30,236; 39,928 e 41,506 ppm, respectivamente. Pode-se observar que mesmo para a solução de calibrantes, os desvios obtidos para os diferentes solventes utilizados são semelhantes, mas com uma pequena melhora para a menor concentração de TFA.

\subsubsection{Análises das amostras de microalgas}

As análises das amostras utilizando a matriz SDHB com os diferentes solventes (TA50, 1 TA50 e 2,5TA50), aos quais foram adicionado 0,$1 ; 1$ e $2,5 \%$ de TFA, foram conduzidas sob as seguintes condições: PIE $100 \mathrm{~ns}, \mathrm{IS}_{1} 25 \mathrm{kV}, \mathrm{IS}_{2} 23,55 \mathrm{kV}$, abertura das lentes de $7 \mathrm{kV}$, número de "shots" de 10000 e potência do laser de $95 \%$.

\subsection{Chlorella vulgaris $(\mathrm{Cv})$}

Para a espécie Cv, Figura 67, observa-se uma diminuição das intensidades dos picos, principalmente na faixa de 4-7 kDa e acima de $8 \mathrm{kDa}$, com o aumento da concentração de TFA. Por outro lado, na faixa de massa entre 7-8 kDa observa-se picos muito mais intensos com aumento da concentração de TFA. Não foram observados picos em razão massa/carga superior a $12 \mathrm{kDa}$ em nenhum dos experimentos. 


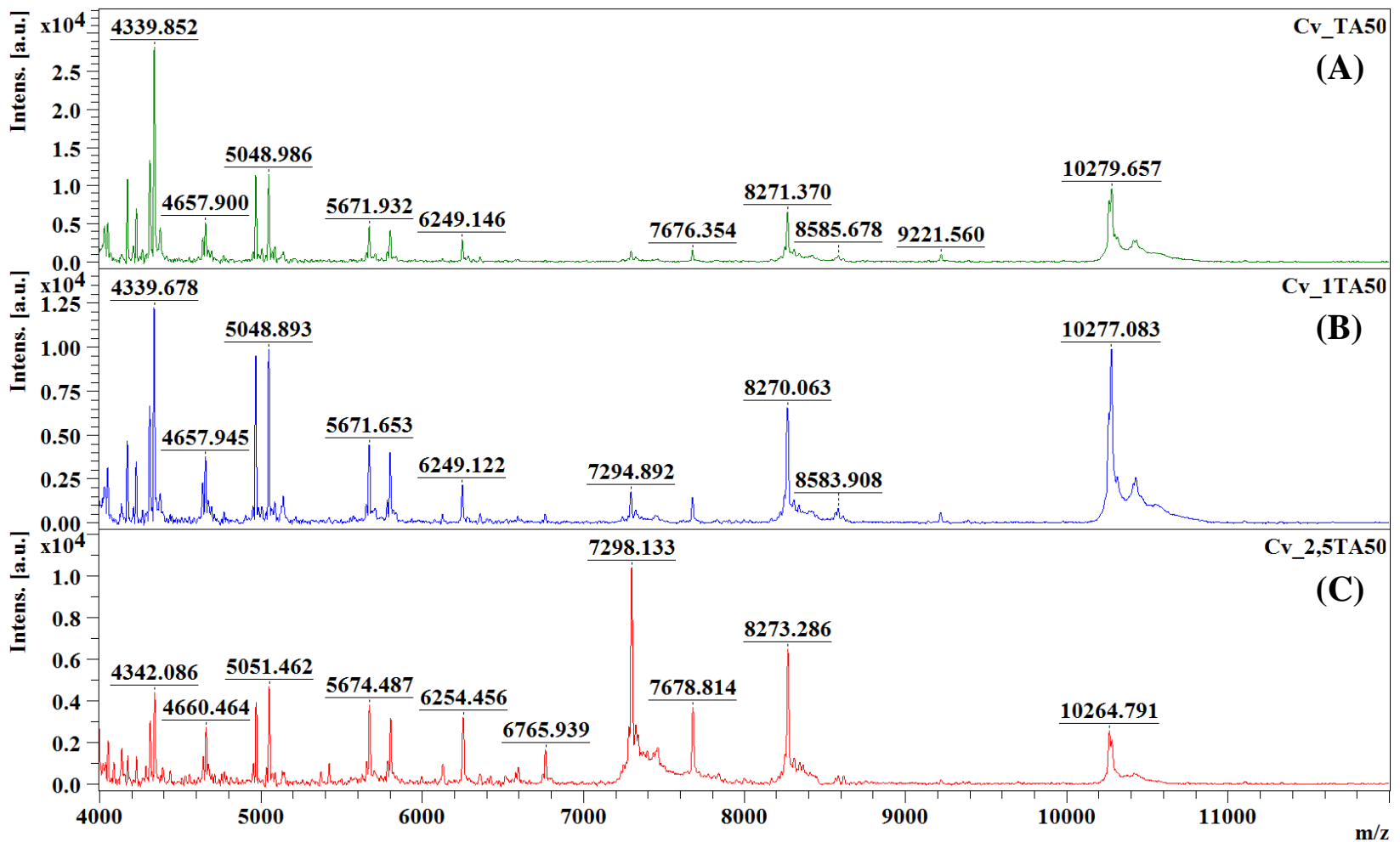

Figura 67: Perfis de espectros de massas do tipo MALDI-TOF obtido para a microalga Cv no estudo dos diferentes teores de TFA no solvente da matriz sDHB, TA50 (A), 1TA50 (B) e 2,5TA50 (C).

\subsection{Chlorella sp. (Csp)}

Para a espécie Csp, Figura 68, observa-se uma diminuição das intensidades dos picos com aumento da concentração de TFA. Não foram observados picos em razão massa/carga superior a $12 \mathrm{kDa}$ em nenhum dos experimentos. 


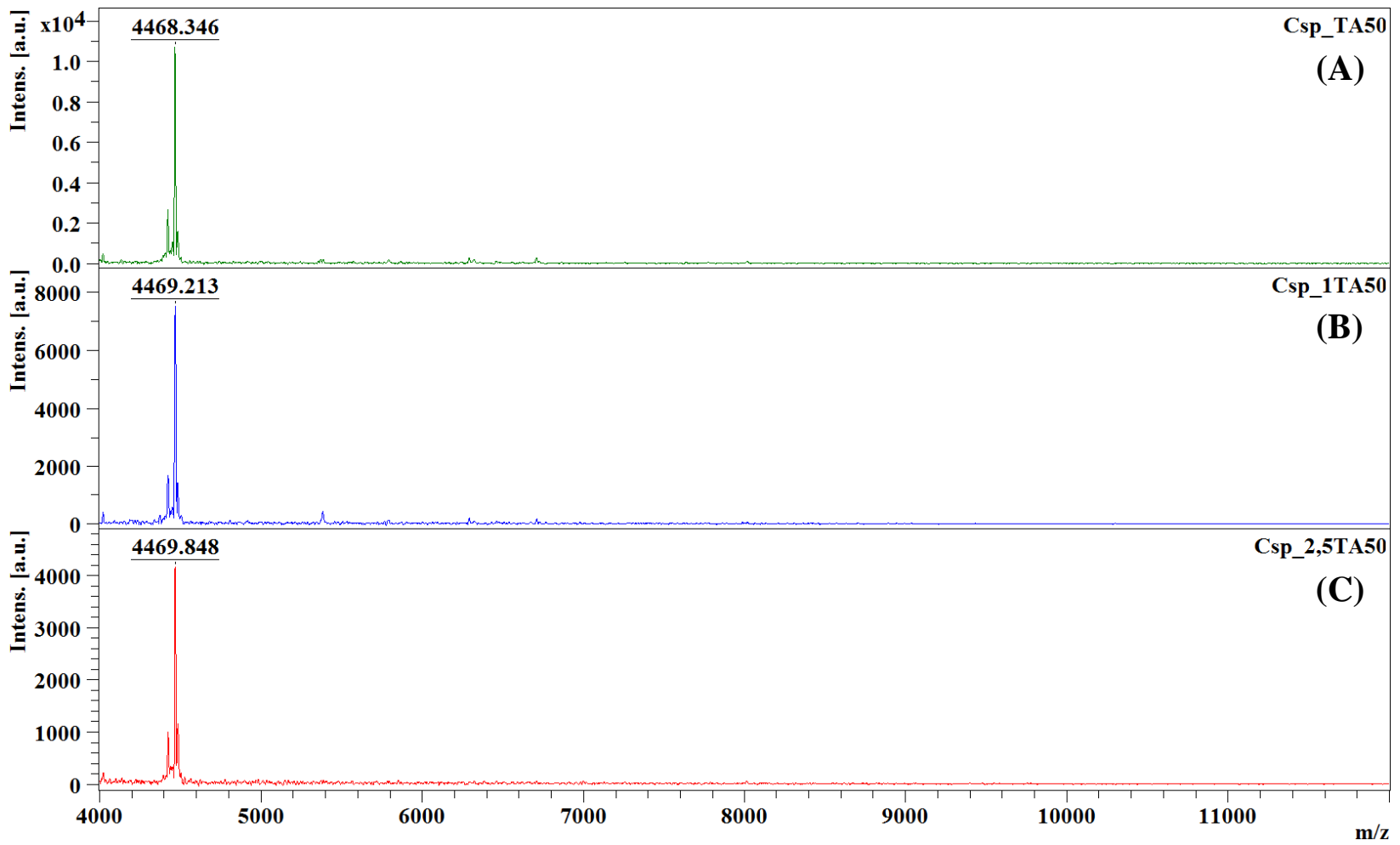

Figura 68: Perfis de espectros de massas do tipo MALDI-TOF obtido para a microalga Csp no estudo dos diferentes teores de TFA no solvente da matriz sDHB, TA50 (A), 1TA50 (B) e 2,5TA50 (C).

\subsection{Desmodesmus sp. (Dsp)}

Para a espécie Dsp quase não são observadas diferenças entre os espectros com os diferentes teores de TFA utilizados, Figura 69. Para o uso do solvente 1TA50, observa-se um discreto aumento na intensidade dos picos. Novamente, não foram observados picos em razão massa/carga superior a $12 \mathrm{kDa}$ em nenhum dos experimentos. 


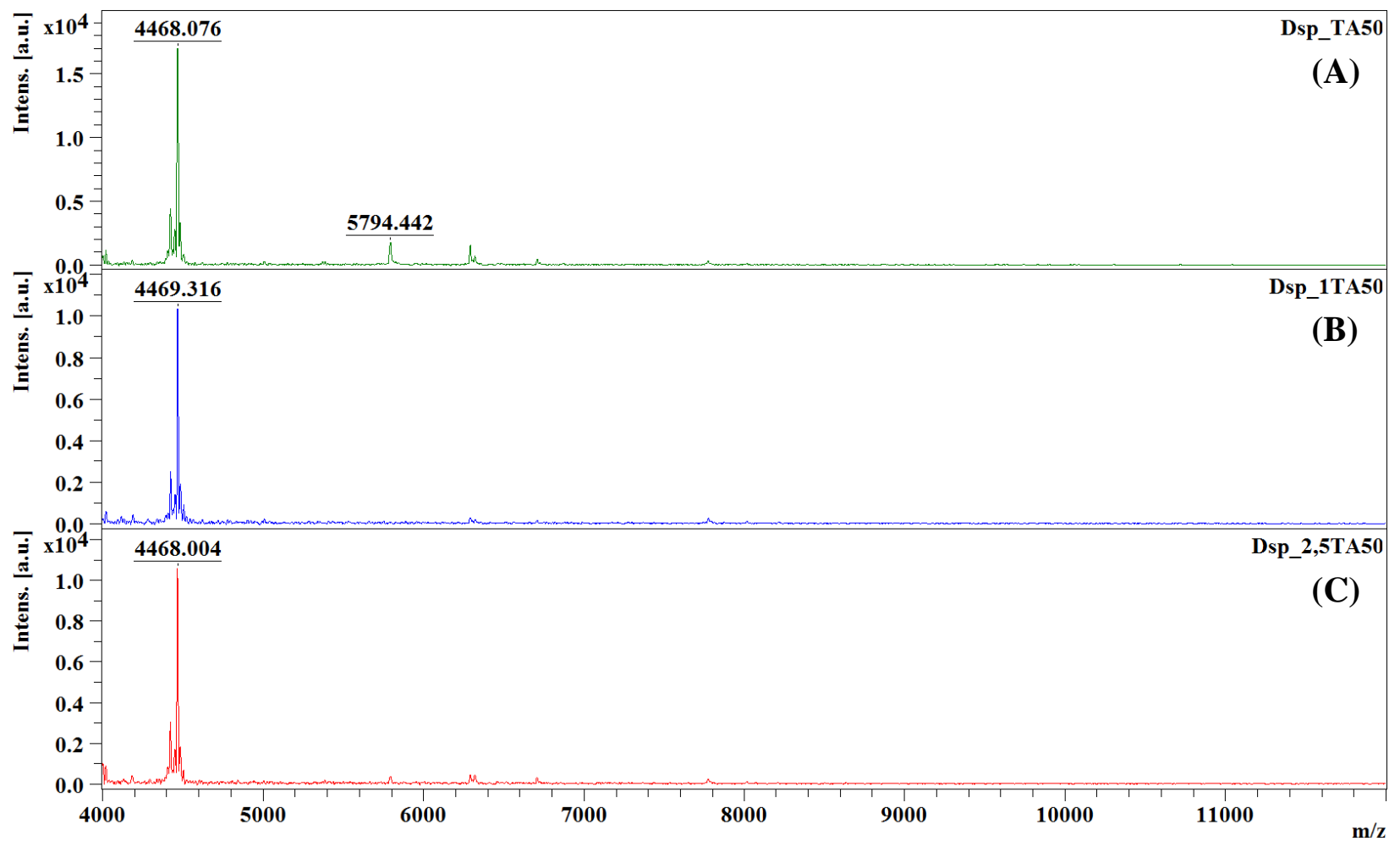

Figura 69: Perfis de espectros de massas do tipo MALDI-TOF obtido para a microalga Dsp no estudo dos diferentes teores de TFA no solvente da matriz sDHB, TA50 (A), 1TA50 (B) e 2,5TA50 (C).

\subsection{Monoraphidium sp. (Msp)}

Como observado na Figura 70, para a espécie Msp a maior intensidade foi obtida para o uso do solvente 1TA50. Intensidades bastante similares com o uso do solvente 1TA50 foram obtidas quando utilizado o solvente TA50. Não foram observados picos em razão massa/carga superior a $12 \mathrm{kDa}$ em nenhum dos experimentos. 


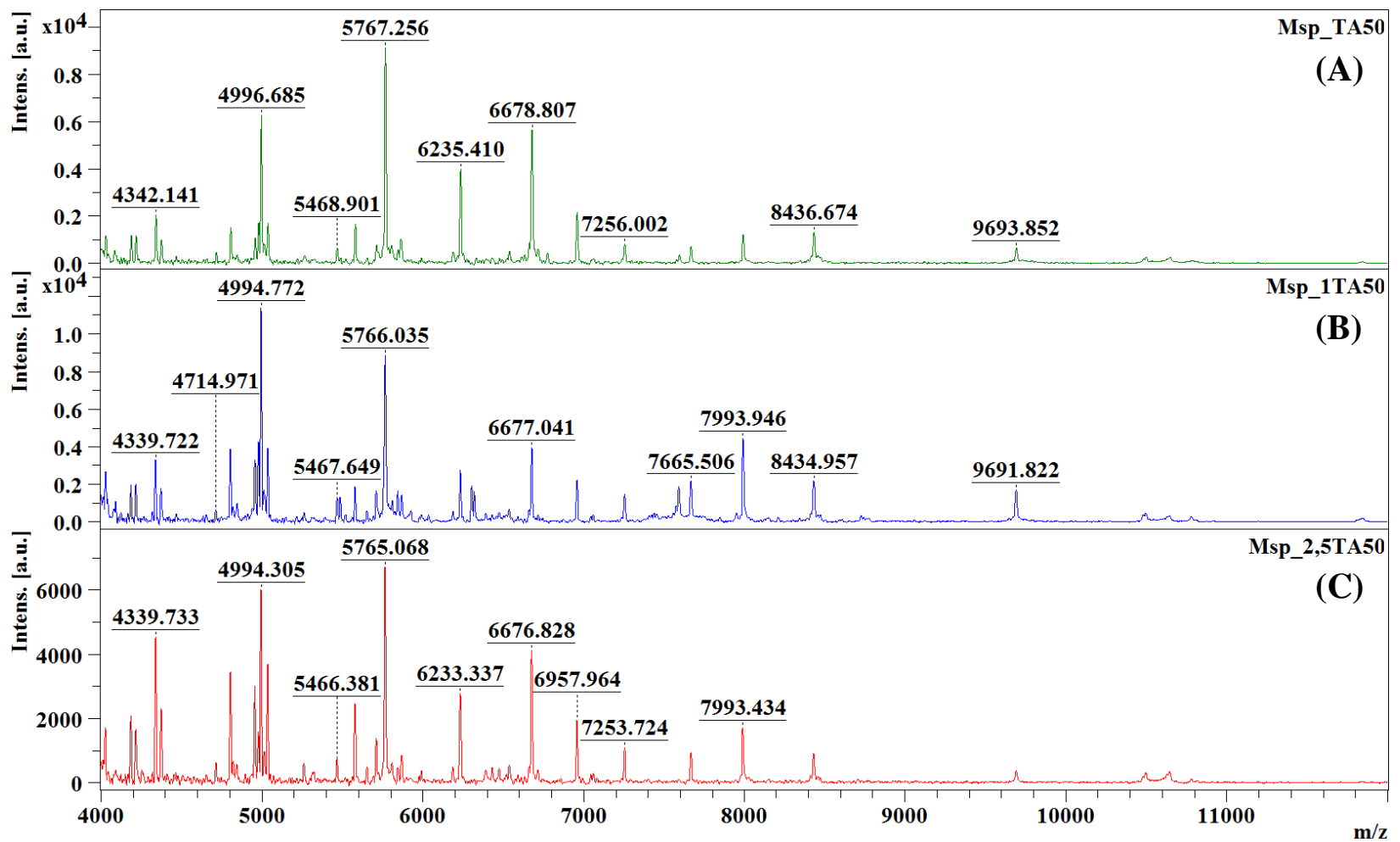

Figura 70: Perfis de espectros de massas do tipo MALDI obtido para a microalga Msp no estudo dos diferentes teores de TFA no solvente da matriz sDHB, TA50 (A), 1TA50 (B) e 2,5TA50 (C).

\subsection{Oocystis sp. (Osp)}

Para a espécie Osp, Figura 71, observa-se uma diminuição das intensidades dos picos com o aumento da concentração de TFA. Não foram observados picos em razão massa/carga superior a $12 \mathrm{kDa}$ em nenhum dos experimentos. 


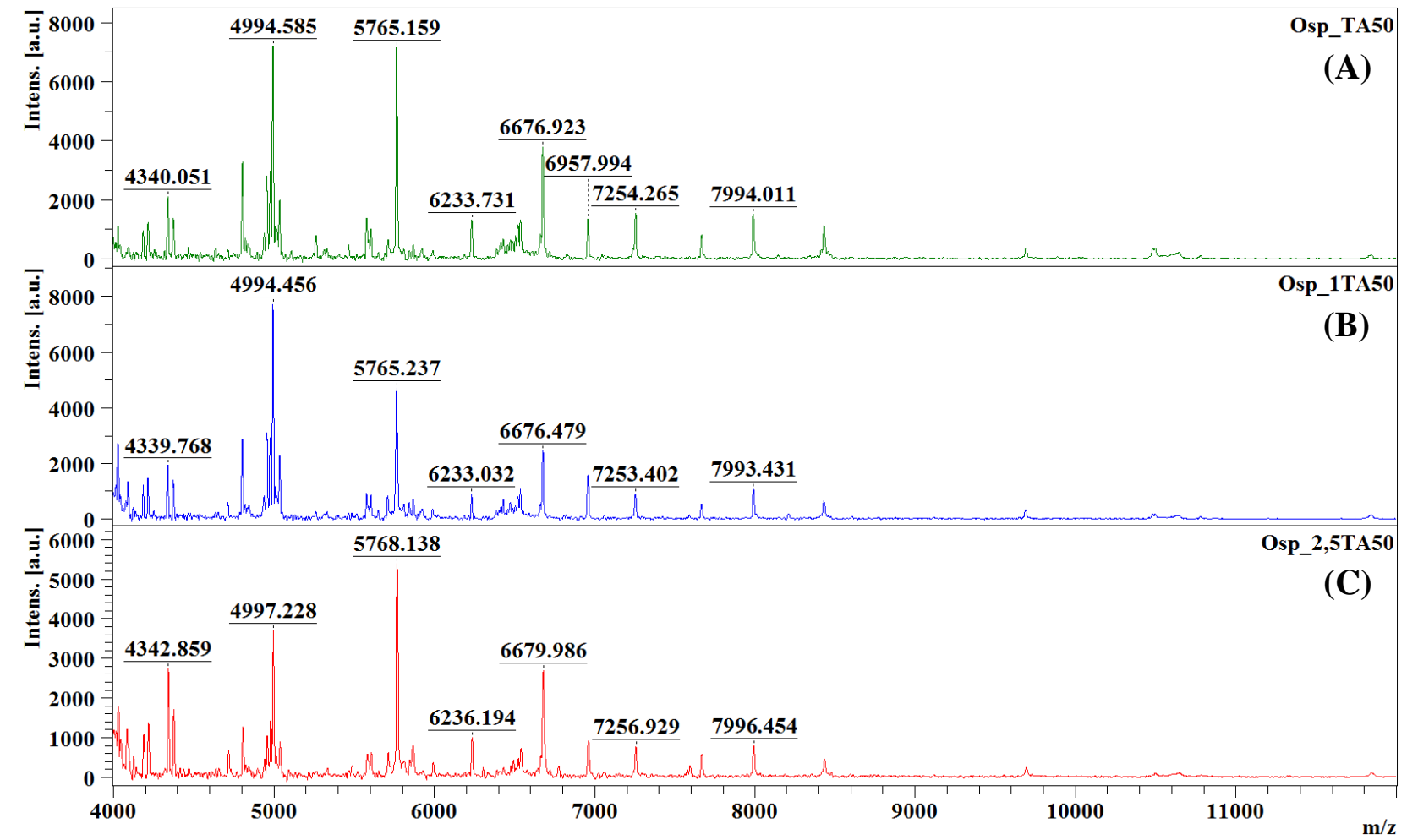

Figura 71: Perfis de espectros de massas do tipo MALDI-TOF obtido para a microalga Osp no estudo dos diferentes teores de TFA no solvente da matriz sDHB, TA50 (A), 1TA50 (B) e 2,5TA50 (C).

Como as diferenças observadas para a maioria das amostras foram bastante discretas, novamente os espectros foram processados e as 3 variáveis (3 tipos de solventes) foram avaliadas de acordo com os parâmetros P1, P2 e P3, os quais foram classificados de 1 a 3, sendo o valor 3 atribuído ao melhor desempenho e o valor 1 atribuído ao pior desempenho, Tabela 27. 
Tabela 27: Estudo comparativo do aumento do teor de TFA no solvente da matriz sDHB.

\begin{tabular}{|c|c|c|c|c|c|c|c|c|c|c|}
\hline \multirow{2}{*}{$\begin{array}{l}\text { Espécie de } \\
\text { Microalga }\end{array}$} & \multicolumn{3}{|c|}{ Solvente } & \multicolumn{2}{|c|}{ S/R (+Int) } & \multicolumn{2}{|c|}{$\begin{array}{c}\text { Intensidade } \\
(+ \text { Int })\end{array}$} & \multicolumn{2}{|c|}{$\begin{array}{c}\text { Número de } \\
\text { Íons }\end{array}$} & \multirow[t]{2}{*}{ Soma } \\
\hline & TA50 & 1TA50 & 2,5TA50 & P1 & Classif. & $\mathbf{P 2}$ & Classif. & P3 & Classif. & \\
\hline \multirow{3}{*}{$\mathrm{Cv}$} & + & 0 & 0 & 86 & 3 & 28143 & 3 & 63 & 3 & 9 \\
\hline & 0 & + & 0 & 43 & 1 & 12219 & 2 & 51 & 1 & 4 \\
\hline & 0 & 0 & + & 75 & 2 & 10383 & 1 & 57 & 2 & 5 \\
\hline \multirow{3}{*}{ Csp } & + & 0 & 0 & 112 & 3 & 10698 & 3 & 5 & 3 & 9 \\
\hline & 0 & + & 0 & 86 & 2 & 7509 & 2 & 3 & 2 & 6 \\
\hline & 0 & 0 & + & 59 & 1 & 4154 & 1 & 3 & 2 & 5 \\
\hline \multirow{3}{*}{ Dsp } & + & 0 & 0 & 120 & 3 & 16967 & 3 & 11 & 3 & 9 \\
\hline & 0 & + & 0 & 82 & 2 & 10342 & 1 & 6 & 1 & 4 \\
\hline & 0 & 0 & + & 78 & 1 & 10584 & 2 & 9 & 2 & 5 \\
\hline \multirow{3}{*}{ Msp } & + & 0 & 0 & 76 & 3 & 9105 & 2 & 30 & 2 & 7 \\
\hline & 0 & + & 0 & 52 & 2 & 11363 & 1 & 40 & 3 & 6 \\
\hline & 0 & 0 & + & 43 & 1 & 6698 & 3 & 28 & 1 & 5 \\
\hline \multirow{3}{*}{ Osp } & + & 0 & 0 & 39 & 1 & 7213 & 2 & 32 & 3 & 6 \\
\hline & 0 & + & 0 & 58 & 3 & 7699 & 3 & 31 & 2 & 8 \\
\hline & 0 & 0 & + & 51 & 2 & 5383 & 1 & 26 & 1 & 4 \\
\hline
\end{tabular}

Pode-se observar, Tabela 27, que para as microalgas Cv, Csp, Dsp e Msp o melhor solvente para a matriz sDHB é o TA50. Já para a espécie Osp, o solvente que apresentou a melhor somatória na classificação foi o 1TA50. Para todas as amostras o solvente menos eficiente foi o 2,5TA50. Dessa forma, foi mantido o uso do solvente padrão TA50 como solvente da matriz uma vez que o ganho em resultados não foi suficiente para justificar o aumento na concentração de TFA no solvente da matriz, o que geraria aumento de custos e preocupação com o descarte.

\subsubsection{Adição de isopropanol ao solvente da matriz SDHB}

McDaniel e Bullman (2013) verificaram que a adição de 15\% de isopropanol ao solvente da matriz favorece uma a cristalização mais homogênea, melhorando a coleta de dados e consequentemente os resultados.

Baseando-se nesse estudo, foi realizado um teste visando verificar a influência da adição de $15 \%$ de isopropanol no solvente da matriz sDHB utilizada na análise de proteínas em amostras de microalgas liofilizadas.

Primeiramente foi verificada a distribuição da matriz sobre a amostra, Figura 72, onde foi observado uma maior homogeneidade na distribuição da matriz no "spot", Figura 71B, 
onde houve adição de isopropanol ao solvente da matriz, quando comparado ao uso da matriz sDHB sem adição de isopropanol (Figura 72A), corroborando com dados obtidos por McDaniel e Bullman (2013).
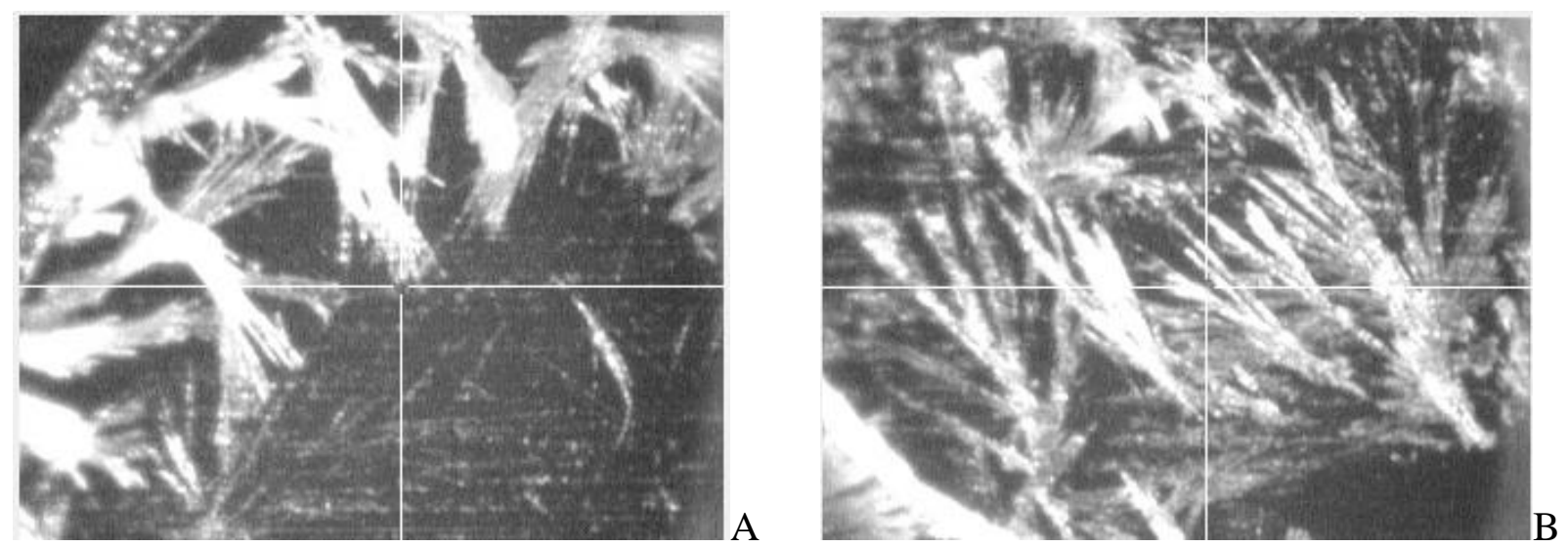

Figura 72: Distribuição da matriz sDHB no "spot", sem adição de isopropanol (A) e com adição de isopropanol (B).

\subsubsection{Calibração}

A calibração, preparada de acordo com o item 4.2.3.3, foi conduzida sob os seguintes parâmetros: PIE $100 \mathrm{~ns}, \mathrm{IS}_{1} 25 \mathrm{kV}, \mathrm{IS}_{2} 23,55 \mathrm{kV}$, abertura das lentes de $7 \mathrm{kV}$, número de "shots" de 10000 e potência do laser de $73 \%$.

Os desvios padrões da qualidade da calibração observados para o solvente da matriz com (ISOTA50) e sem a adição (TA50) de isopropanol foram 43,065 e 62,623 ppm, respectivamente. Pode-se observar que a adição de isopropanol ao solvente da matriz favoreceu a qualidade dos espectros apresentando desvio inferior quando comparado ao uso do solvente sem a adição de isopropanol.

\subsubsection{Análises das amostras de microalgas}

As análises das amostras utilizando os solventes TA50 e ISOTA50 foram conduzidas sob os seguintes parâmetros: PIE $100 \mathrm{~ns}, \mathrm{IS}_{1} 25 \mathrm{kV}, \mathrm{IS}_{2} 23 \mathrm{kV}$, abertura das lentes de $7 \mathrm{kV}$, número de "shots" de 10000 e potência do laser de $95 \%$. 


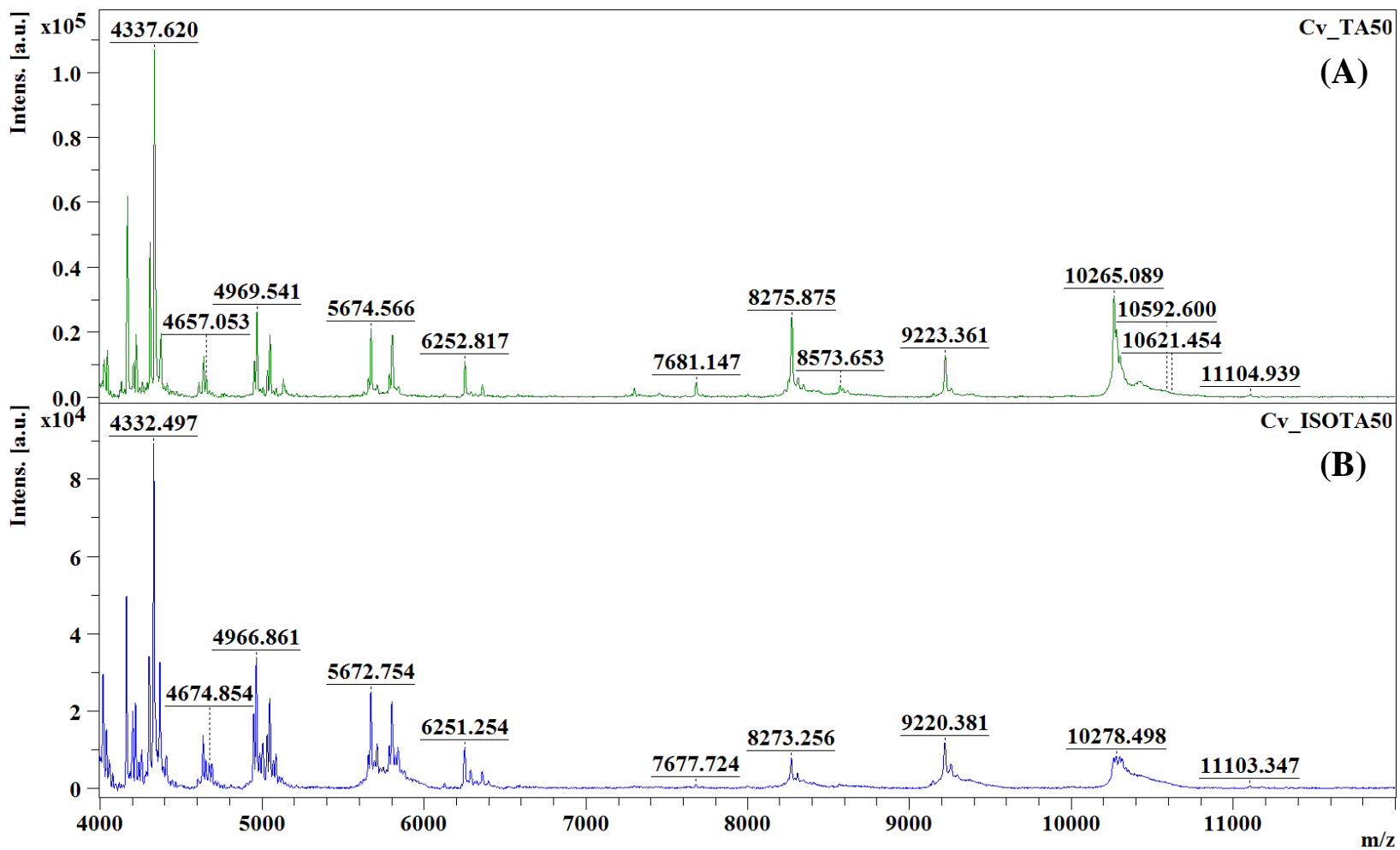

Figura 73: Comparação dos perfis dos espectros de massas do tipo MALDI-TOF utilizando os solventes TA50 (A) e ISOTA50 (B) na resuspensão da microalga Cv.

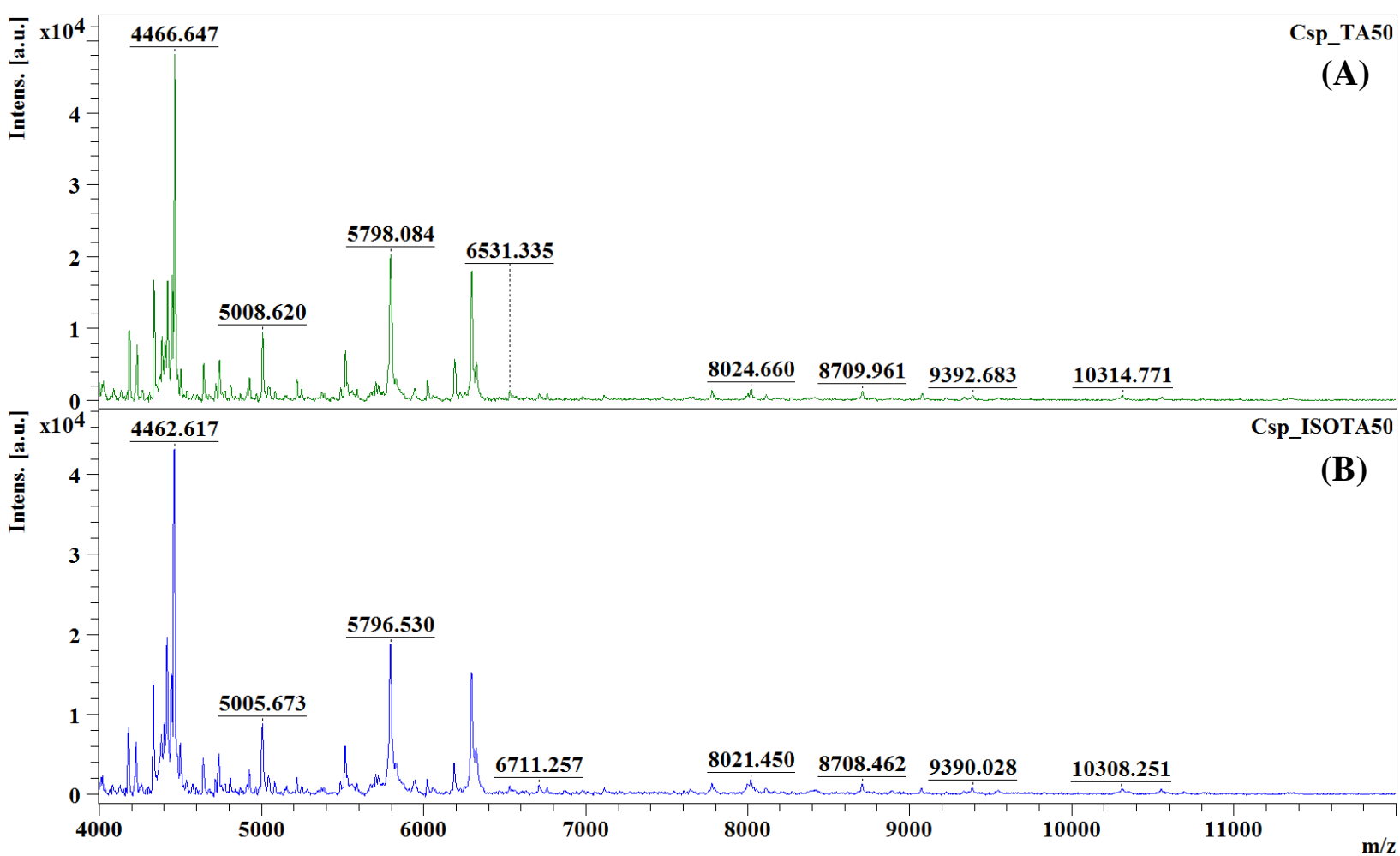

Figura 74: Comparação dos perfis dos espectros de massas do tipo MALDI-TOF utilizando os solventes TA50 (A) e ISOTA50 (B) na resuspensão da microalga Csp. 


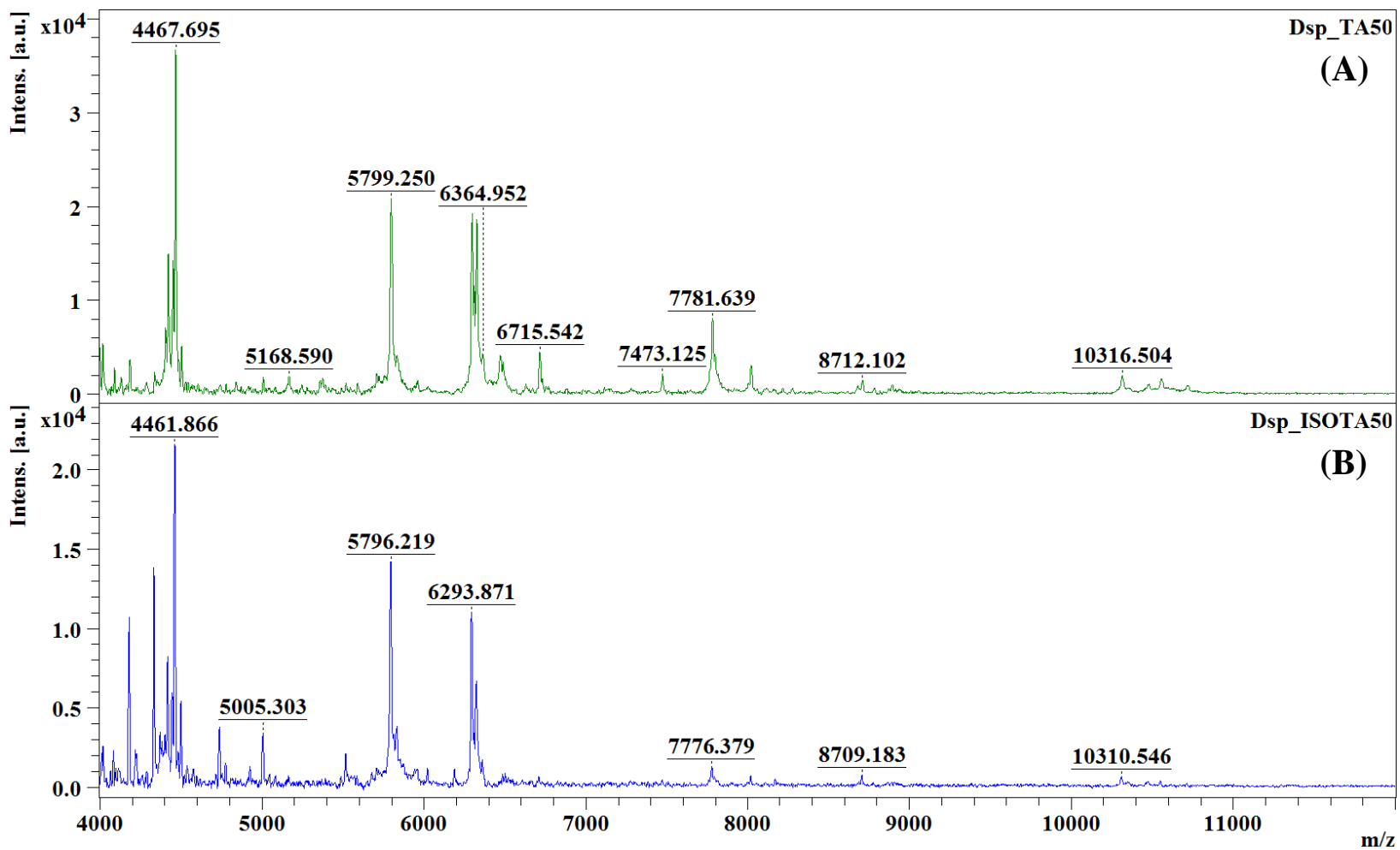

Figura 75: Comparação dos perfis dos espectros de massas do tipo MALDI-TOF utilizando os solventes TA50 (A) e ISOTA50 (B) na resuspensão da microalga Dsp.

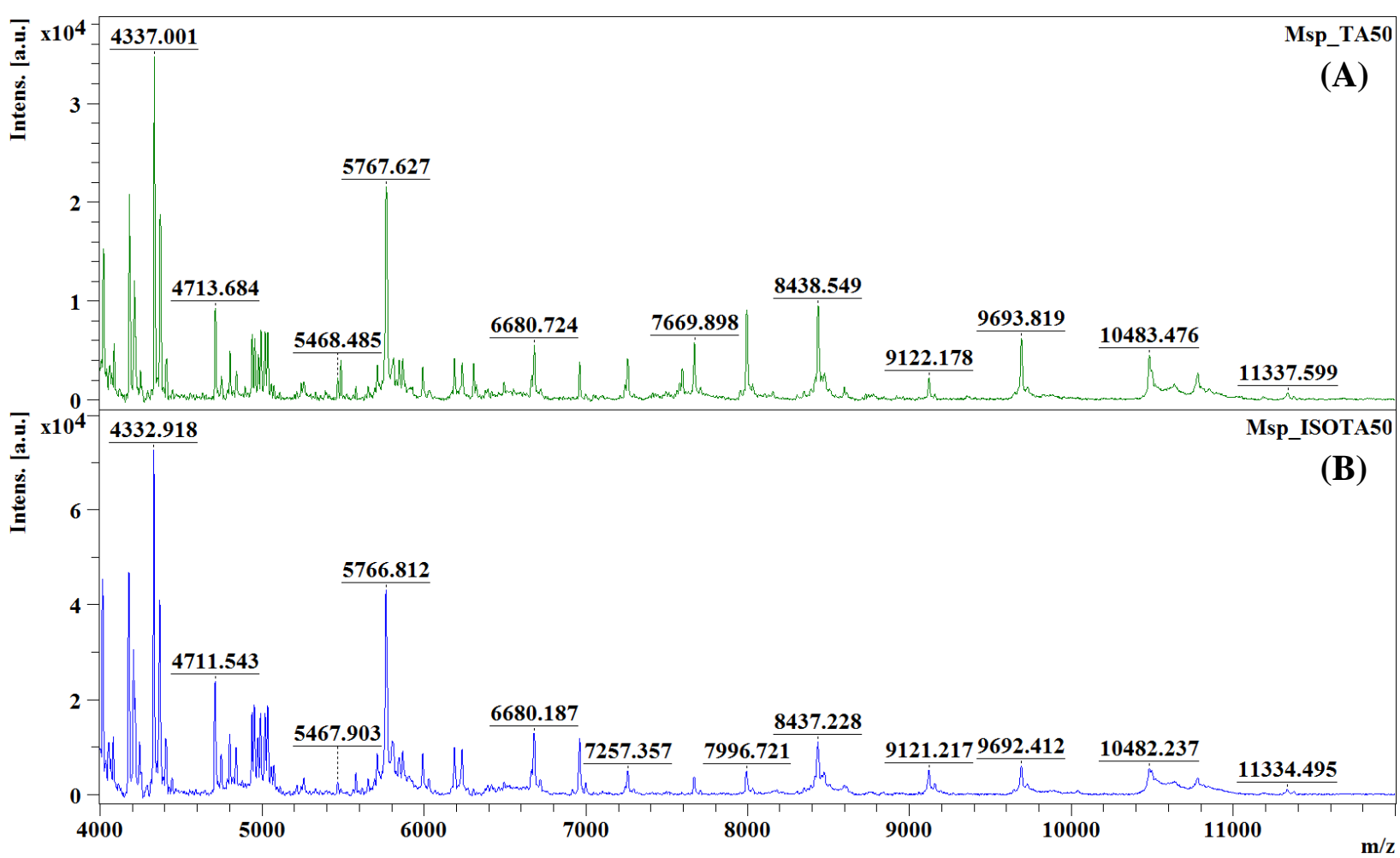

Figura 76: Comparação dos perfis dos espectros de massas do tipo MALDI-TOF utilizando os solventes TA50 (A) e ISOTA50 (B) na resuspensão da microalga Msp. 


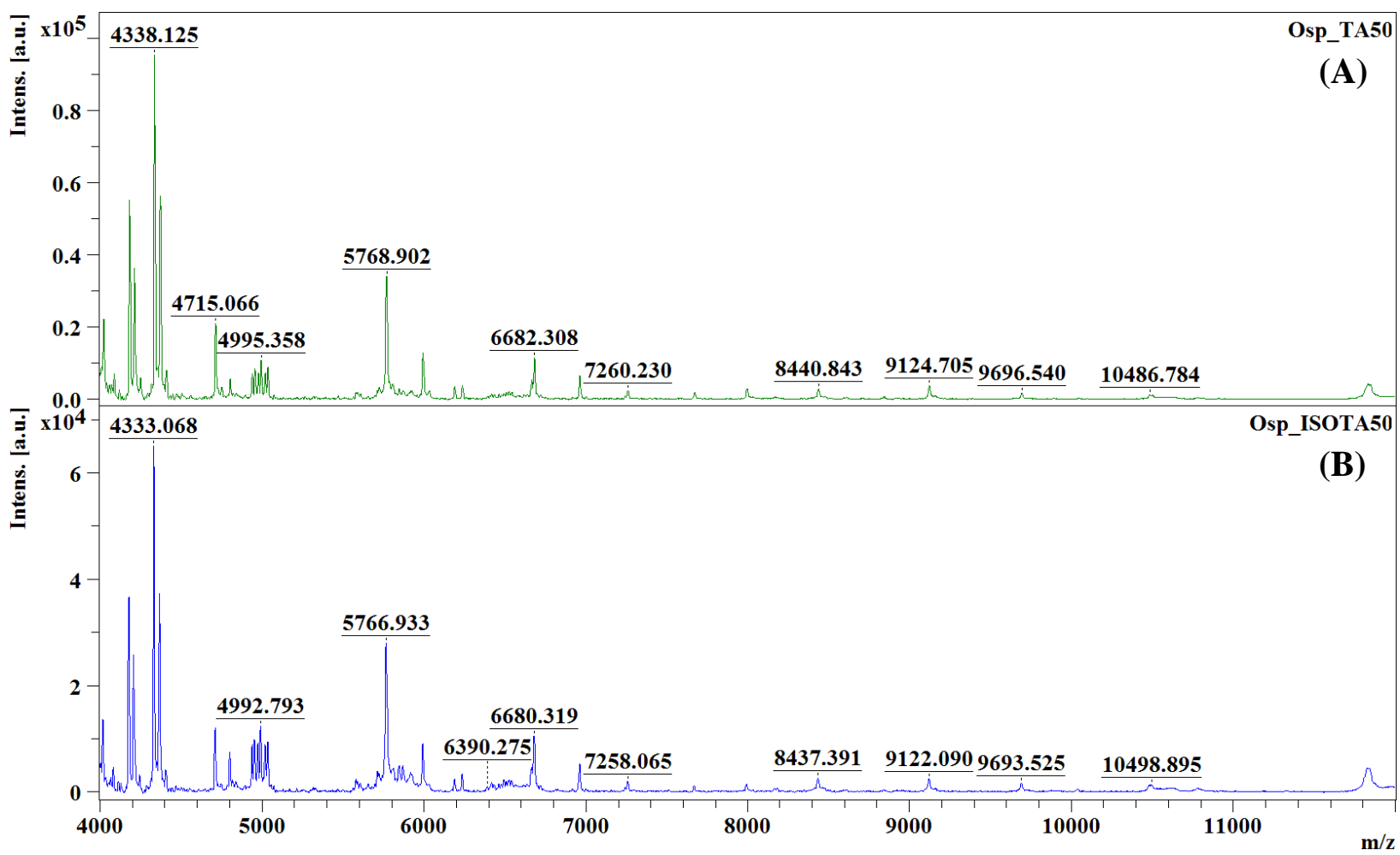

Figura 77: Comparação dos perfis dos espectros de massas do tipo MALDI-TOF utilizando os solventes TA50 (A) e ISOTA50 (B) na resuspensão da microalga Osp.

Para a todas as espécies Cv, Csp, Dsp, Msp e Osp, conforme observado, respectivamente, nas Figuras 73-77, ambos os solventes estudados, TA50 e ISOTA50 apresentaram perfil proteico semelhante, porém a intensidade dos picos foi maior utilizando o solvente TA50. Para a microalga $\mathrm{Cv}$ esse aumento na intensidade é observado principalmente em faixa de massa acima de $7 \mathrm{kDa}$ e para a microalga Dsp, alguns picos acima de 6,5 kDa só são observados quando o solvente TA50 é utilizado. Ao contrário, para a espécie Msp, foi observado um aumento na intensidade dos picos para o uso do solvente ISOTA50. Para a espécie Csp não foram observadas grandes diferenças entre os espectros utilizando a matriz sDHB com os solventes TA50 e ISOTA50.

Para ajudar na avaliação dos espectros, novamente os parâmetros P1, P2 e P3 foram analisados, sendo o valor 1 foi atribuído ao pior desempenho e o valor 2 ao melhor desempenho. 
Tabela 28: Estudo comparativo da adição de isopropanol ao solvente da matriz sDHB.

\begin{tabular}{|c|c|c|c|c|c|c|c|c|c|}
\hline \multirow{2}{*}{$\begin{array}{l}\text { Espécie de } \\
\text { Microalga }\end{array}$} & \multicolumn{2}{|c|}{ Solvente } & \multicolumn{2}{|c|}{ S/R (+Int) } & \multicolumn{2}{|c|}{$\begin{array}{c}\text { Intensidade } \\
\quad(+ \text { Int })\end{array}$} & \multicolumn{2}{|c|}{$\begin{array}{c}\text { Número de } \\
\text { Íons }\end{array}$} & \multirow[t]{2}{*}{ Soma } \\
\hline & TA50 & ISOTA50 & P1 & Classif. & $\mathbf{P 2}$ & Classif. & P3 & Classif. & \\
\hline \multirow{2}{*}{$\mathbf{C v}$} & + & 0 & 183 & 2 & 106773 & 2 & 217 & 2 & 6 \\
\hline & 0 & + & 146 & 1 & 89487 & 1 & 96 & 1 & 3 \\
\hline \multirow{2}{*}{ Csp } & + & 0 & 56 & 2 & 48081 & 2 & 60 & 1 & 5 \\
\hline & 0 & + & 53 & 1 & 43250 & 1 & 80 & 2 & 4 \\
\hline \multirow{2}{*}{ Dsp } & + & 0 & 37 & 1 & 36667 & 2 & 86 & 2 & 5 \\
\hline & 0 & + & 38 & 2 & 21653 & 1 & 70 & 1 & 4 \\
\hline \multirow{2}{*}{ Msp } & + & 0 & 52 & 1 & 34722 & 1 & 153 & 1 & 3 \\
\hline & 0 & + & 62 & 2 & 72721 & 2 & 188 & 2 & 6 \\
\hline \multirow{2}{*}{ Osp } & + & 0 & 75 & 1 & 16719 & 2 & 38 & 2 & 5 \\
\hline & 0 & + & 76 & 2 & 7812 & 1 & 32 & 1 & 4 \\
\hline
\end{tabular}

Na Tabela 28 é observado que para as microalgas Cv, Csp, Dsp, e Osp a adição de isopropanol não melhorou os parâmetros P1, P2 e P3. O oposto aconteceu com a amostra de Msp, sendo que a adição de $15 \%$ de isopropanol ao solvente da matriz sDHB apresentou uma discreta melhora em todos os parâmetros. Como para a maioria das amostras o melhor solvente foi o TA50, este foi mantido para o posterior estudo. Mais uma vez a pequena melhora nos resultados obtidos para a microalga Dsp com a adição de isopropanol ao solvente da matriz não justifica a adição de outro reagente ao experimento.

\subsubsection{Influência da concentração de TFA no solvente das microalgas}

Neste estudo foi realizado um teste com o objetivo de verificar a influência do aumento da concentração de TFA no solvente para a resuspensão das amostras de microalgas na análise do perfil proteico das células de microalgas liofilizadas. Foram usados como solvente TA50, 1TA50 e 2,5TA50, contendo 0,1; 1 e 2,5\% de TFA respectivamente, preparados conforme descrito no item 4.3.3.1. As amostras de microalgas foram pesadas igualmente para garantir que a quantidade inicial das amostras fosse a mesma.

\subsubsection{Calibração}

A calibração, preparada de acordo com o item 4.2.3.3, foi conduzida sob os seguintes parâmetros: PIE $100 \mathrm{~ns}, \mathrm{IS}_{1} 25 \mathrm{kV}$, IS $23,55 \mathrm{kV}$, abertura das lentes de $7 \mathrm{kV}$, número de "shots" de 10000 e potência do laser de $73 \%$. Os desvios padrões da qualidade da calibração 
observados para o uso dos solventes TA50, 1TA50 e 2,5TA50 foram 28,033; 108,684 e 173,96 ppm, respectivamente. Pode-se observar que o aumento do teor de TFA ao solvente é inversamente proporcional aos desvios obtidos na calibração. Ou seja, o melhor resultado obtido foi com a menor concentração de TFA no solvente.

\subsubsection{Análises das amostras de microalgas}

As análises das amostras de microalgas das espécies Cv, Csp, Dsp, Msp e Osp, Figuras 77-81, respectivamente, utilizando os solventes TA50, 1TA50 e 2,5TA50 foram conduzidas sob as seguintes condições: PIE $100 \mathrm{~ns}, \mathrm{IS}_{1} 25 \mathrm{kV}, \mathrm{IS}_{2} 23 \mathrm{kV}$, abertura das lentes de $7 \mathrm{kV}$, número de "shots" de 10000 e potência do laser de $95 \%$.

\subsection{Chlorella vulgaris $(\mathrm{Cv})$}

Para a espécie $\mathrm{Cv}$, o uso do TA50, Figura 78A, apresentou maiores intensidade e resolução dos picos quando comparado ao uso dos solventes 1TA50 e 2,5TA50, respectivamente, Figuras 78B e 78C.

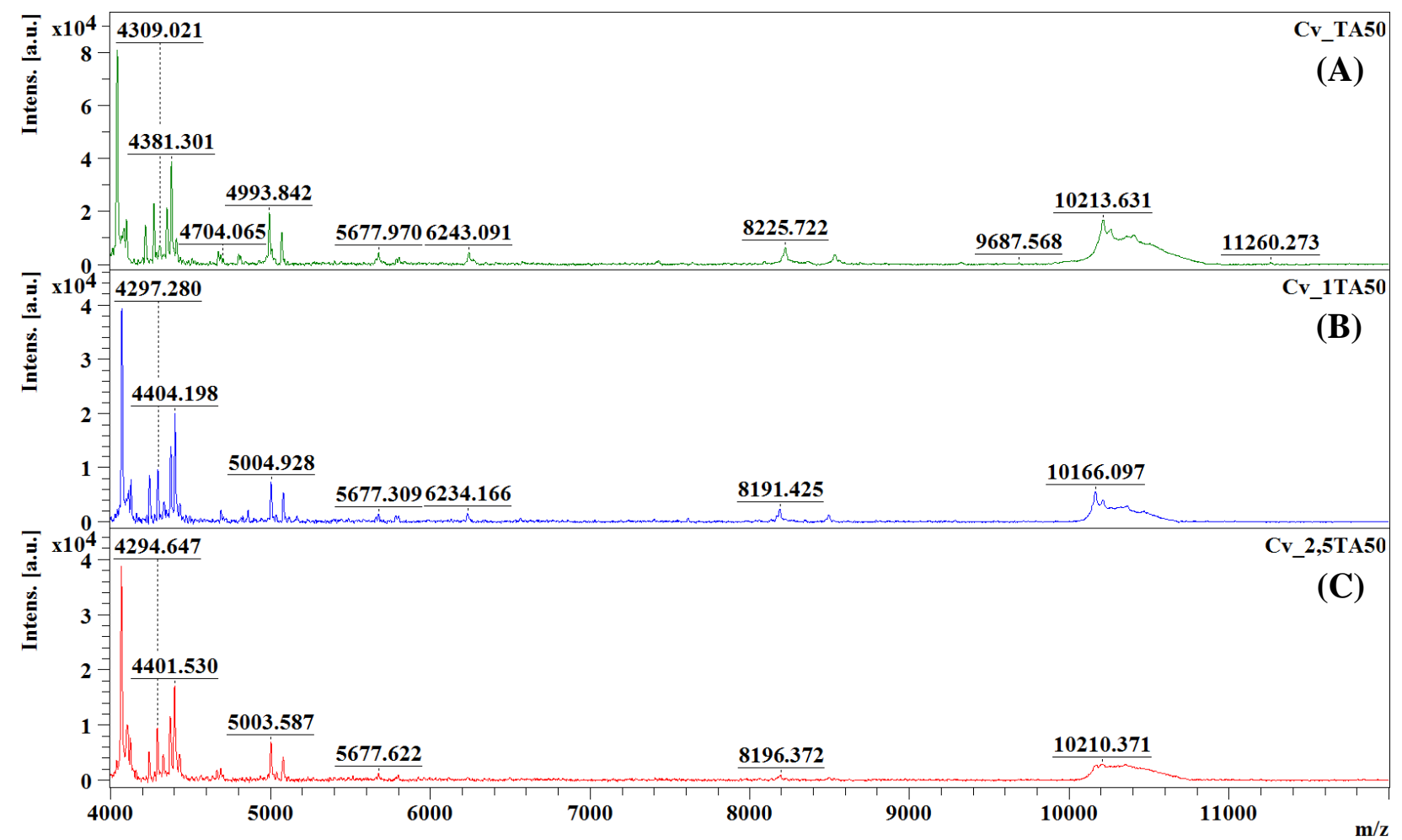

Figura 78: Perfis de espectros de massas do tipo MALDI-TOF obtido no estudo dos diferentes solventes, TA50 (A), 1TA50 (B) e 2,5TA50 (C), utilizados na amostra da microalga Cv. 


\subsection{Chlorella sp. (Csp)}

Para a espécie Csp, Figura 79, não foram observadas grandes diferenças entre os espectros utilizando os diferentes solventes 1TA50, Figura 79B, e 2,5TA50, Figura 79C. Entretanto, a utilização do solvente TA50 apresentou íons com maiores intensidades, Figura 79A.

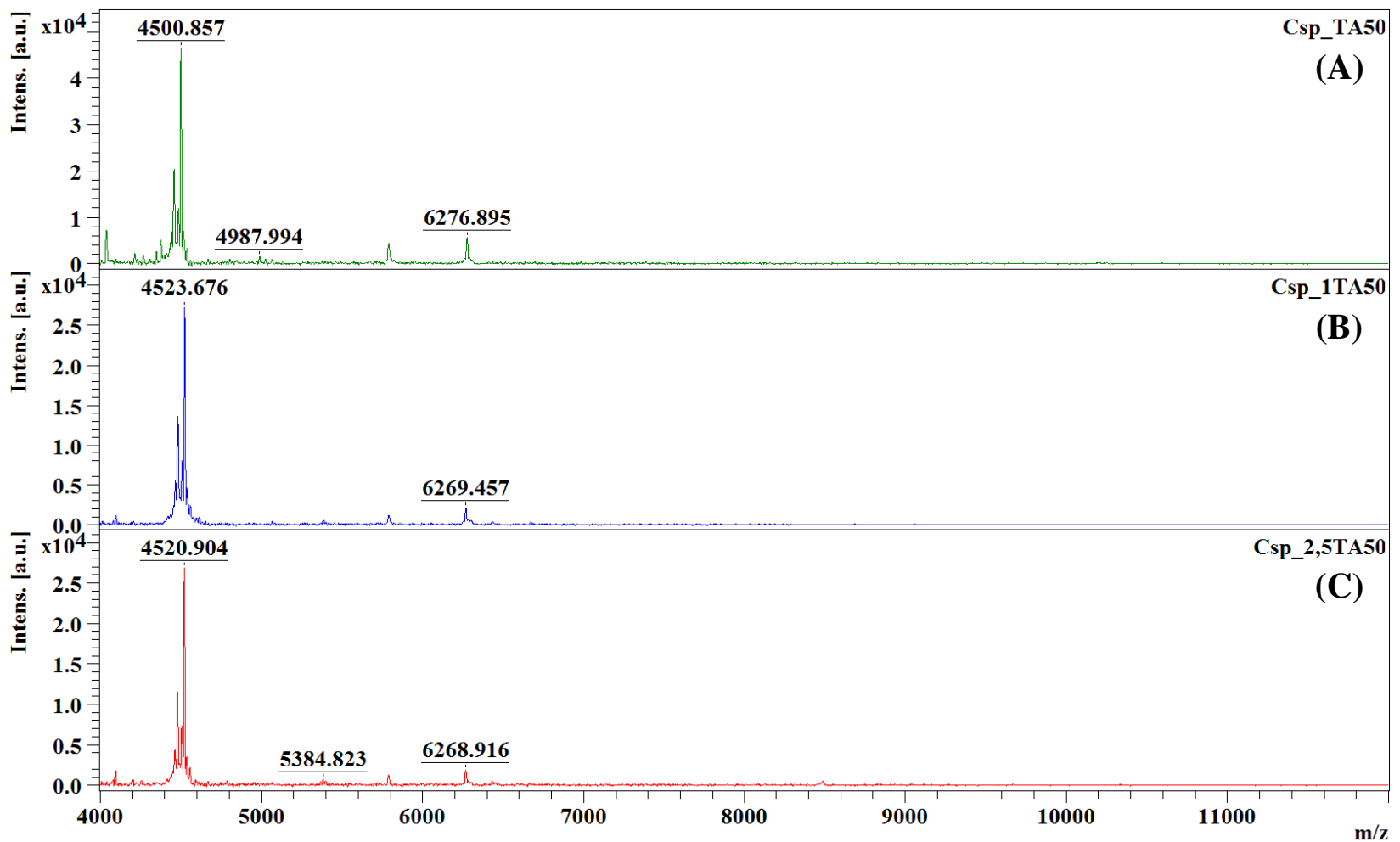

Figura 79: Perfis de espectros de massas do tipo MALDI-TOF obtido no estudo dos diferentes solventes, TA50 (A), 1TA50 (B) e 2,5TA50 (C), utilizados na amostra da microalga Csp.

\subsection{Desmodesmus sp. (Dsp)}

Para a espécie Dsp, Figura 80, assim como para as espécies de microalgas Cv e Csp, o uso do solvente TA50 utilizado na resuspensão da amostra de microalga apresentou maior intensidade dos picos, principalmente em faixa de massa superiores a 5,5kDa, Figura 80A. 


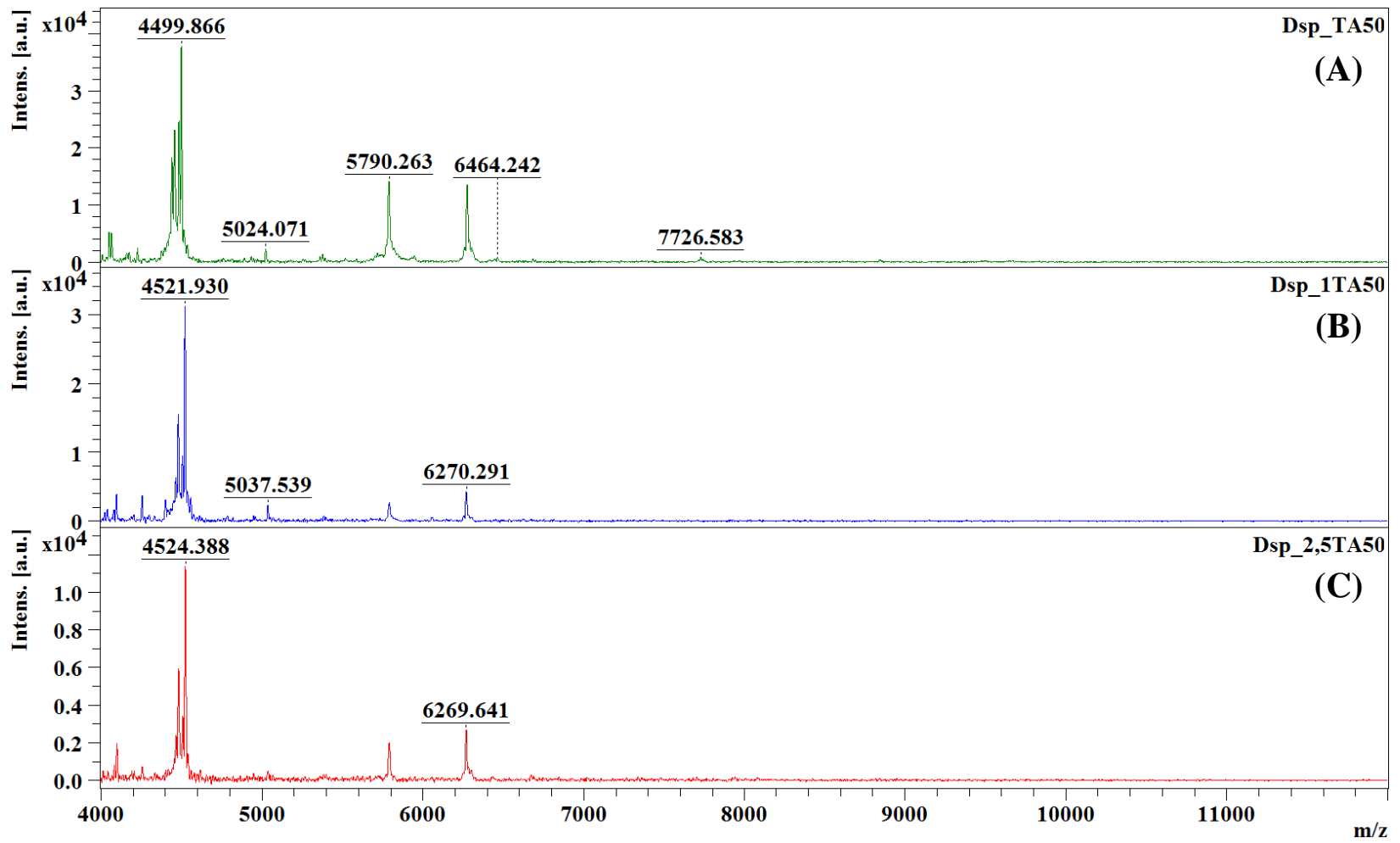

Figura 80: Perfis de espectros de massas do tipo MALDI-TOF obtido no estudo dos diferentes solventes, TA50 (A), 1TA50 (B) e 2,5TA50 (C), utilizados na amostra da microalga Dsp.

\subsection{Monoraphidium sp. (Msp)}

O uso do solvente 1TA50 na resuspensão da amostra de microalga Msp apresentou um leve aumento na intensidade dos picos, Figura 81B, quando comparada ao uso do solvente TA50, Figura 81A. Novamente o uso do solvente 2,5TA50 apresentou as menores intensidades, Figura 81C. 


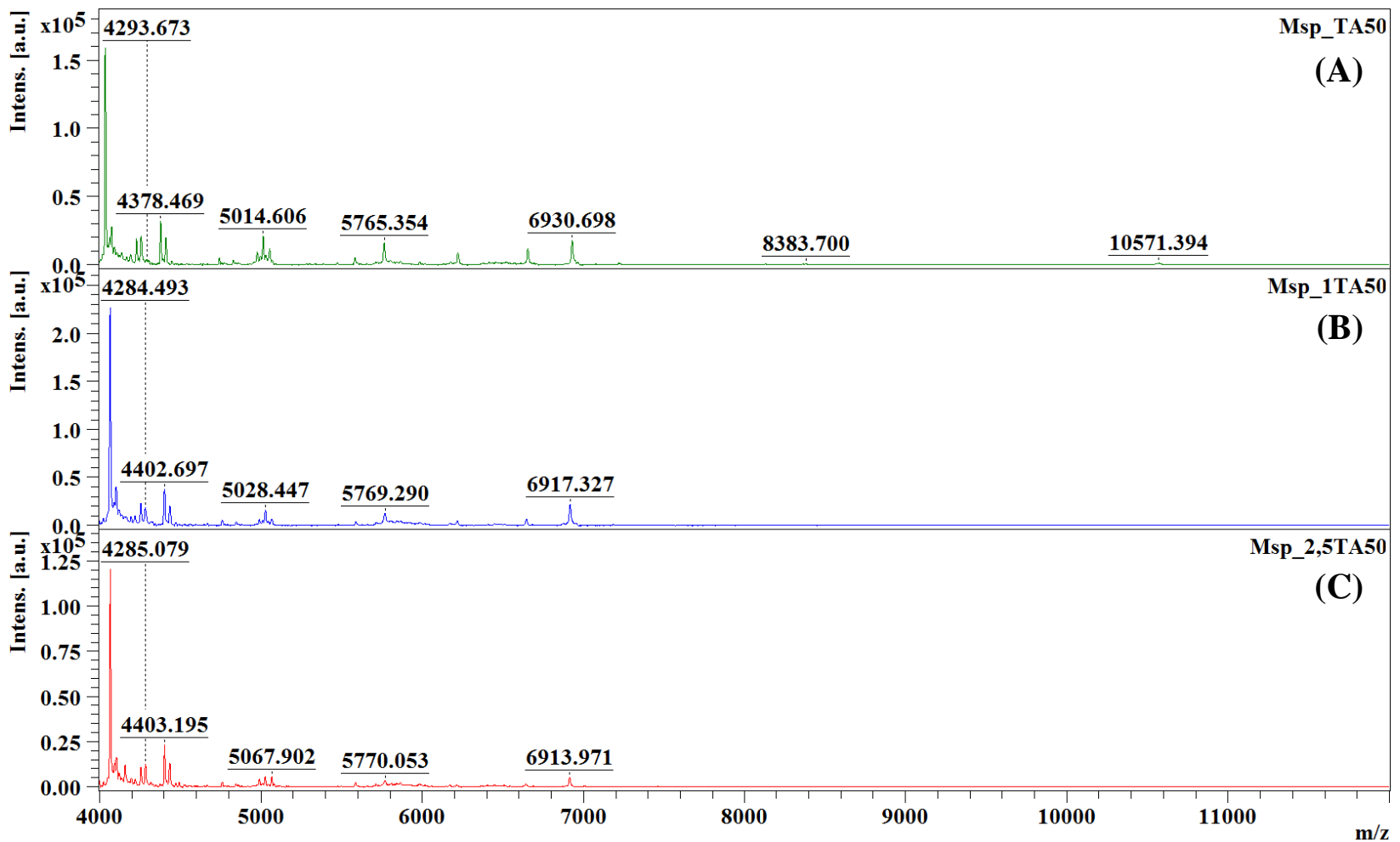

Figura 81: Perfis de espectros de massas do tipo MALDI-TOF obtido no estudo dos diferentes solventes, TA50 (A), 1TA50 (B) e 2,5TA50 (C), utilizados na amostra da microalga Msp.

\subsection{Oocystis sp. (Osp)}

Para a espécie Osp, assim como para as espécies Cv, Csp e Dsp, novamente o uso do solvente TA50 apresentou um aumento na intensidade dos picos, Figura 82A, quando comparada ao uso dos solventes 1TA50 e 2,5TA50, respectivamente, Figuras 82B e 82C. 


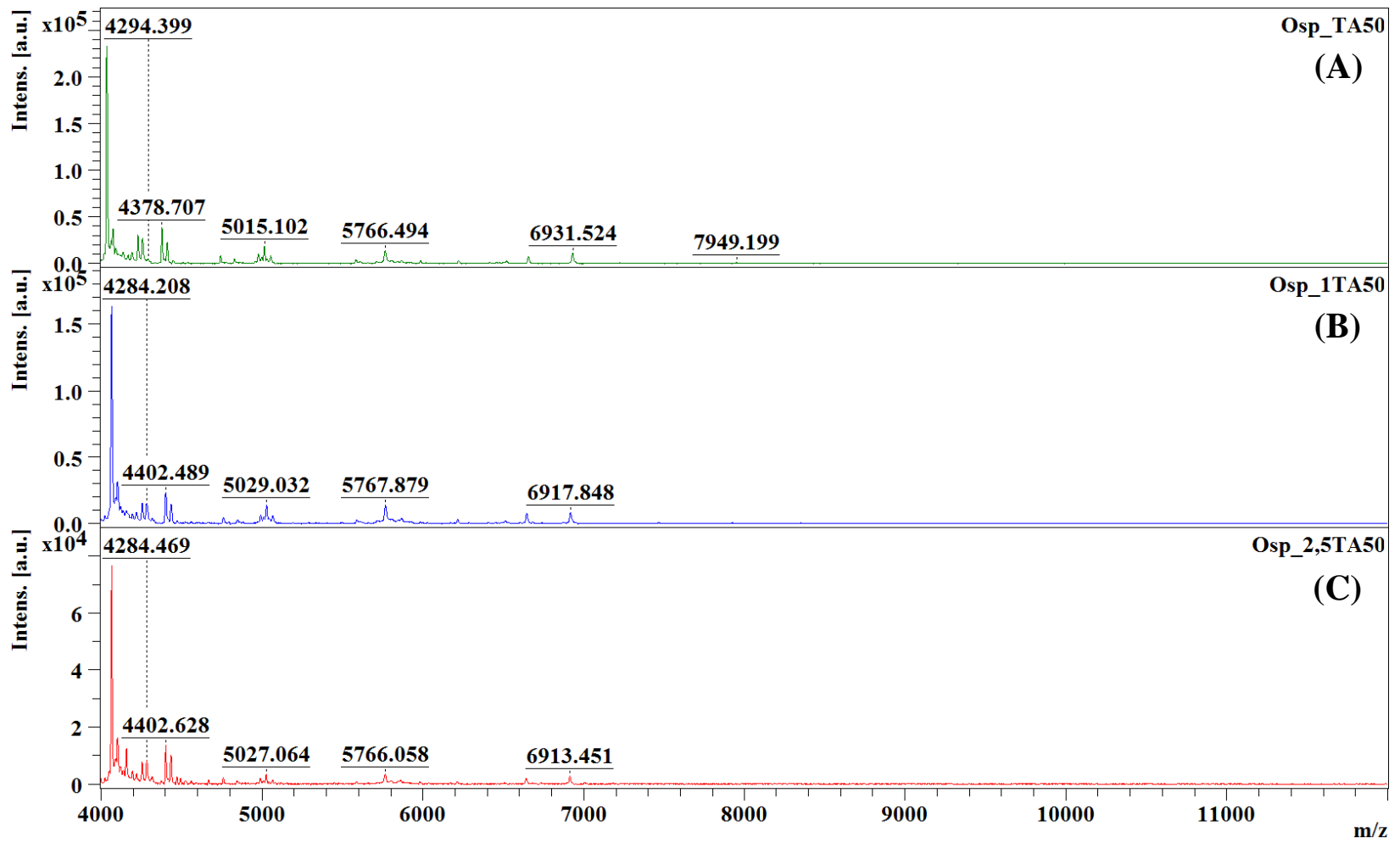

Figura 82: Perfis de espectros de massas do tipo MALDI-TOF obtido no estudo dos diferentes solventes, TA50 (A), 1TA50 (B) e 2,5TA50 (C), utilizados na amostra da microalga Osp.

Uma vez mais os parâmetros P1, P2 e P3 foram analisados para auxiliar na avaliação do melhor solvente das amostras de microalgas, sendo o valor 1 foi atribuído ao pior desempenho e o valor 3 ao melhor desempenho.

Na Tabela 29 foi observado que para todas as microalgas estudadas nesse trabalho, Cv, Csp, Dsp, Msp e Osp, a maior somatória para os parâmetros analisados P1, P2 e P3 foi obtida com o uso do solvente TA50, sendo então o solvente escolhido como sendo o solvente mais adequado para a resuspensão das amostras de microalgas liofilizadas na análise do perfil proteico. 
Tabela 29: Estudo comparativo do uso dos solventes TA50, 1TA50 e 2,5TA50 na amostra.

\begin{tabular}{c|ccc|c|c|c|c|c|c|c}
\hline \multirow{2}{*}{$\begin{array}{c}\text { Espécie de } \\
\text { Microalga }\end{array}$} & \multicolumn{3}{|c|}{ Solvente } & \multicolumn{2}{c|}{ S/R (+Int) } & \multicolumn{2}{c|}{$\begin{array}{c}\text { Intensidade } \\
\text { (+Int) }\end{array}$} & \multicolumn{2}{c|}{$\begin{array}{c}\text { Número de } \\
\text { Íons }\end{array}$} & Soma \\
\cline { 2 - 11 } & TA50 & 1TA50 & 2,5TA50 & P1 & Classif. & P2 & Classif. & P3 & Classif. & \\
\hline \multirow{3}{*}{ Cv } & + & 0 & 0 & 73 & 3 & 80874 & 3 & 85 & 3 & 9 \\
& 0 & + & 0 & 67 & 2 & 39396 & 2 & 73 & 1 & 5 \\
& 0 & 0 & + & 66 & 1 & 38704 & 1 & 77 & 2 & 4 \\
\hline \multirow{3}{*}{ Csp } & + & 0 & 0 & 92 & 3 & 46502 & 3 & 26 & 3 & 9 \\
& 0 & + & 0 & 145 & 1 & 27202 & 2 & 18 & 2 & 5 \\
& 0 & 0 & + & 98 & 2 & 26862 & 1 & 18 & 2 & 5 \\
\hline \multirow{3}{*}{ Dsp } & + & 0 & 0 & 80 & 2 & 37866 & 3 & 40 & 3 & 8 \\
& 0 & + & 0 & 90 & 3 & 31210 & 2 & 32 & 2 & 7 \\
& 0 & 0 & + & 47 & 1 & 11381 & 1 & 13 & 1 & 3 \\
\hline \multirow{3}{*}{ Msp } & + & 0 & 0 & 252 & 2 & 158821 & 2 & 81 & 3 & 7 \\
& 0 & + & 0 & 345 & 1 & 226427 & 3 & 73 & 1 & 5 \\
& 0 & 0 & + & 313 & 3 & 120477 & 1 & 74 & 2 & 6 \\
\hline \multirow{3}{*}{ Osp } & + & 0 & 0 & 364 & 3 & 232687 & 3 & 61 & 2 & 8 \\
& 0 & + & 0 & 288 & 2 & 163244 & 2 & 62 & 3 & 7 \\
& 0 & 0 & + & 192 & 1 & 76486 & 1 & 51 & 1 & 3 \\
\hline
\end{tabular}

Após todos os estudos de MALDI, foi verificado que as melhores condições para a análise de proteínas a partir de células de microalgas liofilizadas são: uso da placa "polished", em modo linear, com PIE de 100 ns, matriz sDHB, e solvente de matriz e de amostra TA50.

\subsection{PERFIL PROTEICO AO LONGO DA CURVA DE CRESCIMENTO}

\subsubsection{Calibração}

Tendo em vista que as condições para obtenção dos melhores espectros de massas do tipo MALDI-TOF para as amostras de microalgas são usando a matriz sDHB, com solvente TA50 sem adição de isopropanol e PIE 100 ns, foi realizado um comparativo entre os perfis dos espectros de massas ao longo da curva de crescimento sob essas condições os quais foram comparados com os dados anteriores, item 5.2., para as espécies Cv, Csp, Dsp, Msp e Osp, Figuras 83-87, respectivamente. 

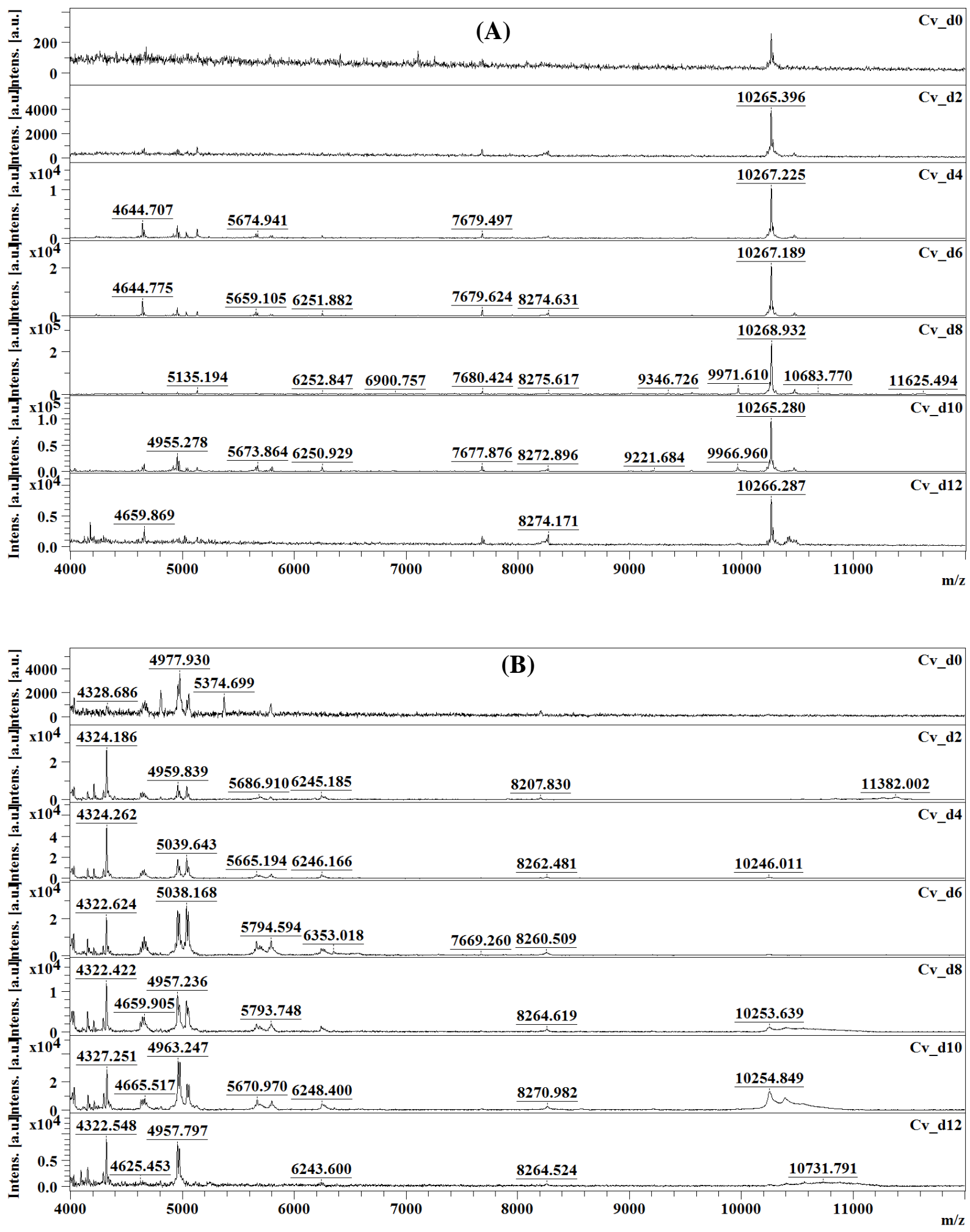

Figura 83: Perfis dos espectros de massas do tipo MALDI-TOF ao longo do crescimento do dia 0 ao dia 12 (coletas a cada 2 dias) da espécie $\mathrm{Cv}$ comparando os parâmetros e condições de análise antigos (A) e parâmetros e condições de análise otimizadas (B). 

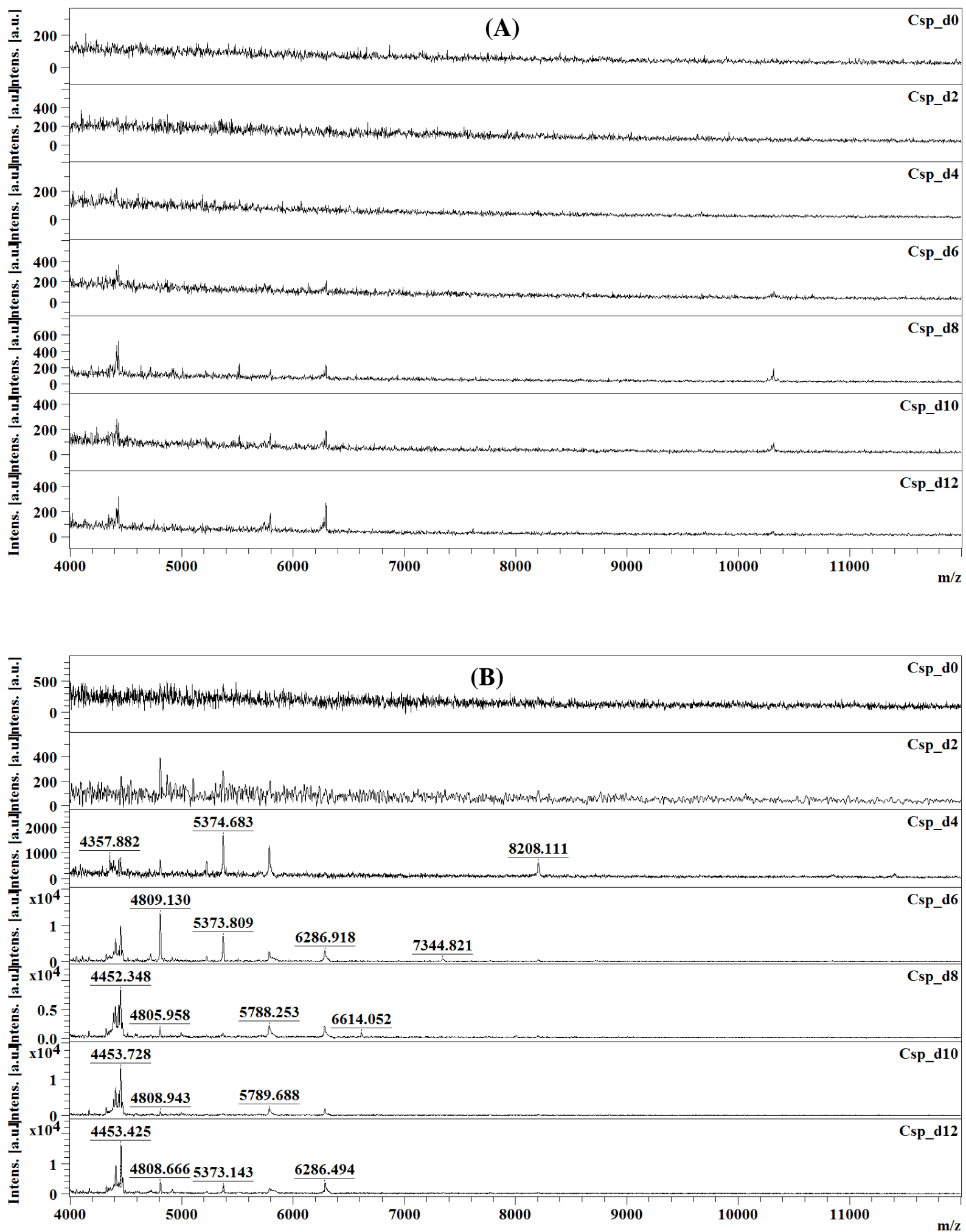

Figura 84: Perfis dos espectros de massas do tipo MALDI-TOF ao longo do crescimento do dia 0 ao dia 12 (coletas a cada 2 dias) da espécie Csp comparando os parâmetros e condições de análise antigos (A) e parâmetros e condições de análise otimizadas (B). 

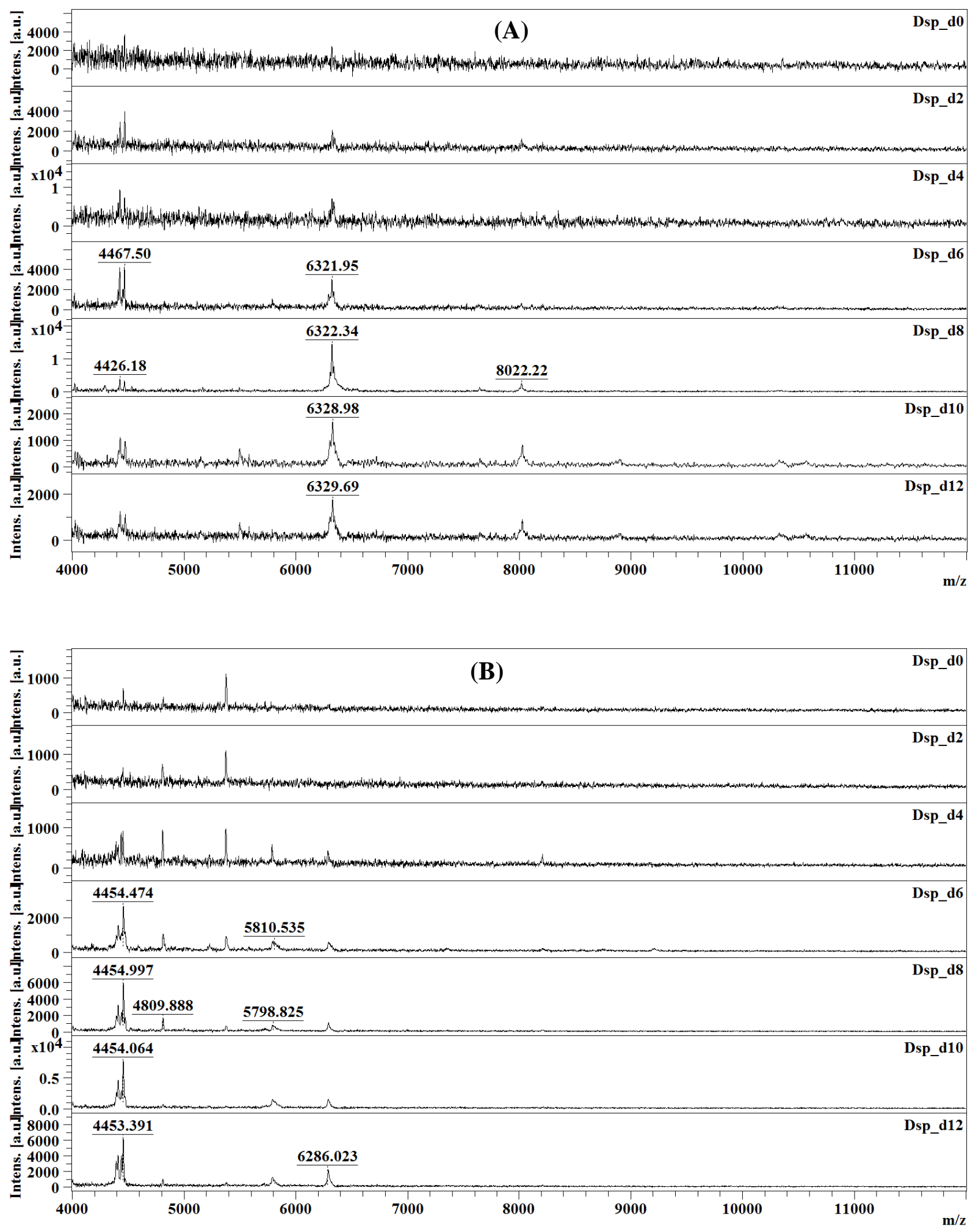

Figura 85: Perfis dos espectros de massas do tipo MALDI-TOF ao longo do crescimento do dia 0 ao dia 12 (coletas a cada 2 dias) da espécie Dsp comparando os parâmetros e condições de análise antigos (A) e parâmetros e condições de análise otimizadas (B). 

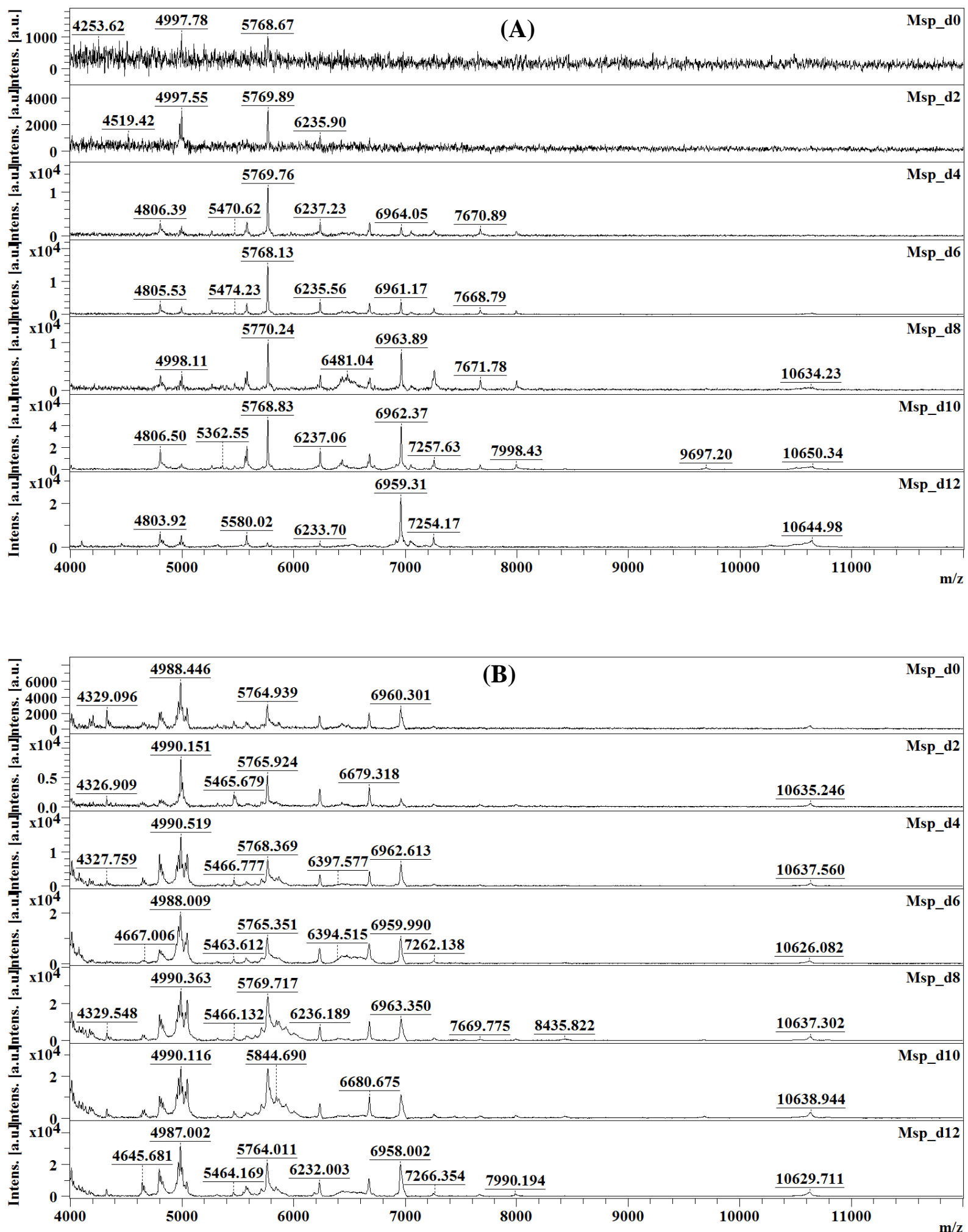

Figura 86: Perfis dos espectros de massas do tipo MALDI-TOF ao longo do crescimento do dia 0 ao dia 12 (coletas a cada 2 dias) da espécie Msp comparando os parâmetros e condições de análise antigos (A) e parâmetros e condições de análise otimizadas (B). 

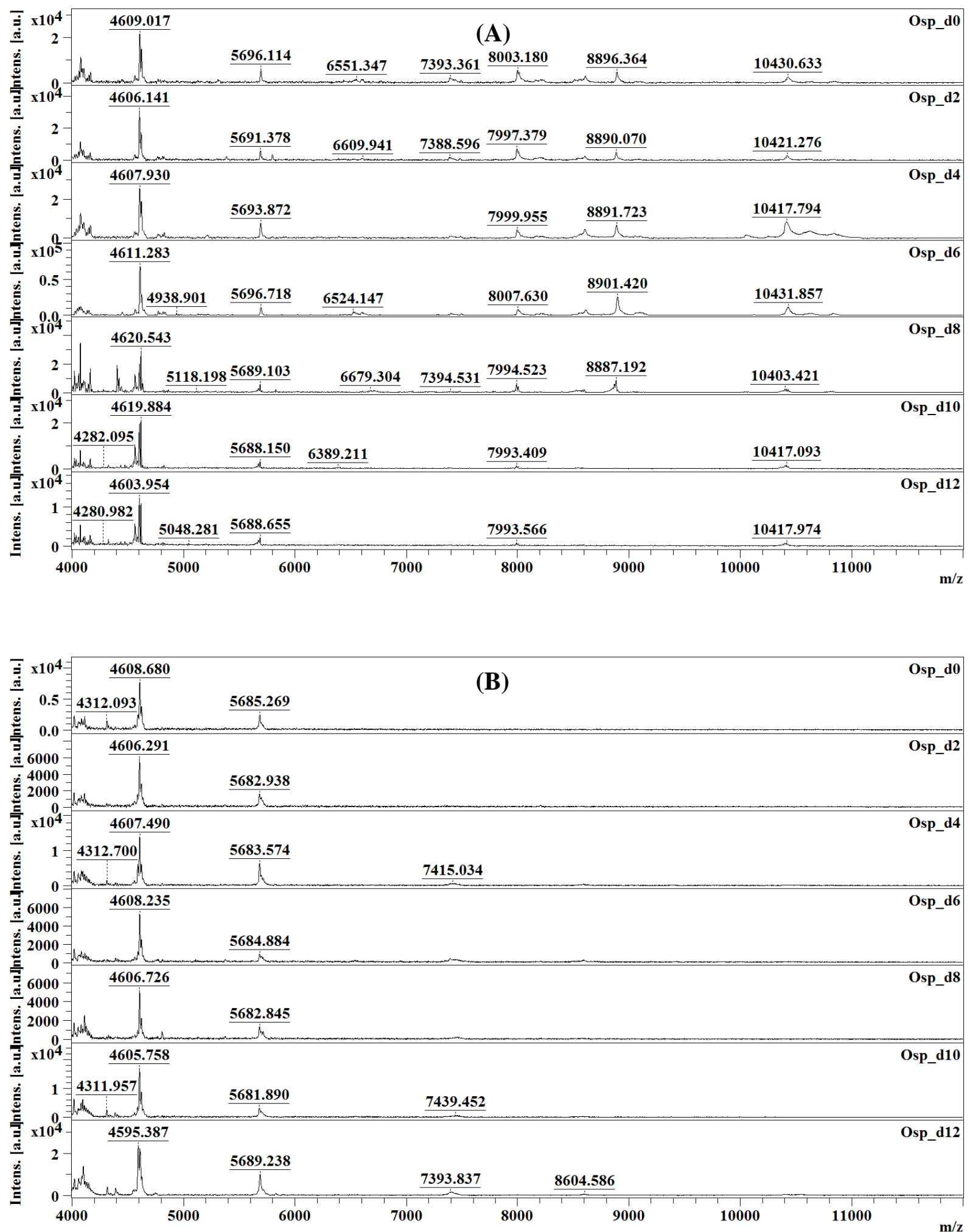

Figura 87: Perfis dos espectros de massas do tipo MALDI-TOF ao longo do crescimento do dia 0 ao dia 12 (coletas a cada 2 dias) da espécie Osp comparando os parâmetros e condições de análise antigos (A) e parâmetros e condições de análise otimizadas (B). 
Pode-se observar, Figuras 83-87, respectivamente para as espécies Cv, Csp, Dsp, Msp e Osp, que houve uma considerável melhora nas intensidades dos picos, já que as amostras, ainda que em baixa concentração, dessorvem e ionizam com mais facilidade, promovendo espectros mais bem resolvidos. Novamente o perfil de proteínas é bastante similar ao longo da curva de crescimento. Dessa forma, o uso da matriz sDHB, solvente TA50 para amostra e matriz, sob as condições de análise placa "polished", PIE 100 ns, $\mathrm{IS}_{2} 23 \mathrm{kV}$ se mostrou muito mais efetivo para a análise de proteínas a partir de amostras de microalgas.

\subsection{PERFIL LIPÍDICO DAS ESPÉCIES DE MICROALGAS ESTUDADAS}

Como estudo complementar, foi realizada a análise do perfil de ácidos graxos saturados e insaturadas para as espécies de microalgas em cultivos de 12 e 8 dias, fase estacionária e final da fase exponencial respectivamente, tendo em vista o trabalho de Fidalgo e colaboradores (1998) no qual eles afirmam que o início da fase estacionária é a melhor fase para se alcançar maior produtividade lipídica.

Os lipídios extraídos utilizando o procedimento utilizado por Vieler e colaboradores (2007) e solubilizados na mistura metanol e clorofórmio foram analisados por cromatografia gasosa acoplada à espectrometria de massas.

Foram considerados somente a distribuição dos ácidos graxos para cada cultivo analisado e os dados estão apresentados na Tabela 30.

Tabela 30: Perfil lipídico obtido através da cromatografia gasosa acoplada à espectrometria de massas para cultivos de microalgas de 12 e 8 dias.

\begin{tabular}{|c|c|c|c|c|c|c|c|c|c|c|}
\hline \multirow{3}{*}{ Ácido graxo } & \multicolumn{5}{|c|}{12 dias de cultivo } & \multicolumn{5}{|c|}{8 dias de cultivo } \\
\hline & Cv & $C s p$ & $D s p$ & Msp & Osp & $C v$ & Csp & $D s p$ & Msp & Osp \\
\hline & \multicolumn{5}{|c|}{$\%$} & \multicolumn{5}{|c|}{$\%$} \\
\hline C14:0 & ND & ND & 0,42 & 2,36 & ND & ND & 0,61 & 0,22 & 3 & ND \\
\hline C15:0 & ND & ND & ND & ND & ND & ND & ND & ND & ND & 0,36 \\
\hline C16:0 & 76,37 & 71,16 & 41,09 & 71,62 & 74,28 & 53,7 & 69,4 & 48,29 & 68,23 & 75,42 \\
\hline C18:0 & 2,10 & 14,01 & 3,69 & 11,23 & 9,87 & 1,13 & 4,72 & 1,71 & 4,49 & 4,30 \\
\hline C24:0 & ND & ND & ND & 3,04 & 0,52 & ND & ND & ND & ND & ND \\
\hline C18:1 & 6,31 & 0,28 & 19,04 & 0,49 & 7,22 & ND & ND & 0,16 & ND & ND \\
\hline C18:2 & 13,23 & 8,17 & 35,75 & 0,71 & 4,22 & 27,19 & 8,32 & 49,39 & 11,67 & 6,23 \\
\hline C18:3 & ND & ND & ND & ND & ND & 3,00 & ND & ND & 1,34 & ND \\
\hline C20:5 & ND & ND & ND & ND & ND & 1,40 & ND & ND & ND & ND \\
\hline C22:6 & 4,09 & 6,37 & ND & 8,68 & 3,88 & 14,7 & 16,95 & ND & 11,27 & 13,68 \\
\hline Total saturados & 78,78 & 87,95 & 55,71 & 91,96 & 85,49 & 56,45 & 78,07 & 53,66 & 70,33 & 78,85 \\
\hline Total insaturados & 21,22 & 12,05 & 44,28 & 7,36 & 14,34 & 44,11 & 21,93 & 46,23 & 29,67 & 21,15 \\
\hline
\end{tabular}

* ND: não detectado 
A distribuição do perfil lipídico mostrou que para todas as espécies, os cultivos de 12 dias favorece a produção dos ácidos graxos C16:0, C18:2 e C18:0 e em menores porcentagens C14:0, C15:0, C18:1 e C22:6.

Nos cultivos de 8 dias, foi predominante a obtenção de ácidos C16:0, C18:2 e C22:6, corroborando com o estudo de Pektov e García (2007) para Chlorella vulgaris. Bertoldi e colaboradores (2006) também obtiveram um perfil semelhante após cultivos de 7 dias da espécie Chlorella vulgaris, obtendo ácidos graxos 16:0, 18:0 e 18:1.

Foi observado que, para os cultivos de 8 dias, as proporções dos ácidos C22:6 e C18:2 aumentaram enquanto a proporção de C18:0 foi reduzida para todas as espécies de microalgas estudadas. Em geral, o teor de ácidos insaturados foi maior para cultivos de 8 dias, para todas as espécies. A espécie que apresentou maior teor de ácido saturado foi a Monoraphidium $s p$ com $91,96 \%$ para cultivos de 12 dias.

É reportado que a composição lipídica das microalgas pode variar de acordo com a fase de crescimento em que ela se encontram. Isto pode explicar o fato de que as células que se encontram na fase exponencial apresentam maior quantidade de ácidos graxos insaturados. Ao entrar na fase de desaceleração, a escassez de nutrientes e a alta densidade celular, que geram um pequeno aumento na temperatura, podem interferir na composição lipídica, conforme reportado por Renaud e colaboradores (2004). Neste estudo, foram obervados aumentos na produção de ácidos graxos saturados C14:0, C16:0 e C18:0 e diminuição dos ácidos graxos insaturados, com o aumento da temperatura.

Para a produção de biodiesel, ácidos graxos saturados contendo entre 14 e 18 carbonos são os ideais (CHISTI, 2007). Desta forma, as espécies de microalgas desse estudo que podem ser destinadas a produção de biodiesel são Chlorella vulgaris, Chlorella sp, Monoraphidium sp. e Oocystis sp., em cultivos de 8 dias.

Jiang e colaboradores (1999) afirmaram a importância terapêutica dos ácidos graxos poliinsaturados (PUFAs) como sustâncias nutricionais. Dessa forma, a espécies Desmodesmus $s p .$, por possuir alto conteúdo de ácidos graxos insaturados, pode ser destinada a suplemento alimentar. 


\section{CONCLUSÕES}

O mapeamento do agitador orbital através das curvas de crescimento da microalga Chlorella vulgaris foi analisado estatisticamente e tendo em vista que havia diferenças significativas entre suas linhas e posições devido as diferenças de intensidade luminosa, foi desenvolvido um sistema de cultivo composto por uma caixa de alumínio e lâmpadas com intensidades ajustadas, com o objetivo de homogeneizar a intensidade luminosa em cada posição do agitador orbital, permitindo uma maior reprodutibilidade dos experimentos. Foi também determinado o tempo de pré-inóculo de 4 dias para garantir que a condição inicial de todos os cultivos fossem as mesmas.

Após a realização de duas curvas de crescimento, o sistema de cultivo apresentou reprodutibilidade e ainda foi observado que as microalgas do gênero Chlorella e do gênero Desmodesmus apresentaram maiores concentrações após 12 dias, quando comparadas aos gêneros Monoraphidium e Oocystis. Foi observado que as microalgas do gênero Chlorella e do gênero Desmodesmus apresentaram maiores valores para $\mu_{\max }, 0,30$ e 0,29 dia $^{-1}$, respectivamente quando comparadas aos gêneros Monoraphidium e Oocystis que apresentaram 0,25 e $0,24 \mathrm{dia}^{-1}$, respectivamente.

Tendo em vista os inúmeros desafios em pesquisas para transformar biomassa de microalgas em energia alternativa ao petróleo, este estudo teve como objetivo principal o desenvolvimento de uma metodologia de preparo e análise de amostras de microalgas liofilizadas utilizando a espectrometria de massas do tipo MALDI para determinação do seu perfil proteico posteriormente auxiliando na construção um banco de dados para caracterização rápida de espécies.

A análise do perfil proteico, ao longo da curva de crescimento de todas as espécies de microalgas estudadas, Cv, Csp, Dsp, Msp e Osp, mostrou-se bastante semelhante, independente da fase de crescimento em que a microalga se encontra, podendo estas serem consideradas proteínas conservadas, podendo ser utilizadas para identificação das espécies.

A dificuldade na aquisição de espectros bem resolvidos levou à estudos para otimização da metodologia de preparo de amostra e aquisição de dados, com variações em diversos parâmetros de análise. As avaliações dos espectros foram baseadas no número de íons (P1), relação sinal/ruído do pico base (P2) e intensidade do pico base (P3). 
Foram testadas duas placas de amostragem a "anchorchip" e a "polished", para a maioria das amostras, o uso da placa "polished" se mostrou mais efetivo, apresentando espectros com picos mais intensos e mais bem definidos.

A espectrometria de massas do tipo MALDI permite dois tipos de análises, nos modos refletor e linear. Para as amostras de microalgas, o modo linear apresentou picos mais bem resolvidos, quando comparado o modo refletor, no qual o caminho a ser percorrido pelos íons é maior, exigindo uma maior aceleração dos íons para chegar ao detector.

Outro parâmetro de análise avaliado foi o valor de PIE, que é o tempo, em nanosegundos, entre os pulsos de laser para atingir a amostra. Dentre os valores utilizados, 100ns foi o que apresentou a melhor compensação da distribuição das velocidades iniciais fazendo com que os íons com mesma razão $\mathrm{m} / \mathrm{z}$ cheguem simultaneamente no detector, melhorando a resolução e intensidade dos picos.

O parâmetro $\mathrm{IS}_{2}$, que é a voltagem aplicada ao eletrodo para acelerar os íons em direção ao detector, também foi estudado e o valor de $\mathrm{IS}_{2}$ que gerou o melhor perfil de espectro para amostras de microalgas foi de $23 \mathrm{kV}$.

Foi observado que os perfis proteicos das microalgas sofrem forte influência da matriz utilizada. Com isso, foi observado que para as amostras Cv, Csp, Dsp e Msp, o uso da matriz sDHB se mostrou mais efetivo, do que quando utilizadas as matrizes SA, HCCA e DHB, ainda que a sDHB apresente desvantagem na sua cristalização em forma de anel no spot, o que dificulta a aquisição de espectros bem resolvidos. Somente para a amostra Osp, a matriz mais efetiva foi a HCCA, porém o ganho na utilização dessa matriz não foi muito superior aos resultados obtidos com o uso da matriz sDHB, a qual foi então escolhida para os próximos estudos.

Foi também estudada a influência da concentração TFA no solvente da matriz sDHB, e observou-se mudanças bastante discretas, principalmente com o uso do solvente TA50 e 1TA50. Para as microalgas Cv, Csp, Dsp e Msp o melhor solvente para a matriz sDHB foi o TA50. Já para a espécie Osp, o solvente que apresentou a melhor desempenho foi o 1TA50. Entretanto, o solvente TA50 foi escolhido como solvente da matriz uma vez que o ganho em resultados não foi suficiente para justificar o aumento na concentração de TFA no solvente da matriz.

Tendo em vista a cristalização não homogênea de matrizes contendo DHB em sua composição, foi estudada a adição de $15 \%$ de isopropanol à matriz sDHB, com o objetivos de promover uma maior homogeneidade da distribuição da matriz no spot, auxiliando na 
aquisição de espectros de massas bem resolvidos. Para a todas as espécies o solvente da matriz sem adição de isopropanol (TA50) proporcionou maiores intensidades dos picos, sendo que para a microalga $\mathrm{Cv}$ esse aumento na intensidade foi observado principalmente em faixa de massa acima de $7 \mathrm{kDa}$ e para a microalga Dsp, alguns picos acima de 6,5 kDa só são observados quando o solvente TA50 é utilizado. Já para a espécie Msp, foi observado um aumento na intensidade dos picos para o uso do solvente ISOTA50, ou seja, com adição de isopropanol. Para a espécie Csp não foram observadas grandes diferenças entre os espectros utilizando a matriz sDHB com os solventes TA50 e ISOTA50. Desta forma descarta-se o uso de isopropanol, pois os pequenos ganhos não justificam a utilização da grande quantidade deste solvente.

Um último estudo visando verificar a influência do aumento da concentração de TFA no solvente das amostras de microalgas foi realizado e foi observado que o uso do solvente TA50 foi o mais adequado para a resuspensão das amostras de microalgas liofilizadas na análise do perfil proteico.

Após todos os estudos de metodologia de preparação de amostra e análises de MALDI verificou-se que a técnica é bastante interessante para diferenciar as espécies de microalgas, assim como já acontece com fungos e bactérias, pois é possível medir o peso molecular das proteínas das microalgas e o conjunto desses picos representa o chamado fingerprint das proteínas das microalgas. Pode-se concluir que as melhores condições para a análise de proteínas a partir de células de microalgas liofilizadas são: uso da placa "polished", em modo linear, com PIE de 100 ns, $\mathrm{IS}_{2} 23 \mathrm{kV}$, matriz sDHB, e solvente de matriz e de amostra TA50.

Com relação aos lipídios, foi observada uma distribuição lipídica predominante dos ácidos graxos C16:0, C18:2 e C18:0 de para os cultivos de 12 dias e C16:0, C18:2 e C22:6 para os cultivos de 8 dias. Entretanto, as proporções de C22:6 e C18:2 aumentaram para os cultivos de 8 dias.

Tendo em vista que para a produção de biodiesel, os ácidos graxos devem conter entre 14 e 18 carbonos, dentre as espécies de microalgas utilizadas, Chlorella vulgaris, Chlorella sp, Monoraphidium sp. e Oocystis sp. em cultivos de 8 dias podem ser convertidas em biocombustível. 


\section{PUBLICAÇÕES E PARTICIPAÇÕES EM CONGRESSOS}

1. RODRIGUES, T. T. M., ANDRADE, L. M. ; DO NASCIMENTO, C. A.O. ; SECKLER, M. M. . Production of microalgae of Chlorella vulgaris specie and characterization of its pyrolysis products. Em: XVIII Congresso Brasileiro de Engenharia Química -COBEQ, 2012, Buzios-RJ-Brasil.

2. ANDRADE, L. M. ; MENDES, M. A. ; NASCIMENTO, C. A. O. . Extração e Identificação Lipídica da Microalga Chlorella vulgaris por Espectrometria de Massas. Em: II Simpósio Brasileiro de Potencial Energético das Microalgas, 2012, Natal-RN-Brasil.

3. ANDRADE, L. M. ; MENDES, M. A. ; NASCIMENTO, C. A. O. . Evaluation of Ligth Intensisty in Cultivation in Shaker of Chlorella vulgaris. Em: XIX Simpósio Nacional de Bioprocessos-SINAFERM, 2013, Foz do Iguaçu-PR-Brasil.

4. ANDRADE, L. M. ; MENDES, M. A. ; NASCIMENTO, C. A. O. . Mass Spectrometric Characterization of Chlorella vulgaris. Em: BIT's $2^{\text {nd }}$ Annual International Congress of Algae - AICA, 2013. (Apresentação Oral), Hangzhou CA-CHINA.

5. ANDRADE, L. M. ; SILVEIRA, C. A. ; MENDES, M. A. ; NASCIMENTO, C. A. O. . Modeling of $\mathrm{CO}_{2}$ Capture using Microalgae. Em: 13 Annual Meeting of American Institute of Chemical Engineering - AICHE, 2013. (Apresentação Oral), San Francisco-CA-USA.

6. ANDRADE, L. M. ; MENDES, M. A. ; KOWALSKI, P. ; NASCIMENTO, C. A. O. . Comparative Study of the Efficiency of Different Matrices for the Analysis of Microalgae Intact cells by MALDI TOF TOF Technique. Em: 62nd Annual Conference on Mass Spectrometry and Allied Topics - ASMS, 2014. BaltimoreMD-USA.

\section{PUBLICAÇÕES EM REVISTA CIENTÍFICA}

ANDRADE, L. M. ; MENDES, M. A. ; KOWALSKI, P. ; NASCIMENTO, C. A. O. . Comparative study of different matrix/solvent systems for the analysis of crude lyoplilized microalgal preparations using MALDI-TOF-MS. Rapid communications in Mass Spectrometry - Submetido.

\section{DOUTORADO SANDUICHE}

Durante o período de doutoramento, foi realizado um doutorado sanduiche com duração de 6 meses (setembro de 2013 a março de 2014) na Bruker Daltonics, em BillericaMA-USA, com financiamento proveniente do programa Ciências sem Fronteiras (CsF). 


\section{SUGESTÕES PARA CONTINUIDADE DO TRABALHO}

1) Utilização de lâmpadas de LED nos cultivos - tendo em vista a necessidade de uma fonte de iluminação para o crescimento das microalgas e a dificuldade no uso de lâmpadas fluorescentes devido a instabilidade e aquecimento que proporciona, e ainda, nos últimos 5 anos tem sido observado que o uso de LEDs favorece o crescimento das microalgas muito mais do que as lâmpadas fluorescentes, pois praticamente todos os comprimentos de onda são absorvidos pelas microalgas, as quais são altamente sensíveis à intensidade luminosa.

2) Mistura de Matrizes - Tendo em vista que a melhor matriz encontrada nesse trabalho foi a sDHB e mesmo com os estudos de solvente, adicionando TFA ou ISO, ainda há a formação de um anel de cristais, deixando a amostra heterogênea e dificultando a aquisição automática dos espectros, a combinação de matrizes pode ser uma alternativa para tentar melhorar a distribuição dos cristais nas amostras e facilitar a aquisição de bons espectros.

3) Padronização da Concentração de Amostra - A padronização da concentração de amostra, pode levar a resultados ainda mais reprodutivos. Com isso, a minha sugestão seria separação de diversas alíquotas de uma mesma curva de crescimento, no mesmo tempo, para análise das variáveis da técnica de MALDI-TOF-MS.

4) Digestão e Sequenciamento das amostras - Realizar a análises de MALDI-TOF-MS para as amostras digeridas, visando conhecer mais a fundo a respeito do perfil de proteínas das microalgas, bem como poder identificar as principais proteínas presentes.

5) Quantificação lipídica- Realizar a quantificação de lipídios totais bem como a quantificação dos lipídios encontrados utilizando padrões de calibração. 


\section{REFERÊNCIAS BIBLIOGRÁFICAS}

ANDERSEN, R. Algal Culturing Technique.San Diego: Elservier. 2005.

BECKER, E. W. Microalgae as a source of protein. Biotechnology Advanced, p. 207-210 2007.

BECKER, W. HANDBOOK of microalgae culture: biotechnology and applied phycology. Londres: Blackwell Science. 2004.

BEN - Balanço Energético Nacional - MINISTÉRIO DAS MINAS E ENERGIA. (2013). Disponível em: <http://www.mme.gov.br/mme/galerias/arquivos/publicacoes/BEN/2_-_BEN_-_Ano_Base/1__BEN_Portugues_-_Inglxs_-_Completo.pdf>. Acesso em 23 de abr. 2014.

BERENGUEL, M., RODRÍGUEZ, F., ACIÉN, F., GARCÍA, J. Model predictive control of pH in tubular photobioreactors. Journal of Process Control, p. 377-387, 2004.

BERTOLDI, C. F., SANT'ANNA, E., BRAGA, M., OLIVEIRA, J. L. Lipids, fatty acids composition and carotenoids of Chlorella vulgaris cultivated in hydroponic wastewater. Grasas y Aceites, p. 270$274,2006$.

BIZZINI, A., DURUSSEL, C., BILLE, J., GREUB, G., PROD'HOM, G. Performance of MatrixAssisted Laser Desorption/Ionization Time-of-Flight Mass Spectrometry for the identification of bacterial strains routinely isolated in a clinical microbiology laboratory. Clinical Microbiology and Infection, p. 1549-1554, 2010.

BOROWITZKA, M. A. Commercial production of microalgae: ponds, tanks, tubes and fermenters. Journal of Biotechnology, p. 313-321, 1999.

BOX, G. E., HUNTER, J. S., HUNTER, W. G. Statistcs for Experimenters. New Jersey: WileyInterscience, 2005.

BRUKER - Optimization of MALDI-TOFMS acquisition parameters in Flex Control.

BRUKER (2012 a) - Bruker Guide to MALDI Sample Preparation - MALDI Preparation Protocols. Revision 2. Disponível em <http://www.ispybio.com/search/protocols/maldi\%20protocol1.pdf >. p 1$19,2012$.

BRUKER (2012 b) - Protein Calibration Standard I Disponível em <http://www.bruker.com/products/mass-spectrometry-and-separations/literature/literatureroom/instruction-for-use.html?eID=dam_frontend_push\&docID=49113>. Acesso em 20 de set. de 2013. 
BRUKER (2013a) - MALDI-TOFMass Spectrometry: microflex LRF Operator Training. v.2, p 1-49, 2013.

BRUKER (2013b) - Instructions for use MTP Anchorchip Targets BC, Revision 2. Disponivel em $<$ http://www.bruker.com/products/mass-spectrometry-and-separations/literature/literatureroom/instruction-for-use.html?eID=dam_frontend_push\&docID=54045> Acesso em 20 de set. de 2013.

CAMACHO, A., WIT, R. Effect of nitrogen and phosphorous additions on a benthic microbial mat from a hypersaline lake. Aquatic Microbial Ecology, 261-273, 2003.

CAVALLARO, S., MONDELLO, N., FRENI, S. L. Hydrogen produced from ethanol reforming molten carbonate fuel cell. Journal of Power Sources, pp. 198-204, 2001.

CHAGAS, B. M., FILHO, O. C., PICARDO, M. C., ARAÚJO, O. Q., da SILVA, A. F., CHALOUB, R. M. (19-22 de Setembro de 2010). Otimização da Produção de Lipidios pela Microalga Marinha Isochysis galbana sob condições de estresse nutricional. COBEQ - XVIII Congresso Brasileiro de Engenharia Química, p. 1733-1741.

CHAVES, M. C. C., GOMES, C. F. S. Avaliação de biocombustíveis utilizando o apoio multicritério à decisão. Production Journal, pp. 495-507, 2013.

CHEN, C. Y., YEH, K. L., AISYAH, R., LEE, D. J., CHANG, J. S. Cultivation, photobioreactor design and harvesting of microalgae for biodiesel production: A critical review. Bioresource Technology, p. 71-81, 2011.

CHINNASAMY, S., RAMAKRISHNAN, B., BHATNAGAR, A., DAS, K. C. Biomass Production Potential of a Wastewater Alga Chlorella vulgaris ARC 1 under Elevated Levels of $\mathrm{CO}_{2}$ and Temperature. International Journal of Molecular Sciences, p. 518-532, 2009.

CHISTI, Y. Biodiesel from microalgae. Biotechnology Advances, p. 294-306, 2007.

CHISTI, Y. Microalgae: our marine forests. Biotechnology Advances, p. 565-567, 2004.

COP 15. Disponível em: <http://www.cop15.gov.br/> Acesso em 29 de set. 2011.

CORNELL, C. B. Disponível em: <http://gas2.com.br> Acesso em 29 de set. 2011.

CORREA DO LAGO, A. A. (2006) - CDES - CONSELHO DE DESENVOLVIMENTO ECONÔMICO E SOCIAL. Disponível em: <http://http://www.cdes.gov.br〉 Acesso em 16 abr. 2014.

COSTA, J. A., RADMANN, E. M., CERQUEIRA, V. S., dos SANTOS, G. C., CALHEIROS, M. N. Perfil de Ácidos Graxos das Microalgas Chlorella vulgaris e Chlorella Minutissima cultivadas em diferentes condições. Alimentos e Nutrição, p. 429-436, 2006. 
COUTTEAU, P. Manual on the Production and Use of Live Food for Aquaculture. Rome: Fao Fisheries Technical Paper, 1996.

COUTTEAU, P., SORGELOOS, P. The requirement for live algae and their replacement by artificial diets in the hatchery and nursery rearing of bivalve molluscs: an international survey. The Journal of Shellfish Research, p. 467-476, 1992.

CRAMPON, C., BOUTIN, O., BADENS, E. Supercritical Carbon Dioxide Extraction of Molecules of Interest from Microalgae and Seaweeds. Industrial and Engineering Chemistry Research, p. 8941$8953,2011$.

CUNHA, V. P. Crescimento, Clorofila e Lipídio da Microalgas Scenedesmus. Blumenau, Santa Catarina, Brasil, 2011.

D’OCA, M. G. M., VIÊGAS, C. V., MACHADO, D. O. (13-15 de Novembro de 2008). Extração de óleo da microalga Chlorella pyrenoidosa visando à produção de biodiesel. $16 \mathrm{SBQSul}$ - XVI Encontro de Química da Região Sul . Blumenau, Santa Catarina, Brasil.

DANTAS, D. M., DRUMMOND, A. R., dos SANTOS, L. B., dos SANTOS, F. K., BEZERRA, R. D., GÁLVEZ, A. O. (7-10 de Junho de 2010). Extração de Óleo de Microalga Ultizando Ultrassom com Diferentes Solventes Visando a Produção de Biodiesel. IV Congresso Brasileiro de Mamona e I Simpósio Internacional de Oleaginosas Energéticas . João Pessoa, Paraíba, Brasil.

ESTEVES, F. A. Fundamentos de Limnologia. Rio de Janeiro: Inteligência, 1998.

FIDALGO, J. P., CID, A., TORRES, E., SUKENIK, A., HERRERO, C.. Effects of nitrogen source and growth phase on proximate biochemical composition, lipid classes and fatty acid profile of the marine microalga Isochrysis galbana. Aquaculture, p. 105-116, 1998.

FISHMAN, D., MAJUMDAR, R., MORELLO, J., PATE, R., YANG, J. (2010). EERE, Disponível em: <http://www1.eere.energy.gov> Acesso em 29 set. 2010.

GANTT, S. L., VALENTINE, N. B., SAENZ, A. J., KINGSLEY, M. T., WAHL, K. L. Use of an Internal Control for Matrix-Assisted Laser Desorption/Ionization Time-of-Flight Mass Spectrometry Analysis of Bacteria. Journal of the American Society for Mass Spectrometry, p. 1131-1137, 1999.

GLADUE, R. M. Heterotrophic microalgae production: potencial for application to aquaculture feeds. Rotifer and Microalgae culture systems, p. 276-286, 1991.

GOUVEIA, L., OLIVEIRA, A. C. Microalgae as a raw material for biofuels production. Journal of Industrial Microbiology and Biotechnology, p. 269-274, 2009.

GREENPEACE. (1971). Disponível em: <http://www.greenpeace.org> Acesso em 29 set. 2010. 
HU, G., FAN, Y., ZHANG, L., YUAN, C., WANG, J., LI, W. Enhanced Lipid Productivity and Photosynthesis Efficiency in a Desmodesmus sp. Mutant Indued by Heavy Carbon Ions. PLOS One Journal. 2013.

IEA - INSTITUTE ENERGY AGENCY. Disponível em: <http://www.iea.org> Acesso em 29 set. 2011.

JIANG, Y. Production potential of docosahexaenoic acid by heterotrophic dinoflagelate Crypthecodinium cohnii. Process Biochemistry, p. 633-637, 1999.

JORNAL A FOLHA DE SÃO PAULO. Disponível em: <http://noticias.uol.com.br/ciencia/ultimasnoticias/bbc/2013/11/14/emissoes-de-co2-pode-tornar-oceanos-170-mais-acidos-ate-2100-dizestudo.htm> Acesso em 01 de fev. 2014.

JORNAL O ESTADO DE SÃO PAULO. (2005). Disponível em:

<http://www.estadao.com.br/arquivo/vidae/2005/not20050214p117.htm> Acesso em 18 abr. 2012.

KELLER, B. O., LI, L. Three_Layer Matrix/Sample Preparation Method for MALDI MS Analysis of Low Nanomolar Portein Samples. Journal of the American Society for Mass Spectrometry, p. 780785, 2006.

KERBY, N. W., STEWART, W. D. The biotechnology of microalgae and cyanobacteria. Oxford: Oxford University Press. 1989.

KLASSON, K. T., CLAUSEN, M., GADDY, E. C. Bioreactor design for synthesis gas fermentations. Fuel, p. 605-614, 1991.

KNOTHE, G., KRAL, J., GERPEN, J. V., RAMOS, L. P. (2006). Manual de Biodiesel. São Paulo: Blucher.

LAVENS, P., SORGELOOS, P. Manual on the production and use os live food for aquaculture. Rome: FAO Fisheries Technical Paper. 1996.

LIANG, Y., SARKANY, N., CUI, Y. Biomass and lipid productivities of Chlorella vulgaris under autotrophic, heterotrophic and mixotrophic growth conditions. Biotechnololy Letters, p. 1043-1049, 2009.

LOURENÇO, S. O. Cultivo de Microalgas Marinhas: princípios e aplicações. São Carlos: Rima. 2006.

LOURENÇO, S. O., VIEIRA, A. A. Culture collections of microalgae and cyanobacteria in Brazil: progress and constraints. Nova Hedwigia, p. 149-173, 2004. 
LV, J.-M., CHENG, L.-H., XU, X.-H., ZHANG, L., CHEN, H.-L. Enhance lipid production of Chlorella vulgaris by adjustment of cultivation conditions. Bioresource Technology. p. 6797-6804, 2010.

MAHBOOB, S., RAUF, A., ASHRAF, M., SULTANA, T., SULTANA, S., JABEEN, F. High-density growth and crude protein productivity of a thermotolerant Chlorella vulgaris: production kinectis and thermodynamics. Aqualculture International, p. 455-466, 2012.

MARINHO, Y. F., SANTOS, A. P., SANTOS, L. B., VASCONCELOS, R. F., KALAZANS, N. K., NASCIMENTO, R. D. (2009). IX Jornada de Ensino, Pesquisa e extensão. Recife.

MATA, M. T., MARTINS, A. A., CAETANO, N. S. Microalage for biodiesel production and other applications: A review. Renewable and Sustainable Energy Reviews, p. 217-232, 2010.

MAYO, A. W., NOIKE, T. Response of mixed cultures of Chlorella vulgaris and heterotrophic bacteria to variation of pH. Water Science and Technology, p. 285-294, 1994.

McDANIEL, J., BULLMAN, A. Optimization of MALDI-TOF-ISD (Ion-Source-Decay) for protein profile. 40th Annual Analytical Chemistry Meeting of Federation of Analytical Chemistry and Spectroscopy Societies. Milwalkee. 2013.

MEHLITZ, T. H. Influence and Heat Management Requirements of Microalgae Cultivation in Photobioreactors. San Luis Obispo, USA. 2009.

MONTEIRO, M. P., LUCHESE, R. H., ABSHER, T. M. Effect of three different types of culture conditions on Spirulina maxima growth. Brazilian Archives of Biollogy and Technology, p. 369373,2010 .

MORETTI, A., FERNANDEZ-CRIADO, M. P., CITTOLIN, G., GUIDASTRI, R. Manual on Hatchery Production of Seabass and Gilthead Seabream. Roma: Food and Agriculture Organization of the United Nations. 1999.

MULLER, P., Li, X. P., NIYOGI, K. K. Non-Photochemical Quenching: A Response to Excess Light Energy. Plant Physiology, p. 1558-1566, 2001.

MURUGAIYAN, J., AHRLOLDT, J., KOWBEL, V., ROESLER, U. Establishment of a matrixassisted laser desorption ionization time-offlight mass spectrometry database for rapid identification of infectious achlorophyllous green micro-algae of the genus Prototheca. Clinical Microbiology and Infection, p. 461-46, 2012.

OLSSOM, L., NIELSEN, J. On-line and In-Situ monitoring of biomass in submergerd cultivations. Trends in Biotechnology, p. 517-522, 1997. 
PAZ, B., RIOBÓ, P., FRANCO, J. M. Preliminary study for rapid determination of phycotoxins in microalgae whole cells using matrix-assisted laser desorption/ ionization time-of-flight mass spectrometry. Rapid Communications in Mass Spectrometry, p. 3627-3639, 2011.

PERRINE, Z., NEGI, S., SAYRE, R. T. Optimization of photosynthetic light energy utilization by microalgae. Algal Research, p. 134-142, 2012.

PETROV, G., GARCIA, G. Wich are fatty acids of the green alga Chlorella? Biochemical Systematics and Ecology, p. 270-274, 2007.

REDAELLI, C., KOCHEM, L. H., DIERINGS, T. J., ROMAN, G. M., MARCILIO, N. R., RECH, R. (2011). Influencia da Intensidade da Luz sobre a Biofixação de Carbono em Chlorella minutíssima. III Congresso Brasileiro de Carvão Mineral. Rio Grande do Sul.

RENAUD, S. M., SHOU, H. C., PARRY, D. L., THINH, L. V., WOO, K. C. Effect of temperature on the growth, total lipid content and fatty acid composition of recently isolated tropical microalgae Isochrysis sp., Nitzschia closterium, Nitzschia paleacea, and commercial species Isochrysis sp. Journal of Applied Phycology, p. 79-99, 2004.

REVISTA BRASILIS. Disponível em <http://revista.brasil.gov.br> Acesso em 16 abr. 2014.

RICHMOND, A. (2004). Principles for attaining maximal microalgal productivity in photobioreactors: an overview. Hydrobiologia, p. 33-37.

RUIZ-MARIN, A., MENDOZA-ESPINOSA, L. G., STEPHENSON, T. Growth and nutrient removal in free and immobilized green algae in batch and semi-continuous cultures treating real wastewater.

Bioresource Technology, p. 58-64, 2010.

SASI, D. Biokinetic behavior of Chlorella vulgaris in a continuously stirred bioreactor and a circulating loop photobioreactor. Saskatoon, Saskatchewan, Canadá. 2009.

SCHMIDELL, W., LIMA, U. A., E., A., BORZANI, W. Engenharia Bioquímica. São Paulo: Edgar Blücher Ltda. $1^{a}$ edição. v2, 2001. 541p.

SHIMADZU - ANALYTICAL AND MEASURING INSTRUMENTS.Disponível em: <http://www.shimadzu.com.br/analitica/produtos/biotech/axima.shtml> Acesso em 10 de set. de 2012.

SOLETTO, D., BINAGHI, L., LODI, A., CARVALHO, J., CONVERTI, A. Batch and fedbatch cultivations of Spirulina platensis using ammonium sulphate and urea as nitrogen sources.

Aquaculture, p. 217-224, 2010.

TINDALE, A. Biology: A concise Revision Course for CXC. London: Great Britain. 1988 
TREDICI, M. R. Mass production of microalgae: photobioreactors. In: Handbook of microalgal culture: biotechnology and applied phicology (pp. 178-214). Oxford: Blackwell Science. 2004.

VAUGHAN, A. (02 de September de 2009). THE GUARDIAN-Carbon emissions per person, by country. Disponível em: <The Guardian:

http://www.theguardian.com/environment/datablog/2009/sep/02/carbon-emissions-per-person-capita.> Acesso em 09 de out. de 2014.

VIAN, C. E. (2006). Perspectivas da Agroenergia no Brasil. XLVI CONGRESSO DA SOCIEDADE BRASILEIRA DE ECONOMIA, ADMINISTRAÇÃO E SOCIOLOGIA RURAL. Piracicaba: SOCIEDADE BRASILEIRA DE ECONOMIA, ADMINISTRAÇÃO E SOCIOLOGIA RURAL.

VIELER, A., WILHELM, C., GOSS, R., SUB, R., SCHILLER, J. The lipid composition of the unicellular green alga Chlamydomonas reinhardtii and the diatom Cyclotella meneghiniana investigated by MALDI-TOF MS and TLC. Chemistry and Physics of Lipids, p.143-155, 2007.

VOILAND, A. (21 de January de 2010). NASA - 2009: Second Warmest Year on Record; End of Warmest Decade. Disponível em: <NASA Official: http://www.nasa.gov/topics/earth/features/tempanalysis-2009.html> Acesso em 09 de Out de 2014.

WILKINSON, W. R., GUSEV, A. I., PROCTOR, A., HOUALLA, M., HERCULES, D. M. Selection of internal standars for quantitative analysis by matrix-assited laser desorption-ionization (MALDI) time-of-flight mass spectrometry. Fresenius Journal of Analytical Chemistry, p. 241-24, 1996.

YU, X., ZHAO, P., HE, C., LI, J., TANG, X., ZHOU, J. Isolation of a novel strain of Monoraphidium $s p$. and characterization of its potential application as biodiesel feedstock. Bioresource Technology, p. 121-256, 2013. 


\section{ANEXOS}

Anexo I: Lista de Reagentes Químicos

- Acetona $\left(\mathrm{C}_{3} \mathrm{H}_{6} \mathrm{O}\right)-$ marca Synth, $\mathrm{PM}=58,08 \mathrm{~g} / \mathrm{mol}$

- Acetonitrila $\left(\mathrm{C}_{2} \mathrm{H}_{3} \mathrm{~N}\right)$ - marca Merck, 99,9\%, PM=41,05 g/mol

- Ácido Bórico $\left(\mathrm{H}_{3} \mathrm{BO}_{3}\right)$ - marca Vetec, $99,5 \%, \mathrm{PM}=61,83 \mathrm{~g} / \mathrm{mol}$

- Ácido Clorídrico $(\mathrm{HCl})$ - marca Vetec, $\mathrm{PM}=36,46 \mathrm{~g} / \mathrm{mol}$

- Ácido etilenodiamino tetra-acético (NaEDTA . 2 $\mathrm{H}_{2} \mathrm{O}$ ) - marca Vetec, 99\%, PM=372,24 g/mol

- Ácido Fórmico $\left(\mathrm{CH}_{2} \mathrm{O}_{2}\right)$ - marca Synth, $88 \%, \mathrm{PM}=46,01 \mathrm{~g} / \mathrm{mol}$

- Ácido Sinapínico (SA)- marca Sigma Aldrich, PM=225,08 g/mol

- Ácido $\alpha$-ciano-4-hidroxicinamico (HCCA) - marca Sigma Aldrich, PM=189,17 g/mol

- Ácido 2,5-Dihidroxibenzóico (DHB) - marca Bruker Daltonics, PM=154,12 g/mol

- Água deionizada

- Bicarbonato de Sódio $\left(\mathrm{NaHCO}_{3}\right)$ - marca Reatec, 99,7\%, PM=84,01 g/mol

- Cloreto de Cálcio $\left(\mathrm{CaCl}_{2} \cdot 2 \mathrm{H}_{2} \mathrm{O}\right)$ - marca Merck, 99\%, PM=147,02 g/mol

- Cloreto de Cobalto $\left(\mathrm{CoCl}_{2} \cdot 6 \mathrm{H}_{2} \mathrm{O}\right)$ - marca Mallinckrodt, 98\%, $\mathrm{PM}=237,93 \mathrm{~g} / \mathrm{mol}$

- Cloreto de Ferro $\left(\mathrm{FeCl}_{3} \cdot 6 \mathrm{H}_{2} \mathrm{O}\right)$ - marca Merck, 99\%, $\mathrm{PM}=270,33 \mathrm{~g} / \mathrm{mol}$

- Cloreto de Manganês $\left(\mathrm{MnCl}_{2}\right.$. 4H $\left.\mathrm{H}_{2} \mathrm{O}\right)$ - marca Vetec, 99\%, PM=197,90 g/mol

- Etanol $\left(\mathrm{CH}_{3} \mathrm{CH}_{2} \mathrm{OH}\right)$ - marca Vetec, $99,8 \%, \mathrm{PM}=46,06 \mathrm{~g} / \mathrm{mol}$

- Fosfato de Potássio monobásico $\left(\mathrm{K}_{2} \mathrm{HPO}_{2}\right)$ - marca JTBaker, 99,1\%, PM=174,18 g/mol

- Hexano $\left(\mathrm{C}_{6} \mathrm{H}_{14}\right)$ - marca Vetec, $99 \%, \mathrm{PM}=86,18 \mathrm{~g} / \mathrm{mol}$

- Hidróxido de Sódio $(\mathrm{NaOH})$-marca Merck, 99\%, PM=39,99g/mol

- Isopropanol $\left(\mathrm{C}_{3} \mathrm{H}_{8} \mathrm{O}\right)$ - marca Sigma Aldrich, 99,9\%, $\mathrm{PM}=60,10 \mathrm{~g} / \mathrm{mol}$

- Metanol $\left(\mathrm{CH}_{3} \mathrm{OH}\right)$ - marca Merck, 99,9\%,PM=32,04 g/mol

- Molibidato de Sódio $\left(\mathrm{Na}_{2} \mathrm{MoO}_{4} \cdot 2 \mathrm{H}_{2} \mathrm{O}\right)$ - marca Vetec, 99,5\%, PM=241,95 g/mol

- Nitrato de Sódio (NaNO3) - marca Vetec, 99\%, PM=84,99 g/mol

- sDHB - 90\% de DHB com 10\% de ácido 2-hidroxi-5-methoxibenzóico - marca Bruker Daltonics, $\mathrm{PM}=168,15 \mathrm{~g} / \mathrm{mol}$

- Silicato de Sódio $\left(\mathrm{Na}_{2} \mathrm{SiO}_{3} \cdot 9 \mathrm{H}_{2} \mathrm{O}\right)$ - marca Vetec, $98 \%, \mathrm{PM}=284,19 \mathrm{~g} / \mathrm{mol}$

- Solução de Calibrantes Standard I - marca Bruker Daltonics

- Sulfato de Cobre $\left(\mathrm{CuSO}_{4}\right.$. 5 $\left.\mathrm{H}_{2} \mathrm{O}\right)$ - marca Vetec, 98\%, $\mathrm{PM}=249,68 \mathrm{~g} / \mathrm{mol}$

- Sulfato de Magnésio $\left(\mathrm{MgSO}_{4}\right.$. 7 $\left.\mathrm{H}_{2} \mathrm{O}\right)$ - marca Mallinckrodt, 98\%, $\mathrm{PM}=246,47 \mathrm{~g} / \mathrm{mol}$

- Sulfato de Zinco $\left(\mathrm{ZnSO}_{4}\right.$. 7 $\left.\mathrm{H}_{2} \mathrm{O}\right)$ - marca Vetec, 99\%, PM=287,54 g/mol 
Anexo II: Lista de Equipamentos

- Analisador de Carbono Orgânico Total, modelo 5000A - marca Shimadzu

- Autoclave, modelo AV-300, marca Phoenix Luterco

- Balança analítica, modelo AUW220D - marca Shimadzu

- Bomba de vácuo, modelo WP6111560 - marca Millipore

- Centrífuga, modelo CR F5110 - marca Himac

- Concentrador, modelo centrivap concentrator - marca Labconco

- Cromatógrafo gasoso acoplado à um espectrômetro de massas, modelo CG MS QP 2010 Plus - marca Shimadzu

- Espectrofotômetro UV, modelo UV2600 - marca Shimadzu

- Espectrômetro de massas MALDI, modelo Ultraflextreme II - marca Bruker

- Fluxo laminar, modelo ESCO Laminar Flow Cabinet - marca opti.MAR

- Geladeira DBO, modelo TE391 - marca TECNAL

- Lâmpadas mini-Lynxs espiral branca fria com potência 11W - marca Sylvania

- Liofilizador, modelo Freezone 4,5 - marca Labconco

- Luminárias de mesa - marca fozlux

- Luxímetro, modelo lux \&fc - marca Light Meter

- Membranas n. 1. - Marca Whatman, porosidade de 0,45 $\mu \mathrm{m}$

- Micro-ondas, modelo M304 - marca CCE

- Microscópio óptico, modelo BX 60microscópio óptico - marca Olympus,

- MILIQ, modelo Q-Gard1 - marca Millipore

- Mini centrifuga, modelo 5452 - marca Eppendorf

- Placa “anchorchip”, modelo MTP384 - marca Bruker

- Placa "polished", modelo MTP 384 - marca Bruker

- Shaker agitador orbital, modelo 109/1TC - marca Ethik Technology

- Ultrassom, modelo F5110 - marca Fisher Scientific

- Vortex, modelo AP59 - marca Phoenix Luterco 
Anexo III: Curva cinética da fase exponencial em todas as posições do agitador orbital
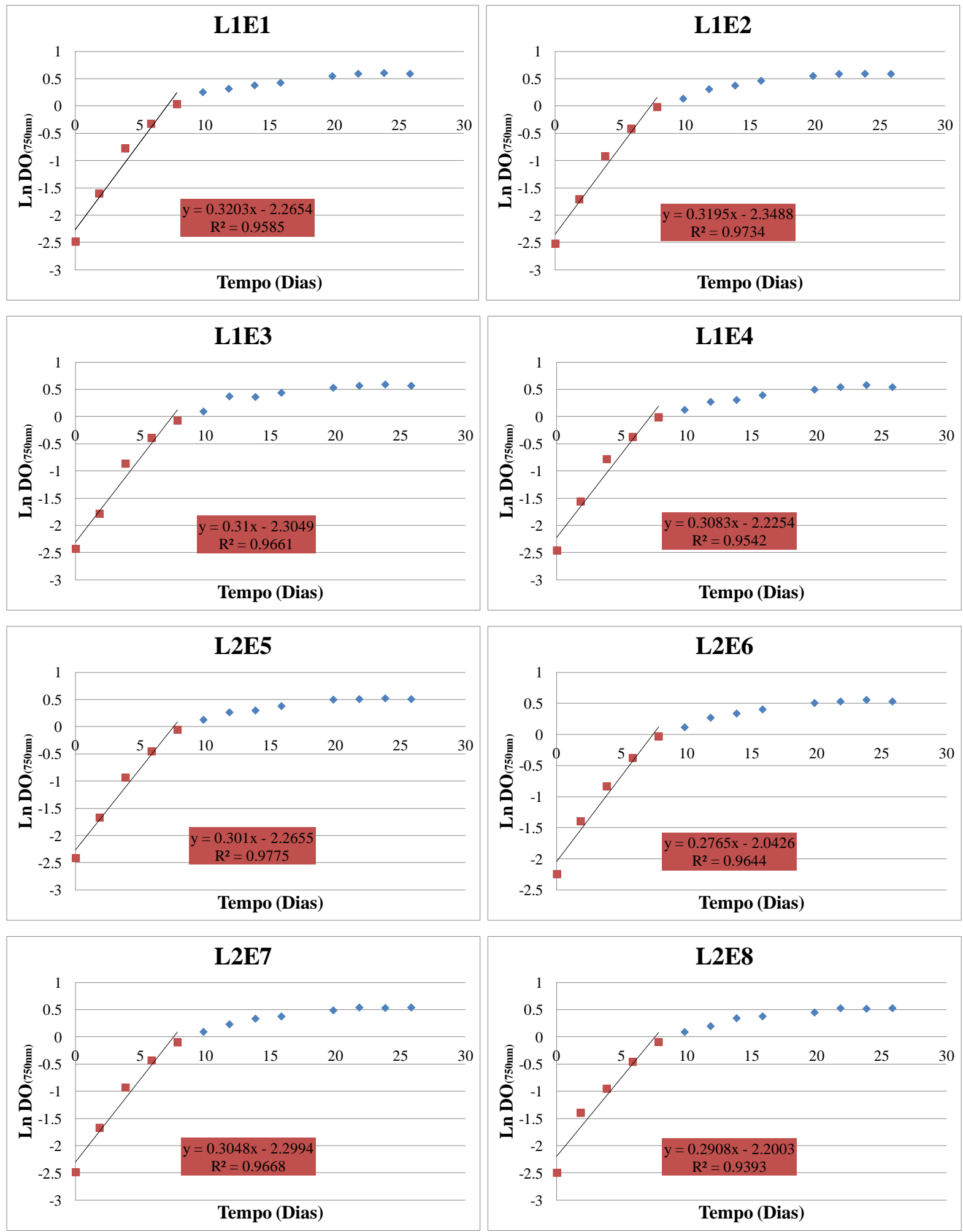

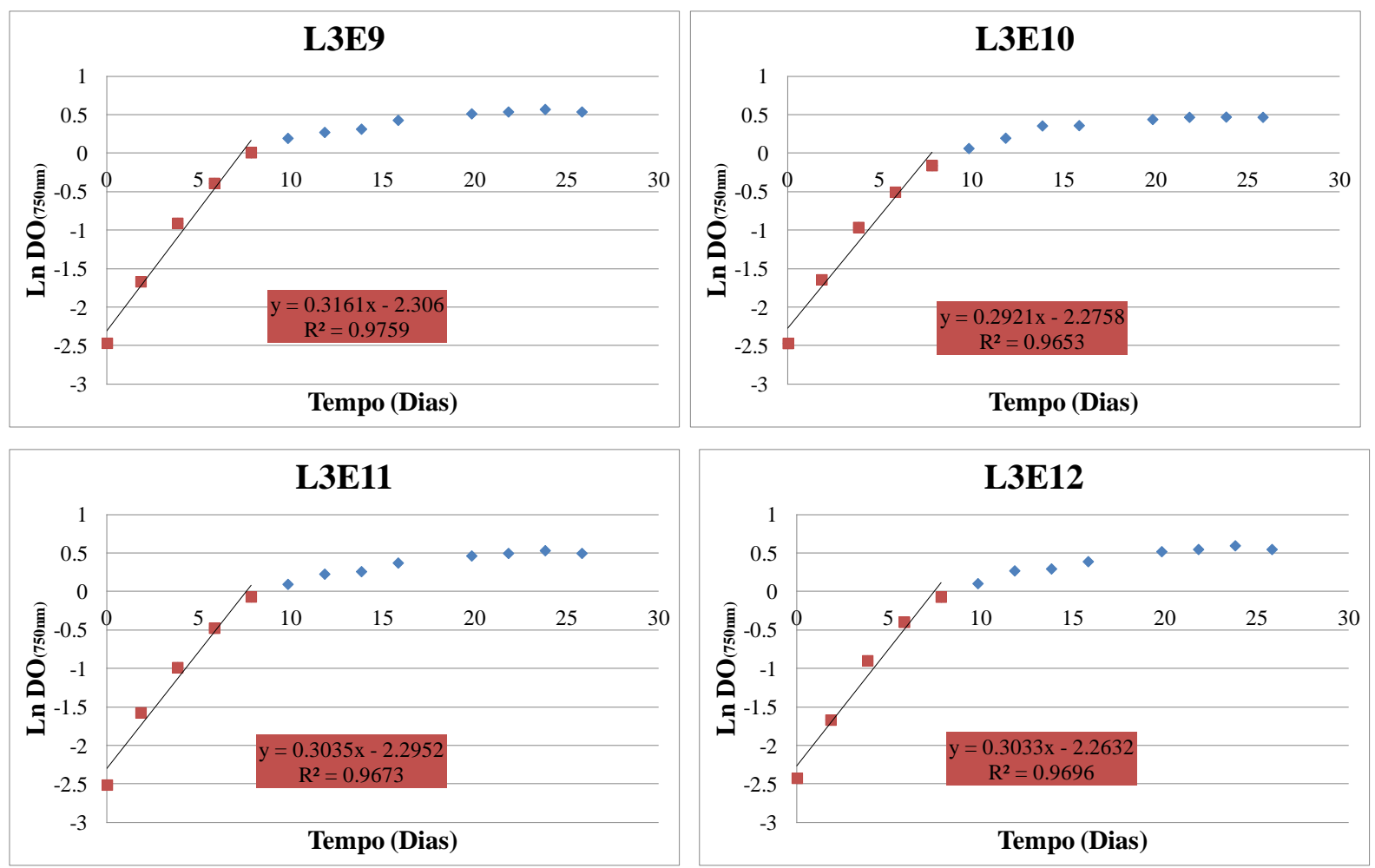
Anexo IV: Dados de absorbância a 750nm ao longo da curva de crescimento utilizada na análise estatística

\begin{tabular}{|c|c|c|c|c|c|c|c|}
\hline Dia & Linhas & Posições & Medida 1 & Medida 2 & Medida 3 & Média & Média da Linha \\
\hline \multirow{12}{*}{$\mathbf{0}$} & \multirow{4}{*}{1} & 1 & 0,0837 & 0,0837 & 0,0833 & 0,0836 & \multirow{4}{*}{0,0846} \\
\hline & & 2 & 0,0815 & 0,0807 & 0,0799 & 0,0807 & \\
\hline & & 3 & 0,0874 & 0,0889 & 0,0885 & 0,0883 & \\
\hline & & 4 & 0,0846 & 0,0874 & 0,0854 & 0,0858 & \\
\hline & \multirow{4}{*}{2} & 5 & 0,0896 & 0,0898 & 0,0900 & 0,0898 & \multirow{4}{*}{0,0872} \\
\hline & & 6 & 0,0923 & 0,0936 & 0,0933 & 0,0931 & \\
\hline & & 7 & 0,0836 & 0,0839 & 0,0829 & 0,0835 & \\
\hline & & 8 & 0,0860 & 0,0813 & 0,0805 & 0,0826 & \\
\hline & \multirow{4}{*}{3} & 9 & 0,0838 & 0,0852 & 0,0858 & 0,0849 & \multirow{4}{*}{0,0849} \\
\hline & & 10 & 0,0829 & 0,0852 & 0,0860 & 0,0847 & \\
\hline & & 11 & 0,0814 & 0,0812 & 0,0810 & 0,0812 & \\
\hline & & 12 & 0,0887 & 0,0897 & 0,0875 & 0,0886 & \\
\hline \multirow{12}{*}{2} & \multirow{4}{*}{1} & 1 & 0,1821 & 0,1813 & 0,1662 & 0,1765 & \multirow{4}{*}{0,1844} \\
\hline & & 2 & 0,1818 & 0,1821 & 0,1813 & 0,1817 & \\
\hline & & 3 & 0,1662 & 0,1681 & 0,1707 & 0,1683 & \\
\hline & & 4 & 0,2120 & 0,2110 & 0,2104 & 0,2111 & \\
\hline & \multirow{4}{*}{2} & 5 & 0,1876 & 0,1896 & 0,1898 & 0,1890 & \multirow{4}{*}{0,2187} \\
\hline & & 6 & 0,2483 & 0,2492 & 0,2478 & 0,2484 & \\
\hline & & 7 & 0,1880 & 0,1887 & 0,1898 & 0,1888 & \\
\hline & & 8 & 0,2483 & 0,2492 & 0,2478 & 0,2484 & \\
\hline & \multirow{4}{*}{3} & 9 & 0,1880 & 0,1887 & 0,1896 & 0,1888 & \multirow{4}{*}{0,1947} \\
\hline & & 10 & 0,1945 & 0,1934 & 0,1931 & 0,1937 & \\
\hline & & 11 & 0,2089 & 0,2071 & 0,2066 & 0,2075 & \\
\hline & & 12 & 0,1887 & 0,1890 & 0,1888 & 0,1888 & \\
\hline \multirow{12}{*}{4} & \multirow{4}{*}{1} & 1 & 0,4626 & 0,4618 & 0,4619 & 0,4613 & \multirow{4}{*}{0,4358} \\
\hline & & 2 & 0,3995 & 0,4006 & 0,3996 & 0,3988 & \\
\hline & & 3 & 0,4225 & 0,4229 & 0,4225 & 0,4222 & \\
\hline & & 4 & 0,4600 & 0,4589 & 0,4589 & 0,4579 & \\
\hline & \multirow{4}{*}{2} & 5 & 0,3931 & 0,3954 & 0,3948 & 0,3959 & \multirow{4}{*}{0,4034} \\
\hline & & 6 & 0,4332 & 0,4363 & 0,4354 & 0,4366 & \\
\hline & & 7 & 0,3949 & 0,3957 & 0,3957 & 0,3964 & \\
\hline & & 8 & 0,3884 & 0,3865 & 0,3876 & 0,3879 & \\
\hline & \multirow{4}{*}{3} & 9 & 0,4036 & 0,4011 & 0,4038 & 0,4067 & \multirow{4}{*}{0,3920} \\
\hline & & 10 & 0,3825 & 0,3817 & 0,3824 & 0,3831 & \\
\hline & & 11 & 0,3738 & 0,3702 & 0,3735 & 0,3766 & \\
\hline & & 12 & 0,4068 & 0,4085 & 0,4081 & 0,4090 & \\
\hline & & 1 & 0,7255 & 0,7270 & 0,7260 & 0,7262 & \\
\hline & & 2 & 0,6602 & 0,6619 & 0,6625 & 0,6615 & \\
\hline & 1 & 3 & 0,6762 & 0,6768 & 0,6769 & 0,6766 & 0,6889 \\
\hline & & 4 & 0,6916 & 0,6909 & 0,6907 & 0,6911 & \\
\hline & & 5 & 0,6385 & 0,6386 & 0,6362 & 0,6378 & \\
\hline 6 & ? & 6 & 0,6880 & 0,6888 & 0,6874 & 0,6881 & \\
\hline & 2 & 7 & 0,6515 & 0,6505 & 0,6503 & 0,6508 & 0,6528 \\
\hline & & 8 & 0,6323 & 0,6348 & 0,6366 & 0,6346 & \\
\hline & & 9 & 0,6790 & 0,6784 & 0,6781 & 0,6785 & \\
\hline & & 10 & 0,6040 & 0,6050 & 0,6048 & 0,6046 & \\
\hline & 3 & 11 & 0,6203 & 0,6230 & 0,6252 & 0,6228 & 0,6447 \\
\hline & & 12 & 0,6728 & 0,6739 & 0,6717 & 0,6728 & \\
\hline
\end{tabular}




\begin{tabular}{|c|c|c|c|c|c|c|c|}
\hline Dia & Linhas & Posições & Medida 1 & Medida 2 & Medida 3 & Média & Média da Linha \\
\hline \multirow{12}{*}{8} & \multirow{4}{*}{1} & 1 & 1,0380 & 1,0404 & 1,0374 & 1,0386 & \multirow{4}{*}{0,9875} \\
\hline & & 2 & 0,9860 & 0,9858 & 0,9854 & 0,9857 & \\
\hline & & 3 & 0,9324 & 0,9322 & 0,9350 & 0,9332 & \\
\hline & & 4 & 0,9942 & 0,9920 & 0,9910 & 0,9924 & \\
\hline & \multirow{4}{*}{2} & 5 & 0,9526 & 0,9480 & 0,9474 & 0,9493 & \multirow{4}{*}{0,9361} \\
\hline & & 6 & 0,9784 & 0,9744 & 0,9708 & 0,9745 & \\
\hline & & 7 & 0,9114 & 0,9064 & 0,9050 & 0,9076 & \\
\hline & & 8 & 0,9096 & 0,9128 & 0,9162 & 0,9129 & \\
\hline & \multirow{4}{*}{3} & 9 & 1,0120 & 1,0096 & 1,0082 & 1,0099 & \multirow{4}{*}{0,9331} \\
\hline & & 10 & 0,8530 & 0,8534 & 0,8554 & 0,8539 & \\
\hline & & 11 & 0,9360 & 0,9354 & 0,9346 & 0,9353 & \\
\hline & & 12 & 0,9316 & 0,9332 & 0,9346 & 0,9331 & \\
\hline \multirow{12}{*}{10} & \multirow{4}{*}{1} & 1 & 1,2974 & 1,2922 & 1,2904 & 1,2933 & \multirow{4}{*}{1,1697} \\
\hline & & 2 & 1,1486 & 1,1478 & 1,1482 & 1,1482 & \\
\hline & & 3 & 1,1440 & 1,1420 & 1,1450 & 1,1021 & \\
\hline & & 4 & 1,1352 & 1,1348 & 1,1358 & 1,1353 & \\
\hline & \multirow{4}{*}{2} & 5 & 1,1412 & 1,1398 & 1,1386 & 1,1399 & \multirow{4}{*}{1,1165} \\
\hline & & 6 & 1,1292 & 1,1260 & 1,1254 & 1,1269 & \\
\hline & & 7 & 1,1010 & 1,1012 & 1,1012 & 1,1011 & \\
\hline & & 8 & 1,0984 & 1,0970 & 1,0984 & 1,0979 & \\
\hline & \multirow{4}{*}{3} & 9 & 1,2200 & 1,2166 & 1,2136 & 1,2167 & \multirow{4}{*}{1,1242} \\
\hline & & 10 & 1,0668 & 1,0676 & 1,0658 & 1,0667 & \\
\hline & & 11 & 1,0658 & 1,1202 & 1,1186 & 1,1015 & \\
\hline & & 12 & 1,1102 & 1,1170 & 1,1078 & 1,1117 & \\
\hline \multirow{12}{*}{12} & \multirow{4}{*}{1} & 1 & 1,3820 & 1,3710 & 1,3806 & 1,3779 & \multirow{4}{*}{1,3788} \\
\hline & & 2 & 1,3674 & 1,3662 & 1,3646 & 1,3661 & \\
\hline & & 3 & 1,4548 & 1,4578 & 1,4546 & 1,4557 & \\
\hline & & 4 & 1,3190 & 1,3156 & 1,3124 & 1,3157 & \\
\hline & \multirow{4}{*}{2} & 5 & 1,3052 & 1,3056 & 1,3120 & 1,3076 & \multirow{4}{*}{1,2777} \\
\hline & & 6 & 1,3116 & 1,3152 & 1,3176 & 1,3148 & \\
\hline & & 7 & 1,2636 & 1,2666 & 1,2656 & 1,2653 & \\
\hline & & 8 & 1,2248 & 1,2238 & 1,2208 & 1,2231 & \\
\hline & \multirow{4}{*}{3} & 9 & 1,3100 & 1,3156 & 1,3188 & 1,3148 & \multirow{4}{*}{1,2761} \\
\hline & & 10 & 1,2188 & 1,2198 & 1,2204 & 1,2197 & \\
\hline & & 11 & 1,2526 & 1,2580 & 1,2622 & 1,2576 & \\
\hline & & 12 & 1,3110 & 1,3132 & 1,3130 & 1,3124 & \\
\hline & & 1 & 1,4704 & 1,4652 & 1,4650 & 1,4669 & \\
\hline & 1 & 2 & 1,4634 & 1,4620 & 1,4580 & 1,4611 & 14327 \\
\hline & 1 & 3 & 1,4358 & 1,4418 & 1,4432 & 1,4403 & 1,4321 \\
\hline & & 4 & 1,3628 & 1,3590 & 1,3656 & 1,3625 & \\
\hline & & 5 & 1,3542 & 1,3544 & 1,3548 & 1,3545 & \\
\hline 14 & 2 & 6 & 1,4014 & 1,4102 & 1,4072 & 1,4063 & 13948 \\
\hline & 2 & 7 & 1,4008 & 1,4008 & 1,4076 & 1,4031 & 1,5940 \\
\hline & & 8 & 1,4150 & 1,4170 & 1,4142 & 1,4154 & \\
\hline & & 9 & 1,3712 & 1,3714 & 1,3714 & 1,3713 & \\
\hline & 3 & 10 & 1,4292 & 1,4304 & 1,4312 & 1,4303 & \\
\hline & & 11 & 1,2950 & 1,2996 & 1,3028 & 1,2991 & 1,5011 \\
\hline & & 12 & 1,3436 & 1,3446 & 1,3496 & 1,3459 & \\
\hline
\end{tabular}




\begin{tabular}{|c|c|c|c|c|c|c|c|}
\hline Dia & Linhas & Posições & Medida 1 & Medida 2 & Medida 3 & Média & Média da Linha \\
\hline \multirow{12}{*}{16} & \multirow{4}{*}{1} & 1 & 1,5364 & 1,5352 & 1,5365 & 1,5380 & \multirow{4}{*}{1,5429} \\
\hline & & 2 & 1,5962 & 1,5918 & 1,5942 & 1,5946 & \\
\hline & & 3 & 1,5548 & 1,5516 & 1,5541 & 1,5558 & \\
\hline & & 4 & 1,4884 & 1,4852 & 1,4866 & 1,4862 & \\
\hline & \multirow{4}{*}{2} & 5 & 1,4660 & 1,4652 & 1,4668 & 1,4692 & \multirow{4}{*}{1,4739} \\
\hline & & 6 & 1,5070 & 1,5070 & 1,5025 & 1,4936 & \\
\hline & & 7 & 1,4600 & 1,4654 & 1,4620 & 1,4606 & \\
\hline & & 8 & 1,4638 & 1,4598 & 1,4641 & 1,4688 & \\
\hline & \multirow{4}{*}{3} & 9 & 1,5350 & 1,5384 & 1,5383 & 1,5414 & \multirow{4}{*}{1,4768} \\
\hline & & 10 & 1,4372 & 1,4324 & 1,4361 & 1,4388 & \\
\hline & & 11 & 1,4526 & 1,4546 & 1,4533 & 1,4526 & \\
\hline & & 12 & 1,4790 & 1,4780 & 1,4794 & 1,4812 & \\
\hline \multirow{12}{*}{20} & \multirow{4}{*}{1} & 1 & 1,7308 & 1,7358 & 1,7400 & 1,7355 & \multirow{4}{*}{1,7073} \\
\hline & & 2 & 1,7432 & 1,7398 & 1,7400 & 1,7410 & \\
\hline & & 3 & 1,7038 & 1,7046 & 1,7074 & 1,7053 & \\
\hline & & 4 & 1,6460 & 1,6500 & 1,6464 & 1,6475 & \\
\hline & \multirow{4}{*}{2} & 5 & 1,6524 & 1,6516 & 1,6494 & 1,6511 & \multirow{4}{*}{1,6304} \\
\hline & & 6 & 1,6774 & 1,6612 & 1,6588 & 1,6658 & \\
\hline & & 7 & 1,6362 & 1,6350 & 1,6292 & 1,6335 & \\
\hline & & 8 & 1,5756 & 1,5706 & 1,5668 & 1,5710 & \\
\hline & \multirow{4}{*}{3} & 9 & 1,6802 & 1,6710 & 1,6706 & 1,6739 & \multirow{4}{*}{1,6265} \\
\hline & & 10 & 1,5600 & 1,5550 & 1,5514 & 1,5555 & \\
\hline & & 11 & 1,5932 & 1,5942 & 1,5908 & 1,5927 & \\
\hline & & 12 & 1,6834 & 1,6850 & 1,6828 & 1,6837 & \\
\hline \multirow{12}{*}{22} & \multirow{4}{*}{1} & 1 & 1,8176 & 1,8098 & 1,8104 & 1,8126 & \multirow{4}{*}{1,7785} \\
\hline & & 2 & 1,8048 & 1,8052 & 1,8094 & 1,8065 & \\
\hline & & 3 & 1,7658 & 1,7706 & 1,7732 & 1,7699 & \\
\hline & & 4 & 1,7218 & 1,7218 & 1,7312 & 1,7249 & \\
\hline & \multirow{4}{*}{2} & 5 & 1,6682 & 1,6668 & 1,6650 & 1,6667 & \multirow{4}{*}{1,6988} \\
\hline & & 6 & 1,7042 & 1,7022 & 1,7124 & 1,7063 & \\
\hline & & 7 & 1,7196 & 1,7284 & 1,7212 & 1,7231 & \\
\hline & & 8 & 1,6390 & 1,8328 & 1,6262 & 1,6993 & \\
\hline & \multirow{4}{*}{3} & 9 & 1,7114 & 1,7146 & 1,7186 & 1,7149 & \multirow{4}{*}{1,6736} \\
\hline & & 10 & 1,6104 & 1,5982 & 1,5912 & 1,5999 & \\
\hline & & 11 & 1,6452 & 1,6474 & 1,6466 & 1,6464 & \\
\hline & & 12 & 1,7316 & 1,7334 & 1,7340 & 1,7330 & \\
\hline & & 1 & 1,8378 & 1,8348 & 1,8396 & 1,8374 & \\
\hline & & 2 & 1,8368 & 1,8018 & 1,8066 & 1,8151 & \\
\hline & 1 & 3 & 1,8084 & 1,8098 & 1,8170 & 1,8117 & 1,8142 \\
\hline & & 4 & 1,783 & 1,7968 & 1,7974 & 1,7924 & \\
\hline & & 5 & 1,6902 & 1,6958 & 1,688 & 1,6913 & \\
\hline 24 & 2 & 6 & 1,7502 & 1,7500 & 1,7506 & 1,7503 & \\
\hline & 2 & 7 & 1,7132 & 1,7092 & 1,7042 & 1,7089 & 1,7087 \\
\hline & & 8 & 1,6838 & 1,6856 & 1,6836 & 1,6843 & \\
\hline & & 9 & 1,7732 & 1,774 & 1,7686 & 1,7719 & \\
\hline & & 10 & 1,6034 & 1,6054 & 1,6054 & 1,6047 & \\
\hline & 3 & 11 & 1,7102 & 1,7060 & 1,7016 & 1,7059 & 1,7252 \\
\hline & & 12 & 1,8206 & 1,8164 & 1,8172 & 1,8181 & \\
\hline
\end{tabular}




\begin{tabular}{|c|c|c|c|c|c|c|c|}
\hline Dia & Linhas & Posições & Medida 1 & Medida 2 & Medida 3 & Média & Média da Linha \\
\hline \multirow{12}{*}{26} & \multirow{4}{*}{1} & 1 & 1,8176 & 1,8098 & 1,8104 & 1,8126 & \multirow{4}{*}{1,7785} \\
\hline & & 2 & 1,8048 & 1,8052 & 1,8094 & 1,8065 & \\
\hline & & 3 & 1,7658 & 1,7706 & 1,7732 & 1,7699 & \\
\hline & & 4 & 1,7218 & 1,7218 & 1,7312 & 1,7249 & \\
\hline & \multirow{4}{*}{2} & 5 & 1,6682 & 1,6668 & 1,665 & 1,6667 & \multirow{4}{*}{1,6988} \\
\hline & & 6 & 1,7042 & 1,7022 & 1,7124 & 1,7063 & \\
\hline & & 7 & 1,7196 & 1,7284 & 1,7212 & 1,7231 & \\
\hline & & 8 & 1,6390 & 1,8328 & 1,6262 & 1,6993 & \\
\hline & \multirow{4}{*}{3} & 9 & 1,7114 & 1,7146 & 1,7186 & 1,7149 & \multirow{4}{*}{1,6736} \\
\hline & & 10 & 1,6104 & 1,5982 & 1,5912 & 1,5999 & \\
\hline & & 11 & 1,6452 & 1,6474 & 1,6466 & 1,6464 & \\
\hline & & 12 & 1,7316 & 1,7334 & 1,734 & 1,7330 & \\
\hline
\end{tabular}


Anexo V: Tabela de distribuição de FSnedecor ao nível de probabilidade 5\%.

\begin{tabular}{|c|c|c|c|c|c|c|c|c|c|c|c|c|c|c|c|c|c|c|c|c|}
\hline GL & & & & & & & & & & & & & V1 & & & & & & & \\
\hline V2 & 1 & 2 & 3 & 4 & 5 & 6 & 7 & 8 & 9 & 10 & 11 & 12 & 13 & 14 & 15 & 20 & 40 & 60 & 120 & 240 \\
\hline 1 & 161.4 & 199.5 & 215.7 & 224.6 & 230.2 & 234.0 & 236.8 & 238.9 & 240.5 & 241.9 & 243.0 & 243.9 & 244.7 & 245.4 & 245.9 & 248.0 & 251.1 & 252.2 & 253.3 & 253.8 \\
\hline 2 & 18.513 & 19.000 & 19.164 & 19.247 & 19.296 & 19.329 & 19.353 & $\begin{array}{ll}3 & 19.371\end{array}$ & 19.385 & 19.396 & 19.405 & 19.412 & 19.419 & 19.424 & 19.429 & 19.446 & 19.471 & 19.479 & 19.487 & 19.492 \\
\hline 3 & 10.128 & 9.552 & 9.277 & 9.117 & 9.013 & 8.941 & 8.887 & 8.845 & 8.812 & 8.785 & 8.763 & 8.745 & 8.729 & 8.715 & 8.703 & 8.660 & 8.594 & 8.572 & 8.549 & 8.538 \\
\hline 4 & 7.709 & 6.944 & 6.591 & 6.388 & 6.256 & 6.163 & 6.094 & 6.041 & 5.999 & 5.964 & 5.936 & 5.912 & 5.891 & 5.873 & 5.858 & 5.803 & 5.717 & 5.688 & 5.658 & 5.643 \\
\hline 5 & 6.608 & 5.786 & 5.409 & 5.192 & 5.050 & 4.950 & 4.876 & 4.818 & 4.772 & 4.735 & 4.704 & 4.678 & 4.655 & 4.636 & 4.619 & 4.558 & 4.464 & 4.431 & 4.398 & 4.382 \\
\hline 6 & 5.987 & 5.143 & 4.757 & 4.534 & 4.387 & 4.284 & 4.207 & 4.147 & 4.099 & 4.060 & 4.027 & 4.000 & 3.976 & 3.956 & 3.938 & 3.874 & 3.774 & 3.740 & 3.705 & 3.687 \\
\hline 7 & 5.591 & 4.737 & 4.347 & 4.120 & 3.972 & 3.866 & 3.787 & 3.726 & 3.677 & 3.637 & 3.603 & 575 & & 3.529 & 3.511 & 3.445 & 3.340 & 3.304 & 3.267 & 3.249 \\
\hline 8 & 5.318 & 4.459 & 4.066 & 3.838 & 3.688 & 3.581 & 3.500 & 3.438 & 3.388 & 3.347 & 3.313 & 3.284 & 3.259 & 3.237 & 3.218 & 3.150 & 3.043 & 3.005 & 2.967 & 2.947 \\
\hline 9 & 5.117 & 4.256 & 3.863 & 3.633 & 3.482 & 3.374 & 3.293 & 3.230 & 3.179 & 3.137 & 3.102 & 3.073 & 3.048 & 3.025 & 3.006 & 2.936 & 2.826 & 2.787 & 2.748 & 2.727 \\
\hline 10 & 4.965 & 4.103 & 3.708 & 3.478 & 3.326 & 3.217 & 3.135 & 3.072 & 3.020 & 2.978 & 2.943 & 2.913 & 2.887 & 2.865 & 2.845 & 2.774 & 2.661 & 2.621 & 2.580 & 2.559 \\
\hline 11 & 4.844 & 3.982 & 3.587 & 3.357 & 3.204 & 3.095 & 3.012 & 2.948 & 2.896 & 2.854 & 2.818 & 788 & & 739 & 2.719 & 2.646 & 2.531 & 2.490 & 2.448 & 2.426 \\
\hline 12 & 4.747 & 3.885 & 3.490 & 3.259 & 3.106 & 2.996 & 2.913 & 2.849 & 2.796 & 2.753 & 2.717 & 2.687 & 2.660 & 2.637 & 2.617 & 2.544 & 2.426 & 2.384 & 2.341 & 2.319 \\
\hline 13 & 4.667 & 3.806 & 3.411 & 3.179 & 3.025 & 2.915 & 2.832 & 2.767 & 2.714 & 2.671 & 2.635 & 2.604 & 2.577 & 2.554 & 2.533 & 2.459 & 2.339 & 2.297 & 2.252 & 2.230 \\
\hline 14 & 4.600 & 3.739 & 3.344 & 3.112 & 2.958 & 2.848 & 2.764 & 2.699 & 2.646 & 2.602 & 2.565 & 2.534 & 2.507 & 2.484 & 2.463 & 2.388 & 2.266 & 2.223 & 2.178 & 2.155 \\
\hline 15 & 4.543 & 3.682 & 3.287 & 3.056 & 2.901 & 2.790 & 2.707 & 2.641 & 2.588 & 2.544 & 2.507 & 2.475 & 448 & 2.424 & 2.403 & 2.328 & 2.204 & 2.160 & 2.114 & 2.090 \\
\hline 16 & 4.494 & 3.634 & 3.239 & 3.007 & 2.852 & 2.741 & 2.657 & 2.591 & 2.538 & 2.494 & 2.456 & 2.425 & & 2.373 & 2.352 & 2.276 & 2.151 & 2.106 & 2.059 & 2.035 \\
\hline 17 & 4.451 & 3.592 & 3.197 & 2.965 & 2.810 & 2.699 & 2.614 & 2.548 & 2.494 & 2.450 & 2.413 & 2.381 & 2.353 & 2.329 & 2.308 & 2.230 & 2.104 & 2.058 & 2.011 & 1.986 \\
\hline 18 & 4.414 & 3.555 & 3.160 & 2.928 & 2.773 & 2.661 & 2.577 & 2.510 & 2.456 & 2.412 & 2.374 & 2.342 & 2.314 & 2.290 & 2.269 & 2. 191 & 2.063 & 2.017 & 1.968 & 1.943 \\
\hline 19 & 4.381 & 3.522 & 3.127 & 2.895 & 2.740 & 2.628 & 2.544 & 2.477 & 2.423 & 2.378 & 2.340 & 2.308 & 2.280 & 2.256 & 2.234 & 2.155 & 2.026 & 1.980 & 1.930 & 1.905 \\
\hline 20 & 4.351 & 3.493 & 3.098 & 2.866 & 2.711 & 2.599 & 2.514 & 2.447 & 2.393 & 2.348 & 2.310 & 2.278 & 2.250 & 2.225 & 2.203 & 2.124 & 1.994 & 1.946 & 1.896 & 1.870 \\
\hline 21 & 4.325 & 3.467 & 3.072 & 2.840 & 2.685 & 2.573 & 2.488 & 2.420 & 2.366 & 2.321 & 2.283 & 2.250 & 2.222 & 2.197 & 2.176 & 2.096 & 1.965 & 1.916 & 1.866 & 1.839 \\
\hline 22 & 4.301 & 3.443 & 3.049 & 2.817 & 2.661 & 2.549 & 2.464 & 2.397 & 2.342 & 2.297 & 2.259 & 2.226 & 198 & 2.173 & 151 & 2.071 & 1.938 & 1.889 & 1.838 & 1.811 \\
\hline 23 & 4.279 & 3.422 & 3.028 & 2.796 & 2.640 & 2.528 & 2.442 & 2.375 & 2.320 & 2.275 & 2.236 & 2.204 & 2.175 & 2.150 & 2.128 & 2.048 & 1.914 & 1.865 & 1.813 & 1.785 \\
\hline 24 & 4.260 & 3.403 & 3.009 & 2.776 & 2.621 & 2.508 & 2.423 & 2.355 & 2.300 & 2.255 & 2.216 & 2.183 & 2.155 & 2.130 & 2.108 & 2.027 & 1.892 & 1.842 & 1.790 & 1.762 \\
\hline 25 & 4.242 & 3.385 & 2.991 & 2.759 & 2.603 & 2.490 & 2.405 & 2.337 & 2.282 & 2.236 & 2.198 & 2.165 & 2.136 & 2.111 & 2.089 & 2.007 & 1.872 & 1.822 & 1.768 & 1.740 \\
\hline 26 & 4.225 & 3.369 & 2.975 & 2.743 & 2.587 & 2.474 & 2.388 & 2.321 & 2.265 & 2.220 & 2.181 & 2.148 & 2.119 & 2.094 & 2.072 & 1.990 & 1.853 & 1.803 & 1.749 & 1.720 \\
\hline 27 & 4.210 & 3.354 & 2.960 & 2.728 & 2.572 & 2.459 & 2.373 & 2.305 & 2.250 & 2.204 & 2.166 & 2.132 & 2.103 & 2.078 & 2.056 & 1.974 & 1.836 & 1.785 & 1.731 & 1.702 \\
\hline 28 & 4.196 & 3.340 & 2.947 & 2.714 & 2.558 & 2.445 & 2.359 & 2.291 & 2.236 & 2.190 & 2.151 & 2.118 & 2.089 & 2.064 & 2.041 & 1.959 & 1.820 & 1.769 & 1.714 & 1.685 \\
\hline 29 & 4.183 & 3.328 & 2.934 & 2.701 & 2.545 & 2.432 & 2.346 & 2.278 & 2.223 & 2.177 & 2.138 & 2.104 & 2.075 & 2.050 & 2.027 & 1.945 & 1.806 & 1.754 & 1.698 & 1.669 \\
\hline 30 & 4.171 & 3.316 & 2.922 & 2.690 & 2.534 & 2.421 & 2.334 & 2.266 & 2.211 & 2.165 & 2.126 & 2.092 & 2.063 & 2.037 & 2.015 & 1.932 & 1.792 & 1.740 & 1.683 & 1.654 \\
\hline 40 & 4.085 & 3.232 & 2.839 & 2.606 & 2.449 & 2.336 & 2.249 & 2.180 & 2.124 & 2.077 & 2.038 & 2.003 & 1.974 & 1.948 & 1.924 & 1.839 & 1.693 & 1.637 & 1.577 & 1.544 \\
\hline 50 & 4.034 & 3.183 & 2.790 & 2.557 & 2.400 & 2.286 & 2.199 & 2.130 & 2.073 & 2.026 & 1.986 & 1.952 & & 1.895 & 1.871 & 1.784 & 1.634 & 1.576 & 1.511 & 1.476 \\
\hline 60 & 4.001 & 3.150 & 2.758 & 2.525 & 2.368 & 2.254 & 2. 167 & 2.097 & 2.040 & 1.993 & 1.952 & 1.917 & 1.887 & 1.860 & 1.836 & 1.748 & 1.594 & 1.534 & 1.467 & 1.430 \\
\hline 80 & 3.960 & 3.111 & 2.719 & 2.486 & 2.329 & 2.214 & 2.126 & 2.056 & 1.999 & 1.951 & 1.910 & 1.875 & 1.845 & 1.817 & 1.793 & 1.703 & 1.545 & 1.482 & 1.411 & 1.370 \\
\hline 100 & 3.936 & 3.087 & 2.696 & 2.463 & 2.305 & 2.191 & 2.103 & 2.032 & 1.975 & 1.927 & 1.886 & 1.850 & 1.819 & 1.792 & 1.768 & 1.676 & 1.515 & 1.450 & 1.376 & 1.333 \\
\hline 120 & 3.920 & 3.072 & 2.680 & 2.447 & 2.290 & 2.175 & 2.087 & 2.016 & 1.959 & 1.910 & 1.869 & 1.834 & 1.803 & 1.775 & 1.750 & 1.659 & 1.495 & 1.429 & 1.352 & 1.307 \\
\hline 240 & 3.881 & 3.033 & 2.642 & 2.409 & 2.252 & 2.136 & 2.048 & 1.977 & 1.919 & 1.870 & 1.829 & 1.793 & 1.761 & 1.733 & 1.708 & 1.614 & 1.445 & 1.375 & 1.290 & 1.237 \\
\hline
\end{tabular}

onde: $\mathrm{n}=$ graus de liberdade do tratamento e $\mathrm{m}=$ graus de liberdade dos resíduos 